\title{
DISPOSIÇÃO DE RESÍDUOS GERADOS EM LABORATÓRIO: \\ avaliação dos procedimentos adotados por três instituições públicas
}

\section{MARIA DE FÁTIMA MENEZES PEDROZO}

Tese de Doutorado apresentada ao Departamento de Saúde Ambiental da Faculdade de Saúde Pública da Universidade de São Paulo para obtenção do grau de Doutor.

Área de concentração: Saúde ambiental

ORIENTADOR: Prof. Dr. ARLINDO

PHILIPPI Jr

São Paulo

- 2000 - 
“Ela está no horizonte... Me aproximo dois passos, ela se afasta dois passos. Caminho dez passos e o horizonte corre dez passos. Por mais que eu caminhe jamais a alcançarei. Para que serve a utopia? Serve para isso: para caminhar".

As palavras andantes, Eduardo Galeano 


\section{a Nanna e Dani,}

luzes do meu caminho,

privados, por tantas vezes,

da minha presença e carinho

durante a finalização

deste trabalho

aos meus pais,

que me ensinaram a caminhar

aos meus irmãos,

que me escutam no meu silêncio

a todos aqueles, e são muitos,

que se juntaram a mim, em pontos

diferentes da minha caminhada,

firmaram o passo e sorriram comigo

na alegria e seguraram-me as mãos na tristeza.

Olhando para esses tesouros, percebo a extensão da minha riqueza e agradeço a Deus por isso. 


\section{Agradecimentos}

Ao prof. Dr. Arlindo Philippi Jr., pelo apoio e incentivo na realização deste trabalho.

À prof.a. Dra. Maria Regina Alves Cardoso, pela carinhosa e valiosa orientação na análise estatística dos dados coletados e na construção do modelo.

Aos profs. Drs. Sérgio Colacioppo e Jorge da Rocha Gomes, pela colaboração inestimável na elaboração deste projeto.

Aos diretores e corpo funcional das Instituições avaliadas, por terem viabilizado a execução deste trabalho.

Às diretorias do Instituto Médico Legal de São Paulo e do Núcleo de Toxicologia Forense, por possibilitarem a minha participação nesse programa de pós graduação.

Aos funcionários do Núcleo de Toxicologia Forense - IML/SP, pela compreensão e amizade.

À prof.a. Dra. Alice Chasin, pelo companheirismo e amizade e pelas valiosas discussões, revisões e sugestões.

Ao Adalberto Mansur, meu irmão do coração, pelo carinho com que se responsabilizou, por várias vezes, pelas minhas atribuições funcionais e especialmente, por me fazer rir. 
Às prof.as. Elizabeth Nascimento e Petra Sanchez Sanchez, pelas referências bibliográficas e revisões de alguns dos textos.

Ao corpo funcional da biblioteca da Faculdade de Saúde Pública, pelo carinhoso atendimento e pelo empenho na obtenção $e$ normalização das referências.

Ao Arthur, por cuidar das crianças e pelas soluções e execução da arte final. 


\section{RESUMO}

Pedrozo, MFM. Disposição de resíduos gerados em laboratório: Avaliação dos procedimentos adotados por três Instituições Públicas. São Paulo; 2000. [Tese de Doutorado- Faculdade de Saúde Pública da USP].

Em função da diversidade dos resíduos gerados, a disposição adequada dos rejeitos de laboratório é incipiente. Para atender às boas práticas de laboratório e as exigências legais é mister implementá-la. Para avaliar os procedimentos adotados em três instituições públicas, designadas A, B e C, foram entrevistados 124 analistas de nível superior e médio, 50 docentes, 14 pós-graduandos e 4 estagiários de iniciação científica, e responderam a questionário específico 89 analistas e pós-graduandos. Através desses instrumentos, identificou-se os tipos e quantidades de resíduos gerados nessas instituições; analisou-se os procedimentos adotados no descarte dos resíduos gerados, em situação de rotina e emergência; verificou-se, por meio de modelos de regressão logística, as variáveis associadas à percepção do corpo funcional quanto ao correto descarte dos resíduos gerados e discutiu-se possíveis impactos sobre a saúde humana. Residuos infectantes e especiais são gerados nessas instituições. Procede-se corretamente o descarte dos residuos infectantes na Instituição $\mathrm{A}$ e na maioria dos laboratórios da Instituição B e incorretamente na Instituição C. Dentre os resíduos especiais, encontram-se substâncias inflamáveis, corrosivas, reativas e tóxicas. Observou-se que 48,8 \% dos funcionários da Instituição A, 44,5\% dos funcionários da Instituição B e 100,0 \% dos funcionários da Instituição C procedem, rotineiramente, o descarte incorreto de uma ou mais das substâncias ou materiais por eles manipulados. Em caso de derramamento dessas substâncias ou fluidos biológicos, essas percentagens passam para $76,8 \%, 83,4 \%$ e $87,1 \%$, respectivamente. Dentre os fatores associados ao procedimento correto de descarte encontram-se a necessidade do conhecimento das etapas do gerenciamento e dos dados toxicológicos de cada substância manipulada, além do adequado treinamento do corpo funcional para o correto descarte. Fica, assim, demonstrado que a implantação de programa de gerenciamento de resíduos passa obrigatoriamente pelo envolvimento institucional baseado na decisão administrativa, orçamento compatível e programa educacional consistente.

Descritores: Resíduos químicos. Residuos biológicos. Tratamento. Efeitos nocivos. 


\section{SUMMARY}

Pedrozo, MFM. Disposição de resíduos gerados em laboratório: Avaliação dos procedimentos adotados por três Instituições Públicas.[Laboratory waste management: evaluation of the disposal procedures adopted by three public institutions]. São Paulo; 2000. [Tese de Doutorado - Faculdade de Saúde Pública da USP].

The large variety of small amounts of laboratory wastes difficult their management. To fulfill Good Laboratory Practices and meet legal guidelines, proper disposal procedures must to be adopted. In order to evaluate the procedures adopted in three public institutions, referred in this study as A, B and C, 124 high school and college graduated lab analysts; 50 professors, 14 graduation students and 4 scientific investigator trainees were interviewed. In addition, 89 analysts and post graduation students answered a questionnaire. The types and quantities of lab wastes were identified and the disposal procedures were analyzed, in routine and emergency conditions. The perception for the correct disposal of the wastes generated was analyzed through a logistic regression modeling and possible impacts on human heath were discussed. Infectious and chemical wastes are generated in these institutions. Institution $\mathbf{A}$ and most of the labs in the Institution B followed the correct disposal procedure for infectious waste, however Institution $\mathrm{C}$ did not so. Among chemical waste, flammable, corrosive, reactive and toxic substances were found. $48 \%$ of the Institution A personnel, $44,5 \%$ of Institution B workers and $100 \%$ of the Institution C personnel disposed off incorrectly one or more of these substances or wastes. In accidental hazardous waste spill, the percentages were $76,8 \%, 83 \%$ and $87,1 \%$, respectively, for Institution A, B and C. Among the facts associated with the correct disposal procedure , there should be included the knowledge of the waste management steps and toxicological data for each of the substances handled as well as adequate waste management training. Therefore, waste management should be mandatory in routine institutional criteria and be based on administrative decision, budget compatibility and consistent educational program.

Descriptors: Chemical waste. Infectious waste. Waste treatment. Toxic effects. 


\section{ÍNDICE}

1. INTRODUÇÃO 1

2. GERENCIAMENTO DOS RESİDUOS GERADOS 5

2.1. Etapas do gerenciamento 5

2.1.1. Identificação e classificação 5

2.1.2. Segregação 10

2.1.3. Acondicionamento dos resíduos 12

2.1.4. Tratamento de resíduos 14

2.1.5. Armazenamento 18

2.1.6. Transporte 22

2.1.7. Disposição Final 22

3. EFEITOS À SAÙDE 25

3.1. Risco químico 25

3.1.1. Avaliação de risco 25

3.1.1.1. Identificação do perigo 26

3.1.1.2. Avaliação da relação dose-resposta 27

3.1.1.3. Caracterização da exposição 34

3.1.1.4. Caracterização do risco 35

3.1.2. Percepção e comunicação do risco 36

3.2. Risco biológico 38

3.2.1- Avaliação do risco biológico 39

3.3 Minimização dos riscos 43

4. OBJETIVOS

$\begin{array}{ll}\text { 4.1 Objetivos gerais } & 47\end{array}$

$\begin{array}{ll}\text { 4.2. Objetivos específicos } & 47\end{array}$

5. METODOLOGIA

5.1. População estudada $\quad 48$

5.2. Levantamento dos resíduos gerados e dos 49 procedimentos adotados para o descarte em situações de rotina 
5.3 Levantamento dos procedimentos a serem adotados na manipulação e descarte dos resíduos gerados em situação de emergência nas Instituições estudadas

5.4. O estado da arte quanto ao gerenciamento dos resíduos gerados.

5.5. Análise dos dados obtidos

5.5.1. Procedimentos de descarte adotados 51

5.5.1.1. Situação de rotina 51

5.5.1.2. Situação de emergência 52

5.5.2. Referente à entrada e análise estatística dos dados 52 coletados

5.6. Verificação da percepção do corpo funcional 54

5.7. Discussão dos possíveis impactos dos resíduos 55 identificados sobre a saúde humana

5.8. Avaliação do envolvimento institucional 55

em programa de gerenciamento de resíduos

6. QUESTÕES ÉTICAS

55

7. RESULTADOS

7.1 População estudada 56

$\begin{array}{ll}\text { 7.2. Levantamento dos resíduos gerados } & 57\end{array}$

7.2.1. Resíduos especiais

7.2.1.1. Resíduos contendo substâncias inflamáveis $\quad 57$

7.2.1.2. Resíduos contendo substâncias corrosivas 64

7.2.1.3. Resíduos contendo substâncias reativas $\quad 68$

7.2.1.4. Resíduos contendo substâncias tóxicas $\quad 70$

7.2.1.5. Resíduos contendo substâncias radioativas $\quad 75$

7.2.1.6. Resíduos contendo medicamentos $\quad 76$

7.2.1.7. Resíduos de corantes $\quad 77$

7.2.2. Resíduos contendo substâncias químicas 79 classificadas como não perigosas

7.2.3. Resíduos contendo material infectante ou outras matrizes manipuladas pelas Instituições avaliadas 7.2.3.1. Instituição A

7.2.3.2. Instituição B 81

7.2.3.3. Instituição C $\quad 82$

7.3 Avaliação dos procedimentos adotados em situações 84 de emergência 
7.4. $O$ estado da arte quanto ao gerenciamento dos resíduos gerados 87

7.5 Avaliação da percepção do corpo funcional 89

7.6. Discussão dos possíveis impactos sobre a saúde humana 92 provocados pelos resíduos perigosos gerados nas instituições estudadas

7.7. Avaliação do envolvimento institucional em programa de gerenciamento de resíduos

8. DISCUSSÃo

93

9. CONCLUSÕES

99

10. RECOMENDAÇÕES 126

11. REFERÊNCIAS 129

\section{ANEXOS}

Anexo 1 - Caracterização de resíduos químicos não listados e

Concentração máxima de alguns constituintes no lixiviado

Anexo2 -Protocolo para identificação de substâncias químicas

Desconhecidas

Anexo 3 - Fluxograma para a caracterização de substâncias químicas desconhecidas

Anexo 4 - Tratamentos adotados para diferentes categorias de

Resíduos de Serviço de Saúde.

Anexo 5 - Algumas opções de tratamento de Resíduos de Serviço de

Saúde - Vantagens e desvantagens

Anexo 6 - Utilização e eficácia de diferentes descontaminantes em Laboratório

Anexo 7 - Incompatibilidade de substâncias químicas

Anexo 8 - Exemplos de reações entre resíduos incompatíveis

Anexo 9 - Segregação de substâncias químicas de acordo com a classificação

Anexo 10 - Roteiro de entrevista com membro da Comissão de gerenciamento de resíduos

Anexo 11- Roteiro de entrevista com o responsável pelo laboratório

Anexo 12 - Roteiro de entrevista com os técnicos e analistas

Anexo13 - Questionário para técnicos e analistas de laboratório

Anexo 14 - Termo de consentimento

Anexo 15 - Resíduos contendo substâncias inflamáveis gerados pelas Instituições avaliadas

Anexo 16 - Resíduos contendo substâncias corrosivas gerados pelas 
Anexo 17 - Resíduos contendo substâncias reativas gerados pelas

Instituições avaliadas

Anexo 18 - Resíduos contendo substâncias tóxicas gerados pelas

A62

Instituições avaliadas

Anexo19 - Resíduos contendo substâncias não perigosas

A70

gerados pelas Instituições avaliadas

Anexo20 - Estado da Arte quanto ao tratamento e disposição

A86

de resíduos

Anexo 21 - Cuidados na manipulação, Padrões de segurança e

Al12

Síndrome tóxica decorrente da exposição ocupacional à

substâncias perigosas 


\section{LISTA DE TABELAS, FIGURAS E QUADROS}

Tabela 1 - Minimização de resíduos perigosos no local de geração

Tabela 2- Comparação dos custos do gerenciamento de resíduos, com e sem o tratamento prévio - Universidade de Indiana, 1987

Tabela 3- Exemplificação dos custos dos tratamentos de Resíduos de Serviço de Saúde na Suíça

Tabela 4 - Comparação entre Mistura de resíduos e Lab Pack

Figura 1- Ilustração gráfica da dose de Benchmark (BD)

Tabela 5 - Comparação entre as DNEAO e dose Benchmark estimadas para algumas substâncias

Figura 2 - Procedimento adotado para estimar os fatores de incerteza

Tabela 6 - Risco de infecção, morbidade e mortalidade para

Rotavírus e vírus da Hepatite A

Figura 3- Principais substâncias inflamáveis utilizadas pelas instituições estudadas

Tabela 7 - Característica do procedimento de descarte de substâncias inflamáveis, adotado em situação de rotina, segundo a Instituição de estudo

Tabela 8 - Característica do procedimento de descarte adotado para os resíduos contendo substâncias inflamáveis, em situação de rotina, segundo o departamento/divisão de cada Instituição de estudo

Tabela 9- Característica do procedimento de disposição rotineiramente adotado para os residuos inflamáveis, segundo a formação dos funcionários

Tabela 10- Característica do procedimento de disposição rotineiramente adotado para os resíduos inflamáveis, segundo o tempo de formado dos funcionários 
Tabela 11- Característica do procedimento de disposição rotineiramente

Adotado para os resíduos inflamáveis, segundo o periodo de tempo na função

Tabela 12 - Tipo de procedimento de descarte rotineiramente empregado para os residuos contendo substâncias inflamáveis, segundo a existência de programa de descarte institucionalizado

Tabela 13 - Tipo de procedimento de descarte rotineiramente adotado para os resíduos inflamáveis, segundo o conhecimento dos dados toxicológicos da substância manipulada

Tabela 14 - Tipo de procedimento de descarte rotineiramente adotado para os resíduos inflamáveis, segundo a compreensão da complexidade desses procedimentos

Tabela 15- Tipo de procedimento de descarte rotineiramente adotado para os resíduos inflamáveis, segundo a existência de programa educacional institucionalizado

Tabela 16- Tipo de procedimento de descarte rotineiramente adotado para os residuos inflamáveis, segundo a existência de treinamento para a correta disposição desses resíduos

Figura 4 - Principias substâncias corrosivas presentes nos residuos gerados pelas Instituições avaliadas

Tabela 17: Característica do procedimento rotineiramente empregado 66 no descarte de resíduos contendo substâncias corrosivas, segundo a Instituição de estudo

Tabela 18 - Característica do procedimento de descarte adotado para 66 os resíduos contendo substâncias corrosivas, segundo o departamento ou divisão de cada Instituição de estudo

Tabela 19 - Característica do procedimento de disposição rotineiramente Adotado para os resíduos corrosivos, segundo a formação dos funcionários

Tabela 20 - Tipo de procedimento de descarte rotineiramente empregado para os resíduos corrosivos, segundo a existência de programa de descarte institucionalizado 
Tabela 21 - Característica do procedimento de descarte de residuos contendo substâncias Reativas, segundo a Instituição de estudo

Tabela 22 - Característica do procedimento de descarte adotado para os resíduos contendo substâncias reativas, em situação de rotina, segundo o departamento ou divisão de cada Instituição de estudo

Figura 5 - Principais solventes clorados utilizados nas instituições estudadas

Figura 6 - Sais metálicos manipulados nas Instituições avaliadas

Figura 7- Utilização de Brometo de etídio pelas Instituições A e B

Figura 8- Reveladores empregados nos imunoensaios realizados nas

Tabela 23 - Característica do procedimento de descarte de resíduos contendo solventes clorados, segundo a Instituição de estudo

Tabela 24 - Característica do procedimento de descarte de resíduos contendo metais segundo a Instituição de estudo

Tabela 25 - Característica do procedimento de descarte de residuos contendo outras substâncias tóxicas, segundo a Instituição de estudo

Tabela 26 - Residuos contendo substâncias radioativas produzidos pela Instituição A e procedimento de descarte adotado.

Tabela 27 - Residuos contendo substâncias radioativas produzidos pela Instituição B e procedimento de descarte adotado

Tabela 28 - Característica do procedimento de descarte de resíduos contendo material Radioativo, segundo a Instituição de estudo

Tabela 29 - Tratamento e descarte adotado para os resíduos contendo fármacos analisados na instituição $\mathrm{B}$

Tabela 30 - Corantes utilizados na Instituição A e descarte adotado

Tabela 31 - Corantes utilizados na Instituição B e descarte adotado

Tabela 32 - Corantes utilizados na Instituição C e descarte adotado

Tabela 33 - Característica do procedimento de descarte, adotado em situação de emergência, segundo a Instituição de estudo 
Tabela 34- Característica do procedimento de descarte, adotado em situação de emergência, segundo o departamento ou divisão de cada instituição

Tabela 35 - Característica do procedimento de descarte, adotado em situação de emergência, segundo a formação dos funcionários

Tabela 36- Característica do procedimento laboratorial de descarte, adotado em situação de emergência, segundo a categoria do material manipulado

Tabela 37 - Tipo de procedimento de descarte laboratorial adotado em situação de emergência, segundo o conhecimento dos dados toxicológicos da substância manipulada

Tabela 38- Percepção da existência de programa de treinamento para situações de emergência, segundo departamento ou divisão da Instituição $\mathrm{A}$ a que pertence o funcionário

Tabela 39 - Percepção da existência de programa de treinamento para situações de emergência, segundo departamento ou divisão da Instituição B.

Tabela 40 - Odds ratio, significância e intervalo de confiança de $95 \%$ para as variáveis que compõem o modelo de regressão logística considerando o procedimento rotineiro de descarte dos resíduos gerados.

Tabela 41 - Odds ratio, significância e intervalo de confiança de $95 \%$ para as variáveis que compõem o modelo de regressão logística considerando o procedimento de descarte dos resíduos gerados adotado em situações de emergência.

Tabela 42 - Característica do procedimento laboratorial de descarte, adotado 95 em situação de rotina, segundo a Instituição de estudo

Tabela 43 - Tipo de procedimento adotado quando do derramamento de resíduos perigosos ou infectantes, segundo a Instituição de estudo

Tabela A-1 - Limites máximos permitidos no extrato obtido por lixiviação do resíduo estudado

Tabela A-2 -Protocolo para identificação de substâncias químicas desconhecidas A7

Figura A-1 -Fluxograma para a caracterização de substâncias químicas desconhecidas

Tabela A-3 - Tratamentos adequados para as diferentes categorias de Resíduos de Serviço de Saúde 
de Resíduos de Serviço de Saúde

Tabela A-5 - Utilização e eficácia dos diferentes descontaminantes em laboratórios clínicos e de pesquisa

Tabela A-6 - Incompatibilidade dos diferentes grupos químicos

Tabela A-7- Geração de calor ou reações violentas como resultado da mistura das substâncias do grupo A com B.

Tabela A-8 - Explosão, fogo, geração de gás inflamável

(hidrogênio) como conseqüências da mistura de materiais dos grupos 2-A com 2-B.

Tabela A-9 - Geração de gás cianídrico e sulfúrico como conseqüência da interação do grupo 3-A com 3-B.

Tabela A-10 - Explosão, fogo, geração de calor ou de gases

inflamáveis ou tóxicos como consequêencia da interação entre os materiais do grupo 4-A com 4-B.

Tabela A-11 - Explosão, fogo e reações violentas como conseqüência da mistura de materiais listados no grupo 5-A com 5-B.

Tabela A-12 - Explosão, fogo, reações violentas como conseqüência da reação entre substâncias do grupo 6-A com 6-B.

Quadro A-1 -Segregação de substâncias perigosas. requisitos a serem observados dependendo da classificação da substância.

Tabela A-13- Residuos contendo substâncias classificadas como inflamáveis gerados pela Instituição A e descarte adotado

Tabela A-14- Resíduos contendo substâncias classificadas como inflamáveis gerados pela Instituição B e descarte adotado

Tabela A-15- Resíduos contendo substâncias classificadas como inflamáveis gerados pela Instituição $\mathrm{C}$ e descarte adotado

Tabela A-16- Resíduos contendo substâncias classificadas como corrosivas gerados pela Instituição A e descarte adotado

Tabela A-17- Residuos contendo substâncias classificadas como corrosivas gerados pela Instituição B e descarte adotado 
Tabela A-19- Resíduos contendo substâncias classificadas como reativas gerados pela Instituição A e descarte adotado

Tabela A-20- Resíduos contendo substâncias classificadas como reativas gerados pela Instituição B e descarte adotado

Tabela A-21- Resíduos contendo substâncias classificadas como A61 reativas gerados pela Instituição $\mathrm{C}$ e descarte adotado

Tabela A-22- Resíduos contendo substâncias classificadas como A63 tóxicas gerados pela Instituição A e descarte adotado

Tabela A-23- Resíduos contendo substâncias classificadas como A66 tóxicas gerados pela Instituição $B$ e descarte adotado

Tabela A-24- Resíduos contendo substâncias classificadas como A69 tóxicas gerados pela Instituição $\mathrm{C}$ e descarte adotado

Tabela A-25- Resíduos contendo substâncias classificadas como A71 não perigosas gerados pela Instituição A e descarte adotado

Tabela A-26- Resíduos contendo substâncias classificadas como A77 não perigosas gerados pela Instituição B e descarte adotado

Tabela A-27- Resíduos contendo substâncias classificadas como A84 não perigosas gerados pela Instituição $\mathrm{C}$ e descarte adotado

Tabela A-28 - Tratamento, disposição, incompatibilidade A87 e procedimentos a serem adotados em situações de emergência para substâncias inflamáveis levantadas

Tabela A-29 - Tratamento, disposição, incompatibilidade A93 e procedimentos a serem adotados em situações de emergência para substâncias corrosivas levantadas

Tabela A-30 - Tratamento, disposição, incompatibilidade A98 e procedimentos a serem adotados em situações de emergência para substâncias reativas levantadas

Tabela A-31 - Tratamento, disposição, incompatibilidade e procedimentos a serem adotados em situações de emergência para substâncias tóxicas levantadas.

Tabela A-32 - Tratamento, disposição, incompatibilidade e procedimentos a serem adotados em situações de emergência para substâncias radiativas levantadas. 
Tabela A-33 - Cuidados na manipulação, Limites de exposição para o ambiente de trabalho e efeitos nocivos na exposição aguda e crônica das principais substâncias químicas levantadas nas três Instituições avaliadas

Tabela A-34- Parâmetros utilizados na extrapolação das doses A128 de referência disponiveis na literatura para algumas das substâncias manipuladas nas Instituições avaliadas.

Tabela A-35- Níveis de risco mínimo estabelecidos para algumas das substâncias manipuladas pelas Instituições de estudo 


\section{GLOSSÁRIO}

- ASTDR - Agency for Toxic Substances and Disease Registry - Agência para o registro de Substâncias tóxias e doenças.

- Avaliação de risco (Risk Assessment) - é o processo que estabelece informações relacionadas a niveis aceitóveis de um risco e/ou niveis de risco para um individuo, grupo, sociedade ou meio ambiente ( SRA, 1999).

$\grave{E}$ o processo de avaliação das propriedades tóxicas das substâncias químicas e das condições de exposição para se determinar a probabilidade com que o homem será afetado e para se caracterizar a natureza dos efeitos adversos que poderão ser experimentados. (DERELANKO e HOLLINGER, 1995)

- Biotransformação é toda alteração que ocorre na estrutura química da substância, no organismo (OGA, 1996).

- Carcinogênicos genotóxicos substância carcinogênica que atua diretamente sobre o material genético (mutação).

- Carcinogênico não genotóxicos ou epigenético- substância que favorece o desenvolvimento tumoral sem atuar diretamente sobre o material genético.

- CEPA - Canadian Environmental Protection Act - Ato legislativo de Proteção Ambiental Canadense

- CNEN - Comissão Nacional de Energia Nuclear

- Dose de Benchmark (DB) - limite de confiança inferior (LCI) da dose que produz uma resposta (efeito crítico) em 5 a $10 \%$ da população de estudo

- Dose-efeito - relação entre a dose e gradação do efeito na população, entendendo-se efeito como uma alteração biológica medida através de uma escala graduada de severidade, ainda que, para certos niveis de exposição só se possa descrever um efeito qualitativo (SRA, 1999).

- Dose-resposta - a correlação entre a dose (nivel de exposição) e a proporção da população que apresenta um efeito especifico (resposta) (SRA, 1999).

- Dose ou concentração tumorigênica $5 \%\left(\mathbf{D T}_{5}\right)$ - dose capaz de promover a formação de tumores em $5 \%$ da população estudada

- DNEAO - Dose de nenhum efeito adverso observado

- EPI- equipamento de proteção individual 
- Índice de Exposição ou Potência (IEP) obtido dividindo-se a ingestão ou exposição diária estimada para o homem pela DT $_{5}$.

- INMETRO - Instituto Nacional de Metrologia, Normatização e Qualidade Industrial

-

- IPEN - Instituto de Pesquisas Energéticas e Nucleares

- IRIS - Integrated Risk Information System- Sistema da agência americana de meio ambiente - EPA que integra informações sobre risco.

- Monitorização $=$ monitoramento

- Monitorização biológica- segundo o comitê misto CCE/OSHANIOSH, é a medida e avaliação de agentes quimicos ou de seus produtos de biotransformação em tecidos, secreções, ar exalado ou alguma combinação destes para estimar a exposição ou o risco à saúde quando comparada com uma referência apropriada (OGA, 1996)

- NRM (Nível de risco mínimo) é uma estimativa da exposição humana diária a substâncias perigosas, presentes no meio ambiente, sem o risco considerável de se observar efeitos adversos durante um determinado tempo de exposição (ASTDR, 1999).

- Perigo - é a condição ou situação física que apresenta uma potencial consequência indesejável, como injúria a vida(SRA, 1999).

É a propriedade intrínseca ou capacidade de uma substância ou agente de causar uma alteração do estado de saúde (FAUSTMAN e OMENN, 1996).

- POPs -procedimentos operacionais padrão

- Risco é a probabilidade de ocorrência de um dano à saúde em determinadas condições de exposição (FAUSTMAN e OMENN, 1996)..

$\grave{E}$ o potencial de ocorrência de uma conseqüência indesejável, adversa à vida, saúde, propriedade ou meio ambiente; a estimativa do risco é geralmente baseada no valor esperado da probabilidade condicional ao evento multiplicado pelas suas conseqüências, dado que ele ocorra (SRA, 1999).

- RSS - resíduos de serviços de saúde

- TLV- TWA - Limite de exposição - Média Ponderada - a concentração média ponderada pelo tempo para uma jornada normal de 8 horas diárias e 40 horas semanais, para a qual a maioria dos trabalhadores pode estar repetidamente exposta, dia após dia, sem sofrer efeitos adversos à saúde. (ACGIH, 1999)

- TLV - STEL - Limite de Exposição - Exposição de curta duração - $\dot{e} a$ concentração a que os trabalhadores podem estar expostos continuamente por 
um periodo curto sem sofrer: 1) irrtiação; 2) lesão tissular crônica ou irreversivel; ou 3) narcose em grau suficiente para aumentar a predisposição à acidentes, impedir auto-salvamento ou reduzir significativamente a eficiência no trabalho, cuidando-se para que o limite de exposição - média ponderada (TLVTWA) não seja utltrapassado. ... Um STEL é definido como uma exposição média ponderada pelo tempo durante 15 minutos que não pode ser excedida em nenhum momento da jornada de trabalho, mesmo que a concentração média ponderada para 8 horas esteja dentro dos limites de exposição- média ponderada. (ACGIH, 1999)

- Toxicante ou agente tóxico é a entidade química capaz de causar dano a um sistema biológico, alterando seriamente uma função ou levando-o à morte, sob certas condições de exposição( OGA, 1996).

- Toxicocinética é o estudo da relação entre a quantidade de um agente tóxico que atua sobre o organismo e a concentração do mesmo no plasma, relacionando os processos de absorção, distribuição e eliminação do agente, em função do tempo. (OGA, 1996).

- Toxicodinâmica é o estudo da natureza da ação tóxica exercida por substâncias químicas sobre o sistema biológico, sob os pontos de vista bioquímico e molecular. (OGA, 1996).

- U.S. DOE (U. S. Department of Energy)- Departamento de Energia dos EUA

- U.S. EPA (U. S. Environmental Protection Agency) - Agência de Proteção Ambiental dos EUA.

- U.S. NAS (National Academy of Sciences) - Academia Nacional de Ciências dos EUA

- Xenobiótico - qualquer substância estranha ao organismo 


\section{INTRODUÇÃO}

As expectativas do consumidor contemporâneo em relação à qualidade dos produtos e serviços oferecidos provocou, mundialmente, a crescente conscientização da necessidade de se introduzir modificações nos modelos de produção e desenvolvimento para atingir e assegurar um bom desempenho econômico. Tornouse compulsório crescer economicamente garantindo a qualidade total dos insumos gerados.

O desenvolvimento econômico deve ser construído de forma sustentável, integrando os vários segmentos sociais e suas necessidades à qualidade dos produtos, sem prejuizo da qualidade ambiental. Para viabilizar este desenvolvimento sustentável, várias normas foram geradas - ISOGUIDES, procurando treinar o olhar da sociedade para as novas exigências, orientando a implantação e implementação de sistemas de qualidade e diretrizes que complementem os requisitos específicos de produtos ou serviços apresentados nas especificações técnicas ( ABNT- ISO 9000, 1990 ).

Este sistema aplica-se a todas as atividades relativas a qualidade de um bem ou serviço, incluindo os laboratórios químicos, acadêmicos e de análises, os quais têm se preocupado, na última década, em garantir a qualidade total dos serviços prestados. A comprovação de sua competência e melhoria da qualidade dos serviços prestados, requer a implantação de um Programa de Segurança de Qualidade, condição si ne qua non para seu credenciamento junto aos órgãos oficiais, os quais atuam em conformidade com as normas internacionais (INTERNATIONAL STANDARD ORGANIZATION - ISO/IEC guide 17025, 1998).

Os requisitos fundamentais para a implantação do Programa de Segurança de Qualidade contemplam, dentre outros aspectos, todas as fases de execução do ensaio: o planejamento do estudo, a validação da metodologia e a confeç̧ão dos 
procedimentos operacionais padrão ao descarte dos resíduos gerados durante a sua condução. Transcende, portanto, os aspectos relacionados à obtenção de um resultado confiável, estendendo-se, também, ao manuseio e descarte dos resíduos gerados durante a condução do estudo, os quais segundo a Norma n. ${ }^{\circ}$ NIE-DINQP 093 que trata dos Critérios para o credenciamento de laboratório de ensaio segundo os Princípios das Boas Práticas de Laboratórios do Instituto Nacional de Metrologia, Normatização e Qualidade Industrial - INMETRO (1998) ... devem ser efetuados de acordo com a legislação vigente. Isto inclui coleta, armazenamento, locais de descarte, procedimentos de transporte e descontaminação adequados.

No entanto, em função dos pequenos volumes e da diversidade dos resíduos gerados, a disposição adequada dos rejeitos de laboratório é, ainda, incipiente. Até a década de 80, a preocupação dos países desenvolvidos ateve-se aos geradores de grandes quantidades de resíduos, presumindo-se que os geradores de pequenas quantidades estavam aptos para o descarte adequado de seus rejeitos e/ou, em decorrência do pequeno volume, seus impactos ambientais poderiam ser considerados desprezíveis.

Em 1985, contudo, a U. S. Environmental Protection Agency - EPA atentou para este aspecto, regulamentando como estabelecimentos geradores de pequenas quantidades de resíduos, as atividades e serviços que produzem de 100 a $1000 \mathrm{Kg}$ de resíduos perigosos por mês e menos de $1 \mathrm{Kg}$ de resíduo perigoso que apresente toxicidade aguda elevada, conforme o documento 40 CFR 260, parte 10. Encontramse nesta categoria os museus de arte, serviços de manutenção de linhas aéreas e de edificios, hospitais veterinários, pavimentação e laboratórios fotográficos, acadêmicos, de pesquisa e de análises, os quais devem proceder o descarte dos resíduos gerados de acordo com as exigências legais (ACS, 1994; FORMAGGIA, 1994; HALL, 1989; PHIFER e McTIGUE, 1988).

Como algumas dessas atividades não geram as quantidades de resíduos perigosos acima mencionadas, a EPA para garantir que os resíduos perigosos gerados recebessem a adequada disposição, estabeleceu, na década de 90 , que aqueles que 
produzem menos de $100 \mathrm{~kg} /$ mês de residuos perigosos e não mais que $1 \mathrm{~g} / \mathrm{mês}$ de residuos perigosos que apresentem toxicidade aguda elevada, estão desobrigados de vários controles e regulamentações, classificando-os como geradores de pequenas quantidades sendo condicionalmente dispensados de alguns registros, autorizações e controles (ACS, 1994).

De modo geral, os laboratórios da comunidade científica americana geram menos de $0,1 \%$ do total de resíduos perigosos regulamentados pela EPA. Entretanto, alguns dos residuos gerados contém metais, dioxinas, ftalatos lixiviados dos plásticos de cloreto de vinila utilizados e outras substâncias químicas que podem persistir no meio ambiente e serem prejudiciais à saúde humana (PINHOLSTER, 2000). Resíduos infectantes gerados nessas instituições podem contaminar as águas e contribuir com os estimados 7 milhões de casos anuais de infecções microbianas, veiculadas por esse meio, nos Estados Unidos (BLACK, 2000).

Esses fatos estimularam a criação de um programa intitulado Labs for the $21^{s t}$ century, patrocinados pela EPA e pelo U. S. Department of Energy - DOE, congregando, em setembro de 1999, especialistas do setor privado e público para discutirem estratégias e tecnologias e racionalizar o uso de energia elétrica e a promover gestão ambiental nos laboratórios. (USEPA, 2000).

É mister a implementação de uma política de gerenciamento de resíduos de laboratório. Tal ação, em nível nacional, além de atender as Boas Práticas de Laboratório (BPL) e as exigências da Vigilância Sanitária (CVS, 2000), pode minimizar ou até mesmo, impedir os efeitos adversos causados por esses resíduos, do ponto de vista ocupacional, sanitário e ambiental, quando efetuada racional e adequadamente, atendendo, assim, à Lei de Crimes Ambientais.

A Lei Federal $n^{\circ} .9 .605$ de 12 de fevereiro de 1998 e regulamentada em 21 de setembro de 1999, conhecida como Lei de Crimes Ambientais, define o arcabouço jurídico - legal para o efetivo exercício de uma ação em defesa do meio ambiente e consequentemente da população. Responsabiliza administrativa, civil e penalmente as pessoas juridicas e físicas, autoras e co-autoras de condutas ou atividades lesivas 
ao meio ambiente. As infrações administrativas são punidas, em primeiro lugar, com a advertência, seguida de multa simples ou diária. Paralelamente ao processo administrativo se dá a ação penal, cujas sanções vão desde a prestação de serviços à comunidade, interdição temporária de direitos, suspensão parcial ou total das atividades, prestação pecuniária, recolhimento domiciliar até reclusão de seis meses a cinco anos, dependendo do artigo infringido (BRASIL, 1998) Neste contexto, o gerenciamento de resíduos emerge como uma questão importante a ser estudada e implantada. 


\section{Gerenciamento dos resíduos gerados}

Devido a diversidade da composição dos resíduos gerados em laboratórios substâncias inflamáveis, explosivas, corrosivas, de toxicidade relativamente elevada, patogènicas, material perfurantes e cortantes - algumas etapas devem ser seguidas para o efetivo gerenciamento: identificação, caracterização, segregação, acondicionamento, tratamento, armazenamento, transporte e disposição final, concomitantemente, ao uso de equipamentos de proteção, conscientização e treinamento do pessoal para o manuseio seguro do ponto de vista de saúde pública e meio ambiente.

A estratégia mais utilizada para o gerenciamento de residuos perigosos consiste no seu acompanhamento do local de geração até sua disposição final, e é aplicável também aos resíduos de laboratório (FURS, 1993; NRC, 1995). As distintas etapas se processam dentro ou fora dos limites do estabelecimento gerador, o qual é considerado responsável por todas as etapas do gerenciamento, mesmo quando contrata os serviços de transporte, tratamento e disposição final de seus resíduos, tornando-se co-responsável em caso de acidente. Em alguns países, a legislação vigente é explicita sobre este aspecto, em outros, ele existe, gerencial mas não juridicamente e em outros, ainda, sequer é cogitado (RISSO, 1993).

\subsection{Etapas do gerenciamento}

\subsubsection{Identificação e classificação}

A identificação e classificação dos resíduos gerados deve oferecer informação necessária e suficiente para a disposição dos mesmos e implica na realização de um levantamento sobre os tipos de resíduos gerados, volume, e local de geração.

No Brasil, a classificação de resíduos é realizada através de normas e resoluções. A Associação Brasileira de Normas Técnicas - ABNT, através de normas regulamentadoras, dispõe sobre a classificação dos resíduos sólidos por meio da 
NBR 10.004 (1985) e sobre a terminologia, classificação, manuseio e coleta dos Resíduos de Serviços de Saúde por meio da NBR 12.807, NBR 12.808, NBR 12.809 e NBR 12.810, respectivamente, publicadas em 1993. Por sua vez, o Conselho Nacional do Meio Ambiente (CONAMA), na Resolução n 5, de 05/08/93, classifica os resíduos oriundos de serviços de saúde, portos e aeroportos em quatro grupos distintos, utilizando-se do conceito de resíduo sólido estabelecido pela NBR 10.004 . É, então, importante entender os conceitos de resíduos sólidos e resíduos perigosos para se classificar adequadamente os resíduos de laboratório.

A NBR 10.004 (1985) define resíduos sólidos como os residuos no estado sólido e semi sólido, que resultam de atividade da comunidade de origem: industrial, doméstica, hospitalar, comercial, agrícola, de serviços e de varrição. Ficam incluídos nesta definição os lodos provenientes de sistemas de tratamento de água, aqueles gerados em equipamentos e instalações de controle de poluição, bem como liquidos cujas particularidades tornem inviável o seu lançamento na rede pública de esgotos ou corpos de água, ou exijam para isso soluções técnica e economicamente inviáveis em face à melhor tecnologia disponível. E classifica-os em: Classe I residuos perigosos, Classe II - resíduos não-inertes e Classe III - resíduos inertes.

Segundo essa norma, os resíduos Classe I são aqueles que apresentam periculosidade ou uma das seguintes caracteristicas: inflamabilidade, corrosividade, reatividade, toxicidade ou patogenicidade. E periculosidade consta ser uma característica apresentada por um resíduo, que em função de suas propriedades fisicas, químicas ou infecto-contagiosas, pode apresentar:

a) risco à saúde pública, provocando ou acentuando, de forma significativa, um aumento de mortalidade ou incidência de doenças, e/ou;

b) risco ao meio ambiente, quando o residuo é mamuseado ou destinado de forma inadequada.

Os laboratórios que manipulam material biológico geram resíduos de serviços de saúde - RSS, enquadrados como resíduos perigosos devido aos riscos à saúde 
pública (BOATRIGH e col., 1993; BURKE, 1992; BUSH e col., 1991; BYRNS e BURKE, 1992; FLEMING e col., 1993; FORMAGGIA, 1994; USEPA, 1986).

Os RSS estão classificados em três categorias: resíduos infectantes, classificados como classe A; resíduo especial, classificado como classe $\mathrm{B}$ e resíduo comum, classificado como classe C (ABNT - NBR 12.808, 1993). Os resíduos infectantes - classe $\mathbf{A}$, encontram-se divididos em :

- Tipo A.1 - Biológico: cultura, inóculo, mistura de microorganismos e meio de cultura inoculado proveniente de laboratório clínico ou de pesquisa, vacina vencida ou inutilizada, filtro de gases aspirados de áreas contaminadas por agentes infectantes e qualquer resíduo contaminado por estes materiais.

- Tipo A.2 - Sangue e hemoderivados: bolsa de sangue após transfusão, com prazo de validade vencido ou sorologia positiva, amostra de sangue para análise, soro, plasma e outros subprodutos.

- Tipo A.3 - Cirúrgico, anatomopatológico e exudato: tecido, órgão, feto, peça anatômica, sangue e outros líquidos orgânicos resultantes de cirurgia, necrópsia e resíduos contaminados por estes materiais.

- Tipo A.4 - Perfurante ou cortante: agulha, pipeta, lâmina de bisturi e vidro.

- Tipo A.5 - Animal contaminado- carcaça ou parte de animal inoculado, exposto à microorganismos patogênicos ou portador da doença infecto-contagiosa, bem como resíduos que tenham estado em contato com este.

- Tipo A.6 - Assistência ao paciente: secreções, excreções e demais líquidos orgânicos procedentes de pacientes, bem como os resíduos contaminados por estes materiais, inclusive restos de refeições.

Por sua vez, o resíduo especial, classe B, encontra-se sub-dividido em:

- Tipo B.1 - Rejeito radioativo: material radioativo ou contaminado, com radionuclídeos, proveniente de laboratórios de análises clínicas, serviços de medicina nuclear e radioterapia, regulamentado pela Resolução CNEN-NE 6.05 (CNEN, 1985).

- Tipo B.2 - Resíduo farmacêutico: medicamento vencido, contaminado, interditado ou não utilizado 
- Tipo B.3 - Residuo químico perigoso: residuo tóxico, corrosivo, inflamável, explosivo, reativo, genotóxico ou mutagênico, regulamentado pela norma NBR 10.004 .

Todos os residuos que não se enquadram nos tipos $\mathrm{A}$ e $\mathrm{B}$ e que, por sua semelhança aos residuos domésticos, não ofereçam risco adicional à saúde pública, como por exemplo: residuo de atividade administrativa, dos serviços de varrição e limpeza de jardins e restos alimentares que não entraram em contato com pacientes estão classificados como residuo comum, classe $\mathrm{C}$.

A Resolução n5 do CONAMA de 1993, classifica os resíduos sólidos em:

- Grupo $\mathrm{A}$ : residuos que apresentam risco potencial à saúde pública e ao meio ambiente devido a presença de agentes biológicos.

Enquadram-se neste grupo, dentre outros: sangue e hemoderivados, animais usados em experimentação, bem como os materiais que tenham entrado em contato com os mesmos; excreções, secreções e líquidos orgânicos; meios de cultura; tecidos, órgãos, fetos e peças anatômicas; filtros de gases aspirados de área contaminada; resíduos advindos de áreas de isolamento; restos alimentares de unidade de isolamento; resíduos de laboratório de análises clínicas; residuos de unidade de atendimento ambulatorial; resíduos de sanitários de unidade de internação de enfermaria e animais mortos a bordo dos meios de transporte, objeto desta resolução. Neste grupo incluem-se, dentre outros, os objetos perfurantes ou cortantes, capazes de causar punctura ou corte, tais como lâminas de barbear, bisturi, agulhas, escalpes, vidros, quebrados, etc., provenientes de estabelecimentos prestadores de serviços de saúde.

- Grupo B: residuos que apresentam risco potencial à saúde pública e ao meio ambiente devido às suas características químicas.

Enquadram-se neste grupo, dentre outros:

a) drogas quimioterápicas e produtos por elas contaminados;

b) residuos farmacêuticos (medicamentos vencidos, contaminados, interditados ou não utilizados); $\mathbf{e}$,

c) demais produtos considerados perigosos, conforme classificação da NBR 10004 da ABNT. 
- Grupo C: rejeitos radioativos. Enquadram-se neste grupo os materiais radioativos ou contaminados com radionucleotídeos, provenientes de laboratórios de análises clínicas, serviços de medicina nuclear e radioterapia, segundo Resolução CNEN 6.05.

- Grupo D: resíduos comuns são todo os demais que não se enquadram nos grupos descritos anteriormente.

Independente da norma ou resolução utilizada, os residuos devem ser classificados, então, em resíduos perigosos e não perigosos, infectantes ou não infectantes, radioativos ou uma mistura destes. A identificação do local de geração e volume de cada resíduo ou mistura de resíduos permite dimensionar os espaços físicos necessários para a manipulação dos mesmos, decidir satisfatoriamente sobre quais as alternativas técnicas viáveis para a disposição de cada fração componente ou selecionar os equipamentos e dispositivos mais convenientes para tal propósito, a partir do que será possível segregar, acondicionar, tratar previamente - se houver a necessidade ou oportunidade, armazenar e transportar ao destino final cada uma das frações classificadas (RISSO, 1993; USEPA, 1986).

Devido à diversidade das substâncias químicas utilizadas em laboratório, a classificação dos resíduos provenientes dessas substâncias exige o conhecimento de suas propriedades físico-químicas - inflamabilidade, corrosividade, reatividade - e de sua toxicidade, como discriminado, no anexo 1, pela ABNT - NBR 10.004 (1993) ou pela EPA (ACS ,1994).

Para resíduos químicos desconhecidos, geralmente, não é necessário determinar precisamente a estrutura molecular deste material, sendo suficiente a caracterização de sua periculosidade através da descrição física do resíduo ou de suas diferentes camadas e verificação de sua: solubilidade ou reatividade com a água; $\mathrm{pH}$; inflamabilidade; presença de oxidantes; presença de halogênios; presença de material radioativo; presença de sulfetos e cianetos; presença de material infectante; presença de outros constituintes tóxicos, como alguns compostos metálicos. Em geral, essas informações satisfazem as exigências legais e da unidade de tratamento Se isso não 
for suficiente, análises químicas mais especificas e sofisticadas, empregando técnicas como cromatografia líquida e em fase gasosa, espectrometria de massa, infravermelho ou espectrofotometria de absorção atômica, devem ser realizadas para o gerenciamento adequado do resíduo (ACS, 1994; FURS, 1993; NRC, 1995).

Os procedimentos mais simples para identificação dos parâmetros acima descritos encontram-se listados no anexo 2 e uma marcha analítica é apresentada no anexo 3. A realização desses testes exige a adoção de medidas de segurança como o uso de equipamentos de proteção individual e manipulação dos resíduos e reagentes em capelas químicas. Especial atenção deve ser dedicada a este aspecto quando da manipulação de resíduos antigos, devido a possibilidade de alteração das substâncias presentes e formação de outras, de elevada periculosidade, como os peróxidos (ACS, 1994; FURS, 1993; NRC, 1995).

\subsubsection{Segregação}

A diversidade dos resíduos de laboratório exige a devida segregação para assegurar que cada fração receba apropriado manuseio, tratamento e disposição final. A segregação deve ser implantada no local de geração do resíduo, separando as frações infecciosas e perigosas das não infecciosas e não perigosas, permitindo a reutilização, recuperação ou reciclagem de alguns resíduos e o encaminhamento à coleta municipal da fração considerada comum ou inerte (FLEMING e col., 1993; HATFIELD e DAVID, 1993; NRC,1995; PHIFER e McTIGUE, 1988; RISSO, 1993; SILVERMAN, 1992; STRICOFF e WALTERS, 1995; USEPA, 1990 a).

A triagem preliminar realizada para caracterizar os residuos gerados permite separá-los em resíduos desconhecidos e os de composição ou origem conhecida. Estes últimos são, seqüencialmente, subdivididos em grupos de acordo com as propriedades físico-químicas aliadas à normatização e a compatibilidade química, tratamento a ser realizado - estabilização e incineração, por exemplo, e critérios adotados pela unidade de disposição (ACS, 1994; FURS, 1993; NCR, 1995). 
A minimização dos riscos está diretamente relacionada com a segregação. É uma estratégia utilizada para redução do volume total ou da toxicidade do resíduo gerado, antes de submetê-lo a tratamento ou descartá-lo. Este termo inclui a redução da quantidade de resíduos gerados no estabelecimento, através da adoção de micrométodos; substituição dos produtos utilizados por outros de menor toxicidade; recuperação, reutilização ou reciclagem dos mesmos e pré- tratamento para redução ou eliminação da periculosidade (ACS, 1994; FURS, 1993; NCR, 1995; PRÜSS e col.,1999; SILVERMAN, 1992; STRICOFF; USEPA, 1990 a e WALTERS, 1995). A Tabela 1 apresenta, a título de exemplo, procedimentos e respectivos métodos para a minimização dos resíduos de laboratório.

Tabela 1 - Minimização de resíduos perigosos no local de geração.

\begin{tabular}{|c|c|c|}
\hline Procedimento & Método & Exemplo \\
\hline $\begin{array}{l}\text { Eliminação da } \\
\text { periculosidade }\end{array}$ & $\begin{array}{l}\text { modificação do processo por } \\
\text { um que não gere resíduo } \\
\text { perigoso }\end{array}$ & $\begin{array}{l}\text { substituição de solução } \\
\text { sulfocrômica na lavagem de } \\
\text { vidraria por sabões como } \\
\text { ALCONOX }\end{array}$ \\
\hline $\begin{array}{l}\text { Redução da periculosidade } \\
\text { do material puro }\end{array}$ & $\begin{array}{l}\text { substituição de materiais } \\
\text { perigosos/tóxicos por menos } \\
\text { tóxicos }\end{array}$ & $\begin{array}{l}\text { Uso de naftilenodiamina em } \\
\text { substituição ao l-naftol. } \\
\text { Uso de tolueno em substituição ao } \\
\text { benzeno }\end{array}$ \\
\hline Limitar a aquisição & minimizar o supérfluo & $\begin{array}{l}\text { comprar menos ou frascos } \\
\text { menores; restringir a aquisição de } \\
\text { substâncias químicas que se } \\
\text { degradam facilmente. }\end{array}$ \\
\hline Limitar o uso & $\begin{array}{l}\text { redução da escala de } \\
\text { procedimentos ou processos }\end{array}$ & micro-análise \\
\hline Uso do resíduo & $\begin{array}{l}\text { a. reutilização } \\
\text { b. reciclagem } \\
\text { c. recuperação }\end{array}$ & $\begin{array}{l}\text { a. uso de resíduos básicos para } \\
\text { neutralizar ácidos } \\
\text { b. destilação de solventes } \\
\text { c. recuperação de cádmio } \\
\text { metálico com ácido nítrico }\end{array}$ \\
\hline $\begin{array}{l}\text { Redução do volume de } \\
\text { resíduo }\end{array}$ & $\begin{array}{l}\text { mistura dos líquidos } \\
\text { compativeis }\end{array}$ & $\begin{array}{l}\text { mistura de solventes e ácidos; } \\
\text { precipitação dos materiais tóxicos } \\
\text { da solução }\end{array}$ \\
\hline $\begin{array}{l}\text { Redução da periculosidade } \\
\text { do resíduo }\end{array}$ & tratamento do resíduo & $\begin{array}{l}\text { redução dos ácidos e oxidantes; } \\
\text { quelação ou estabilização dos } \\
\text { materiais tóxicos }\end{array}$ \\
\hline
\end{tabular}

Fonte: American Chemical Societv Task Force on Laboratorv Waste Management. 1994 - modificada. 
A recuperação, reciclagem e reutilização de substâncias químicas não parecem, à princípio, uma opção economicamente sedutora. No entanto, o elevado custo para a incineração de pequenas quantidade de residuos ou, a exemplo dos paises desenvolvidos, a dificuldade em se encaminhar os rejeitos para aterros sanitários pela diminuição de sua capacidade nestes locais, torna interessante esta opção quando da obrigatoriedade da correta disposição dos resíduos de laboratório. (ACS, 1994; FURS, 1993; NRC, 1995; PHIFER e McTIGUE, 1988).

A efetiva segregação e conseqüente minimização dos resíduos gerados, são fatores de segurança importantes para o pessoal que os manipula - interna e externamente ao estabelecimento - para os indivíduos que operam as instalações de tratamento ou disposição, e para o público em geral (CIRCULO DE TRABAJO de LAGA, 1992; CUTHEL, 1993; FLEMING e col., 1993 , FURS, 1993; HATFIELD e DAVID, 1993; USEPA, 1990 a; WATTS e col., 1997).

\subsubsection{Acondicionamento dos resíduos}

Os resíduos segregados devem ser propriamente acondicionados para o armazenamento temporário até o tratamento, transporte ou disposição final. $O$ acondicionamento, como definido pela ABNT na NBR 12.807 (1993), é o ato de embalar os RSS, em recipientes para protegê-los de risco e facilitar o seu transporte, devendo ser executado no momento de sua geração, no seu local de origem ou próximo, e com a correta identificação (ABNT-NBR 12.809, 1993; CIRCULO DE TRABAJO de LAGA, 1992; FURS, 1993; NRC, 1995; RISSO, 1993).

Os recipientes utilizados para residuos farmacêuticos e químicos perigosos devem ser adequados ao seu tipo/classe, quantidade e características físico-químicas visando o melhor manuseio e proteção do pessoal encarregado de sua coleta e remoção. Portanto, o tamanho, forma e material dos recipientes devem assegurar a resistência, integridade e fechamento de modo a não possibilitar vazamento, utilizando-se somente dois terços de sua capacidade.(ABNT-NBR 12.809, 1993). 
Estes recipientes devem ser identificados adequadamente. Os rótulos, devem conter informação suficiente para assegurar o manuseio e a disposição segura, incluindo a data de início da acumulação, os nomes químicos dos principais componentes e qualquer integrante de menor interesse que seja perigoso, sua concentração, e principais características físico-químicas. Devem ainda indicar se o rejeito é tóxico, reativo, corrosivo para pele ou metal, inflamável, irritante para pele e mucosas, ou se provoca dano quando inalado (ACS, 1994; FLEMING e col., 1993; FURS, 1993; NCR, 1995).

A reutilização do frasco original da substância química reduz os custos no acondicionamento, porém, aumenta o risco do armazenamento por elevar o número de recipientes primários, o que torna necessário avaliar o binômio custo/beneficio (NCR, 1995; RISSO,1993; STRICOFF e WALTERS, 1995).

O uso de saco plástico branco para resíduos infectantes é recomendado por ser prático, eficiente, reduzir a exposição do manipulador no contato direto com os resíduos, melhorar as condições de higiene e descarte. Para seu fechamento é necessário retirar o excesso de ar, cuidando para não inalá-lo, torcer e amarrar sua abertura com arame, nó, ou barbante ( ABNT- NBR 12809, 1993, RISSO, 1993).

Os residuos perfurantes e cortantes devem ser acondicionados em recipientes rígidos com sistema de fechamento e identificação adequados, antes de serem lançados nos sacos plásticos (ABNT - NBR 12.809, 1993; BUSH e col. 1991, FORMAGGIA, 1994; RISSO, 1993).

A separação dos resíduos perfurantes e cortantes dos demais, em recipientes rígidos, é sempre recomendada, devido ao perigo de acidentes em função de sua natureza e por estarem, com freqüência, em contato com material infectante (FORMAGGIA, 1994; RISSO, 1993).

Os resíduos classificados como comuns podem ser acondicionados em sacos plásticos de qualquer cor (FORMAGGIA, 1994). Os resíduos químicos não classificados como perigosos também podem ser considerados resíduos comuns. 


\subsubsection{Tratamento de resíduos}

Com o objetivo de reduzir os riscos e facilitar a sua disposição final, os resíduos podem ser submetidos a processos, técnicas ou métodos de tratamento que alterem seu caráter ou sua composição, considerando manipulação e custo. Estes procedimentos podem ocorrer no próprio local de geração ou externamente e são aplicáveis tanto aos resíduos químicos como aos infectantes.

É possível reduzir ou eliminar a periculosidade de muitas substâncias químicas através de processos químicas e biológicas realizados no próprio laboratório. Dentre os diversos métodos disponiveis pode-se destacar o tratamento químico - uma opção barata para disposição de pequenas quantidades de resíduos, utilizado, especialmente, para carcinógenos como aflatoxinas, N-nitrosaminas, agentes alquilantes, compostos halogenados e hidrazina e para mutágenos como o brometo de etídio; a neutralização de ácidos e bases minerais os quais podem, após a realização deste procedimento, serem lançados na rede de esgoto; a destilação de solventes e a biodegradação, aeróbica ou anaeróbica, de substâncias químicas, como fenóis, álcoois e cetonas (FURS, 1993; HATFIELD e DAVID, 1992; LUNN e SAMSONE, 1994; NRC, 1995; PICOT e GRENOUILLET, 1995; SAMBROOK e col., 1989; STRICOFF e WALTERS, 1995).

Os métodos mais utilizados no tratamento de RSS são a esterilização a gás ou vapor, desinfeção química por adição de peróxido de hidrogênio, hipocloritos, ácidos, álcoois, compostos de amônio quaternário ou cetona e incineração, após a compactação ou trituração dos resíduos se necessário. Esses resíduos podem, ainda, ser tratados por ativação térmica, irradiação ou por plasma (BOATRIGH, e col., 1993; BURKE, 1992; BUSH, e col., 1991; BYRNS,e BURKE, 1992; COSTELLO e EMERY, 1994; FLEMING e col., 1993; MARCHESE, 1993; PRÜSS e col., 1999;USEPA, 1986; USEPA, 1990 b).

Informações referentes à aplicação de diferentes métodos de tratamento por categoria de residuo, destacando-se suas vantagens, desvantagens e eficácia encontram-se disponíveis nos anexos 4,5 e 6. 
$\mathrm{O}$ resíduo gerado em laboratório pode conter uma mistura de diferentes classes de rejeitos: biológico, químico e radioativo, e, por isso, requer considerações especiais quanto aos métodos de tratamento a serem utilizados.

A alternativa menos onerosa e mais eficiente para resíduos químicos que contenham radionucleotídeos de meia-vida curta é o armazenamento no local de geração até seu decaimento para posterior gerenciamento do resíduo químico. $\mathrm{O}$ armazenamento no próprio laboratório não é adequado dada a dificuldade em se manter os níveis de proteção requeridos na área de trabalho. Assim, um local ventilado, com exaustão e filtragem, drenos de piso para coleta de líquidos provenientes de derramamento e sistema que minimize a dispersão e migração do material radioativo para o meio ambiente deve ser providenciado (CNEN, 1985).

Em geral, permite-se o armazenamento de radionucleotídeos de meia-vida $\left(\mathrm{T}_{1 / 2}\right)$ inferior a 65 dias. Após 10 meias-vidas, a mistura de resíduos químicoradioativo pode ser tratada somente como resíduo químico. A EPA limita o tempo de armazenamento de resíduos químicos por 90 dias. $\mathrm{O}$ armazenamento de uma mistura de resíduos químico-radioativo por um período maior requer aprovação das autoridades regionais americanas.(NRC, 1995). No Brasil, a Comissão Nacional de Energia Nuclear - CNEN estabelece que o material radioativo deve permanecer armazenado em local conveniente até que suas concentrações sejam inferiores aos limites especificados na norma CNEN-NE 6.05 (CNEN, 1985).

Com relação à mistura de resíduo químico e infectante, genericamente, recomenda-se que o resíduo infectante seja inativado em primeiro lugar e depois se trate ou se disponha adequadamente o resíduo químico (USNIEHS, 1998). Entretanto, o método de tratamento escolhido para inativar o resíduo biológico pode ser inadequado para o tratamento do resíduo químico ou radioativo. Por exemplo, se o resíduo contém um solvente orgânico e um agente infectante, a autoclavação usualmente empregada para inativar o resíduo biológico é inadequada neste caso, uma vez que, concentrações significativas do solvente podem ser liberadas para a 
atmosfera durante o processo. A destruição térmica deve ser substituida pela desinfecção química (NRC, 1995).

A incineração é o método mais apropriado para disposição de material biológico ou carcaças de animais contaminados ou contendo substâncias químicas, desde que estas não sejam metais (FLEMING e col., 1993).

Os mesmos princípios são válidos para mistura de resíduos biológicos e radioativos. Inativação do resíduo biológico através de desinfecção química, e posterior armazenamento para decaimento do radionucleotídeo (NRC, 1995, USNIEHS, 1998).

O resíduo biológico nessa mistura pode ser tratado por esterilização térmica autoclavação - desde que se monitorize as emissões verificando se estas se encontram abaixo dos valores requeridos, se destine uma única autoclave para esta finalidade, restrinja-se a área durante o período de esterilização e se teste a eficiência da autoclave periodicamente (NRC,1995).

Novas técnicas vêm sendo desenvolvidas para tratamento de misturas de resíduo mas ainda apresentam um alto custo. Cabe destacar dentre elas, a título de exemplo, a peroxidação associada a esterilização com ultravioleta ou ozônio como método de tratamento de soluções aquosas que contenham baixas concentrações de substâncias orgânicas (CHA e col., 1997); a oxidação seca, oxidação fluida ou oxidação térmica capaz de destruir o constituinte químico nas misturas de resíduos, desde que este esteja presente na concentração 1 a 10\% (CHA e col, 1997; USDOE, 1995); a biodegradação como tratamento de resíduos sólidos que contenham concentrações superiores a $1 \%$ de resíduo orgânico. Já estão disponíveis comercialmente bioreatores em escala laboratorial (CHA e col., 1997; NCR, 1995).

KAUFFMAN (1990), ao comparar os gastos com e sem tratamento dos resíduos gerados na Universidade do Estado de Indiana - EUA, no ano de 1987, demonstrou que o tratamento dos resíduos no próprio laboratório/Instituição reduz os 
custos da disposição final, como evidenciado na Tabela 2. Não obstante, é fundamental e imprescindível para estar em conformidade com as Boas Práticas de laboratório que estes procedimentos sejam realizados sob atenta supervisão de pessoal capacitado, ciente das propriedades químicas da substância e de sua toxicidade.

Tabela 2- Comparação dos custos do gerenciamento de resíduos, com e sem o tratamento prévio - Universidade do Estado de Indiana - EUA, 1987

\begin{tabular}{|c|c|c|c|c|c|}
\hline Resíduo & $\begin{array}{l}\text { Tratamento } \\
\text { empregado }\end{array}$ & $\begin{array}{l}\text { Volume } \\
\text { Kg/ano }\end{array}$ & $\begin{array}{c}\text { Custo do } \\
\text { tratamento } \\
\text { USS }\end{array}$ & $\begin{array}{c}\text { Disposição } \\
\text { sem tratamento } \\
\text { prévio } \\
\text { USS } \\
\end{array}$ & $\begin{array}{c}\text { Lucro } \\
\text { USS } \\
\end{array}$ \\
\hline $\begin{array}{l}\text { Ácidos e } \\
\text { alcalis }\end{array}$ & neutralização & 1200 & 600 & 24000 & 23.100 \\
\hline Metais & precipitação & 2800 & 1000 & 56.000 & 55.000 \\
\hline Solventes & destilação & 5.400 & 250 & 5400 & 5150 \\
\hline $\begin{array}{l}\text { Mistura de } \\
\text { solventes } \\
\text { compativeis }\end{array}$ & recuperação & 1.180 & 500 & 23.600 & 23.100 \\
\hline $\begin{array}{l}\text { Outros } \\
\text { reagentes }\end{array}$ & reciclagem & 1.250 & 200 & 12.500 & 12300 \\
\hline
\end{tabular}

A estimativa de custo por tonelada, dependendo da opção de tratamento empregado para resíduos infectantes, é apresentada na Tabela 3.

Tabela 3- Exemplificação dos custos dos tratamentos de Resíduos de Serviço de Saúde na Suíça

\begin{tabular}{ll}
\hline Tratamento empregado & Custo (US\$/tonelada)
\end{tabular}

\begin{tabular}{ll}
\hline Incineração & 380 \\
Autoclavação através de calor úmido $\left(121^{\circ} \mathrm{C}\right)$ & 400 \\
Desinfeção química & 200 \\
\hline
\end{tabular}

Fonte: PRUSS e col, 1999 


\subsubsection{Armazenamento}

Os resíduos não tratados no estabelecimento gerador devem ser armazenados, para posterior transporte ao local de tratamento ou ao destino final. Vários fatores estão envolvidos no armazenamento de resíduos: classe do gerador, compatibilidade, correto acondicionamento, opção pelo método de disposição, características do local de armazenamento e custo.

Exceto quando uma única substância é armazenada para recuperação, a compatibilidade de resíduos perigosos deve ser sempre considerada porque esta etapa envolve muitos resíduos num mesmo contêiner* ou local. Desta forma, a maneira como reagem quando em contato um com o outro deve ser observada (ACS, 1994; BRETHERICK, 1990; NCR, 1995). Pode-se utilizar tabelas de incompatibilidade, como as sugeridas nos anexos 7 e 8 , ou outras fontes de referência como as informações contidas nas fichas de segurança ou a classe de risco a que pertence a substância, uma vez que substâncias com igual código podem ser armazenadas em conjunto.

O anexo 9 apresenta um sistema para segregação de substâncias perigosas. Este sistema pode ser empregado tanto na organização de um almoxarifado quanto na colocação adequada dos resíduos no local de armazenamento por observar a classe química e incompatibilidades entre as diferentes substâncias químicas a serem armazenadas quando da aquisição de reagentes ou presentes nos resíduos gerados. (BERNABEI e LAUTENSCHLAEGER, 1998).

Deve-se verificar, também, a compatibilidade entre o resíduo e o material do recipiente. Esta incompatibilidade pode provocar dano ao manipulador e ao meio ambiente, como ocorre quando ácidos são estocados em tambores de aço e certos hidrocarbonetos em recipientes de plástico. A proximidade do contêiner contendo inflamáveis ao calor, chama ou rede elétrica deve também ser evitada (BRETHERICK, 1990; FURS, 1993; NRC, 1995; PHIFER e McTIGUE, 1988).

\footnotetext{
*Contêiner- equipamento fechado, de capacidade superior a 1001, empregado no armazenamento de recipientes ( ABNT - NBR 12.807, 1993)
} 
As duas maneiras mais práticas de armazenar resíduos são a mistura de substâncias compatíveis num único recipiente ou o armazenamento de substâncias compatíveis em recipientes primários, com volume inferior a $18 \mathrm{l}$, os quais são dispostos em contêiner, em geral, com capacidade para 360 l, chamado de lab pack. Este tipo de armazenamento é utilizado para o transporte de pequenos volumes de diversos resíduos até o local do armazenamento ou do tratamento (ACS, 1994). Os dois tipos de armazenamento são comparados em relação à necessidade de atenção para com a compatibilidade dos resíduos, empenho no acondicionamento, segurança, regulamentações, custo e opções de disposição, apresentados na Tabela 4.

Tabela 4 - Comparação entre Mistura de residuos e Lab Pack

\begin{tabular}{lll}
\hline CONSIDERAÇÕES & MISTURA & LAB PACK \\
\hline Compatibilidade & maior observação & menor observação \\
Acondicionamento & menor empenho & maior empenho \\
Segurança & maior risco & menor risco \\
Regulamentação & poucas & diversas \\
Opções de disposição & maiores & menores \\
Custo & menor & maior \\
\hline
\end{tabular}

Fonte: ACS, 1994

O acondicionamento dos recipientes primários no contêiner exige alguns cuidados. Deve-se evitar que os recipientes primários entrem em contato direto uns com os outros e com a base do tambor onde serão colocados para evitar que possíveis vazamentos ocorram, comprometendo a segurança dos envolvidos e do local. Isto pode ser obtido colocando-se um estrado de madeira na base do contêiner e sobre ele os recipientes primários; o espaço entre a base e o estrado e o espaço entre os frascos deve ser preenchido com material absorvente (FURS, 1993; NRC, 1995; STRICOFF e WALTERS, 1995).

Todo o material contido nesse contêiner único deve estar devidamente listado, especificando-se volume e data do início do acúmulo, atendendo as normas de segurança e as exigências legais . 
O método escolhido e o esquema de segregação dos resíduos depende primariamente do tratamento ou disposição a serem adotados. Os requisitos da unidade de tratamento devem ser atendidos para minimizar os custos e o risco. Por exemplo, alguns incineradores só podem lidar com resíduos líquidos, outros só com sólidos ou resíduos em embalagens como fibras, vidros, embalagens de plástico, e alguns, com recipientes de aço ou tambores. Se a alimentação do incinerador for manual, deve-se observar volume e material da embalagem onde estão acondicionados os resíduos para não comprometer os trabalhadores do local de tratamento e a facilidade com que o forno é alimentado (FURS, 1993; NRC, 1995).

A separação adequada do resíduo que vai para o incinerador é essencial. Uma lista com os resíduos e quantidades presentes no contêiner deve ser fornecida para que se possa avaliar a capacidade comburente dos mesmos e a conseqüente velocidade de alimentação do incinerador. Por exemplo, deve-se evitar acondicionar volumes maiores que cem mililitros de dissulfeto de carbono num mesmo contêiner porque podem provocar uma explosão durante a incineração (NCR, 1995).

Após o correto acondicionamento em contêineres, segundo as exigências do método ou do responsável pela unidade de tratamento ou disposição escolhida, estes são temporariamente armazenados em instalações apropriadas, próximas ao local de geração, porém do lado externo e dentro dos limites do estabelecimento (NCR, 1995).

Dependendo do porte do estabelecimento gerador, poderá haver a necessidade dos dois tipos de abrigo: interno e externo. Os tipos de abrigo têm sua características definidas pela ABNT - NBR 12.809 (1993). Na falta de um abrigo interno apropriado é preferível manter apenas o armazenamento externo dos resíduos sólidos gerados do que utilizar salas inadequadas para este fim.

O abrigo externo deve ser de alvenaria, fechado, com aberturas teladas que permitam a ventilação, ser revestido com material liso lavável e impermeável, ter ralo sifonado, ponto de esgoto sanitário, iluminação artificial externa e interna, e ser de fácil acesso para as operações de coleta interna e externa. Deve ser projetado e 
construído levando em consideração o sistema de coleta de RSS adotado no município, prevendo a separação de áreas, devidamente sinalizadas, para resíduos infectantes e especiais e resíduos comuns (ABNT- NBR 12.809, 1993).

O abrigo deve ser inspecionado regularmente por pessoal treinado. A frequêencia de inspeção depende do nível de atividade e grau de periculosidade; geralmente é semanal. A inspeção inclui verificar se: as diretrizes estabelecidas para o armazenamento estão sendo seguidas; as condições dos contêiners atendem às normas de segurança, não ocorrendo corrosão ou vazamento interno e externo dos mesmos; a segregação dos resíduos contempla os requisitos de compatibilidade; os rótulos de identificação contém data, rol dos resíduos e quantidades, e, os equipamentos de segurança estão operando convenientemente (ABNT- NBR 12.809, 1993).

O tempo de armazenamento também deve ser observado, ainda que a ABNT não faça referência quanto a este aspecto. A legislação americana admite que $200 \mathrm{~kg}$ de resíduos perigosos sejam armazenados por até 90 dias sem a necessidade de se requerer permissão especial. $\dot{E}$ prudente que os resíduos perigosos gerados em laboratório sejam armazenados por periodos inferiores a 1 ano e, em função da limitação do espaço, das normas de incêndio e do potencial risco de derramamento, esse volume de $200 \mathrm{Kg}$ pode ser considerado elevado em se tratando de laboratórios (FURS, 1993; NRC, 1995).

Segundo as normas européias, o período de armazenamento dos resíduos infectantes não deve ser superior a 48 horas no período de inverno e a 24 horas no verão (PRÜSS e col., 1999). Tanto a Resolução n5 do CONAMA (1993) como a Portaria CVS - 01 (2000) não fazem quaisquer referências quanto ao período de armazenamento quer para resíduos infectantes como químicos, o que pode contribuir para situações de risco. 


\subsubsection{Transporte}

Os resíduos, devidamente acondicionados/armazenados, devem ser transportados do local de geração ao local de armazenamento. O sistema de transporte, em geral, pode empregar carrinhos, dutos de gravidade, tubos pneumáticos, elevadores ou carregamento manual. Para o transporte de quantidades superiores a $20 \mathrm{Kg}$, deve-se utilizar carrinhos específicos para transporte, atendendo às especificações da ABNT - NBR 12.810 (1993). O transporte dos recipientes deve ser realizado sem esforço excessivo ou risco de acidente para o funcionário e exige a utilização de equipamento de proteção individual.

A coleta e transporte externo, para fora do estabelecimento, para tratamento ou disposição final, requer cuidados específicos e rígido controle sanitário, sendo exigido pela Companhia de Tecnologia e Saneamento Ambiental - CETESB, o Certificado de autorização de destinação - CADRI e memorial caracterizando o residuo - MCE.

\subsubsection{Disposição Final}

A disposição final dos resíduos envolve seu envio para aterros sanitários, seguindo as exigências técnicas e legais quanto ao correto acondicionamento e tratamento, lançamento na rede de esgoto ou liberação para a atmosfera.

Até o final da década de 70, era comum, nos EUA, a prática de dispor a maioria dos rejeitos de laboratório na rede de esgoto. A partir de 80 , esta disposição indiscriminada, sem levar em consideração a quantidade ou a classe do resíduo, foi considerada inaceitável. O esgoto do laboratório está conectado a rede de esgoto municipal e seus efluentes vão, na maioria das vezes, para o sistema de tratamento. Alguns resíduos podem interferir com o funcionamento apropriado do sistema de tratamento, ou ainda, na tubulação do esgoto do laboratório, algumas substâncias 
quimicas podem apresentar risco de incêndio, explosão ou corrosão (ACS, 1994; FURS, 1993; HALL, 1989; NRC, 1995; SILVERMAN, 1992).

Substâncias químicas inócuas - aquelas que não apresentam características de inflamabilidade, corrosividade, reatividade, toxicidade e patogenicidade e não estão listadas como perigosas podem ser dispostas como lixo comum ou na via hídrica, em quantidades limitadas ao máximo de $500 \mathrm{~g}$ ou algumas centenas de mililitros. A disposição deve ocorrer com um volume de água 100 vezes maior ao que foi descartado. Líquidos imísciveis com a água ou inflamáveis - mesmo os hidrossolúveis - não devem ser dispostos na rede de esgoto (ACS, 1994; FURS, 1993; HALL, 1989; NRC, 1995).

A liberação de vapores para a atmosfera é, também, um método de disposição inaceitável para quantidades superiores a $50 \mathrm{ml}$ de material volátil (STRICOFF e WALTERS, 1995). Quando comparada às emissões industriais, a quantidade e concentrações de substâncias perigosas nos efluentes da capela é pequena, e sua remoção é tecnicamente desafiadora. As capelas de laboratório podem ter a saída de seus vapores redirecionadas para um coletor que impeça a sua liberação direta para o meio ambiente tais como lavadores de gases ou filtros contendo adsorventes como carvão ou alumina ativada e filtros para partículas, High efficency particulate and aerosol - HEPA (FURS, 1993; NRC, 1995). Nenhum desses métodos é, no entanto, totalmente eficaz e exigem manutenção e avaliação periódicas.

Quanto ao resíduos de serviços de saúde, muitos têm sido dispostos diretamente na rede de esgoto. Estes resíduos líquidos incluem resíduos sólidos que foram triturados e resíduos líquidos provenientes de laboratórios de análises - urina, sangue e outros líquidos corporais, medicamentos, além de resíduos químicos.

Em muitos países, como Reino Unido e Austrália, a disposição de pequenas quantidades de certos resíduos de serviço de saúde pode ser aceitável, uma vez que o risco potencial é reduzido através da diluição e dispersão dentro do sistema. Enfatizase, no entanto, a segregação, tratamento - autoclavagem, desinfecção ou incineração 
e trituração dos resíduos no local de geração, antes do lançamento no esgoto ou disposição no aterro sanitário. O lançamento na rede de esgoto está sujeita a aprovação das autoridades competentes (BURKE, 19922; BYRNS E BURKE, 1992; NRC, 1995; RISSO, 1993; USEPA, 1986; USEPA, 1990 b).

É importante lembrar que todas as etapas do processo de gerenciamento devem ser adequadamente registradas e estes registros mantidos mesmo após a disposição final.

Nos Estados Unidos, estes registros são uma exigência legal que auxiliam na monitorização do programa de gerenciamento. Exige-se documentação comprovando a caracterização do residuo, as quantidades geradas por mês e por ano (ACS, 1994; FURS, 1993; HALL, 1989; NRC, 1995; SILVERMAN, 1992). Outros registros úteis na avaliação do programa são: tipos e quantidades de resíduos gerados nos diferentes locais da instituição; custo da disposição dos vários tipos de resíduos e informação sobre tratamento e/ou procedimentos em caso de acidente ou extravasamento (ACS, 1994; WATTS, 1992). 


\section{EFEITOS À SAÚDE}

Discute-se, neste tópico, os aspectos relativos ao risco à saúde considerando a exposição à substâncias químicas e a material infectante.

\subsection{Risco químico}

A presença de resíduos perigosos em vários locais de destinação final é objeto de preocupação mundial (NAVA, 1996). Até o final de 1995, a EPA listou, somente no Estados Unidos, 40.000 locais de destinação final contendo resíduos perigosos (JOHNSON, 1997). Os trabalhadores dessas instalações, a população de entorno e até populações mais distantes encontram-se expostos, em geral, a baixas concentrações desses resíduos através da inalação das poeiras e fumaças emitidos pelo sítio de tratamento ou destinação final, da ingestão de água e alimentos contaminados pela lixiviação desses resíduos do local de destinação para as águas subterrâneas ou superficiais e desta para a cadeia alimentar (ANDELMAN, 1987; PLEUS e KATHRYN, 1996).

Do ponto de vista de saúde pública, a contaminação da água potável é a principal fonte de exposição da população (BOVE, 1996). No entanto, a relação entre a exposição aos resíduos perigosos e seus possíveis efeitos - clínicos e subclínicos sobre a saúde da população é dificil de ser estabelecida em função do grande número de toxicantes presentes nestes locais e das condições de exposição. São, hoje, bastante diferenciados, com manifestações mais insidiosas e sutis, como mutagênese, déficit no desenvolvimento infantil e efeitos psicológicos em adultos e crianças SEVER, 1997; WYES, 1997). Requerem estudos epidemiológicos e de avaliação de risco (DE ROSA, 1998).

\subsubsection{Avaliação de risco}

A avaliação de risco é um arcabouço conceitual que fornece o mecanismo estrutural para, através da revisão de informações relevantes, estimar-se o impacto sobre a saúde e ambiente decorrente da exposição ou presença de determinada 
substância química. E tem por conseqüência lógica, a aplicação da informação obtida no desenvolvimento de medidas práticas - gerenciamento - que permitam salvaguardar a saúde da população (WHO, 1999).

Segundo National Academy of Sciences dos Estados Unidos (US NAS, 1983), citada pelo WHO (1999), são quatro os componentes essenciais e distintos do paradigma integrante da avaliação de risco, a saber:
a) Identificação do perigo (hazard)
b) Avaliação da relação dose-resposta
c) Avaliação da exposição
d) Caracterização do risco

\subsubsection{Identificação do perigo}

A identificação do perigo baseia-se na análise, quali e quantitativa, de todos os dados disponiveis sobre uma dada substância - estudos epidemiológicos, de avaliação de toxicidade, relação estrutura-atividade, mecanismos de toxicidade, dentre outros - ponderando-se as evidências quanto aos efeitos adversos sobre o homem de modo a responder duas questões básicas: esta substância afeta a saúde humana? e em quais circunstâncias os efeitos tóxicos são observados?

Neste contexto, os estudos epidemiológicos fornecem informação melhor fundamentada, evitando a extrapolação da experimentação com animais para o homem. Nesses estudos, integram-se todas as fontes de exposição aos agentes químicos,os fatores de risco associados ao estilo de vida, dieta e hábito de fumar, além de considerarem a heterogeneidade da população humana.

a avaliação dos resultados dos estudos epidemiológicos, no entanto, é, muitas vezes, dificultada pela falta de informação sobre a exposição, tamanho da amostra, estudo de curta duração, vieses e fatores de confusão. Quando não se dispõe de estudos epidemiológicos confiáveis utilizam-se os dados de estudos experimentais 
com animais ou estudos in vitro, como os utilizados na avaliação de genotoxicidade (WHO, 1999).

A expressão da toxicidade de uma substância química depende das caracteristicas da exposição. Além de suas propriedades físico-químicas, deve-se considerar a magnitude, duração e freqüência da exposição, via de introdução e suscetibilidade dos sistemas biológicos - intra e interespécies. Estes parâmetros determinam a disponibilidade química da substância (concentração disponivel no ambiente para interagir com os sistemas biológicos) e devem ser considerados na avaliação do risco da exposição a esse determinado toxicante. $O$ resultado da identificação do perigo é estabelecer, através do julgamento científico, se determinado toxicante pode, em determinadas condições de exposição, provocar um efeito deletério à saúde humana.

\subsubsection{Avaliação da relação dose - resposta}

A avaliação da relação dose-resposta consiste no processo de caracterização da relação entre a dose administrada ou recebida de determinada substância e a incidência de um dado efeito nocivo significativo numa população. Para a maioria dos efeitos tóxicos - neurológicos, comportamentais, imunológicos, carcinogênico não genotóxicos, e outros, considera-se que exista uma dose ou concentração, abaixo da qual efeitos adversos não são observados. Para esses, um valor limite pode ser estabelecido. Para outros tipos de efeitos tóxicos - mutagênicos e carcinogênicos genotóxicos, assume-se a probabilidade de ocorrência de dano em qualquer nível de exposição, ou seja não há limite de tolerância (WHO, 1999).

Se um limite pode ser estabelecido, isto eqüivale assumir que existe um nível de exposição abaixo do qual acredita-se não haver efeitos adversos. Baseando-se na Dose de Nenhum Efeito Adverso Observado (DNEAO) e em fatores de incerteza, este valor limite pode ser estimado. Assim, a DNEAO é crítica e obtida através da relação dose - resposta. Esta relação, na maioria das vezes, é derivada de estudos com animais de experimentação e em geral, disponível somente em doses elevadas. 
A DNEAO obtida depende de:

- Espécie, sexo, idade, linhagem;

- Tamanho da população de estudo;

- Sensibilidade do método utilizado para medir a resposta (efeito crítico);

- Intervalo das doses pré - selecionadas - em geral, três doses. Se o intervalo for grande, o valor de DNEAO observado pode, em alguns casos, ser consideravelmente menor que o verdadeiro.

Para diminuir essa tendenciosidade, vários modelos matemáticos foram propostos, dentre eles o de Benchmarck. A dose de Benchmark (DB) é o limite de confiança inferior (LCI) da dose que produz uma resposta (efeito crítico) em 5 a 10\% da população de estudo (Figura 1). A DB apresenta inúmeras vantagens sobre a DNEAO porque considera: a inclinação da curva dose - resposta para o dado efeito crítico; o tamanho da população e a variabilidade dos dados obtidos. Um número pequeno de animais ou uma grande variação na resposta determinam um intervalo de confiança grande, refletindo a incerteza contida nesses dados. $O$ uso do limite de confiança inferior confere, portanto, qualidade e significância estatística ao achado (WHO, 1994; FARLAND e DOURSON, 1993).

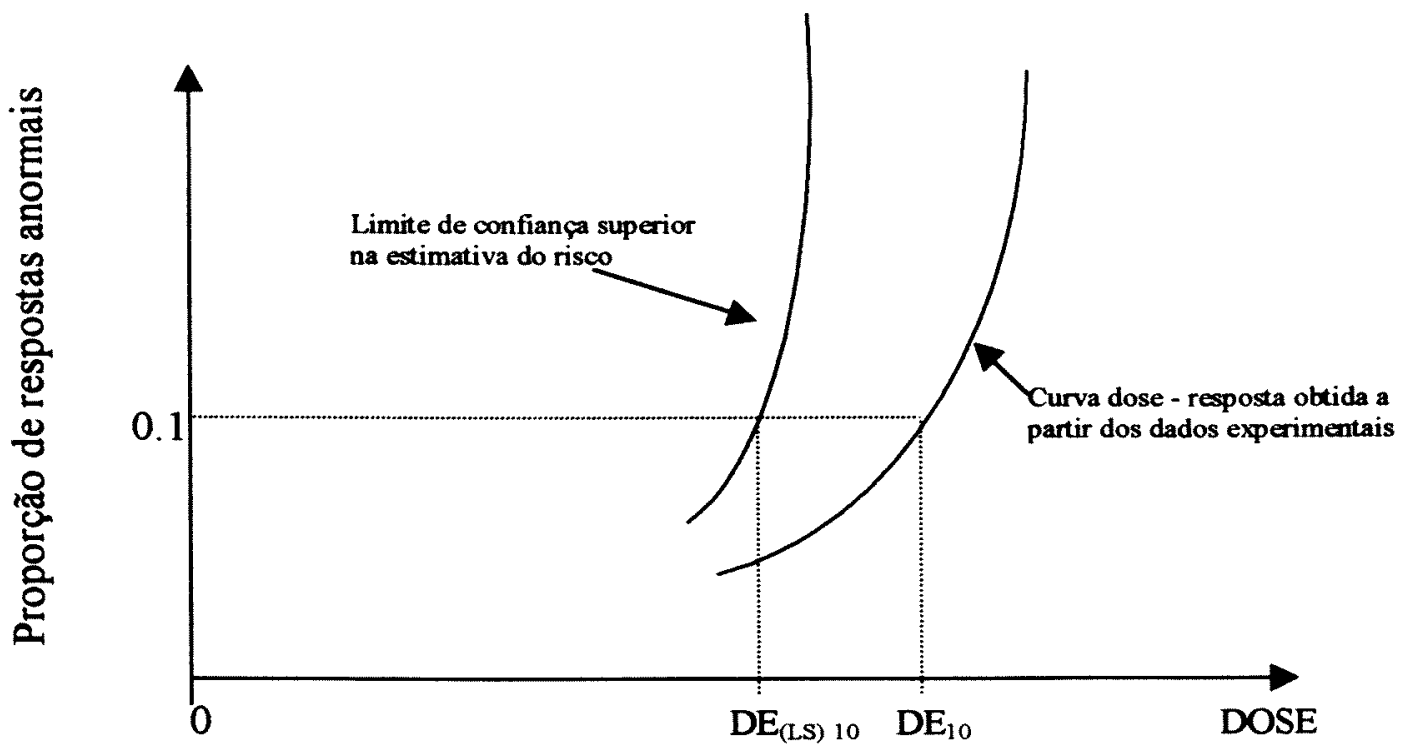

Figura 1- Ilustração gráfica da dose de Benchmark (DB) (WHO, 1994).

No exemplo $\mathrm{DE}_{(\mathrm{LS}) 10}=\mathrm{DB}$. $\mathrm{DB}$ pode também ser calculada como $\mathrm{DE}_{(\mathrm{LS}) \mathrm{s}_{5}} \mathrm{DE}_{(\mathrm{LS}) \text { 1 }}$ ou outros valores. $\mathrm{DE}=$ dose efetiva 
Para comparar a DB com a dose de referência calculada a partir da DNEAO do efeito crítico, FARLAND \& DOURSON (1993) construíram uma tabela, apresentada resumidamente a seguir na Tabela 5, ilustrando essas diferenças. Para cada substância química, a dose de referência foi calculada com base em estudos de toxicidade crônica utilizando-se um fator de incerteza de 100 e as DBs foram estimadas para todos os efeitos caracterizados adequadamente pelas curvas dose resposta nesse ou em outros estudos. Nesta avaliação, a DB foi considerada aquela associada ao limite de confiança inferior $95 \%$ da dose que promoveu uma resposta em $10 \%$ da população.

A extrapolação dos dados obtidos em animais para o homem, e das doses mais elevadas para baixas doses deve considerar as diferenças inter e intra-espécie, quanto à toxicocinética, toxicodinâmica e normalização da dose o que imputa à avaliação da relação dose - resposta maior incerteza do que aquela obtida na identificação do perigo. As concentrações ou doses de referência são obtidas dividindo-se a DNEAO ou DB por fatores de incerteza da ordem de 1 a 10.000. O valor do fator de incerteza a ser aplicado depende da natureza da efeito tóxico, da adequabilidade dos dados utilizados na obtenção da DNEAO ou DB, das variações interespécie e interindividual.

Em geral, um fator de incerteza equivalente a 100 é utilizado, considerando um valor base de 10 para as diferenças interespécies e outros 10 para as variações inter - individuais na ausência de conhecimento especifico sobre a toxicocinética e toxicodinâmica. Se dados relevantes sobre a cinética e mecanismos de ação estão disponiveis, esses fatores de incerteza podem ser subdivididos, reduzindo-se a extensão da incerteza através da incorporação dos dados obtidos para o composto de interesse onde eles existirem, como ilustra a Figura 2 (RENWICK; 1993; WHO, 1999). 
Tabela 5 - Comparação entre as $\mathrm{DNEAO}^{\mathrm{a}} \mathrm{e} \mathrm{DB}^{\mathrm{b}}$ estimadas para algumas substâncias

\begin{tabular}{|c|c|c|c|c|}
\hline Substância & $\begin{array}{c}\text { DNEAO } \\
(\mathrm{mg} / \mathrm{Kg} / \mathrm{d}) \\
\text { efeito crítico }\end{array}$ & $\begin{array}{c}\text { Estudo } \\
\text { espécie, sexo, efeito crítico }\end{array}$ & $\begin{array}{c}\text { DB } \\
(\mathrm{mg} / \mathrm{Kg} / \mathrm{d})\end{array}$ & DB/DNEAO \\
\hline \multirow[t]{6}{*}{ Diclorvós } & 0,08 & $\mathrm{R}, \mathrm{M}$, hiperplasia duto biliar & 2,2 & 30 \\
\hline & aumento & $\mathrm{R}, \mathrm{M}$,inflamação da próstata & 5,8 & 70 \\
\hline & figado & $\mathrm{R}, \mathrm{F}$,inflamação duto biliar & 8,9 & 100 \\
\hline & (Monsanto, 1984)* & $\mathrm{C}, \mathrm{M}$, inflamação renal crônica & 12 & 200 \\
\hline & & $\mathrm{C}, \mathrm{F}$, inflamação renal crônica & 20 & 300 \\
\hline & & $\begin{array}{c}\mathrm{C}, \mathrm{F} \text {, inflamação hepática crônica } \\
(\mathrm{NCI}, 1977)^{*}\end{array}$ & 49 & 600 \\
\hline \multirow[t]{2}{*}{ Paraquat } & 0,45 & $\mathrm{Cc}, \mathrm{M}$, pneumonite crônica & 0,16 & 0,4 \\
\hline & $\begin{array}{l}\text { pneumonite } \\
\text { crônica } \\
\text { (Shell Chemical, 1967)* }\end{array}$ & $\begin{array}{r}\mathrm{Cc}, \mathrm{F}, \text { pneumonite crônica } \\
\text { (Chevron Chem, 1983)* }\end{array}$ & 0,36 & 0,8 \\
\hline \multirow[t]{6}{*}{ Pentaclofenol } & 3 & R,M,pigmentação hepática* & 28 & 9 \\
\hline & doenças renais e & R,F, pigmentação hepática* & 3,0 & 1 \\
\hline & hepáticas & $\mathrm{R}, \mathrm{F}$, pigmentação renal* & 3,7 & 1,2 \\
\hline & (Schwetz ot al, 1978) & $\mathrm{C}, \mathrm{F}$, basofilia hepática** & 23 & 8 \\
\hline & & $\mathrm{C}, \mathrm{M}$, , basofilia hepática** & 24 & 8 \\
\hline & & $\begin{array}{c}\text { *Schwetz of al, } 1978 \\
\text { *NTP, } 1989^{\text {N }}\end{array}$ & & \\
\hline
\end{tabular}

Fonte : FARLAND \& DOURSON, In COTHERN, 1993 - adaptado.

Nota: a DNEAO ( dose de nenhum efeito adverso observado) utilizada como dose de referência especificada no Integrated RisK Information System, USEPA, em 20/07/91. Os valores podem ter mudado desde então.

b. Quando informações em ambos os sexos $(\mathrm{M}=$ macho, $\mathrm{F}=$ fềmea $)$ e diferentes espécies $(\mathrm{R}=\mathrm{rato}, \mathrm{C}=$ camundongo, $\mathrm{Cc}=\mathrm{ca}$ ) estavam disponiveis, DBs (doses benchmarck) foram estimadas.

* = estudos referenciados por FARLAND \& DOURSON, IN COTHERN, 1993. 
SELEÇÃO DO ESTUdO PILOTO

E EFEITO CRÍTICO

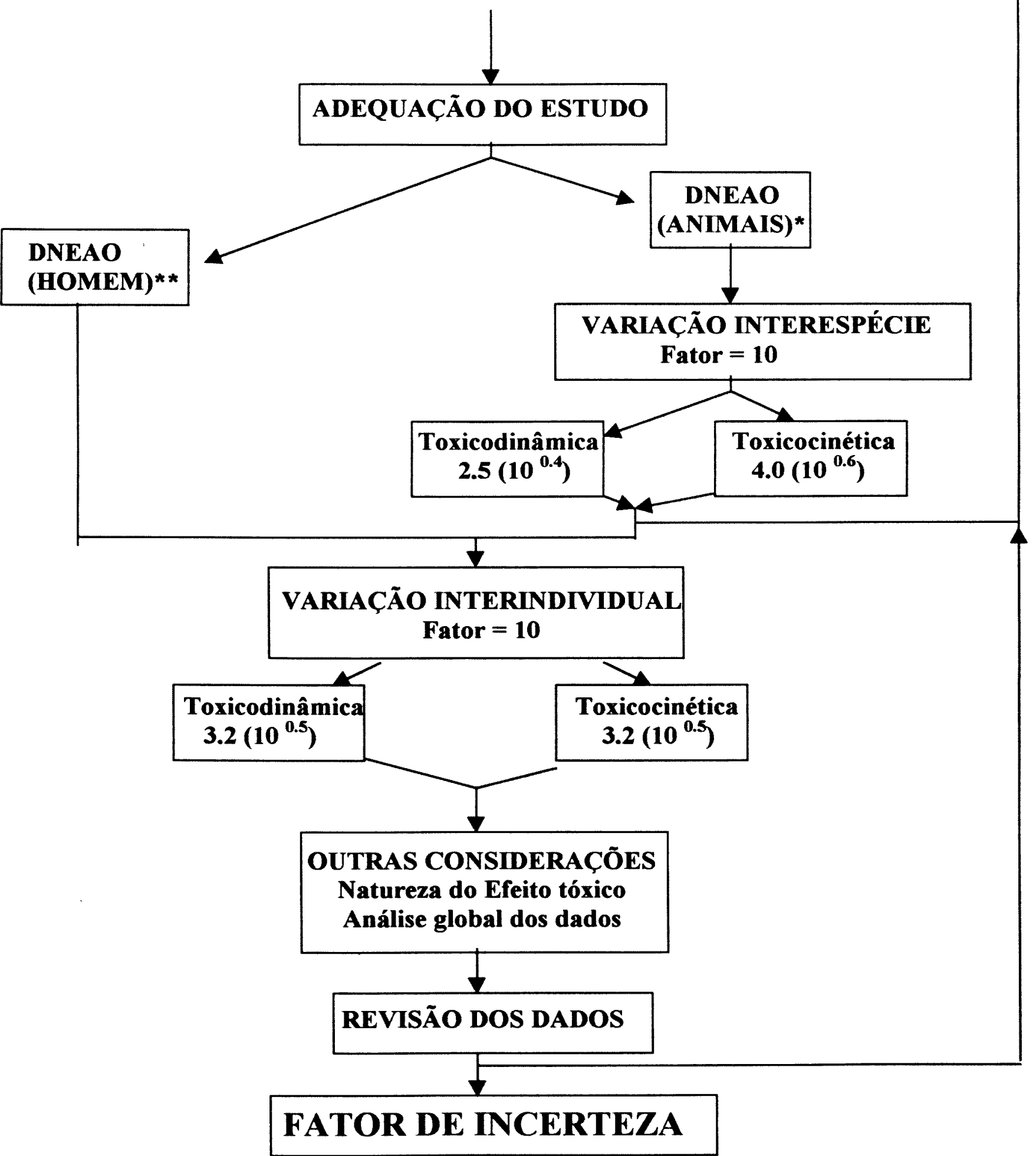

Figura 2 - Procedimento adotado para estimar os fatores de incerteza (who, 1994)

Nota: $\quad$ = DNEAO obtida através estudos com animais de experimentação

** DNEAO obtida através estudos epidemiológicos 
Ainda que para carcinógenos genotóxicos, assuma-se a probabilidade de ocorrência de dano em qualquer nível de exposição, vários métodos tem sido adotados para caracterizar a dose - resposta em exposições a baixas doses. A exemplo das abordagens utilizadas para os efeitos não neoplásicos, os modelos utilizados tendem a incorporar mais e mais os dados científicos disponiveis incluindo-se a mutagenicidade, os diferentes estágios do processo carcinogênico e o tempo de latência do tumor, toxicocinética e variações inter - individuais. Dada a complexidade do efeito crítico em questão várias proposições tem sido feitas, não se definindo até o momento o melhor modelo a ser adotado. Freqüentemente, a formação do aduto de DNA é linear em doses muito baixas (POIRER e BELAND, 1987) e nesses casos, a extrapolação linear pode ser utilizada (WHO, 1999). É considerada, entretanto, muito conservadora, especialmente na ausência de informação sobre o mecanismo de ação tumorigênica (WHO, 1999).

A Canadian Environmental Protection Act - CEPA, citado por WHO (1999), tem adotado a dose ou concentração tumorigênica 5\% (DTs)- dose capaz de promover a formação de tumores em $5 \%$ da população estudada- como base para o desenvolvimento do Índice de Exposição ou Potência (IEP). O IEP é obtido dividindo-se a ingestão ou exposição diária estimada para o homem pela DTs. Um valor de IEP de $10^{-6}$ representa um diferença de 1 milhão de vezes entre a exposição humana e a porção inferior da curva dose - resposta de onde se extrapolou o valor da DT $_{5}$. Qualquer modelo que se ajuste adequadamente aos dados empíricos é capaz de oferecer uma estimativa de $\mathrm{DT}_{5}$ confiável.

Quando não houver evidências de linearidade para a resposta carcinogênica, a USEPA (1996) recomenda que se estime a margem de exposição, dividindo-se o valor equivalente ao limite de confiança superior $(95 \%)$ da dose que promoveu uma resposta anormal em $10 \%$ da população estudada pela exposição ambiental de interesse.

A tendência, nos últimos anos, é a de aperfeiçoar as bases científicas da avaliação dose - resposta para genotóxicos e não genotóxicos incorporando informações sobre a toxicocinética e toxicodinâmica aos modelos matemáticos, uma 
vez que a toxicidade de um dado xenobiótico é resultado da interação entre a substância ou seus produtos de biotransformação com estruturas ou móleculas biológicas.

$\mathrm{O}$ conhecimento de parâmetros fisiológicos, bioquímicos e experimentais permite o estabelecimento da quantidade de toxicante por período encontrada no sítio alvo ou órgãos específicos. Dentre os parâmetros fisiológicos inclui-se o fluxo sangüíneo, a ventilação pulmonar, o volume dos órgãos e as características do crescimento. os coeficientes de partição, as constantes de ligação tissular, as velocidades de biotransformação, metabolismo e a depuração tissular são os parâmetros bioquímicos requeridos. Os parâmetros experimentais exigidos estão associados às vias e duração da exposição, horário adequado para a colheita de amostras tissulares e de excretas e os processos biológicos de injúria, reparo, progressão e expressão da toxicidade (ANDERSEN, 1995; YANG E COL., 1995).

Uma simulação da resposta do modelo pode ser testada contra os dados experimentais disponíveis. Se as predições desviam-se significativamente, alterações na estrutura modelar - consistente com os processos físiológicos e biológicos devem ser consideradas (ANDERSEN, 1995).

Esses modelos fisiológicos representam uma alternativa na extrapolação do dados experimentais por predizerem a dose no tecido alvo para exposição à baixas concentrações do toxicante e em diferentes espécies, incluindo o homem. Tem sido, por esse motivo, utilizados na avaliação de risco de carcinogenicidade de algumas substâncias como o diclorometano.

O diclorometano é oxidado por enzimas do citocromo $\mathrm{P}_{450}$ e conjugado com a glutationa pela catálise da enzima glutationa-S-transferase - GST. Baseados em estudos de mutagenicidade e na relação dose - resposta para a formação do tumor, a carcinogenicidade do diclorometano era presumivelmente associada aos produtos de biotransformação reativos formados via GST. Estas informações indicaram que o 
modelo fisiológico para o diclorometano deveria enfocar a velocidade de conjugação com o glutation.

O modelo considerou as vias oral e inalatória, a biotransformação nos tecidos alvo favorecendo o carcinoma e as diferenças interespécies quanto à toxicocinética, demonstrando que o ser humano é cerca de doze vezes mais suscetivel que o camundongo e seis vezes mais suscetível que o rato para uma dose diária ( $\mathrm{mg} / \mathrm{Kg} / \mathrm{dia}$ ) do carcinógeno. A comparação dos dados obtidos através do modelo físiológico com os derivados da extrapolação de dados evidenciou que o risco de exposição por ingestão ou inalação ao diclorometano foi superestimado pelo método antigo - extrapolação em 100 a 200 vezes (ANDERSEN, 1995).

YANG e col. (1995) utilizaram modelos fisiológicos para avaliar o risco na exposição à misturas de substâncias químicas demonstrando a habilidade do modelo em considerar as possiveis interações toxicocinéticas e toxicodinâmicas; identificar o perigo sem provocar sofrimento aos animais de experimentação; reduzir a aplicação de fatores de incerteza pela sua capacidade na extrapolação das doses e espécies. É claro que os modelos possuem incertezas intrínsecas à sua concepção e devem ser validados através de achados experimentais para serem utilizados como instrumentos de predição.

\subsubsection{Caracterização da exposição}

O objetivo da caracterização da exposição é determinar a natureza e extensão do contato entre o agente de interesse e determinada população. Para tanto, a concentração do toxicante e sua distribuição nas diferentes fases do meio ambiente, as populações de elevado e baixo risco, as contribuições químicas e físicas das várias fontes de emissão, os fatores intervenientes no transporte e distribuição desse agente no meio ambiente - bem como as vias de introdução no ser humano, a duração e freqüência dessa exposição devem ser caracterizados (USNAS, 1983; WHO, 1999). 
A quantificação da exposição pode ser efetuada medindo-se a concentração do toxicante no meio ambiente - no ar, água, solo ou em algum produto com o qual o homem entre em contato- ou a partir da dose interna, pós exposição, através de biomarcadores ou da determinação da carga corpórea desse agente tóxico (LAUWERYS e col., 1995; LOWRY, 1995; WHO,1999).

A monitorização biológica permite integrar a exposição através das diferentes vias de introdução, evitando as múltiplas determinações da concentração dos contaminantes nas diferentes fases do meio ambiente. Não obstante, apresenta algumas limitações para avaliar a dose interna na exposição a resíduos perigosos pela complexidade das misturas químicas encontradas nesses rejeitos. $\mathrm{O}$ uso de modelos fisiológicos baseados na toxicocinética e toxicodinâmica tem contribuido para o dimensionamento mais real da exposição (USNAS, 1983)

A exposição a determinado agente pode variar dependendo do local de moradia, da atividade profissional ou lazer e da faixa etária da população a ser analisada. A falta de informações que definam corretamente as características dessa exposição ou deficiências preditórias inerentes ao modelo adotado determinam incertezas nesta etapa da avaliação do risco (WHO,1993; 1999).

\subsubsection{Caracterização do risco}

É a avaliação e integração de todos os dados utilizados para verificar a natureza, relevância e, onde possivel, a magnitude do risco ambiental e/ou humano, incluindo as incertezas que acompanham essa exposição específica; ou seja, a probabilidade de ocorrência de um dado efeito adverso em determinadas condições de exposição (WHO, 1999).

As decisões concernentes ao gerenciamento dos riscos são feitas com base na identificação do perigo, na caracterização da exposição e na análise do potencial risco desse impacto sobre individuos, grupos, populações e meio ambiente. Envolve considerações sócio - econômicas, políticas, avaliações dos binômios risco - 
beneficio e custo - beneficio, no sentido de se estabelecer medidas ou ações que permitam reduzir os riscos observados. Reconhece-se como elementos importantes nessa tomada de decisões, a percepção e comunicação do risco.

Não se concebe a vida moderna sem o uso de substâncias químicas. Entretanto, apesar dos benefícios sociais, danos a saúde estão associados à exposição durante produção, utilização ou descarte de aproximadamente 100.000 substâncias químicas ou 4 milhões de misturas e formulações comercialmente disponíveis. Neste contexto, a avaliação e o gerenciamento dos riscos decorrente da exposição a esses agentes encontram-se dentre as prioridades do desenvolvimento sustentável., porém, em função desse número elevado e da concomitância de várias substâncias no organismo e/ou meio ambiente, as avaliações tornam-se complexas, dificultando as decisões a serem tomadas (WHO, 1999).

\subsubsection{Percepção e comunicação do risco}

O gerenciamento do risco é fundamentalmente uma questão de valores. De acordo com muitos pesquisadores, a causa fundamental das divergências sobre os riscos ambientais decorre da diferença de percepção entre os especialistas - analistas de risco - e o público (FISCHOFF e col., 1993; MORGAN, 1993; OLECKNO, 1993; SOKOLOWSKA e TYSZKA, 1995).

Estudos realizados demonstraram que as pessoas quando solicitadas para classificar as várias atividades e tecnologias em termo de risco, produziram listas cujas ordens não correspondiam exatamente à realidade. Como resultado, alguns analistas de risco concluíram que os conhecimentos da população eram inadequados e que suas opiniões não eram relevantes. Entretanto, quando solicitados para relacionar o perigo em termos do número de mortes ou danos causados/ano, o faziam muito bem.

Segundo NARDOCCI (1999), as pesquisas sobre como as pessoas julgam risco demonstraram que os eventos relatados como de maior probabilidade são os 
mais recentes em suas mentes. Os riscos associados a maiores benefícios são os mais aceitos pela população e os eventos catastróficos e incontroláveis, aqueles que devem ser priorizados com relação à adoção de medidas para sua redução.

A população relaciona os riscos baseando-se no conhecimento do processo em questão, em quão equitativa é a distribuição do perigo, na facilidade em controlar a exposição e se o risco é assumido voluntariamente. Utiliza a intuição, os sentidos e as emoções. E por isso, muitas vezes, ocorrem diferenças na percepção do risco (NEIL e col., 1994).

Uma vez que o risco tenha sido identificado e analisado, a compreensão da percepção e da validação psicossocial da população é crítica. Como a população vê e avalia os riscos em particular determina qual das muitas alterações deve ser realizada. Portanto, as decisões a serem tomadas no gerenciamento de risco estão intrinsecamente relacionadas à percepção dos envolvidos, a população (MORGAN, 1993).

Vários autores recomendam a construção de modelos mentais (mental models) para avaliar a percepção do risco por auxiliarem o raciocínio da população e elucidarem os riscos e perigos decorrentes do emprego de diferentes tecnologias. Em essência, esses modelos são ferramentas cognitivas que permitem racionalizar e ordenar o que seria incompreensível e desordenado, determinando, por exemplo, quais são os fatores específicos que podem levar a população a acreditar que aquela exposição a um dado toxicante determine uma intoxicação aguda ou um dano sério e desconhecido à sua saúde (FISCHCOFF e col. 1993; MacGREGOR, 1996).

Assim, os sintomas causados por alguma doença, como uma gripe, podem ser incorretamente atribuídos à exposição química. Ou, os individuos experimentam uma série de alterações somáticas e as associam à exposição simplesmente porque esperam que isso ocorra, evidenciando que os processos psicológicos desempenham um papel importante na percepção do risco. Além desses fatores, o estresse e os sentidos - olfato e visão - também estão envolvidos na percepção dos efeitos 
adversos decorrentes da exposição a agentes químicos (FISCHCOFF e col. 1993; MacGREGOR, 1996)

Os meios de comunicação tem um papel importante na percepção e comunicação do risco. Reportagens científicas aumentam o conhecimento da população sobre determinado assunto e por isso, devem ser criteriosas e não sensacionalistas. Não obstante, o nível de incerteza presente na ciência pode ser desconfortante e causar confusão na população. E quando o público julga que a comunidade científica não compreende um risco, a sua tendência é desconsiderar a opinião científica, aumentando a sua confiança em seus modelos mentais intuitivos. (MacGREGOR, 1996; NEIL e col., 1994). Não há diferença na preocupação quanto aos riscos ambientais em populações de paises ricos e pobres.. O contexto econômico, entretanto, favorece a maior tolerância aos riscos nos países menos abastados (SOKOLOWSKA e TYSZKA, 1995).

A educação da população é fundamental no gerenciamento do risco. É necessário, entretanto, informar adequadamente essa população. A essência de uma boa comunicação do risco exige apreender o que a população já acredita, trabalhar a comunicação a partir deste conhecimento e das decisões que a população tem que enfrentar e então, submeter a mensagem resultante à cuidadosa avaliação (FISCHOFF e col., 1993; MORGAN, 1993; OLECKNO, 1993).

\subsection{Risco biológico}

A utilização, estudo, cultivo, produção ou modificação de microrganismos patogênicos selvagens - atenuados ou recombinados, amostras biológicas, culturas de células, material proveniente de biópsias e experimentação com animais representam as principais fontes de contaminação no laboratório clínico, toxicológico ou de pesquisa. $\mathrm{Na}$ maioria dos casos, a via de introdução não pode ser especificada, atribuindo-se a contaminação à inalação de aerossóis infectantes (PICOT e GRENOUILLET, 1995; PRÜSS, 1999). 
Há uma particular preocupação quanto à infecção por vírus da imudeficiência humana (HIV) e virus da hepatite B e $C$, para os quais existem fortes evidências de transmissão via RSS. A existência de bactérias resistentes à antibióticos e desinfetantes químicos tem aumentado os riscos oriundos de uma manipulação inadequada desses resíduos. Foi demonstrado, por exemplo, que plasmídeos obtidos em laboratório e presentes nos RSS foram transferidos para bactérias nativas através do sistema de disposição dos rejeitos (PRÜSS, 1999).

O risco decorrente dos RSS está associado à saude ocupacional de quem manipula estes resíduos, quando da execução da sua rotina de trabalho - como por exemplo, ferimento com agulha contaminada ou contato com sangue contaminado através de ferimentos das mãos; inalação de aerodispersóides durante o procedimento analítico ou provenientes do interior do saco de residuos, no momento de fechá-lo - e ao meio ambiente, pela disposição inadequada em lixões a céu aberto ou até em cursos d'água, possibilitando a contaminação de mananciais e dos catadores, que podem até reutilizar ou vender embalagens descartadas (NAVA, 1996)

\subsection{1 - Avaliação do risco biológico}

Os processos de tratamento da água de abastecimento têm contribuído para a diminuição da ocorrência de doenças infecciosas. Entretanto, quer pela ineficiência do processo de tratamento adotado na remoção de todos os patógenos presentes na água, quer pela contaminação após o tratamento ou até pelo não tratamento do suprimento contaminado, ainda se observa enfermidades cujos agentes etiológicos são veiculados através da ingestão de água (GERBA e ROSE, 1993).

A estimativa desse impacto é dificil de ser determinada epidemiologicamente uma vez que os niveis de exposição são muito baixos. Mesmo assim, a avaliação do risco biológico, envolvendo as quatro etapas já descritas para o risco químico, deve ser realizada.

Tomando-se, como exemplo, os vírus entéricos pode-se afirmar que essa presenca na água representa um potencial para a infeccão de indivíduos suscetíveis, 
ainda que os surtos de enfermidades veiculadas pela água não tenham sido demonstrados para todos os vírus entéricos. Identifica-se, desta forma, o risco.

É importante caracterizar a concentração de contaminantes que afeta a saúde da população exposta - curva dose-resposta. Porém, nem todos os indivíduos infectados desenvolverão a doença. A probabilidade de desenvolvimento clínico da enfermidade, ao menos para o rotavírus, parece estar relacionada à dose que cada indivíduo ingere, ao tipo e linhagem do vírus, à idade do hospedeiro, ao seu estado nutricional e à imunidade pré- existente.

A determinação da dose infectante em animais e posterior extrapolação para o homem não é geralmente possível para agentes infecciosos, já que o homem é o único hospedeiro ou o hospedeiro primário. A maioria dos dados sobre doses infectantes foi gerado com vacinas virais atenuadas ou linhagens avirulentas cultivadas em laboratório, superestimando, com freqüência, essas doses. Soma-se a isso, o fato dos estudos serem realizados, na maioria das vezes, com populações de indivíduos normais e saudáveis, reduzindo a probabilidade de infecção em doses baixas do vírus.

Os estudos realizados demonstraram que um pequeno número de vírus entéricos é capaz de causar infecção e doença no hospedeiro suscetível. Modelos para a extrapolação dos dados experimentais para concentrações reais são necessários para se estimar o risco na exposição à baixas doses desses vírus entéricos.

Quanto à caracterização da exposição, a principal via de infecção é a via oral, mas a inalação de aerossóis e o contato das mãos com águas e objetos contaminados podem ser também eficientes. Ao contrário do risco químico, indivíduos que não consomem a água contaminada podem estar em risco. A transmissão viral pode ocorrer de pessoa para pessoa ou pela contaminação dos fômites com os quais os não infectados entram em contato - disseminação secundária. 
Os vírus entéricos humanos podem ser encontrados nas águas superficiais e profundas devido a descarga direta dos efluentes de esgoto nos rios e lagos ou de lodo, vazamentos das linhas de esgoto, utilização de esgoto nas terras cultiváveis, descarga de tanques sépticos, etc. A concentração e os tipos de vírus entéricos no esgoto variam de acordo com a época do ano, incidência de doenças naquela comunidade e de fatores socio-econômicos.

O tratamento do esgoto doméstico por sedimentação reduzirá o número de vírus na descarga mas não os eliminará mesmo após a desinfeção comum. Foram relatados concentrações virais de até $9000 \mathrm{PFU}$ (unidade formadora de placa)/litro para efluentes sedimentados e de 0 a $750 \mathrm{PFU} /$ litro para efluentes clorados. A concentração viral no efluente dependerá de como a planta de tratamento é operada, dos tipos de tratamento, da concentração de desinfetante, do tempo de contato, dentre outros.

Como caracterizar o risco de infecção? A probabilidade de ser infectado após a ingestão de diferentes concentrações de vírus entéricos foi estimada por GERBA \& HASS (1988) citados por GERBA e ROSE (1993). Utilizaram um modelo exponencial modificado : $P=1-(1+N / \beta)^{-\alpha}$

Onde: $\mathrm{N}=\mathrm{n} .{ }^{\circ}$ organismos ingeridos/exposição

$\alpha$ e $\beta$ representam os parâmetros caracterizantes da interação hospedeirovírus, sendo diferentes para cada espécie.

Assumindo-se que uma pessoa consuma 2 litros de água por dia, pode-se estimar a probabilidade de infecção durante aquele dia e tomando-se como constante a concentração viral diária, determinar o risco anual:

$$
1-(1-P)^{365}
$$

e o risco de contrair uma ou mais infecções ao longo da vida:

$$
1-(1-P)^{2550}
$$

A aplicação deste modelo permite estimar os riscos de infecção, desenvolvimento da doença ou óbito para diferentes níveis de exposição como 
exemplificado na Tabela 6. A estimativa do risco de infecção por 1 rotavírus em 100 litros de água pode ser de aproximadamente 1:1000 para uma exposição diária única, elevando-se para 1:3 considerando o risco anual. Os riscos de morbidade e mortalidade também parecem ser significativos para exposições a baixas concentrações de rotavírus e do virus da hepatite A na água potável.

Tabela 6 - Risco de infecção, morbidade e mortalidade para Rotavírus e vírus da Hepatite A

\begin{tabular}{|c|c|c|c|c|}
\hline \multirow{2}{*}{$\begin{array}{l}\text { Concentração } \\
\text { viral/100 I água }\end{array}$} & \multicolumn{2}{|c|}{ Rotavirus } & \multicolumn{2}{|c|}{ Hepatite A } \\
\hline & Diária & Anual & Diária & Anual \\
\hline \multicolumn{5}{|c|}{ Infeccão } \\
\hline 100 & $9,6 \times 10^{-2}$ & 1,0 & $1,8 \times 10^{-3}$ & $5,1 \times 10^{-1}$ \\
\hline 1 & $1,2 \times 10^{-3}$ & $3.6 \times 10^{-1}$ & $1.2 \times 10^{-5}$ & $4,4 \times 10^{-3}$ \\
\hline 0,1 & $1,2 \times 10^{-4}$ & $4,4 \times 10^{-2}$ & $1,8 \times 10^{-6}$ & $6,6 \times 10^{-4}$ \\
\hline \multicolumn{5}{|c|}{ Doença } \\
\hline 100 & $5,3 \times 10^{-2}$ & $5,3 \times 10^{-1}$ & $1,4 \times 10^{-3}$ & $3,9 \times 10^{-1}$ \\
\hline 1 & $6,6 \times 10^{-4}$ & $2,0 \times 10^{-1}$ & $9,0 \times 10^{-6}$ & $3,3 \times 10^{-3}$ \\
\hline 0,1 & $6,6 \times 10^{-5}$ & $2,5 \times 10^{-2}$ & $1,4 \times 10^{-6}$ & $5,0 \times 10^{-4}$ \\
\hline \multicolumn{5}{|c|}{ Mortalidade } \\
\hline 100 & $5,3 \times 10^{-6}$ & $5,3 \times 10^{-5}$ & $8,4 \times 10^{-5}$ & $2,3 \times 10^{-2}$ \\
\hline 1 & $6,6 \times 10^{-8}$ & $2,0 \times 10^{-5}$ & $5,4 \times 10^{-8}$ & $2,0 \times 10^{-5}$ \\
\hline 0,1 & $6,6 \times 10^{-9}$ & $2,5 \times 10^{-6}$ & $8,4 \times 10^{-9}$ & $3,0 \times 10^{-6}$ \\
\hline
\end{tabular}

Fonte: GERBA e ROSE (1993)

Recomenda-se que qualquer processo de tratamento de água deva assegurar à população um risco de infecção inferior a 1:10.000/ano ou seja menor que 1 para 1000 litros de água. A capacidade de remoção das plantas de tratamento deve atender essa recomendação considerando que os métodos de deteç̧ão geralmente apresentam menos de $50 \%$ de eficiência.

Não se deve subestimar o impacto da exposição em niveis baixos de contaminação, considerando-se os custos no tratamento das infecções. $O$ custo de uma gastroenterite bacteriana leve, foi estimado, segundo os autores, em US\$ 221 por caso em 1987. Para os casos que exigiram consulta médica, o valor estimado foi de US\$ 680 e os hospitalizados, US\$ 4.350 por caso. 
A avaliação do risco biológico é relativamente nova e requer melhor compreensão e análise uma vez que transmissões secundárias e até terciárias ocorrem atingindo indivíduos não infectados pelo consumo de água contaminada. Para minimização desse risco, desinfetantes químicos tem sido adicionados à água favorecendo a formação de trialometanos, e gerando um risco químico. O risco resultante da formação de sub-produtos tóxicos na água não deve ser maior do que o risco biológico. Como comparar estes riscos? Qual a abordagem adequada para essa comparação: através da mortalidade, da morbidade e custo no tratamento?. Várias dúvidas persistem ainda, porém, é inquestionável a aplicabilidade da avaliação do risco biológico no gerenciamento dos processos de tratamento e disposição de resíduos de serviços de saúde.

\subsection{Minimização dos riscos}

Os riscos decorrentes da exposição a agentes infecctantes ou a substâncias químicas em laboratórios podem ser reduzidos através da adoção de procedimentos adequados e do treinamento dos envolvidos.

Com relação às substâncias químicas, deve-se observar as Boas Práticas de Laboratório evitando-se a inalação, ingestão e o contato com a pele e mucosa ocular destas substâncias. Para tanto, é inadequado comer, beber e fumar ou pipetar diretamente com a boca as substâncias químicas perigosas. $\mathrm{O}$ uso de avental, luvas adequadas, máscaras, óculos ou, protetores faciais são recomendados. A manipulação de substâncias voláteis ou reconhecidamente tóxicas ou ainda, de toxicidade desconhecida dever ser realizada em capelas químicas (FURS, 1993; NRC, 1995; PICOT e GRENOUILLET, 1995; STRICOFF e WALTERS, 1995).

Quanto aos agentes infectantes, os procedimentos adotados dependem da classificação do laboratório. Nesta classificação, leva-se em consideração tanto o risco para o analista como o risco para a comunidade e meio ambiente determinados pela patogenicidade e virulência do microorganismo, sua resistência, modo de contaminação, existência de prevenção ou tratamento da doença e condições de 
manipulação (MICHIGAN STATE UNIVERSITY, 1999a; PICOT e GRENOUILLET, 1995; SANCHEZ, 1998*; STRICOFF e WALTERS, 1995).

O modo de transmissão e a presença de hospedeiros suscetíveis estão condicionados aos níveis de imunidade, à densidade populacional, a presença de vetores apropriados e aos procedimentos de higiene ambiental. Quanto às medidas de prevenção destacam-se as profiláticas, como as vacinas, as medidas de saneamento básico, a eliminação de reservatórios de artrópodes vetores e a restrição da importação de animais ou produto de animais infectados. A disponibilidade de tratamento compreende a imunização passiva e vacinação, antibiótico e quimioterapia, considerando-se a possibilidade do desenvolvimento de cepas resistentes (SANCHEZ, 1998).

Os laboratórios classe 1 são aqueles que manipulam microorganismos não patogênicos, como por exemplo, a Escherichia coli. Os classe 2 incluem microorganismos de risco moderado ao operador mas limitado e pequeno risco para a comunidade. Existe tratamento preventivo - vacinação. Alguns exemplos: Listeria monocytogenes, Staphylococcus aureus, Corynebacterium diphteriae, Candida albicans, Entamoeba histolytica, Schistosoma (FURS, 1993; MICHIGAN STATE UNIVERSITY, 1999a; PICOT e GRENOUILLET, 1995; SANCHEZ, 1998).

Os microorganismos manipulados em laboratórios classe 3 são aqueles querepresentam um sério risco para o manipulador e um risco moderado para a comunidade. Tratamentos profiláticos existem algumas vezes. São exemplos: Chlamydia psittacci, Mycobacterium tuberculosis, vírus da hepatite B, não A e não B, Herpes B, HTLV 1 e 2 , HIV, febre amarela e dengue, Blastomycoces dermatiolis, Leishmania, Toxoplasma gondii, Trypanosoma cruzi. Os Laboratórios classe 4 manipulam microorganismos que apresentam sério risco para o analista e para a comunidade. Não existe tratamento e o risco de propagação é elevado. Vírus Lassa, Marrupo, Crimea, febre hemorrágicas do Congo e o parasita Nagleria fowleri são

\footnotetext{
* Sanchez PS. Biossegurança em laboratórios microbiológicos. São Paulo; 1998.(apostila).
} 
alguns exemplos (FURS, 1993; MICHIGAN STATE UNIVERSITY, 1999a; PICOT e GRENOUILLET, 1995; SANCHEZ, 1998).

Os procedimentos básicos são: proibição de pipetar com a boca, comer, beber, fumar ou guardar alimentos nas geladeiras e congeladores do laboratório; limitar ou restringir o acesso ao laboratório; descontaminar as superficies de trabalho diariamente ou após derramamento de material viável; lavar as mãos após manipulação de material biológico, dos animais e antes de deixar o laboratório; minimizar a formação de aerossóis (MICHIGAN STATE UNIVERSITY, 1999a; PICOT e GRENOUILLET, 1995; SANCHEZ, 1998; STRICOFF e WALTERS, 1995).

Os laboratórios - biossegurança nivel 1 e 2 , devem utilizar adequadamente seringas e agulhas e avental e luvas como equipamentos de proteção. Para os laboratórios - biossegurança nível 3 , as recomendações incluem o uso de equipamentos de proteção especiais como aventais de plástico e máscaras cirúrgicas e a manipulação em capelas de fluxo laminar. Os Classe 4 exigem um vestiário na entrada do laboratório e saída após ducha de descontaminação e transferência do material, acessórios e vestimentas para sala de fumigação (MICHIGAN STATE UNIVERSITY, 1999a; PICOT e GRENOUILLET, 1995; SANCHEZ, 1998; STRICOFF e WALTERS, 1995).

Além de procedimentos de rotina, o pessoal dos laboratórios químico e biológicos deve estar preparado para situações de emergência. Devem ser treinados para notificar um incêndio, dano, derramamento de substância química; conhecer a localização dos equipamentos de emergência como chuveiros, lava - olhos, extintores e acessórios para a contenção de derramamentos e das saidas para evacuação do laboratório. Estas informações devem constar dos procedimentos de emergência do laboratório e da Instituição (FURS, 1993; NRC, 1995)

Em caso de acidente o pessoal que trabalha no laboratório deve ser notificado para que, na eventualidade da liberação de vapores tóxicos, estes possam evacuar rapidamente o local. O local onde são guardadas as fichas de segurança de cada produto quimico deve ser conhecido para que os procedimentos adequados de 
emergência possam ser adotados quando um indivíduo é contaminado pela substância química.

Cada laboratório deve manter um Kit para controlar as situações de derramamento. Várias substâncias podem ser utilizadas:

- vermiculita, areia e outros materiais inertes disponíveis comercialmente. Papel não é um material inerte e não deve ser utilizado para limpeza de agentes oxidantes como o ácido nítrico;

- agentes neutralizantes para derramamento de ácidos como carbonato ou bicarbonato de sódio;

- agentes neutralizantes para derramamento de alcalis como bissulfato de sódio ou ácido cítrico;

- desinfetantes químicos, no caso de resíduos infectantes.

Além de equipamento de proteção individual como, luvas, óculos, pró-pés, o derramamento de substâncias altamente tóxicas exige pessoal adequadamente treinado. A ocorrência de qualquer incidente deve ser notificada (CUTHEL, 1993; NRC, 1995; PRÜSS, 1999). 


\section{OBJETIVOS}

\subsection{Objetivo geral}

Analisar os procedimentos de descarte de resíduos de laboratório em três instituições públicas, visando oferecer subsídios para a adoção de procedimentos de disposição de resíduos de laboratório.

\subsection{Objetivos Específicos}

- Identificar tipos e quantidades de resíduos produzidos nas Instituições avaliadas, em situações de rotina;

- Identificar os procedimentos a serem adotados na manipulação e descarte dos resíduos gerados em situações de emergência nas Instituições avaliadas;

- Analisar procedimentos adotados após a classificação dos resíduos segundo as exigências legais e com base no conhecimento do estado da arte quanto às medidas de segurança, tratamento e disposição final de cada resíduo perigoso produzido;

- Verificar a percepção do corpo funcional técnico e científico quanto à necessidade do correto descarte dos resíduos gerados;

- Discutir possíveis impactos dos resíduos perigosos gerados sobre a saúde humana;

- Avaliar as dificuldades na implantação do programa institucional de gerenciamento relacionadas à complexidade do processo e ao envolvimento dos funcionários. 


\section{METODOLOGIA}

\subsection{População estudada}

Este estudo descritivo foi conduzido em três Instituições Públicas constituídas por laboratórios que realizam análises de forma rotineira, laboratórios de pesquisa e acadêmicos, doravante designadas Instituição A, Instituição B e Instituição C. Somente as Instituições A e B apresentam programa de gerenciamento de resíduos já implantado ou em fase de implantação.

Cada unidade de estudo - Instituição A, B ou C - realiza, tanto intra como inter institucionalmente, determinações analíticas caracteristicamente diferentes quanto à matriz analisada (fluidos biológicos, alimentos, fármacos, líquidos, pós, dentre outros), bem como quanto a finalidade dessa análise.

A Instituição A possui mais de mil funcionários, dos quais, estão sediados na capital, 216 (duzentos e dezesseis) analistas de nivel superior e 73 (setenta e três) de nível médio. Encontra-se dividida em quatro departamentos que abrigam 45 (quarenta e cinco) laboratórios e um setor de lavagem e descontaminação de material e resíduos biológicos e um biotério.

A Instituição B é composta por 72 (setenta e dois) docentes, 19 (dezenove) técnicos de nível superior e 37 (trinta e sete) técnicos de nível médio. Também se apresenta dividida em quatro departamentos, com 28 (vinte e oito) laboratórios e um biotério, o qual encontrava-se em reforma no momento da coleta dos dados. Incluiuse na população de estudo pós-graduandos e estagiários de iniciação científica indicados por cada um dos docentes e que puderam ser localizados durante o período de coleta de dados. Esses elementos foram incluidos por realizarem trabalho efetivo nas instalações enfocadas.

A Instituição C é composta por diversos departamentos, mas somente dois deles apresentam laboratórios, num total de cinco, os quais constituem objeto desta 
pesquisa. Apresentam 41 (quarenta e um) técnicos de nivel superior e 14 (quatorze) de nivel médio desempenhando suas funções nesses laboratórios.

Visando a minuciosa caracterização das populações de estudo, foram entrevistados, após agendamento prévio, individualmente e em seu local de trabalho: um representante da comissão de gerenciamento de residuos e todos os responsáveis por cada laboratório, utilizando-se o roteiro de entrevistas apresentados nos anexos 10 e 11 , respectivamente. $\mathrm{Na}$ Instituição $\mathrm{C}$, entrevistou-se somente três dos responsáveis pelos cinco laboratórios; em um deles, pela indisponibilidade na agenda durante os dois meses em que ali se coletou dados e no outro, pelo fato da chefia encontrar-se em fase de substituição.

\subsection{Levantamento dos resíduos gerados e dos procedimentos adotados para o descarte em situações de rotina}

Os resíduos gerados foram levantados através das entrevistas, previamente agendadas, realizadas com os responsáveis e docentes dos diferentes laboratórios de cada Instituição estudada e através de uma amostra aleatória dos analistas, pósgraduandos e estagiários por eles indicados. Os anexos 11 e 12 apresentam os roteiros de entrevistas utilizados. Durante as entrevistas, quando disponível, utilizouse os procedimentos operacionais padrão (POPs) para cada método analítico empregado, objetivando a identificação mais acurada dos resíduos produzidos.

As informações coletadas permitiram verificar o descarte empregado para os resíduos gerados em situação de rotina e constituem os dados primários obtidos neste estudo, fundamentando as demais inferências. 


\subsection{Levantamento dos procedimentos a serem adotados na manipulação e descarte dos resíduos gerados em situação de emergência nas Instituições estudadas}

O conhecimento dos procedimentos a serem adotados em situações de emergência - incêndio, explosão, derramamento e possíveis incompatibilidades, foi avaliado através das questões abertas formuladas nas entrevistas, realizadas com os responsáveis e docente de cada laboratório e analistas e pós-graduandos, bem como através do questionário aplicado aos demais analistas dessas instituições, que aderiram voluntariamente à solicitação. Estes questionários, mais simplificados, foram entregues a cada funcionário para posterior preenchimento em período que the fosse mais conveniente, fixando-se uma data para seu recolhimento. Solicitou-se que esse preenchimento fosse feito individualmente. $O$ roteiro das entrevistas $e$ questionários utilizados encontram-se nos anexos 11, 12 e 13.

O conhecimento das medidas a serem adotadas nas referidas situações de emergência foi realizado primordialmente de forma espontânea, considerando-se também as respostas induzidas quando não houve tal possibilidade.

\subsection{O estado da arte quanto ao gerenciamento dos resíduos gerados.}

As condutas tecnicamente recomendadas quanto à problemática de resíduos de laboratório, gerados em situação de rotina e emergência, foram obtidas através de exaustiva revisão bibliográfica. Enfocou-se o tratamento a ser empregado para redução da periculosidade de determinado resíduo e respectivo custo, as medidas de segurança a serem adotadas em caso de incêndio e derramamento e, ainda, a observação da compatibilidade das substâncias manipuladas para a minimização da probabilidade de ocorrência de acidentes. 


\subsection{Análise dos dados obtidos}

Os dados coletados foram analisados quanto aos resíduos gerados e os procedimentos de descarte adotados e quanto as respostas às diferentes questões formuladas nas entrevistas e questionários para avaliação da percepção e condutas em diferentes situações do cotidiano do laboratório.

\subsubsection{Procedimentos de descarte adotados}

Os procedimentos de descarte adotados foram analisados para as situações de rotina e emergência.

\subsubsection{Situação de rotina}

Os dados coletados foram divididos em duas categorias: resíduos infectantes e resíduos especiais. Para os resíduos especiais, listaram-se as substâncias químicas e radioativas manipuladas em cada Instituição estudada, segundo as suas características. As substâncias químicas foram classificadas em perigosas e nãoperigosas dependendo de suas propriedades: inflamabilidade, reatividade, corrosividade e toxicidade, de acordo com a $\mathrm{NBr}$ 10.004. Foram classificados como não perigosas aquelas que não apresentam nenhuma das características mencionadas.

$\mathrm{Na}$ maioria das vezes, os resíduos gerados consistem de misturas de substâncias químicas ou misturas de resíduos - químico e infectante ou químico e radioativo. A presença de uma substância perigosa, radioativa ou infectante na mistura confere periculosidade ao resíduo gerado, exigindo um procedimento distinto para o seu correto descarte. Para facilitar a identificação das substâncias que conferem periculosidade aos resíduos produzidos, os dados coletados foram tabulados por substância química e não por resíduo gerado, permitindo a caracterização da periculosidade daquele ou de qualquer outro resíduo. Para efeito de tabulação, optou-se pela discriminação da substância e citação do volume gerado e da mistura que integrava. 
O volume de residuos gerados foi expresso em litro ou mililitro/mês de líquido concentrado ou em grama ou miligrama/mês de sólido utilizado, recalculando-se os volumes considerando as concentrações das soluções manipuladas e o peso molecular dos sais e do íon envolvido.

Os corantes, muitos deles suspeitos de carcinogenicidade ou teratogenicidade, foram listados em separado visto que a Portaria CVS-01/2000 considera os resíduos contendo essas substâncias como perigosos.

Através do estado da arte estabelecido para cada resíduo perigoso gerado, considerando o tratamento e disposição recomendados, avaliou-se o procedimento de descarte rotineiramente empregado nessas instituições de estudo.

\subsubsection{Situação de emergência}

A análise do procedimento adotado nas situações de emergência foi efetuada por comparação com os procedimentos considerados de excelência e relatados na literatura consultada.

\subsubsection{Referente à entrada e análise estatística dos dados coletados}

O banco de dados foi construido a partir dos instrumentos de coleta de informação empregados (entrevistas e questionários), utilizando-se o EPI-INFO versão 6.04 b (CDC - WHO, 1997). Após o levantamento dos resíduos gerados em cada instituição estudada e do confronto do procedimento adotado frente às exigências legais e ao estado da arte - considerando as situações de rotina e emergência, julgou-se o descarte realizado. Foi estabelecido, então, se o procedimento adotado era correto ou incorreto, para as situações mencionadas, observando cada categoria de material manipulado. Sendo assim, um mesmo indivíduo, por manipular diferentes categorias de materiais e pela diversidade no procedimento adotado em função do material a ser descartado, foi introduzido no banco de dados tantas vezes quanto o número de categorias de materiais por ele 
manipulado. Por conseguinte, o banco construido tem 866 entradas correspondentes às 281 entrevistas e questionários realizados.

Foram levantados os dados para as seguintes variáveis :

- Variável dependente: procedimento de descarte (correto e incorreto).

Avaliado em duas situações: rotina e emergência.

- Variáveis independentes:

0 Instituição estudada: A, B, C.

$\checkmark \quad$ Laboratórios estudados em cada uma das Instituições

$\checkmark$ Departamento ou divisão onde se encontram os laboratórios

- Número de funcionários de cada laboratório avaliado

Formação do funcionário

Tempo de formado

$\diamond \quad$ Tempo na função

$\diamond \quad$ Existência de programa de gerenciamento de residuos

$\checkmark \quad$ Categoria do material manipulado:

- Conhecimento dos dados toxicológicos de cada substância manipulada

$\checkmark \quad$ Existência de programa educacional

$\checkmark \quad$ Conhecimento das etapas do gerenciamento

$\checkmark \quad$ Existência de treinamento para situações de emergência (institucional)

$\diamond \quad$ Existência de programa de treinamento para situações de emergência (percepção individual)

$\checkmark \quad$ Existência de programa de treinamento para o descarte das substâncias/materiais manipulados

$\checkmark$ Realização de treinamento para lidar com situações de emergência (resposta individual)

0 Dificuldades introduzidas pelo gerenciamento (percepção individual) 


$\begin{array}{ll}0 & \text { Sexo } \\ 0 & \text { Idade } \\ 0 & \text { Importância do gerenciamento de residuos } \\ 0 & \text { Descarte realizado atende as necessidades do laboratório } \\ 0 & \text { Lavagem da vidraria com solução sulfocrômica } \\ 0 & \text { Relevância da toxicidade da substância manipulada e descarte } \\ & \text { a ser adotado quando da validação de uma nova metodologia } \\ 0 & \text { Fichas de segurança dos produtos manipulados } \\ 0 & \text { Uso de equipamentos de proteção individual } \\ & \text { Procedimentos operacionais padrão para as medidas de } \\ & \text { segurança necessárias para a realização das análises }\end{array}$

Foi verificada a associação entre cada variável de interesse (independente) e o procedimento de descarte adotado, nas situações de rotina e emergência, através do $\chi^{2}$

O modelo de regressão logística foi utilizado para avaliar a associação entre as variáveis independentes e o procedimento de descarte dos resíduos gerados nos laboratórios das instituições estudadas, inferindo-se o peso das variáveis selecionadas na percepção dos envolvidos quanto à correta disposição. Nesse estudo foi empregado o pacote estatístico STATA - Statistics Data Analysis, versão 6.0 (STATA CORPORATION, 1999).

\subsection{Verificação da percepção do corpo funcional}

Os fatores associados à percepção dos funcionários dos laboratórios quanto ao correto procedimento de descarte dos resíduos gerados, em situação de rotina e emergência - derramamento - foram estabelecidos por critérios próprios por não se encontrar qualquer referência na literatura sobre o tema. As informações necessárias foram obtidas através das entrevistas realizadas e através da aplicação do questionário. Esses roteiros encontram-se nos anexos 11, 12 e 13. 
As variáveis abordadas, apresentadas no item 5.5.2., foram formuladas com base em hipóteses de percepção levadas pela observação de dados reais, como por exemplo: formação do funcionário, tempo de formado, tempo na função, existência de programa educacional, e outras.

\subsection{Discussão dos possíveis impactos dos resíduos identificados sobre a saúde humana}

A revisão da literatura enfocou os resíduos perigosos, atendo-se tanto à exposição ocupacional como à ambiental. Os dados levantados foram analisados em nível teórico, sem que se pretendesse a avaliação precisa da exposição ocupacional e ambiental. Assim, os dados foram considerados com base em estudos publicados que contemplaram as condições de exposição.

\subsection{Avaliação do envolvimento institucional em programa de gerenciamento de resíduos}

O programa de gerenciamento nas Instituições onde o mesmo está implantado, as dificuldades em sua implantação e os procedimentos de descarte adotados foi obtido através de entrevistas com o representante da Comissão de gerenciamento de resíduos, com os responsáveis, coordenadores e técnicos de cada laboratório. Os resultados desse levantamento foram cotejados com o estado da arte quanto à disposição dos resíduos levantados, nas situações de rotina e emergência.

\section{QUESTÕES ÉTICAS}

As instituições estudadas foram previamente contatadas e informadas sobre o objetivo da pesquisa e o caráter confidencial das informações recebidas.

Todos os participantes da pesquisa também foram instruídos sobre seus objetivos, assinando um termo de consentimento informado (anexo 14). 


\section{RESULTADOS}

\subsection{População estudada}

Dos 280 funcionários da Instituição $\mathrm{A}$, sediados na capital, foram entrevistados 74 (setenta e quatro) funcionários: 70 (setenta) de nível superior e 4 (quatro) de nível médio) e 48 (quarenta e oito) responderam ao questionário: 32 (trinta e dois) de nível superior e 16(dezesseis) de nível médio. Destes 87,7\% eram do sexo feminino, com faixa etária entre 24 a 63 anos, tempo de formado entre 1 a 40 anos e tempo na função entre 6 meses a 33 anos.

$\mathrm{Na}$ Instituição de ensino e pesquisa, Instituição $\mathrm{B}$, foram entrevistados 50 docentes, 10 técnicos de nível superior, 13 técnicos de nível médio, 14 pósgraduandos e 4 estagiários de iniciação científica. Responderam ao questionário: 1 técnico de nível superior, 5 técnicos de nível médio, 24 pós-graduandos e 1 estagiário de iniciação científica. Nesta população, $72,9 \%$ eram do sexo feminino, apresentaram faixa etária entre 20 a 64 anos, tempo de formado entre 6 meses a 36 anos e tempo na função entre 6 meses a 34 anos.

$\mathrm{Na}$ Instituição $\mathrm{C}$ foram entrevistados 27 funcionários sendo apenas 4 técnicos de nível médio. Responderam ao questionário 10 analistas de nível superior. Esta população também se apresentou preponderantemente feminina, $81 \%$, com faixa etária entre 31 a 51 anos, tempo de formado entre 7 a 26 anos e tempo na função entre 6 meses a 24 anos.

\subsection{Levantamento dos resíduos gerados}

Como descrito no item 5.2, os resíduos produzidos nas instituições de estudo foram classificados em especiais e infectantes. Os residuos especiais foram subdivididos nas seguintes categorias: inflamável, corrosivo, reativo, tóxico, resíduos contendo substâncias radioativas, medicamentos e corantes. 
Para permitir a melhor compreensão dos residuos gerados nessas instituições e das matrizes manipuladas, os resíduos não perigosos também foram tabulados e as diferentes matrizes analisadas foram discriminadas.

\subsubsection{Resíduos especiais}

\subsubsection{Resíduos contendo substâncias inflamáveis}

As tabelas A-13, A-14 e A-15 do anexo 15, identificado pela cor vermelha, apresentam os residuos contendo substâncias químicas, classificadas como inflamáveis segundo a $\mathrm{NBr} 10.004$, gerados pelas instituições de estudo, respectivamente, Instituição A, B e C. Nestas tabelas estão discriminados a substância inflamável, seu volume mensal utilizado, o procedimento de descarte adotado, detalhando-se, na medida do possível, a composição da mistura onde se encontra. A tabela abaixo exemplifica a apresentação adotada no anexo em referência.

Tabela - Exemplos de resíduos contendo substâncias classificadas como inflamáveis gerados pela Instituição A e descarte adotado.

\begin{tabular}{|c|c|c|}
\hline Substância & Volume & Descarte adotado \\
\hline Acetato de etila & $6100 \mathrm{ml} / \mathrm{m}$ & $\begin{array}{l}5300 \mathrm{ml} / \mathrm{m} \text { - segregados sendo } 5000 \mathrm{ml} / \mathrm{m} \text { em mistura } \\
\text { com sulfato de cobre ou amônia e } 300 \mathrm{ml} / \mathrm{m} \text { em mistura } \\
\text { com tolueno e ácido fórmico, } 120 \mathrm{ml} / \mathrm{m} \text { segregado em } \\
\text { mistura a acetonitrila e água }(70: 10: 30 \text { de acetato de } \\
\text { etila); } 680 \mathrm{ml} / \mathrm{m} \text { - evaporados em capela química em } \\
\text { mistura com metanol e hidróxido de amônia. }\end{array}$ \\
\hline Acetona & $8300 \mathrm{ml} / \mathrm{m}$ & $\begin{array}{l}4450 \mathrm{ml} / \mathrm{m} \text { segregados para a comissão de } \\
\text { gerenciamento sendo que } 500 \mathrm{ml} / \mathrm{m} \text { em mistura com } \\
\text { água, } 350 \mathrm{ml} / \mathrm{m} \text { em mistura com resíduos de praguicidas } \\
\text { organofosforados, clorados e cumarínicos e } 100 \mathrm{ml} / \mathrm{m} \\
\text { em mistura com o clorofórmio; } 600 \mathrm{ml} / \mathrm{m} \text { são } \\
\text { reutilizados (não há descarte). O restante descartado na } \\
\text { rede de esgoto sendo que } 1300 \mathrm{ml} / \mathrm{m} \text { diluidos com } \\
\text { hipoclorito e destes, } 100 \mathrm{ml} / \mathrm{m} \text { são ainda autoclavados } \\
\text { antes do descarte. }\end{array}$ \\
\hline
\end{tabular}

A comparação entre o volume das principais substâncias inflamáveis geradas pelas Instituições de estudo está ilustrada na Figura 3. 


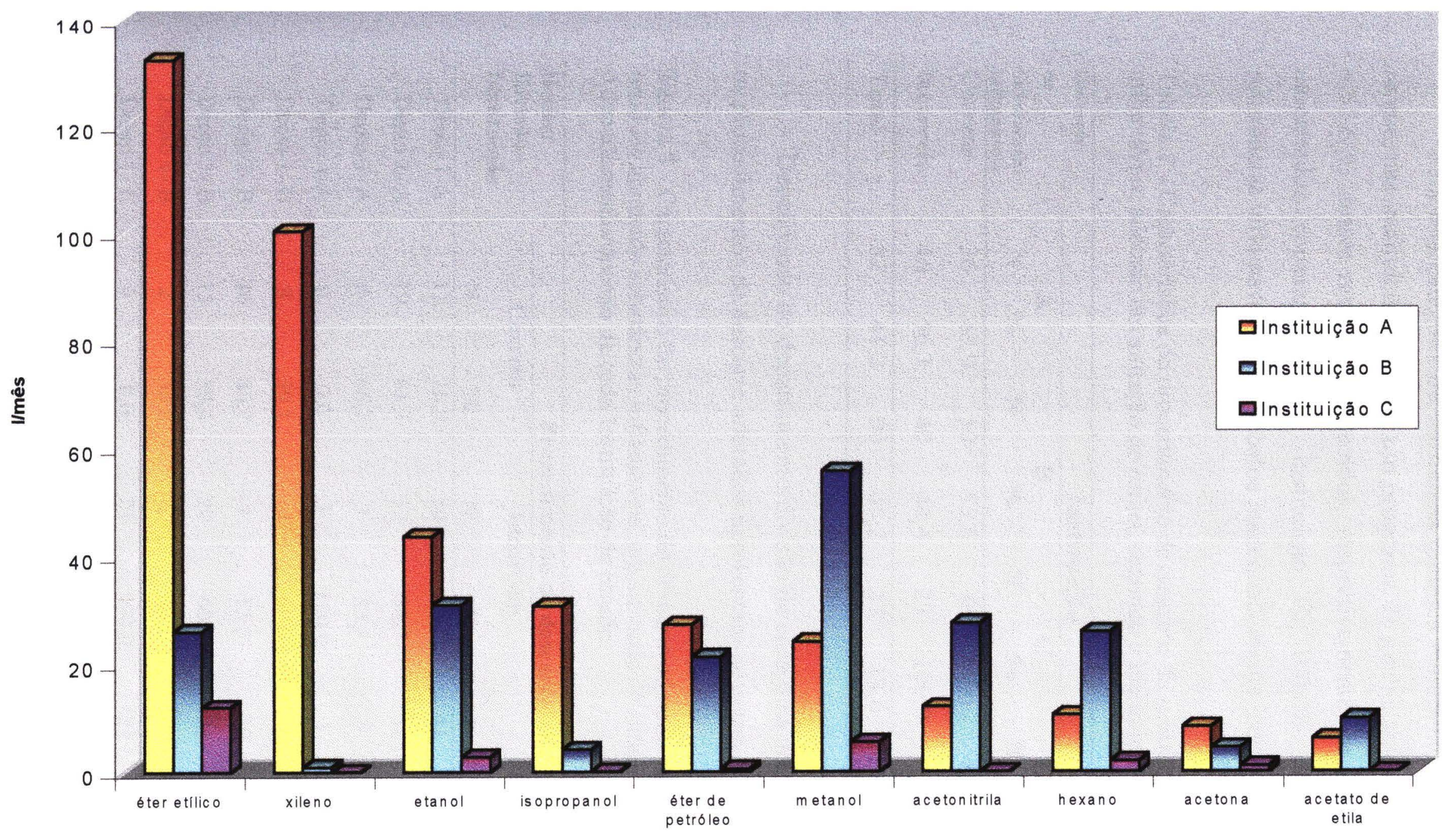

Figura 3- Principais Substâncias inflamáveis utilizadas pelas Instituições estudadas no município de São Paulo, no período de julho de 1999 a fevereiro de 2000. 
Para esta categoria de substância química manipulada - inflamável, verificase que, nas instituições onde há um programa de gerenciamento implantado, 43,9\% e $55,6 \%$ desses residuos produzidos, respectivamente, na Instituição A e B, são descartados corretamente. $\mathrm{Na}$ Instituição $\mathrm{C}, 100,0 \%$ dos resíduos contendo substâncias inflamáveis são dispostos inadequadamente, como evidencia a Tabela 7.

Tabela 7 - Característica do procedimento de descarte de substâncias inflamáveis, adotado em situação de rotina, segundo a Instituição de estudo

\begin{tabular}{|c|c|c|c|c|c|c|c|c|c|}
\hline \multirow{3}{*}{$\begin{array}{l}\text { Descarte } \\
\text { de } \\
\text { Substâncias } \\
\text { inflamáveis }\end{array}$} & \multicolumn{8}{|c|}{ Instituição } & \multirow[b]{3}{*}{$x^{2}=26,125$} \\
\hline & \multicolumn{2}{|c|}{$\mathbf{A}$} & \multicolumn{2}{|c|}{$\mathbf{B}$} & \multicolumn{2}{|c|}{$\mathrm{C}$} & \multicolumn{2}{|c|}{ Total } & \\
\hline & $\mathbf{N}$ & $\%$ & $\mathbf{N}$ & $\%$ & $\mathbf{N}$ & $\%$ & $\mathbf{N}$ & $\%$ & \\
\hline Correto & 36 & 43,9 & 50 & 55,6 & 0 & 0,0 & 86 & 43,2 & $\mathrm{p}=0,000002$ \\
\hline Incorreto & 46 & 56,1 & 40 & 44,4 & 27 & 100,0 & 113 & 56,8 & \\
\hline Total & 82 & 41,2 & 90 & 45,2 & 27 & 13,6 & 199 & 100,0 & \\
\hline
\end{tabular}

Dependendo do departamento/divisão de cada uma das Instituições de estudo, os procedimentos de descarte adotados apresentam-se como ilustrado na Tabela 8.

Tabela 8 - Característica do procedimento de descarte adotado para os resíduos contendo substâncias inflamáveis, em situação de rotina, segundo o departamento/divisão de cada Instituição de estudo

\begin{tabular}{|c|c|c|c|c|c|c|c|}
\hline \multirow{3}{*}{$\begin{array}{l}\text { Depto/ } \\
\text { Divisão - } \\
\text { Instituição }\end{array}$} & \multicolumn{6}{|c|}{ Procedimento de descarte } & \\
\hline & \multicolumn{2}{|c|}{ Correto } & \multicolumn{2}{|c|}{ Incorreto } & \multicolumn{2}{|c|}{ Total } & \\
\hline & $\mathbf{N}$ & $\%$ & $\mathbf{N}$ & $\%$ & $\mathbf{N}$ & $\%$ & \\
\hline Depto 1-A & 11 & 26,8 & 30 & 73,2 & 41 & 20,6 & \\
\hline Depto 2- A & 19 & 61,3 & 12 & 38,7 & 31 & 15,6 & \\
\hline Depto 3- A & 6 & 66,7 & 3 & 33,3 & 9 & 4,5 & \\
\hline Depto 4-A & 0 & 0,0 & 1 & 100,0 & 1 & 0,5 & $x^{2}=55,45$ \\
\hline Depto 1- B & 9 & 39,1 & 14 & 60,9 & 23 & 11,6 & $p=0,00000000$ \\
\hline Depto 2- B & 26 & 86,7 & 4 & 13,3 & 30 & 15,1 & \\
\hline Depto 3- B & 13 & 39,4 & 20 & 60,5 & 33 & 16,6 & \\
\hline Depto 4- B & 2 & 50,0 & 2 & 50,0 & 4 & 2,0 & \\
\hline Depto 1-C & 0 & 0,0 & 21 & 100,0 & 21 & 10,6 & \\
\hline Depto 2-C & 0 & 0,0 & 6 & 100,0 & 6 & 3,0 & \\
\hline Total & 86 & 43,2 & 113 & 56,8 & 199 & 100,0 & \\
\hline
\end{tabular}


A Tabela 9 demonstra a correlação entre a formação do indivíduo e o procedimento de disposição adotado quanto aos resíduos inflamáveis. Da população estudada, considerando-se a manipulação desta categoria de substância, 44,7\% são farmacêuticos e destes $50,6 \%$ dispõem corretamente esses resíduos gerados.

Tabela 9- Característica do procedimento de disposição rotineiramente adotado para os residuos inflamáveis, segundo a formação dos funcionários

\begin{tabular}{|c|c|c|c|c|c|c|c|c|}
\hline \multirow{3}{*}{$\begin{array}{l}\text { Formação } \\
\text { dos } \\
\text { funcionários }\end{array}$} & & \multicolumn{6}{|c|}{ Procedimento de descarte } & \multirow{4}{*}{$\chi^{2}=12,69$} \\
\hline & & \multicolumn{2}{|c|}{ correto } & \multicolumn{2}{|c|}{ incorreto } & \multirow{3}{*}{$\begin{array}{l}\text { Total } \\
\text { N } \\
25\end{array}$} & \multirow{3}{*}{$\frac{\%}{12,6}$} & \\
\hline & & $\mathbf{N}$ & $\%$ & $\mathbf{N}$ & $\%$ & & & \\
\hline Químico & & 15 & 60,0 & 10 & 40,0 & & & \\
\hline Farmacêutico & & 45 & 50,6 & 44 & 49,4 & 89 & 44,7 & $p=0,048221$ \\
\hline Biólogo & & 8 & 29,6 & 19 & 70,4 & 27 & 13,6 & \\
\hline Biomédico & & 2 & 15,4 & 11 & 84,6 & 13 & 6,5 & \\
\hline $\begin{array}{l}\text { Outros profissionais } \\
\text { área da saúde }\end{array}$ & da & 2 & 25,0 & 6 & 75,0 & 8 & 4,0 & \\
\hline $\begin{array}{l}\text { Outros profissionais } \\
\text { área de exatas }\end{array}$ & da & 4 & 44,4 & 5 & 55,6 & 9 & 4,5 & \\
\hline Técnico nivel médio & & 10 & 35,7 & 18 & 64,3 & 28 & 14,1 & \\
\hline Total & & 86 & 43,2 & 113 & 56,8 & 199 & $\overline{100,0}$ & \\
\hline
\end{tabular}

As associações entre o procedimento de descarte empregado e o tempo de formado e tempo na função não se mostraram estatisticamente significativas $\left(\chi^{2}=\right.$ $2,14, p=0,829727$ e $\chi^{2}=0,30, p=0,997728$, respectivamente). Observa-se, no entanto, que o grupo mais representativo da amostra foi constituído por funcionários formados entre 6 e 10 anos ou que encontravam-se na função durante o mesmo período de tempo (Tabelas 10 e 11). 
Tabela 10- Característica do procedimento de disposição rotineiramente adotado para os residuos inflamáveis, segundo o tempo de formado dos funcionários

\begin{tabular}{lcccccc}
\hline \multirow{2}{*}{$\begin{array}{l}\text { Fempo de } \\
\text { formado dos }\end{array}$} & \multicolumn{7}{c}{ correto } & \multicolumn{2}{c}{ incorreto } & Total \\
\cline { 2 - 7 } & $\mathbf{N}$ & $\%$ & $\mathbf{N}$ & $\%$ & $\mathbf{N}$ & $\%$ \\
\hline $0,5-5$ anos & 4 & 50,0 & 4 & 50,0 & 8 & 4,0 \\
$6-10$ anos & 24 & 48,0 & 26 & 52,0 & 50 & 25,1 \\
$11-15$ anos & 12 & 35,2 & 22 & 34,7 & 34 & 17,1 \\
$16-20$ anos & 18 & 42,9 & 24 & 57,1 & 42 & 21,1 \\
$20-25$ anos & 17 & 39,5 & 26 & 60,5 & 43 & 21,6 \\
$26-40$ anos & 11 & 50,0 & 11 & 50,0 & 22 & 11,1 \\
\hline Total & 86 & 43,2 & 113 & 56,8 & 199 & 100,0 \\
\hline
\end{tabular}

Tabela 11 - Característica do procedimento de disposição rotineiramente adotado para os residuos inflamáveis, segundo o tempo na função

\begin{tabular}{lcccccc}
\hline \multirow{2}{*}{$\begin{array}{l}\text { Tempo na } \\
\text { função }\end{array}$} & $\mathbf{c}$ correto & \multicolumn{2}{c}{ incorreto } & Total \\
\cline { 2 - 7 } & $\mathbf{N}$ & $\%$ & $\mathbf{N}$ & $\%$ & $\mathbf{N}$ & $\%$ \\
\hline $0,5-5$ anos & 5 & 45,5 & 6 & 54,5 & 11 & 5,5 \\
$6-10$ anos & 37 & 43,0 & 49 & 57,0 & 86 & 43,2 \\
$11-15$ anos & 18 & 45,0 & 22 & 55,0 & 40 & 20,1 \\
$16-20$ anos & 11 & 40,7 & 16 & 59,3 & 27 & 13,6 \\
$20-25$ anos & 12 & 41,4 & 17 & 58,6 & 29 & 14,6 \\
$26-40$ anos & 3 & 50,0 & 3 & 50,0 & 6 & 3,0 \\
\hline Total & 86 & 43,2 & 113 & 56,8 & 199 & 100,0 \\
\hline
\end{tabular}

A associação entre a variável dependente, procedimento de descarte adotado para os resíduos contendo substâncias inflamáveis e a variável independente, existência de programa de gerenciamento de resíduos, é estatisticamente significativa. A Tabela 12 evidencia que a não existência de um programa de descarte institucionalizado leva a disposição incorreta de resíduos contendo 
substâncias inflamáveis, todavia, a sua existência não garante um procedimento correto em $100,0 \%$ dos casos.

Tabela 12 - Tipo de procedimento de descarte rotineiramente empregado para Os resíduos contendo substâncias inflamáveis, segundo a existência de programa de descarte institucionalizado

\begin{tabular}{|c|c|c|c|c|c|c|c|}
\hline \multirow{3}{*}{$\begin{array}{l}\text { Existência de } \\
\text { Programa de } \\
\text { descarte }\end{array}$} & \multicolumn{6}{|c|}{ Descarte } & \multirow{3}{*}{$\chi 2=20,78$} \\
\hline & \multicolumn{2}{|c|}{ Correto } & \multicolumn{2}{|c|}{ Incorreto } & \multicolumn{2}{|r|}{ Total } & \\
\hline & $\mathbf{N}$ & $\%$ & $\mathbf{N}$ & $\%$ & $\mathbf{N}$ & $\%$ & \\
\hline sim & 86 & 49,7 & 87 & 50,3 & 173 & 86,9 & $p=0,000005$ \\
\hline não & 0 & 100,0 & 26 & 100,0 & 26 & 13,1 & \\
\hline Total & 86 & 43,2 & 113 & 56,8 & 199 & 100,0 & \\
\hline
\end{tabular}

O conhecimento dos dados toxicológicos da substância manipulada não favoreceu o correto descarte de resíduos contendo substâncias inflamáveis, como ilustrado na Tabela 13. As Tabelas 14 e 15 evidenciaram a inexistência da compreensão da complexidade dos procedimentos de descarte e de um programa educacional institucionalizado para esclarecer o corpo funcional quanto aos procedimentos para o correto descarte dos resíduos gerados.

Tabela 13 - Tipo de procedimento de descarte rotineiramente adotado para os resíduos inflamáveis, segundo o conhecimento dos dados toxicológicos da substância manipulada

\begin{tabular}{|c|c|c|c|c|c|c|c|}
\hline \multirow{3}{*}{$\begin{array}{l}\text { Conhecimento dos } \\
\text { dados toricológicos da } \\
\text { suhatáncia } \\
\text { manipulada }\end{array}$} & \multicolumn{6}{|c|}{ Descarte } & \multirow{5}{*}{$\begin{array}{l}\chi 2=2,03 \\
p=0,153902\end{array}$} \\
\hline & \multicolumn{2}{|c|}{ Correto } & \multicolumn{2}{|c|}{ Incorreto } & \multicolumn{2}{|r|}{ Total } & \\
\hline & $\mathbf{N}$ & $\%$ & $\mathbf{N}$ & $\%$ & $\mathbf{N}$ & $\%$ & \\
\hline $\operatorname{sim}$ & 85 & 44,5 & 106 & 55,5 & 191 & 96,0 & \\
\hline não & 01 & 12,5 & 07 & 87,5 & 8 & 4,0 & \\
\hline Total & 86 & 43,2 & 113 & 56,8 & 199 & 100,0 & \\
\hline
\end{tabular}


Tabela 14 - Tipo de procedimento de descarte rotineiramente adotado para os resíduos inflamáveis, segundo a compreensão da complexidade desses procedimentos

\begin{tabular}{|c|c|c|c|c|c|c|c|}
\hline \multirow{3}{*}{$\begin{array}{l}\text { Compreensāo } \\
\text { complexidade } \\
\text { procedimentos } \\
\text { de descarte }\end{array}$} & \multicolumn{6}{|c|}{ Descarte } & \multirow[b]{3}{*}{$\chi^{2}=0,02$} \\
\hline & \multicolumn{2}{|c|}{ Correto } & \multicolumn{2}{|c|}{ Incorreto } & \multicolumn{2}{|r|}{ Total } & \\
\hline & $\mathbf{N}$ & $\%$ & $\mathbf{N}$ & $\%$ & $\mathbf{N}$ & $\%$ & \\
\hline $\operatorname{sim}$ & 1 & 100,0 & 0 & 0,0 & 1 & 0,5 & $p=0,890801$ \\
\hline não & 85 & 42,9 & 113 & 57,1 & 198 & 99,5 & \\
\hline Total & 86 & 43,2 & 113 & 56,8 & 199 & 100,0 & \\
\hline
\end{tabular}

Tabela 15- Tipo de procedimento de descarte rotineiramente adotado para os resíduos inflamáveis, segundo a existência de programa educacional institucionalizado

\begin{tabular}{lccccccc}
\hline $\begin{array}{l}\text { Existência de } \\
\text { programa } \\
\text { educacional }\end{array}$ & \multicolumn{6}{c}{ Correto } & \multicolumn{6}{c}{ Incorreto } & & Total & \\
\cline { 2 - 7 } & $\mathbf{N}$ & $\%$ & $\mathbf{N}$ & $\%$ & $\mathbf{N}$ & $\%$ & $\chi 2=0,0$ \\
\hline sim & 0 & 0,0 & 0 & 0,0 & 0 & 0,0 & $\mathrm{p}=1,000000$ \\
não & 86 & 43,2 & 113 & 56,8 & 199 & 100,0 & \\
\hline Total & 86 & 43,2 & 113 & 56,8 & 199 & 100,0 \\
\hline
\end{tabular}

A existência de treinamento para o correto descarte, segundo a percepção da população estudada, não determinou associação estatisticamente significativa com o procedimento de disposição adotado, como mostra a Tabela 16.

Tabela 16- Tipo de procedimento de descarte rotineiramente adotado para os resíduos inflamáveis, segundo a existência de treinamento para a correta disposição desses resíduos

\begin{tabular}{|c|c|c|c|c|c|c|}
\hline \multirow{3}{*}{$\begin{array}{l}\text { Treino para } \\
\text { o correto descarte }\end{array}$} & \multicolumn{6}{|c|}{ Descarte } \\
\hline & \multicolumn{2}{|c|}{ Correto } & \multicolumn{2}{|c|}{ Incorreto } & \multirow[b]{2}{*}{$\mathbf{N}$} & Total \\
\hline & $\mathbf{N}$ & $\%$ & $\mathbf{N}$ & $\%$ & & $\%$ \\
\hline Sim & 32 & 46,4 & 37 & 53,6 & 69 & 34,7 \\
\hline Não & 54 & 41,5 & 76 & 58,5 & 130 & 65,3 \\
\hline Total & 86 & 43,2 & 113 & 56,8 & 199 & 100,0 \\
\hline
\end{tabular}

$$
\chi^{2}=0,26
$$$$
\mathrm{p}=0,613275
$$ 


\subsubsection{Resíduos contendo substâncias Corrosivas}

As Tabelas A-16, A-17 e A-18 do anexo 16, indicado pela cor cinza, apresentam os resíduos corrosivos gerados, respectivamente, pelas Instituições A, B e C, seu volume e o procedimento de descarte adotado para a substância assim classificada ou para a mistura onde se encontra. A Tabela abaixo exemplifica os resultados apresentados no referido anexo.

Tabela - Exemplo de resíduos contendo substâncias classificadas como corrosivas gerados pela Instituição A e o descarte adotado

\begin{tabular}{|c|c|c|}
\hline Substância & Volume & Descarte adotado \\
\hline Ácido acético & $\begin{array}{c}3265 \mathrm{ml} / \mathrm{m} \\
\text { (concentrado) }\end{array}$ & $\begin{array}{l}\text { Rede de esgoto - cerca de } 1800 \mathrm{ml} / \mathrm{m} \text { em mistura com o } \\
\text { clorofórmio, ácido acético, iodeto de potássio, amido e } \\
\text { tiossulfato de sódio; cerca de } 420 \mathrm{ml} \text { do concentrado como } \\
\text { soluções diluídas } 5 \text { a } 7 \% \text { em mistura com iodeto e tiossulfato } \\
\text { de sódio; } 400 \mathrm{~mL} / \mathrm{m} \text { em mistura com metanol e água; } 50 \\
\mathrm{ml} / \mathrm{m} \text { do concentrado em mistura com ponceau; } 60 \mathrm{mlL} / \mathrm{m} \\
\text { em mistura com formaldeído oxidado à ácido fórmico na } \\
\text { reação; } 85 \mathrm{ml} / \mathrm{m} \text { em mistura com metanol e glicerina; } \\
\text { Nebulizados em capela: cerca de } 10 \mathrm{ml} / \mathrm{m} \text { em mistura com } \\
\text { anisaldeído, metanol e ácido sulfúrico e cerca de } 35 \mathrm{ml} / \mathrm{m} \\
\text { em mistura com iodo, iodeto de potássio e ácido sulfúrico e } \\
\text { nitrato de bismuto. } \\
\text { Segregados cerca de } 165 \mathrm{ml} \text { do concentrado sendo que } 130 \\
\text { ml em mistura com ácido sulfúrico, } 30 \text { ml em mistura com } \\
\text { anidrido acético, ácido sulfúrico e clorofórmio e } 5 \mathrm{ml} \mathrm{em} \\
\text { mistura com ciclohexano e acetato de etila; } \\
\text { Cerca de } 240 \mathrm{~mL} / \mathrm{m} \text { evaporado em capela química em } \\
\text { mistura com o etanol. }\end{array}$ \\
\hline
\end{tabular}

Ácido clorídrico $\quad 3800 \mathrm{ml} / \mathrm{m}$ Cerca de $48 \mathrm{ml} / \mathrm{m}$ do concentrado, equivalente a $900 \mathrm{ml} / \mathrm{m}$ (concentrado) de solução $1 \mathrm{~N}$, segregados em mistura com metais;

Restante descartado na rede de esgoto, destes cerca de 180 $\mathrm{ml} / \mathrm{m}$ do concentrado (solução $2 \mathrm{~N}$ ) em mistura com soro, ácido tioglicólico e ácido tricloracético, $4 \mathrm{ml} / \mathrm{m}$ do concentrado (soluções diluídas $0,1 \mathrm{~N}$ ) em mistura com o princípio ativo de medicamentos; $22 \mathrm{ml} / \mathrm{m}$ em mistura com agentes cromogênicos diluídos com hipoclorito; $500 \mathrm{ml} / \mathrm{m}$ descartados na rede de esgoto sem neutralização, manipulado sob exaustão; $2100 \mathrm{ml} / \mathrm{m}$ neutralizados (titulação ácido-base), a maior parte em mistura com óxido cuproso

A Figura 4 mostra as principais substâncias corrosivas utilizadas pelas instituições estudadas e presentes nos resíduos por elas gerados. 


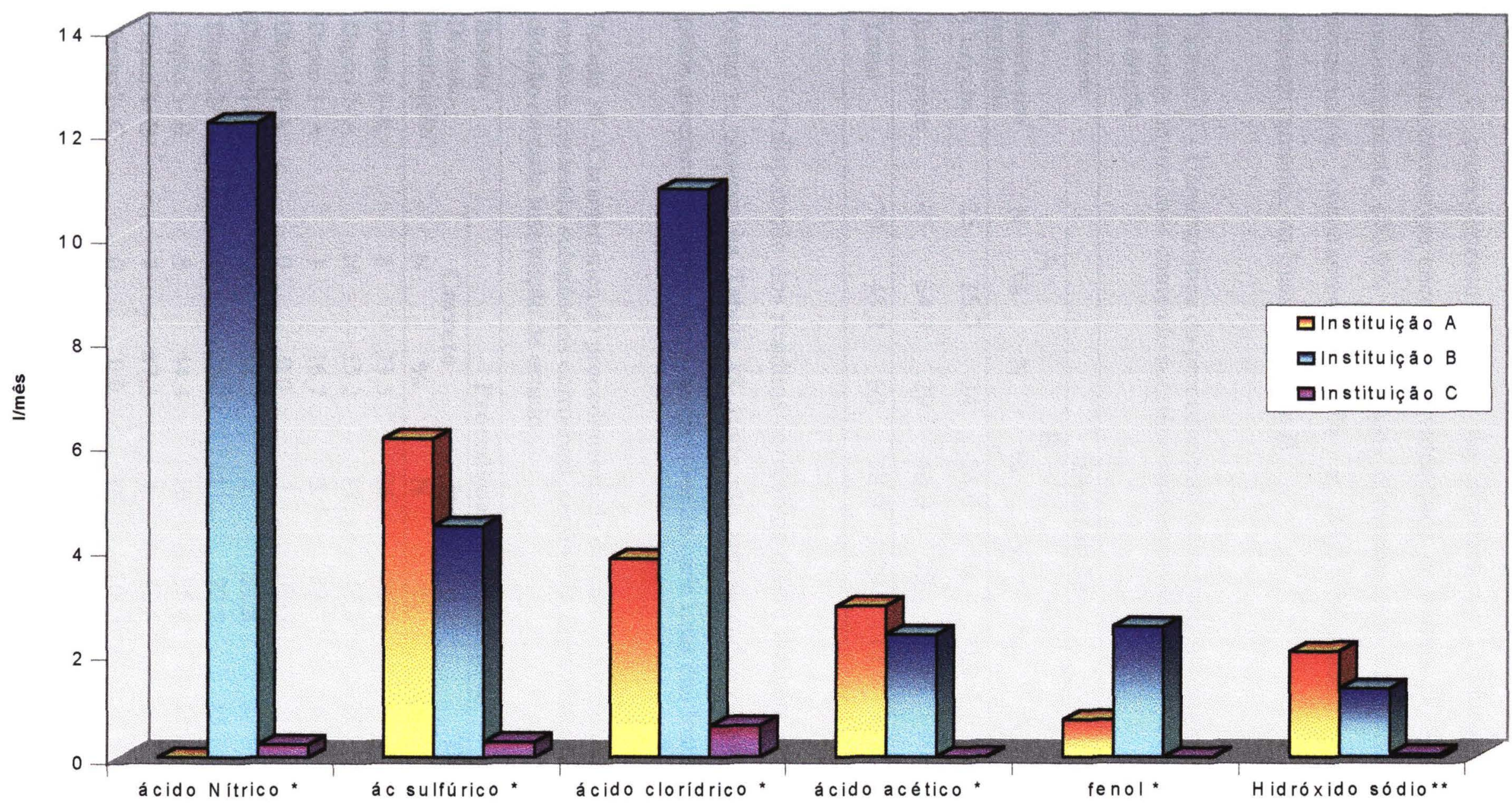

Figura 4 - Principias substâncias corrosivas presentes nos resíduos gerados pelas Instituições estudadas no município de São Paulo, no período de julho de 1999 a fevereiro de 2000. 
O procedimento adotado no descarte de residuos contendo substâncias quimicas corrosivas encontra-se evidenciado na Tabela 17. A Instituição $\mathrm{C}$ descarta incorretamente $100,0 \%$ dos resíduos contendo essa categoria de substâncias. São descartados corretamente $35,7 \%$ e $54,0 \%$ desses resíduos produzidos, respectivamente, na Instituição A e B.

Tabela 17 - Característica do procedimento rotineiramente empregado no descarte de resíduos contendo substâncias corrosivas, segundo a Instituição de estudo

\begin{tabular}{|c|c|c|c|c|c|c|c|c|c|}
\hline \multirow{3}{*}{$\begin{array}{l}\text { Descarte } \\
\text { de } \\
\text { Substâncias } \\
\text { corrosivas }\end{array}$} & \multicolumn{8}{|c|}{ Instituição } & \multirow{3}{*}{$x^{2}=25,01$} \\
\hline & \multicolumn{2}{|c|}{$\mathbf{A}$} & \multicolumn{2}{|c|}{$\mathbf{B}$} & \multicolumn{2}{|c|}{$\mathbf{C}$} & \multicolumn{2}{|c|}{ Total } & \\
\hline & $\mathbf{N}$ & $\%$ & $\mathbf{N}$ & $\%$ & $\mathbf{N}$ & $\%$ & $\mathbf{N}$ & $\%$ & \\
\hline Correto & 25 & 35,7 & 34 & 54,0 & 0 & 0,0 & 59 & 36,4 & $p=0,000004$ \\
\hline Incorreto & 45 & 64,3 & 29 & 46,0 & 29 & 100,0 & 103 & 63,6 & \\
\hline Total & 70 & 43,2 & 63 & 38,9 & 29 & 17,9 & 162 & 100,0 & \\
\hline
\end{tabular}

A disposição dos resíduos corrosivos difere também inter institucionalmente, como se observa na Tabela 18 , onde são apresentados os procedimentos adotados pelos diversos departamentos ou divisões de cada uma das Instituições avaliadas.

Tabela 18 - Característica do procedimento de descarte adotado para os resíduos contendo substâncias corrosivas, segundo o departamento ou divisão de cada Instituição de estudo

\begin{tabular}{|c|c|c|c|c|c|c|c|}
\hline \multirow{3}{*}{$\begin{array}{l}\text { Depto/ } \\
\text { Divisão- } \\
\text { Instituição }\end{array}$} & \multicolumn{6}{|c|}{ Procedimento de descarte } & \\
\hline & \multicolumn{2}{|c|}{ Correto } & \multicolumn{2}{|c|}{ Incorreto } & \multicolumn{2}{|c|}{ Total } & \\
\hline & $\mathbf{N}$ & $\%$ & $\mathbf{N}$ & $\%$ & $\mathbf{N}$ & $\%$ & \\
\hline Depto 1-A & 8 & 23,5 & 26 & 76,5 & 34 & 21,0 & \\
\hline Depto 2- A & 16 & 55,2 & 13 & 44,8 & 29 & 17,9 & \\
\hline Depto 3- A & 1 & 16,7 & 5 & 83,3 & 6 & 3,7 & \\
\hline Depto 4-A & 0 & 0,0 & 1 & 100,0 & 1 & 0,5 & $x^{2}=44,76$ \\
\hline Depto 1- B & 15 & 58,2 & 7 & 31,8 & 22 & 13,6 & \\
\hline Depto 2- B & 4 & 26,7 & 11 & 73,3 & 15 & 9,3 & $\mathrm{p}=0,000000$ \\
\hline Depto 3- B & 8 & 44,4 & 10 & 55,6 & 18 & 11,1 & \\
\hline Depto 4- B & 7 & 87,5 & 1 & 12,5 & 8 & 4,9 & \\
\hline Depto 1- C & 0 & 0,0 & 16 & 100,0 & 16 & 9,9 & \\
\hline Depto 2- C & 0 & 0,0 & 13 & 100,0 & 13 & 8,0 & \\
\hline Total & 59 & 36,4 & 103 & 63,6 & 162 & 100,0 & \\
\hline
\end{tabular}


Dentre a população estudada, são os farmacêuticos e biólogos que manipulam os maiores volumes de resíduos corrosivos, como mostra a Tabela 19; destes, 40,7\% dos farmacêuticos e $17,9 \%$ dos biólogos dispõem adequadamente esses resíduos.

Tabela 19 - Característica do procedimento de disposição rotineiramente adotado para os resíduos corrosivos, segundo a formação dos funcionários

\begin{tabular}{|c|c|c|c|c|c|c|c|}
\hline \multirow{3}{*}{$\begin{array}{l}\text { Formação } \\
\text { dos } \\
\text { funcionários }\end{array}$} & \multicolumn{6}{|c|}{ Procedimento de descarte } & \multirow{4}{*}{$\chi^{2}=14,07$} \\
\hline & \multicolumn{2}{|c|}{ correto } & \multicolumn{2}{|c|}{ incorreto } & \multicolumn{2}{|c|}{ Total } & \\
\hline & $\mathbf{N}$ & $\%$ & $\mathbf{N}$ & $\%$ & $\mathbf{N}$ & $\%$ & \\
\hline Químico & 14 & 60,9 & 9 & 39,1 & 23 & 14,2 & \\
\hline Farmacêutico & 24 & 40,7 & 35 & 59,3 & 59 & 36,4 & $\mathrm{p}=0,028872$ \\
\hline Biólogo & 5 & 17,9 & 23 & 82,1 & 28 & 17,3 & \\
\hline Biomédico & 2 & 18,2 & 9 & 81,8 & 11 & 6,8 & \\
\hline $\begin{array}{l}\text { outros profissionais da } \\
\text { área da saúde }\end{array}$ & 4 & 36,4 & 7 & 53,6 & 11 & 6,8 & \\
\hline $\begin{array}{l}\text { Outros profissionais da } \\
\text { área de exatas }\end{array}$ & 5 & 50,0 & 5 & 50,0 & 10 & 6,2 & \\
\hline Técnico nível médio & 8 & 25,0 & 15 & 75,0 & 20 & 12,3 & \\
\hline Total & 59 & 36,4 & 103 & 63,6 & 162 & 100,0 & \\
\hline
\end{tabular}

As variáveis independentes: tempo de formado e tempo na função não apresentaram associação estatisticamente significativa com o procedimento de descarte adotado, comportando-se de modo semelhante ao relatado para os resíduos inflamáveis. O período de 6 a 10 anos foi o intervalo que apresentou o maior número de funcionários tanto para a variável tempo de formado como para o tempo na função, representando, respectivamente, $26,5 \%$ e $46,9 \%$ da população estudada.

A Tabela 20 apresenta a correlação entre o procedimento de descarte adotado para os resíduos corrosivos e a existência de um programa de gerenciamento de residuos. A disposição adequada ocorre preferentemente nas Instituições onde o programa de gerenciamento está instituído. 
Tabela 20 - Tipo de procedimento de descarte rotineiramente empregado para os residuos corrosivos, segundo a existência de programa de descarte institucionalizado

\begin{tabular}{lcccccc}
\hline Existência de & \multicolumn{6}{c}{ Procedimento de Descarte } \\
Pescama de & \multicolumn{7}{c}{ Correto } & Incorreto & \multicolumn{2}{c}{ Total } \\
\cline { 2 - 7 } & $\mathbf{N}$ & $\%$ & $\mathbf{N}$ & $\%$ & $\mathbf{N}$ & $\%$ \\
\hline sim & 54 & 44,0 & 75 & 56,0 & 134 & 82,7 \\
não & 0 & 0,0 & 28 & 100,0 & 28 & 17,3 \\
\hline Total & 54 & 36,4 & 103 & 63,6 & 162 & 100,0 \\
\hline
\end{tabular}

$\chi 2=17,54$

$\mathrm{p}=0,000028$

As demais variáveis independentes - conhecimento dos dados toxicológicos da substância manipulada, compreensão da complexidade dos procedimentos de descarte, existência de um programa educacional e treinamento para o correto descarte - quando associadas ao procedimento de descarte adotado comportaram-se de forma semelhante ao descrito no item 7.2.1.1, referente aos resíduos inflamáveis.

\subsubsection{Resíduos contendo substâncias reativas}

Os resíduos contendo substâncias reativas gerados nas Instituições A, B e C, encontram-se listados nas Tabelas A-19, A-20 e A-21, respectivamente. Nestas Tabelas, apresentadas no anexo 17 indicado pela cor amarela, estão tabulados, também, os volumes das substâncias reativas manipuladas e o descarte adotado para a mistura que integram, como exemplifica a tabela abaixo.

Tabela - Exemplo de resíduos contendo substâncias classificadas como reativas gerados pela Instituição B e descarte adotado.

\begin{tabular}{lcl}
\hline \multicolumn{1}{c}{ substância } & volume & \multicolumn{1}{c}{ Descarte adotado } \\
\hline Ácido pícrico & $1,68 \mathrm{~g} / \mathrm{m}$ & $\begin{array}{l}\text { Rede de esgoto em mistura com soro, hidróxido de } \\
\text { sódio, destes } 0,36 \mathrm{~g} / \mathrm{m} \text { são previamente diluídos com } \\
\text { hipoclorito. }\end{array}$ \\
$\begin{array}{l}\text { Boridreto de } \\
\text { sódio }\end{array}$ & $4,8 \mathrm{~g} / \mathrm{m}$ & $\begin{array}{l}\text { Rede de esgoto em mistura com hidróxido de amônia, } \\
\text { ácido acético, dimetilsulfóxido e anidrido acético. }\end{array}$ \\
\hline
\end{tabular}


Observa-se, através da análise estatística dos dados referentes aos resíduos reativos, que esse material é manipulado por um pequeno número de analistas. Em geral, independente da Instituição, a disposição desses resíduos é inadequada, como ilustra a Tabela 21. E nem todos os departamentos das Instituições de estudo manipulam resíduos contendo essa categoria de substâncias, o que se evidencia na Tabela 22 .

Tabela 21 - Característica do procedimento de descarte de resíduos contendo substâncias reativas, segundo a Instituição de estudo

\begin{tabular}{|c|c|c|c|c|c|c|c|c|}
\hline \multirow{3}{*}{$\begin{array}{l}\text { Descarte } \\
\text { de } \\
\text { Substâncias } \\
\text { reativas }\end{array}$} & \multicolumn{8}{|c|}{ Instituição } \\
\hline & \multicolumn{2}{|c|}{$\mathbf{A}$} & \multicolumn{2}{|c|}{ B } & \multicolumn{2}{|c|}{$\mathbf{C}$} & \multicolumn{2}{|c|}{ Total } \\
\hline & $\mathbf{N}$ & $\%$ & $\mathbf{N}$ & $\%$ & $\mathbf{N}$ & $\%$ & $\mathbf{N}$ & $\%$ \\
\hline Correto & 3 & 50,0 & 3 & 20 & 0 & 0,0 & 5 & 22,2 \\
\hline Incorreto & 2 & 40,0 & 12 & 80,0 & 7 & 100,0 & 21 & 77,8 \\
\hline Total & 5 & 18,5 & 15 & 55,6 & 7 & 25,9 & 27 & 100,0 \\
\hline
\end{tabular}

$$
\begin{aligned}
& \chi^{2}=6,17 \\
& p=0,045697
\end{aligned}
$$

Tabela 22 - Característica do procedimento de descarte adotado para os resíduos contendo substâncias reativas, em situação de rotina, segundo

\begin{tabular}{|c|c|c|c|c|c|c|c|}
\hline \multirow{3}{*}{$\begin{array}{l}\text { Depto/ } \\
\text { Divisão - } \\
\text { Instituição }\end{array}$} & \multicolumn{6}{|c|}{ Procedimento de descarte } & \\
\hline & \multicolumn{2}{|c|}{ Correto } & \multicolumn{2}{|c|}{ Incorreto } & \multicolumn{2}{|c|}{ Total } & \\
\hline & $\mathbf{N}$ & $\%$ & $\mathbf{N}$ & $\%$ & $\mathbf{N}$ & $\%$ & \\
\hline Depto 1-A & 0 & 0,0 & 0 & 0,0 & 0 & 0,0 & \\
\hline Depto 2- A & 2 & 66,7 & 1 & 33,3 & 3 & 11,1 & \\
\hline Depto 3- A & 1 & 50,0 & 1 & 50,0 & 2 & 7,4 & \\
\hline Depto 4-A & 0 & 0,0 & 0 & 0,0 & 0 & 0,0 & $\chi^{2}=13,31$ \\
\hline Depto 1- B & 0 & 0,0 & 3 & 100,0 & 3 & 11,1 & $p=0,000664$ \\
\hline Depto 2 - B & 3 & 60,0 & 2 & 40,0 & 5 & 18,5 & \\
\hline Depto 3- B & 0 & 0,0 & 7 & 100,0 & 7 & 25,9 & \\
\hline Depto 4- B & 0 & 0,0 & 0 & 0,0 & 0 & 0,0 & \\
\hline Depto 1-C & 0 & 0,0 & 7 & 100,0 & 7 & 25,9 & \\
\hline Depto 2- C & 0 & 0,0 & 0 & 0,0 & 0 & 0,0 & \\
\hline Total & 6 & 22,2 & 21 & 77,8 & 27 & 100,0 & \\
\hline
\end{tabular}
o departamento ou divisão de cada Instituição de estudo 
As demais variáveis analisadas não mostraram correlação estatisticamente significativa ou comportamento diferente do observado para os resíduos inflamáveis e corrosivos.

\subsubsection{Resíduos contendo substâncias tóxicas}

Encontram-se relacionados nas Tabelas A-22, A-23 e A-24, do anexo 18 indicado pela cor azul, os resíduos contendo substâncias tóxicas gerados, respectivamente, nas Instituições $\mathrm{A}, \mathrm{B}$ e $\mathrm{C}$, bem como, a quantidade utilizada e o procedimento de descarte adotado para cada mistura. A Tabela abaixo exemplifica a apresentação adotada no anexo em referência.

Tabela - Resíduos contendo substâncias classificadas como tóxicas geradas pela Instituição C e descarte adotado

$\begin{array}{lll}\text { Substância Quantidade Descarte adotado } & \end{array}$

\begin{tabular}{|c|c|c|}
\hline $\begin{array}{l}\text { Acetato de } \\
\text { chumbo }\end{array}$ & $1 \mathrm{~g} / \mathrm{m}$ & Rede de esgoto em mistura com ácido acético e sangue. \\
\hline $\begin{array}{l}\text { Cloreto de } \\
\text { paládio }\end{array}$ & $1,53 \mathrm{~g} / \mathrm{m}$ & $\begin{array}{l}1,4 \mathrm{~g} / \mathrm{m} \text { nebulizada em capela (solução aquosa); } \\
0,13 \mathrm{~g} / \mathrm{m} \text { descartado na rede de esgoto, sendo que cerca de } 20 \mathrm{mg} / \mathrm{m} \\
\text { como paládio metálico. }\end{array}$ \\
\hline Clorofórmio & $31380 \mathrm{ml} / \mathrm{m}$ & $\begin{array}{l}18100 \mathrm{ml} / \mathrm{m} \text { evaporado em capela em mistura com éter etílico, } 4000 \\
\mathrm{ml} / \mathrm{m} \text { evaporados em mistura com isopropanol; } 4000 \mathrm{ml} / \mathrm{m} \\
\text { evaporados em mistura a acetona; restante descartado na rede de } \\
\text { esgoto esgoto, sendo que: } 5000 \mathrm{ml} / \mathrm{m} \text { em mistura com metanol; } 240 \\
\mathrm{ml} / \mathrm{m} \text { em mistura com tolueno e cerca de } 40 \mathrm{ml} / \mathrm{m} \text { em mistura com } \\
\text { álcool isoamílico e iodeto de sódio }\end{array}$ \\
\hline
\end{tabular}

As Figuras 5 e 6 apresentam os principais solventes clorados e sais metálicos manipulados pelas Instituições de pesquisa.

Ainda que nenhuma norma ou resolução inclua os resíduos mutagênicos como tóxicos, resíduos contendo brometo de etídio e acriflavina foram assim classificados em função da elevada mutagenicidade destas substâncias e da preocupação dos analistas em manipulá-las adequadamente. A Figura 7 evidencia a quantidade de brometo de etídio utilizada pelas Instituições A e B. 


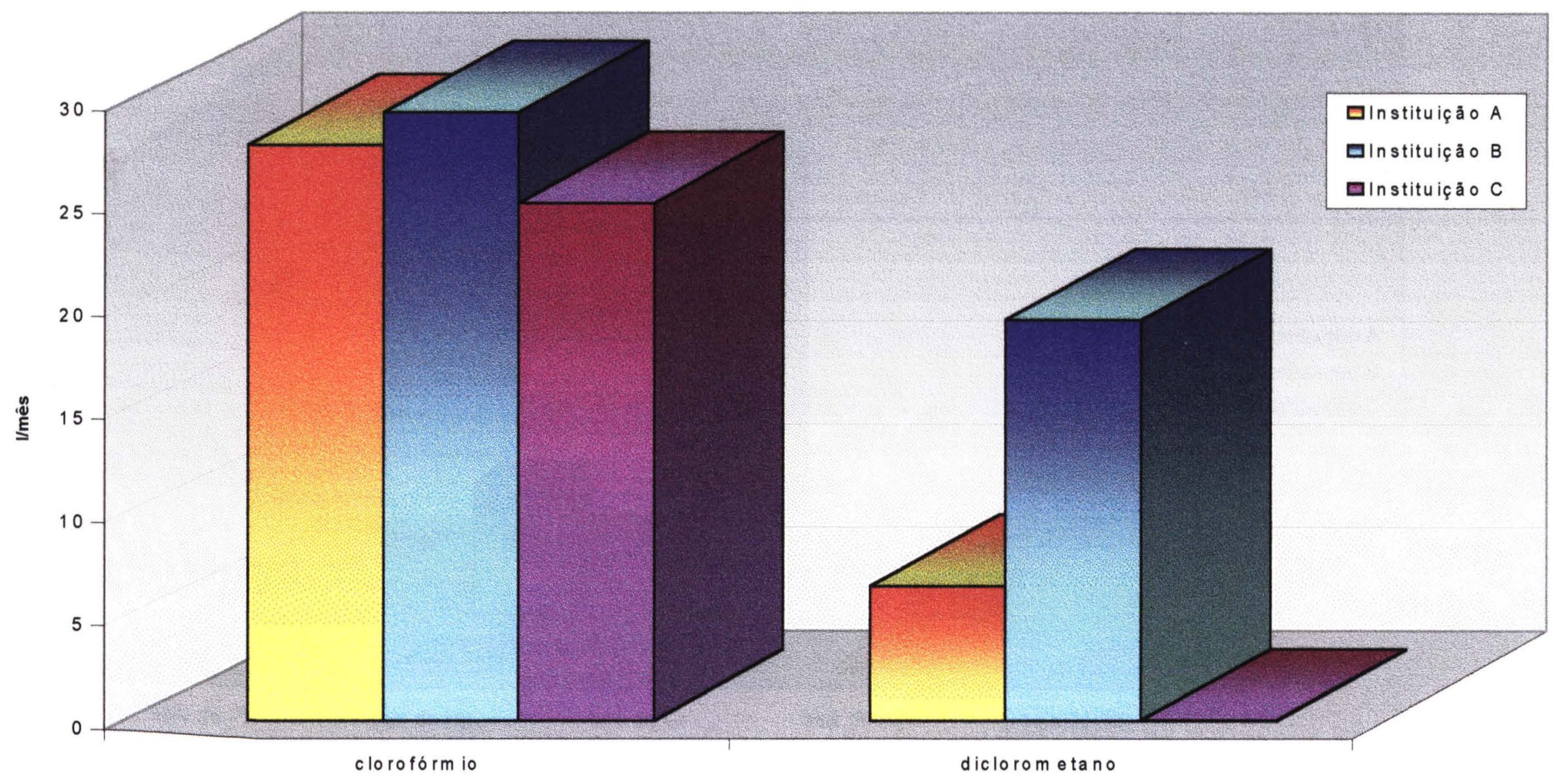

Figura 5 - Principais solventes clorados utilizados nas Instituições estudadas no município de São Paulo, no período de julho de 1999 a fevereiro de 2000. 


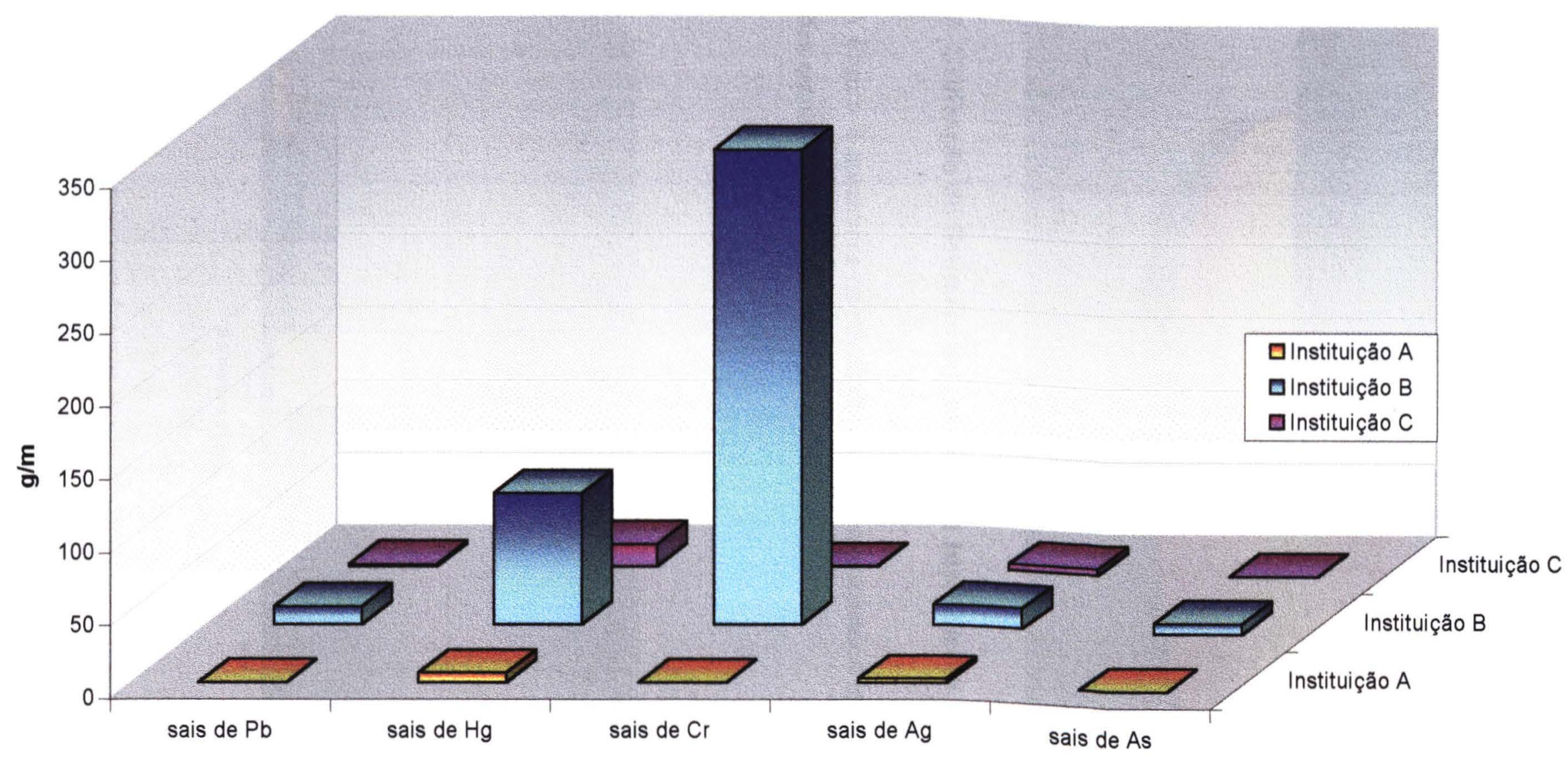

Figura 6 - Sais metálicos manipulados nas Instituições estudadas no município de São Paulo, no período de Julho de 1999 a fevereiro de 2000. 


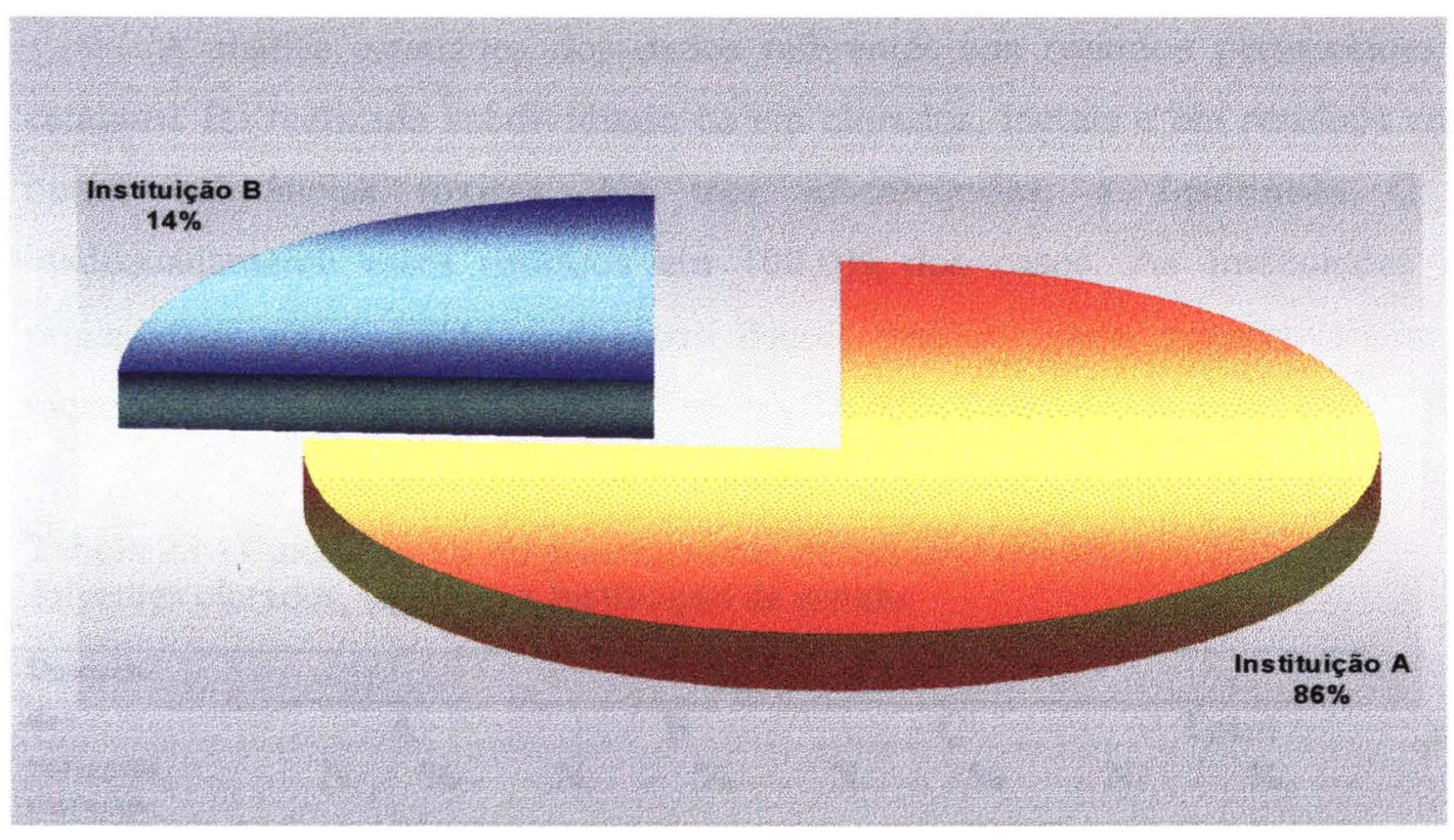

Figura 7- Utilização de Brometo de etídio pelas Instituições A e B

A Figura 8 apresenta os reveladores de imunoensaios mais empregados pelas instituições estudadas.

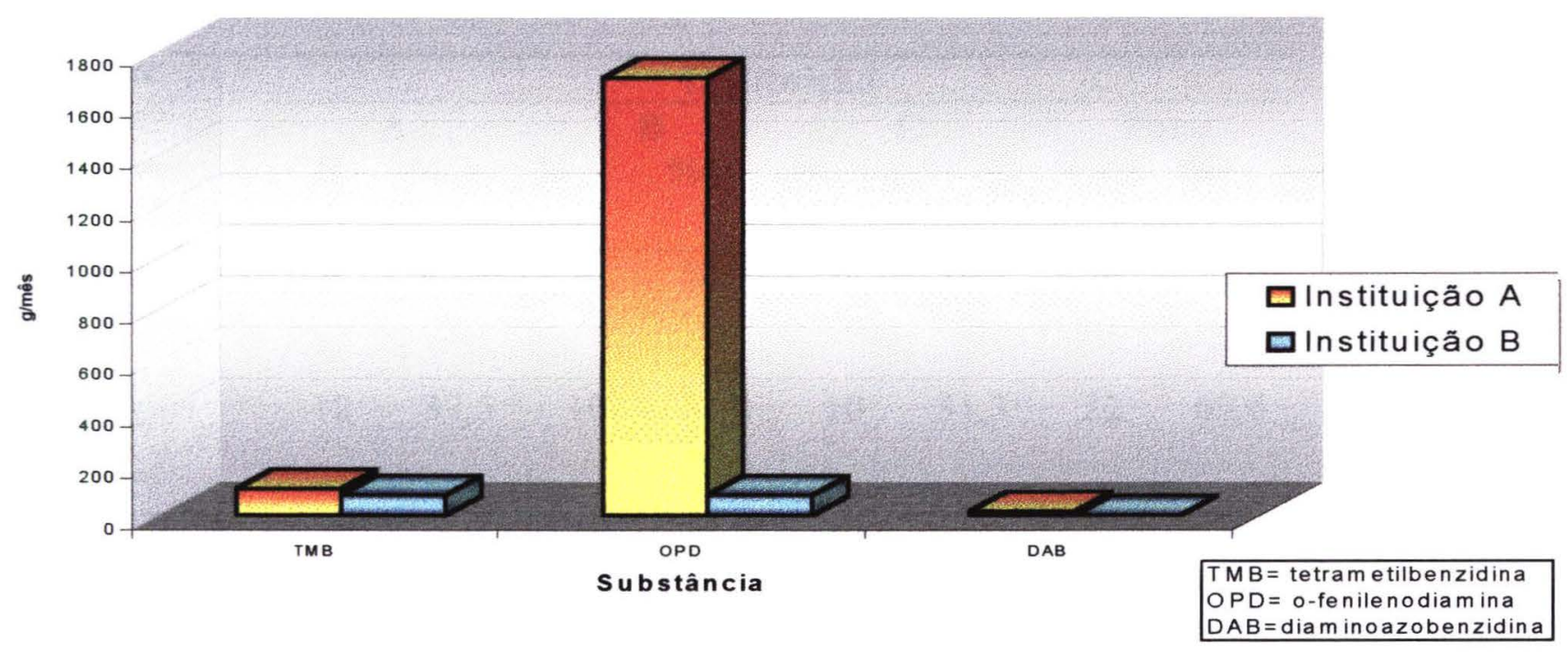

Figura 8- Reveladores empregados nos imunoensaios realizados nas Instituições A e B. 
A análise estatística dos dados referentes aos resíduos pertencentes a esta categoria foi realizada subdividindo-os em clorados, metais e em resíduos contendo outras substâncias tóxicas. $\mathrm{Na}$ três subcategorias, a Instituição $\mathrm{C}$ dispôs inadequadamente esses resíduos em $100,0 \%$ dos casos. As Instituições A e B procederam corretamente o descarte desses resíduos para, respectivamente, pelo menos 35,3 e $54,7 \%$ das misturas (Tabelas 23,24 e 25 ).

Tabela 23 - Característica do procedimento de descarte de resíduos contendo solventes clorados, segundo a Instituição de estudo

\begin{tabular}{|c|c|c|c|c|c|c|c|c|}
\hline \multirow{3}{*}{$\begin{array}{l}\text { Descarte } \\
\text { de } \\
\text { Solventes } \\
\text { clorados }\end{array}$} & \multicolumn{8}{|c|}{ Instituição } \\
\hline & \multicolumn{2}{|c|}{$\mathbf{A}$} & \multicolumn{2}{|c|}{$\mathbf{B}$} & \multicolumn{2}{|c|}{$\mathbf{C}$} & \multicolumn{2}{|c|}{ Total } \\
\hline & $\mathbf{N}$ & $\%$ & $\mathbf{N}$ & $\%$ & $\mathbf{N}$ & $\%$ & $\mathbf{N}$ & $\%$ \\
\hline Correto & 18 & 35,3 & 33 & 54,7 & 0 & 0,0 & 51 & 55,4 \\
\hline Incorreto & 9 & 22,0 & 12 & 29,3 & 20 & 48,8 & 41 & 44,5 \\
\hline Total & 27 & 29,3 & 45 & 48,9 & 20 & 21,7 & 92 & 100,0 \\
\hline
\end{tabular}

Tabela 24 - Característica do procedimento de descarte de resíduos contendo metais segundo a Instituição de estudo

\begin{tabular}{|c|c|c|c|c|c|c|c|c|c|}
\hline \multirow{3}{*}{$\begin{array}{l}\text { Descarte } \\
\text { de } \\
\text { Resíduos } \\
\text { contendo } \\
\text { metais }\end{array}$} & \multicolumn{8}{|c|}{ Instituição } & \\
\hline & \multicolumn{2}{|c|}{$\overline{\mathbf{A}}$} & \multicolumn{2}{|c|}{$\mathbf{B}$} & \multicolumn{2}{|c|}{$\mathbf{C}$} & \multicolumn{2}{|c|}{ Total } & \\
\hline & $\mathbf{N}$ & $\%$ & $\mathbf{N}$ & $\%$ & $\mathbf{N}$ & $\%$ & $\mathbf{N}$ & $\%$ & \\
\hline Correto & 6 & 42,9 & 8 & 57,1 & 0 & 0,0 & 14 & 30,4 & $\chi^{2}=6,12$ \\
\hline Incorreto & 12 & 37,5 & 10 & 31,3 & 10 & 31,3 & 32 & 69,6 & $p=0,047000$ \\
\hline Total & 18 & 39,1 & 18 & 39,1 & 10 & 21,7 & 46 & 100,0 & \\
\hline
\end{tabular}


Tabela 25 - Característica do procedimento de descarte de resíduos contendo outras substâncias tóxicas, segundo a Instituição de estudo

\begin{tabular}{|c|c|c|c|c|c|c|c|c|c|}
\hline \multirow{3}{*}{$\begin{array}{l}\text { Descarte } \\
\text { de } \\
\text { Substâncias } \\
\text { tóxicas }\end{array}$} & \multicolumn{8}{|c|}{ Instituição } & \\
\hline & \multicolumn{2}{|c|}{$\mathbf{A}$} & \multicolumn{2}{|r|}{ B } & \multicolumn{2}{|c|}{$\mathrm{C}$} & \multicolumn{2}{|c|}{ Total } & \\
\hline & $\mathbf{N}$ & $\%$ & $\mathbf{N}$ & $\%$ & $\mathbf{N}$ & $\%$ & $\mathbf{N}$ & $\%$ & \\
\hline Correto & 19 & 45,2 & 23 & 54,8 & 0 & 0,0 & 14 & 30,4 & $\chi^{2}=8,04$ \\
\hline Incorreto & 31 & 51,7 & 21 & 35,0 & 8 & 13,3 & 60 & 58,8 & $\mathrm{n}=0017908$ \\
\hline Total & 50 & 49,0 & 44 & 43,1 & 8 & 7,8 & 102 & 100,0 & \\
\hline
\end{tabular}

A disposição dos resíduos contendo solventes clorados, metais e outras substâncias tóxicas também difere inter institucionalmente, apresentando correlação estatisticamente significativa somente para os clorados e metais $\left(\chi^{2}=39,54\right.$, $\mathrm{p}=000004$ e $\chi^{2}=17,20, p=0,028077$, respectivamente).

O comportamento das demais variáveis selecionadas não diferiu do descrito para os resíduos inflamáveis, corrosivos e reativos.

\subsubsection{Resíduos contendo substâncias radioativas}

Os resíduos contendo substâncias radioativas produzidos nas Instituições A e B encontram-se listados nas Tabelas 26 e 27, especificando-se quantidade e descarte procedido.

Tabela 26 - Residuos contendo substâncias radioativas produzidos pela Instituição A e procedimento de descarte adotado.

\begin{tabular}{lll}
\hline \multicolumn{1}{c}{ Substância } & Quantidade & \multicolumn{1}{c}{ Descarte realizado } \\
\hline $\begin{array}{l}\text { Acetato de } \\
\text { uranila }\end{array}$ & $170 \mathrm{mg} / \mathrm{m}$ & $\begin{array}{l}\text { Descartado como residuo sólido em saco plástico } \\
\text { branco próprio para resíduo de serviço de saúde, } \\
\text { juntamente com amostra; Soluções fora da validade } \\
\text { (não conformes) descartadas na rede de esgoto. }\end{array}$ \\
\end{tabular}

Bactec ${ }^{14} C^{*} \quad 10$ tubos /mês Autoclavados, retirando-se o rótulo e descartados na rede de esgoto. A vidraria também é descartada após a autoclavagem.

* Meio de cultura contendo ${ }^{16} \mathrm{C}$. Segundo informação concedida a atividade é baixa, porém, não foi especificada pelo analista 
Tabela 27 - Resíduos contendo substâncias radioativas produzidos pela Instituição B e procedimento de descarte adotado.

\begin{tabular}{|c|c|c|}
\hline Substância & Quantidade & Descarte realizado \\
\hline $\begin{array}{l}\text { Fósforo } 32 \\
\text { (atividade específica } \\
6000 \mathrm{C} / \mathrm{mmol} \text { ) }\end{array}$ & NE & $\begin{array}{l}\text { Utilizado para marcar as sondas de DNA. Colocado } \\
\text { em contêiner de acrilico de } 1 \mathrm{~cm} \text { de espessura, e após } \\
2-3 \text { meses, descartado na rede de esgoto. }\end{array}$ \\
\hline $\begin{array}{l}\text { Líquido de } \\
\text { cintilação } \\
\text { contendo }{ }^{14} \mathrm{C}\end{array}$ & $\begin{array}{l}0,2 \mathrm{ml} / \mathrm{m} \\
(200 \mu \mathrm{Ci})\end{array}$ & $\begin{array}{l}\text { Segregado em mistura com tampão Tris-EDTA, papa } \\
\text { de tecido, água, NADPH e cloreto de cálcio; } \\
\text { armazenado em capela química onde se manipula } \\
\text { outras substâncias químicas, até ser enviado para o } \\
\text { Instituto de Pesquisas Nucleares - IPEN. }\end{array}$ \\
\hline
\end{tabular}

$\mathrm{O}$ número de funcionários que manipulam resíduos contendo substâncias radioativas é muito pequeno, como mostra a Tabela 28 . Deste modo, a análise das variáveis independentes, considerando esta categoria de material, ficou prejudicada.

Tabela 28 - Característica do procedimento de descarte de resíduos contendo material radioativo, segundo a Instituição estudada

\begin{tabular}{|c|c|c|c|c|c|c|}
\hline \multirow{3}{*}{$\begin{array}{l}\text { Descarte } \\
\text { de Material } \\
\text { Radioativo }\end{array}$} & \multicolumn{6}{|c|}{ Instituição } \\
\hline & \multicolumn{2}{|c|}{$\mathbf{A}$} & \multicolumn{2}{|c|}{$\mathbf{B}$} & \multicolumn{2}{|c|}{ Total } \\
\hline & $\mathbf{N}$ & $\%$ & $\mathrm{~N}$ & $\%$ & $N$ & $\%$ \\
\hline Correto & 0 & 0,0 & 2 & 100,0 & 2 & 33,3 \\
\hline Incorreto & 3 & 75,0 & 1 & 25,0 & 4 & 66,7 \\
\hline Total & 3 & 50,0 & 3 & 50,0 & 6 & 100,0 \\
\hline
\end{tabular}

\subsubsection{Resíduos contendo medicamentos}

As três instituições pesquisadas analisam medicamentos. Entretanto, em função, da diversidade de princípios ativos ou medicamentos analisados mensalmente em cada uma delas, a discriminação dos volumes gerados ficou comprometida. A Instituição $B$ foi a única que relatou tratamento e os procedimentos de descarte adotados para os fármacos antineoplásicos e quimioterápicos manipulados. Ainda que não se tenha os volumes mensais gerados, tendo em vista o objetivo desta pesquisa, esses tratamentos encontram-se descritos na Tabela 29 
Tabela 29 - Tratamento e descarte adotado para os residuos contendo fármacos analisados na instituição B

\begin{tabular}{|c|c|}
\hline Substância & Tratamento/descarte \\
\hline Doxorubicina & $\begin{array}{l}\text { Fármaco diluido na fase móvel (água acetonitrila, acido fosfórico e } \\
\text { metanol) inativado com hipoclorito } 2 \%\end{array}$ \\
\hline Cisplatina & $\begin{array}{l}\text { Fármaco diluído em dimetilformamida e inativado com tiossulfato de } \\
\text { sódio } 1 \% \text { por } 12 \text { horas. }\end{array}$ \\
\hline Carboplatinum & $\begin{array}{l}\text { Fármaco diluído em água e inativado com tiossulfato de sódio } 10 \% \text { por } \\
12 \text { horas. }\end{array}$ \\
\hline $\begin{array}{l}\text { Ácido } \mathrm{N} \text { - } \\
\text { acetilneurâmico }\end{array}$ & Rede de esgoto diluído com água sem tratamento \\
\hline $\begin{array}{l}\text { Sulfametoxazol+ } \\
\text { trimetroprima }\end{array}$ & $\begin{array}{l}\text { Cada } 6 \mathrm{~g} \text { diluídos em } 1 \mathrm{~L} \text { metanol. Segregado para a comissão de } \\
\text { gerenciamento de residuo. }\end{array}$ \\
\hline Vancomicina & $\begin{array}{l}\text { Fármaco diluído na fase móvel trietilamina, acetonitrila e } \\
\text { tetrahidrofurano e segregado para a comissão de descarte }\end{array}$ \\
\hline
\end{tabular}

Os restos de outras especialidades farmacêuticas são descartadas em saco plástico classe II como RSS. Estes medicamentos diluídos são descartados na rede de esgoto. $\mathrm{O}$ mesmo procedimento é adotado na Instituição $\mathrm{A}$.

$\mathrm{Na}$ Instituição $\mathrm{C}$, os laboratórios que manipulam fármacos em diferentes formas farmacêuticas - drágeas, comprimidos, cápsulas, líquidos e emulsões descartam esses resíduos na rede de esgoto, em mistura a pequenas frações de solvente extrator (clorofórmio-éter, etanol ou éter de petróleo). O restante do material é devolvido ao solicitante da pesquisa.

\subsubsection{Residuos de corantes}

De modo geral, os corantes são mutagênicos. Alguns como o Ponceau apresentam dados de carcinogenicidade em animais de experimentação, outros como o azul de metileno e a fucsina são prováveis carcinógenos para o homem (TOMES CPS, 1999). Ainda que nada tenha sido comprovado, esses corantes não devem ser descartados diretamente na rede de esgoto. LUNN e SAMSONE (1994) propõem 
tratar os corantes com resina amberlite XAC-16: $1 \mathrm{~g}$ de resina para cada $20 \mathrm{ml}$ de solução de concentração inferior a $100 \mu \mathrm{g} / \mathrm{mL}$.

As Tabelas 30, 31 e 32 apresentam os corantes utilizados respectivamente, pelas Instituições A, B e C, e o procedimento de descarte adotado para cada mistura.

Tabela 30 - Corantes utilizados na Instituição A e descarte adotado.

\begin{tabular}{|c|c|c|}
\hline Substância & Quantidade & Descarte adotado \\
\hline $\begin{array}{l}\text { Azul de bomofenol } \\
\text { Azul de metileno }\end{array}$ & $\begin{array}{l}9 \mathrm{mg} / \mathrm{m} \\
\text { a. } 4,5 \mathrm{~g} / \mathrm{m} \\
\text { b. } 6,4 \times 10^{-5} \\
\quad \mathrm{~g} / \mathrm{m}\end{array}$ & $\begin{array}{l}\text { Rede de esgoto (indicador de reações) } \\
\text { a. Rede de esgoto sendo que } 3 \mathrm{~g}=1000 \mathrm{ml} / \mathrm{m} \text { solução } \\
0,3 \% \text { em etanol } 95 \% \\
\text { b. Rede de esgoto em mistura com nitrito de sódio, } \\
\text { glicose, NADP e sangue diluídos com hipoclorito. }\end{array}$ \\
\hline Coomassie blue & $1,9 \mathrm{~g} / \mathrm{m}$ & Rede de esgoto - solução em metanol e ácido acético \\
\hline Cristal violeta & $22 \mathrm{~g} / \mathrm{m}$ & Rede de esgoto (solução em mistura com etanol e fenol \\
\hline Eosina & $24 \mathrm{~g} / \mathrm{m}$ & $\begin{array}{l}\text { Segrega-se } 20 \mathrm{~g} / \mathrm{m} \text { em solução aquosa } 2 \% \text { e } 4 \mathrm{~g} / \mathrm{m} \text { de } \\
\text { solução } 1 \% \text { em etanol } 80 \% \text {. }\end{array}$ \\
\hline Fucsina & $80 \mathrm{~g} / \mathrm{m}$ & Rede de esgoto em mistura com fenol e etanol \\
\hline Giemsa & $2,9 \mathrm{~g} / \mathrm{m}$ & Rede de esgoto \\
\hline $\begin{array}{l}\text { Hematoxilina } \\
\text { Ponceau }\end{array}$ & $\begin{array}{l}5 \mathrm{~g} / \mathrm{m} \\
1,2 \mathrm{~g} / \mathrm{m}\end{array}$ & $\begin{array}{l}\text { Segregado em mistura com sulfato de potássio e amônia } \\
\text { Reutilizado várias vezes antes do descarte na rede de esgoto } \\
\text { em mistura com ácido acético ou ácido tricloracético }\end{array}$ \\
\hline Verde de malaquita & $3,2 \mathrm{~g} / \mathrm{m}$ & Rede de esgoto \\
\hline
\end{tabular}

Tabela 31 - Corantes utilizados na Instituição B e descarte adotado

\begin{tabular}{|c|c|c|}
\hline Substância & Quantidade & Descarte adotado \\
\hline Azul da prússia & $0,5 \mathrm{~g} / \mathrm{ano}$ & $\begin{array}{l}\text { Rede de esgoto, em mistura com metanol ou ferricianeto } \\
\text { de potássio, sulfato de alumínio e timol, ou vermelho } \\
\text { neutro ou safranina. }\end{array}$ \\
\hline Azul de astra & $0,75 \mathrm{~g} / \mathrm{m}$ & Rede de esgoto com ácido tartárico e água \\
\hline Azul de bromofenol & $0,01 \mathrm{~g} / \mathrm{m}$ & $\begin{array}{l}\text { Loading buffer descartado com os géis de acrilamida ou } \\
\text { agarose }\end{array}$ \\
\hline Coomassie blue & $2 \mathrm{~g} / \mathrm{m}$ & $\begin{array}{l}\text { Rede de esgoto em mistura com metanol e ácido acético } \\
\text { (cerca de } 1300 \mathrm{~mL} / \mathrm{m})\end{array}$ \\
\hline Cristal violeta & $3,4 \mathrm{~g} / \mathrm{m}$ & $\begin{array}{l}\text { Solução } 2 \% \text { em etanol } 95 \% \text {, descartada na rede de esgoto } \\
\text { com oxalato de amônia. }\end{array}$ \\
\hline Fucsina & $4,1 \mathrm{~g} / \mathrm{m}$ & $\begin{array}{l}\text { Rede de esgoto em mistura com ácido ou com fenol, } \\
\text { Dimetilsulfóxido, etanol, glicerina e água. }\end{array}$ \\
\hline
\end{tabular}


Cont. Tabela 31

\begin{tabular}{|c|c|c|}
\hline Substância & Quantidade & Descarte adotado \\
\hline Giemsa & $160 \mathrm{ml} / \mathrm{a}$ & Rede de esgoto em mistura com tampão fosfato \\
\hline Hematoxilina & $3,5 \mathrm{~g} / \mathrm{a}$ & $\begin{array}{l}\text { Rede de esgoto em mistura com iodeto de potássio, } \\
\text { glicerina e alúmem de potássio. }\end{array}$ \\
\hline Negro de amido & $0,75 \mathrm{~g} / \mathrm{m}$ & Rede de esgoto em mistura com ácido acético e metanol \\
\hline Ponceau & $1 \mathrm{~g} / \mathrm{m}$ & Rede de esgoto \\
\hline Rosenfeld & $740 \mathrm{ml} / \mathrm{m}$ & Rede de esgoto- solução metanólica \\
\hline Safranina & $1,9 \mathrm{~g} / \mathrm{m}$ & Rede de esgoto \\
\hline Sudan black & $\begin{array}{l}\text { a. } 0,54 \mathrm{~g} / \mathrm{ano} \\
\text { b. } 0,05 \mathrm{~g} / \mathrm{m}\end{array}$ & $\begin{array}{l}\text { a. Rede de esgoto em mistura com etanol, fenol e fosfato } \\
\text { de sódio; b. } 0,05 \mathrm{~g} / \mathrm{m} \text { - rede de esgoto em mistura com } \\
\text { etanol e hidróxido de sódio } 5 \% \text {. }\end{array}$ \\
\hline $\begin{array}{l}\text { Verde de bromo } \\
\text { cresol }\end{array}$ & $\begin{array}{l}\text { a. } 0,016 \mathrm{~g} / \mathrm{m} \\
\text { b. } 0,1 \mathrm{~g} / \mathrm{ano}\end{array}$ & $\begin{array}{l}\text { a. Rede de esgoto em mistura com soro, hidróxido, ácido } \\
\text { lático e tween diluídos em hipoclorito; b. Nebulizado na } \\
\text { capela }\end{array}$ \\
\hline Verde de malaquita & $0,5 \mathrm{~g} / \mathrm{ano}$ & Rede de esgoto \\
\hline Vermelho de metila & $0,02 \mathrm{~g} / \mathrm{m}$ & Rede de esgoto em mistura com azul de metileno \\
\hline Vermelho neutro & lg/ano & Rede de esgoto em mistura com azul da prússia. \\
\hline
\end{tabular}

Tabela 32 - Corantes utilizados na Instituição C e descarte adotado

\begin{tabular}{|c|c|c|}
\hline Substância & Quantidade & Descarte realizado \\
\hline $\begin{array}{l}\text { Azul de bromo } \\
\text { fenol }\end{array}$ & $0,002 \mathrm{~g} / \mathrm{m}$ & Arquivado com o gel de acrilamida \\
\hline Eritrozina & $2,5 \mathrm{~g} / \mathrm{m}$ & Rede de esgoto \\
\hline Fast blue B & $2 \mathrm{~g} / \mathrm{m}$ & $\begin{array}{l}\text { Nebulizado em capela e o restante descartado na rede de } \\
\text { esgoto }\end{array}$ \\
\hline Rodamina & $0,5 \mathrm{~g} / \mathrm{m}$ & Nebulizada em capela \\
\hline
\end{tabular}

\subsubsection{Resíduos contendo substâncias químicas classificadas como não perigosas}

As substâncias caracterizadas como não perigosas - não inflamáveis, não corrosivas, não reativas, não tóxicas, segundo a ABNT-NBR 10.004 (1985) e Resolução CONAMA (1993) utilizadas pelas Instituições A, B e C, encontram-se listadas, respectivamente, nas Tabelas A-25, A-26 e A-27, do anexo 19 identificado pela cor laranja. As referidas tabelas apresentam, sempre que possível, o volume 
gerado, a mistura que integram e o descarte adotado, além de referências quanto a mutagenicidade, carcinogenicidade e teratogenicidade em animais de experimentação.

\subsubsection{Resíduos contendo material infectante ou outras matrizes manipuladas pelas Instituições avaliadas}

Para esse tipo de resíduo, foi realizado um levantamento qualitativo das matrizes manipuladas e do procedimento de descarte adotado em cada uma das Instituições.

\subsubsection{Instituição $A$}

Além de medicamentos, esta Instituição manipula alimentos, animais de experimentação e fluidos biológicos diversos. Os restos de alimentos, como os medicamentos, são descartados em saco plástico classe II como RSS. As matrizes diluídas são descartadas na rede de esgoto. Os animais inoculados (carcaças) são também descartados em saco plástico classe II sem tratamento prévio, exceto as carcaças de morcegos que são autoclavadas previamente.

Todas as culturas de células, meios de cultura onde houve crescimento de microorganismos, vidrarias e alças que entraram em contato com material infectante, restos de sangue, soro ou plasma, escarro, líquor, líquido cavitário e muco cervicovaginal são dispostos em caixa de inox para posterior inativação térmica a $120^{\circ} \mathrm{C}$, durante 20 minutos, no setor de lavagem e descontaminação de material. Cerca de 6 toneladas de RSS são autoclavados por mês para, então, serem dispostos em saco plástico classe II. Em alguns laboratórios, dependendo da infectividade do material manipulado, autoclava-se este material no próprio local de geração, para, então, encaminhá-lo à central de inativação térmica. 
Todos os resíduos dos procedimentos analíticos envolvendo essas matrizes são inativados previamente, com hipoclorito, antes do descarte.

As fezes diluídas, restos de fezes e de urina são inativados com hipoclorito $2 \%$, por 12 horas e por 30 minutos, respectivamente, para posterior descarte na rede de esgoto ou em saco plástico classe II.

As lâminas de vidro para imunofluorescência direta são decartadas em caixa de papelão rígido. Aquelas não utilizadas em leituras diretas são descontaminadas em hipoclorito para posterior lavagem e reutilização. Vidrarias quebradas, agulhas e seringas também são descartadas em caixa de papelão rígido.

\subsubsection{Instituição B}

Os procedimentos adotados para manipulação e descarte de matrizes biológicas não é uniforme nesta Instituição. Fluidos biológicos utilizados na pesquisa de microorganismos são descartados após inativação térmica. Restos de soro ou plasma utilizados em determinações bioquímicas (glicose, uréia, creatinina) ou sangue total utilizado em hemogramas são descartados inativados com hipoclorito $2 \%$. Urinas utilizadas em provas bioquímicas - determinação de glicose, uréia, creatinina - e na bioequivalência de fármacos são descartadas sem tratamento prévio, na rede de esgoto. $\mathrm{O}$ mesmo procedimento é adotado para soro e plasma utilizados nas análises de bioequivalência.

As fezes diluídas são descartadas na rede de esgoto sem inativação prévia. Os restos de fezes são descartados em saco plástico classe II também sem prévio tratamento.

Todas as culturas de células, meios de cultura onde houve crescimento de microorganismos, vidrarias e alças que entraram em contato com material infectante e restos de materiais biológicos utilizados nessas pesquisas - sangue, soro ou plasma, 
escarro, liquor, secreções - são inativados térmicamente, por $120{ }^{\circ} \mathrm{C}$ durante 20 minutos, em cada laboratório gerador. O volume de resíduos gerados é variável em função da rotina e etapa da pesquisa a ser executada e por isso, nenhuma estimativa foi feita quanto ao volume mensal gerado.

A Instituição manipula ainda, além de medicamentos, alimentos e animais de experimentação. Os restos de alimentos, como os medicamentos não neoplásicos, são descartados em saco plástico classe II como RSS. Estas matrizes diluídas são descartadas na rede de esgoto. Os animais inoculados (carcaças) são também descartados em saco plástico classe II sem tratamento prévio.

Plasma, soro e urina de animais de experimentação, aos quais se administrou substâncias patogênicas ou não, são descartados sem inativação .

\subsubsection{Instituição C}

Três dos cinco laboratórios que compõem a Instituição $\mathbf{C}$ manipulam material biológico. Em dois deles, em geral estes materiais, sangue e esperma, encontram-se secos em diferentes suportes, como tecidos, instrumentos metálicos, de madeira ou plástico. $\mathrm{O}$ descarte do material ressuspendido é realizado em saco plástico classe I - comum, ou diretamente na rede de esgoto.

O terceiro laboratório manipula grande volume de material biológico fragmentos de figado, rim, cérebro, pulmão; estômago e seu conteúdo, sangue e urina. A papa de tecidos e o conteúdo estomacal são vertidos após extração com solvente orgânico (clorofórmio - éter) sobre uma peneira de plástico. A fração líquida de $\mathrm{pH}$ ácido ou alcalino, juntamente com um pouco do solvente extrator, é descartada na rede de esgoto. O material sólido retido na peneira é descartado no saco plástico classe II, como RSS. O descarte do excedente do 
material biológico enviado é feito do mesmo modo, em saco plástico classe II, sem inativação prévia. Nesta unidade existe a coleta de RSS.

O quarto laboratório integrante desta instituição manipula combustíveis (metanol e gasolina), praguicidas, materiais oxidantes, corrosivos e detergentes, os quais são descartados na rede de esgoto após a execução das análises. No quinto laboratório, as matrizes analisadas compreendem, além dos fármacos, fragmentos vegetais, pós constituídos por anestésicos locais, bicarbonato de sódio, talco, lactose, amido ou cafeína. $O$ resíduos desses materiais é descartado na rede de esgoto em mistura a pequenas frações de solvente extrator (clorofórmio-éter, etanol ou éter de petróleo). O restante do material é devolvido ao solicitante da pesquisa. 


\subsection{Avaliação dos procedimentos adotados em situações de emergência}

Observa-se, através das Tabelas 33, 34, 35, 36 e 37 que o descarte inadequado dos resíduos gerados supera os procedimentos corretos tanto inter como intra institucionalmente e independe da formação do funcionário, da categoria do material manipulado ou do conhecimento de seus efeitos tóxicos.

Tabela 33 - Característica do procedimento de descarte, adotado em situação de emergência, segundo a Instituição de estudo

\begin{tabular}{|c|c|c|c|c|c|c|c|c|c|}
\hline \multirow{3}{*}{$\begin{array}{l}\text { Descarte } \\
\text { Situação de } \\
\text { emergência }\end{array}$} & \multicolumn{8}{|c|}{ Instituição } & \\
\hline & \multicolumn{2}{|r|}{$\mathbf{A}$} & \multicolumn{2}{|c|}{$\mathbf{B}$} & \multicolumn{2}{|c|}{$\mathrm{C}$} & \multicolumn{2}{|c|}{ Total } & \\
\hline & $\mathbf{N}$ & $\%$ & $\mathbf{N}$ & $\%$ & $\mathbf{N}$ & $\%$ & $\begin{array}{l}\mathbf{N} \\
\%\end{array}$ & & \\
\hline Correto & 86 & 23,2 & 59 & 16,6 & 18 & 12,9 & 163 & 18,8 & $x^{2}=8,93$ \\
\hline Incorreto & 285 & 76,8 & 297 & 83,4 & 121 & 87,1 & 703 & 81,2 & $p=0,011514$ \\
\hline Total & 371 & 100,0 & 356 & 100,0 & 139 & 100,0 & 866 & 100,0 & \\
\hline
\end{tabular}

Tabela 34- Característica do procedimento de descarte, adotado em situação de emergência, segundo o departamento ou divisão de cada instituição

\begin{tabular}{|c|c|c|c|c|c|c|c|}
\hline \multirow{3}{*}{$\begin{array}{l}\text { Depto/divisão - } \\
\text { Instituição }\end{array}$} & \multicolumn{6}{|c|}{ Procedimento de descarte } & \multirow{4}{*}{$x^{2}=35,15$} \\
\hline & \multicolumn{2}{|c|}{ correto } & \multicolumn{2}{|c|}{ Incorreto } & \multicolumn{2}{|c|}{ Total } & \\
\hline & $\mathbf{N}$ & $\%$ & $\mathbf{N}$ & $\%$ & $\mathbf{N}$ & $\%$ & \\
\hline Depto $1-\mathrm{A}$ & 64 & 29,4 & 154 & 70,6 & 218 & 100,0 & \\
\hline Depto 2 - A & 8 & 7,5 & 98 & 92,5 & 106 & 100,0 & \\
\hline Depto 3 - A & 12 & 31,6 & 26 & 68,4 & 38 & 100,0 & $p=0,00006$ \\
\hline Depto 4 - A & 2 & 22,2 & 7 & 77,8 & 9 & 100,0 & \\
\hline Depto 1 - B & 11 & 12,4 & 78 & 87,6 & 89 & 100,0 & \\
\hline Depto 2 - B & 17 & 17,9 & 78 & 82,1 & 95 & 100,0 & \\
\hline Depto 3 - B & 26 & 17,6 & 122 & 82,4 & 148 & 100,0 & \\
\hline Depto 4 - B & 5 & 20,8 & 19 & 79,2 & 24 & 100,0 & \\
\hline Depto 1 - C & 14 & 14,6 & 82 & 85,4 & 96 & 100,0 & \\
\hline Depto 2 - C & 4 & 9,3 & 39 & 90,7 & 43 & 100,0 & \\
\hline Total & 163 & 18,8 & 703 & 81,2 & 866 & 100,0 & \\
\hline
\end{tabular}


Tabela 35 - Característica do procedimento de descarte, adotado em situação de emergência, segundo a formação dos funcionários

\begin{tabular}{|c|c|c|c|c|c|c|}
\hline \multirow{3}{*}{$\begin{array}{l}\text { Formação } \\
\text { dos } \\
\text { funcionários }\end{array}$} & \multicolumn{6}{|c|}{ Procedimento de descarte } \\
\hline & \multicolumn{2}{|c|}{ correto } & \multicolumn{2}{|c|}{ Incorreto } & \multicolumn{2}{|c|}{ Total } \\
\hline & $\mathbf{N}$ & $\%$ & $\mathbf{N}$ & $\%$ & $\mathbf{N}$ & $\%$ \\
\hline Químico & 3 & 3,4 & 84 & 96,6 & 87 & 10,0 \\
\hline Farmacêutico & 67 & 18,5 & 295 & 81,5 & 362 & 41,8 \\
\hline Biólogo & 36 & 23,5 & 117 & 76,5 & 153 & 17,7 \\
\hline Biomédico & 19 & 27,9 & 49 & 72,1 & 68 & 7,9 \\
\hline $\begin{array}{l}\text { outros } \\
\text { profissionais da } \\
\text { área da saúde }\end{array}$ & 4 & 8,5 & 43 & 91,5 & 47 & 5,4 \\
\hline $\begin{array}{l}\text { Outros profissionais } \\
\text { da área de exatas }\end{array}$ & 5 & 14,7 & 29 & 85,3 & 34 & 3,9 \\
\hline $\begin{array}{l}\text { Técnico nível } \\
\text { médio }\end{array}$ & 29 & 25,2 & 86 & 74,8 & 115 & 13,3 \\
\hline Total & 163 & 18,8 & 703 & 81,2 & 866 & 100,0 \\
\hline
\end{tabular}

Tabela 36- Característica do procedimento laboratorial de descarte, adotado em situação de emergência, segundo a categoria do material manipulado

\begin{tabular}{lcccccc}
\hline \multirow{2}{*}{$\begin{array}{l}\text { Categoria } \\
\text { do material }\end{array}$} & \multicolumn{6}{c}{ Procedimento de descarte } \\
\cline { 2 - 7 } & $\mathbf{N}$ & $\%$ & $\mathbf{N}$ & $\%$ & $\mathbf{N}$ & $\%$ \\
\hline inflamável & 3 & 1,5 & 196 & 98,5 & 199 & 100,0 \\
solventes clorados & 3 & 3,3 & 89 & 96,7 & 92 & 100,0 \\
metais & 0 & 0,0 & 46 & 100,0 & 46 & 100,0 \\
reativos & 0 & 0,0 & 27 & 100,0 & 27 & 100,0 \\
corrosivos & 16 & 9,9 & 146 & 90,1 & 162 & 100,0 \\
tóxico & 2 & 2,0 & 100 & 98,0 & 102 & 100,0 \\
agente mutagênico & 0 & 0,0 & 51 & 100,0 & 51 & 100,0 \\
material biológico & 135 & 84,9 & 24 & 15,1 & 159 & 100,0 \\
material radioativos & 0 & 0,0 & 6 & 100,0 & 6 & 100,0 \\
medicamentos & 4 & 18,2 & 18 & 81,8 & 22 & 100,0 \\
\hline Total & 163 & 18,8 & 703 & 81,2 & 866 & 100,0 \\
\hline
\end{tabular}

$\chi 2=565,68$

$\mathrm{p}=0,000000$ 
Tabela 37 - Tipo de procedimento de descarte laboratorial adotado em situação de emergência, segundo o conhecimento dos dados toxicológicos da substância manipulada

\begin{tabular}{|c|c|c|c|c|c|c|c|}
\hline \multirow{3}{*}{$\begin{array}{l}\text { Conhecimento dos } \\
\text { dados } \\
\text { toxicológicos da } \\
\text { substância } \\
\text { manipulada }\end{array}$} & \multicolumn{6}{|c|}{ Procedimento de descarte } & \multirow{4}{*}{$\begin{array}{l}\chi^{2}=17,54 \\
p=0,000028\end{array}$} \\
\hline & \multicolumn{2}{|c|}{ Correto } & \multicolumn{2}{|c|}{ Incorreto } & \multicolumn{2}{|c|}{ Total } & \\
\hline & $\mathbf{N}$ & $\%$ & $\mathbf{N}$ & $\%$ & $\mathbf{N}$ & $\%$ & \\
\hline $\operatorname{sim}$ & 161 & 20,7 & 617 & 79,3 & 778 & 89,8 & \\
\hline não & 2 & 2,3 & 86 & 97,7 & 88 & 10,2 & \\
\hline Total & 163 & 18,8 & 703 & 81,2 & 866 & 100,0 & \\
\hline
\end{tabular}

Merece ser destacado ainda que $54,4 \%$ da população de estudo da Instituição A, $83,1 \%$ da Instituição B e 100,0\% dos funcionários da instituição C relataram a inexistência de um programa de treinamento para manipulação e descarte em situações de emergência. Entretanto, esta percepção não é uniforme dentro da mesma unidade laboratorial ou departamento, como mostram as Tabelas 38 e 39.

Tabela 38- Percepção da existência de programa de treinamento para situações de emergência, segundo departamento ou divisão da Instituição A a que pertence o funcionário

\begin{tabular}{|c|c|c|c|c|c|c|c|}
\hline \multirow{3}{*}{$\begin{array}{l}\text { Departamento } \\
\text { ou divisão da } \\
\text { Instituição } \mathbf{A}\end{array}$} & \multicolumn{6}{|c|}{ Existência de programa /situação emergência } & \multirow{4}{*}{$x 2=22,27$} \\
\hline & \multicolumn{2}{|c|}{ sim } & \multicolumn{2}{|c|}{ não } & \multicolumn{2}{|c|}{ Total } & \\
\hline & $\mathbf{N}$ & $\%$ & $\mathbf{N}$ & $\%$ & $\mathbf{N}$ & $\%$ & \\
\hline 1 & 113 & 53,2 & 102 & 46,8 & 218 & 100,0 & \\
\hline 2 & 31 & 29,2 & 71 & 70,8 & 102 & 100,0 & $p=0,000057$ \\
\hline 3 & 21 & 55,3 & 17 & 44,7 & 38 & 100,0 & \\
\hline 4 & 1 & 11,1 & 8 & 88,9 & 9 & 100,0 & \\
\hline Total & 169 & 45,6 & 202 & 54,4 & 371 & 100,0 & \\
\hline
\end{tabular}


Tabela 39 - Percepção da existência de programa de treinamento para situações de emergência, segundo departamento ou divisão da Instituição B.

\begin{tabular}{|c|c|c|c|c|c|c|c|}
\hline \multirow{3}{*}{$\begin{array}{l}\text { Departamento ou } \\
\text { divisão da } \\
\text { Instituição B }\end{array}$} & \multicolumn{6}{|c|}{ Existência de programa /situação emergência } & \multirow{3}{*}{$\chi^{2}=11,82$} \\
\hline & \multicolumn{2}{|c|}{$\operatorname{sim}$} & \multicolumn{2}{|c|}{ não } & \multicolumn{2}{|c|}{ Total } & \\
\hline & $\mathbf{N}$ & $\%$ & $\mathbf{N}$ & $\%$ & $\mathbf{N}$ & $\%$ & \\
\hline 1 & 6 & 6,7 & 83 & 93,3 & 89 & 100,0 & $x 2=11,82$ \\
\hline 2 & 24 & 25,3 & 71 & 74,4 & 95 & 100,0 & $p=0,008037$ \\
\hline 3 & 27 & 18,2 & 121 & 81,8 & 148 & 100,0 & \\
\hline 4 & 3 & 12,5 & 21 & 87,5 & 24 & 100,0 & \\
\hline Total & 50 & 16,9 & 296 & 83,1 & 356 & 100,0 & \\
\hline
\end{tabular}

$\mathrm{Na}$ Instituição A, por exemplo, todos os funcionários avaliados no laboratório codificado como número 1 , responderam sim ao quesito existência de programa de treinamento para situações de emergência. No mesmo departamento, no laboratório número $8,66,7 \%$ dos avaliados responderam não ao quesito. $O$ mesmo ocorreu no laboratório de número 29 , pertencente a outro departamento desta instituição, onde $35,7 \%$ dos funcionários entendem que a instituição não possui tal programa. $\mathrm{Na}$ instituição $\mathrm{B}$, evidenciou-se comportamento semelhante.

\section{4. $O$ estado da arte quanto ao gerenciamento dos resíduos gerados}

Os tratamentos e disposição recomendados na literatura para minimizar a periculosidade dos resíduos que contém as substâncias inflamáveis, corrosivas, reativas, tóxicas e radioativas encontram-se, respectivamente, nas Tabelas A-28, A29, A-30, A-31 e A-32, do anexo 20 indicado pela cor verde. Apresenta-se, ainda, nas referidas Tabelas, o número de registro no Chemical Abstract System - CAS correspondente a cada uma das substâncias perigosas manipuladas, o custo dos tratamentos, a incompatibilidade entre as substâncias e os procedimentos a serem adotados nas situações de emergência - incêndio e derramamento. A Tabela abaixo exemplifica os dados apresentados no anexo mencionado. 
Tabela - Tratamento, disposição e respectivo custo, incompatibilidade e procedimentos a serem adotados em situações de emergência para as substâncias inflamáveis utilizadas nas Instituições estudadas.

\begin{tabular}{|c|c|c|c|c|}
\hline Substância & $\begin{array}{l}\text { Tratamento/ } \\
\text { disposição } \\
\text { recomendada }\end{array}$ & Custo & Incompatibilidade & $\begin{array}{l}\text { Caracteristica relevante } \\
\text { da substância / } \\
\text { Procedimento em } \\
\text { situacōes de emergência }\end{array}$ \\
\hline $\begin{array}{l}\text { Acetaldeido } \\
\text { CAs } 75-07-0\end{array}$ & Incineração & $\begin{array}{l}1 \text { a } 250 \mathrm{Kg}= \\
\text { US\$ } 343,40^{*}\end{array}$ & $\begin{array}{l}\text { Oxidantes fortes. ácidos, } \\
\text { bases, álcoois, amònia. } \\
\text { aminas, fenóis, cetonas. } \\
\text { ácido cianidrico e ácido } \\
\text { sulfidrico. Forma } \\
\text { peróxidos em contato } \\
\text { com o ar. }\end{array}$ & $\begin{array}{ll} & \mathrm{FP}-40^{\circ} \mathrm{C} \\
\text { - } & \text { Incêndio - } \mathrm{CO}_{2}, \text { pó } \\
& \text { químico, água } \\
\text { - } & \text { Derramamento - } \\
\text { areia, vermiculita, } \\
\text { sulfato de sódio }\end{array}$ \\
\hline $\begin{array}{l}\text { Acetato de } \\
\text { butila } \\
\text { CAs 123-364 }\end{array}$ & Incineração & $\begin{array}{l}\text { 1 a } 250 \mathrm{Kg}= \\
\text { USS } 343,40^{*}\end{array}$ & $\begin{array}{l}\text { Nitratos, ácidos fortes, } \\
\text { bases fortes, oxidantes } \\
\text { fortes }\end{array}$ & $\begin{array}{ll}\text { - } & \mathrm{FP} 22^{\circ} \mathrm{C} \\
\text { - } & \text { Incêndio }-\mathrm{CO}_{2} \text {, pó } \\
\text { químico, água } \\
\text { - } \\
\text { Derramamento - } \\
\text { areia vermiculita. }\end{array}$ \\
\hline
\end{tabular}

O custo estimado dos tratamentos propostos foi calculado utilizando-se os valores, em dólares, de reagentes p.a. do catálogo da Sygma- Aldrich (1998). Quanto ao custo da incineração de resíduos perigosos, foram contatadas duas unidades localizadas na grande São Paulo. Apenas uma delas respondeu às solicitações feitas, informando que o faturamento mínimo para quantidades de 1 a $250 \mathrm{~kg}$ de resíduo é equivalente a US\$ 343,40 . Acima de $500 \mathrm{Kg}$, o preço por quilo é em torno de US\$ 1,10 .

Esta unidade de incineração dispõe de um incinerador do tipo forno rotativo que opera a temperatura de $650^{\circ} \mathrm{C}$ e tempo de residência de 30 segundos e câmara de pós - combustão, a temperatura de $1300^{\circ} \mathrm{C}$. Está apta a incinerar sólidos e líquidos orgânicos e resíduos contendo pequenas quantidades de chumbo. Não incinera ácidos orgânicos, metais - particularmente, mercúrio e arsênico - e material radioativo. $O$ material pode ser enviado em bombonas de plástico, tambores ou frascos de vidro. Os resíduos devem ser segregados segundo suas características físico-químicas e acompanhados de memorial de caracterização e certificado de destinação, atendendo às exigências da CETESB. 
Para misturas de resíduos, é necessário enviar uma aliquota desse material para análise e caracterização pelos laboratórios do grupo ao qual está ligado a unidade de incineração para que a adequada caracterização do resíduo, poder calorifero e quantidade de água, enxôfre, fósforo e chumbo possam ser estimadas. Este procedimento transcorre sem ônus para o gerador, nessa unidade de incineração.

\subsection{Avaliação da percepção do corpo funcional}

As Tabelas 40 e 41 apresentam os resultados dos modelos de regressão logística que melhor se ajustaram à população estudada quanto ao procedimento de descarte adotado em situação de rotina e de emergência, respectivamente.

Verifica-se, para a situação de rotina, associação importante entre o conhecimento das etapas de gerenciamento de resíduos e dos dados toxicológicos de cada substância manipulada, o treinamento para o correto descarte dos resíduos gerados, controladas pelas demais variáveis do modelo, número de funcionários de cada laboratório, formação do corpo funcional, tempo na função e categoria do material manipulado.

Deste modo, pode-se afirmar que o funcionário que conhece as etapas de gerenciamento apresenta uma chance 28 vezes maior de descartar corretamente os resíduos em relação àquele que não detém este conhecimento; o conhecimento dos dados toxicológicos de cada substância manipulada eleva em 8,8 vezes a chance do funcionário descartar corretamente o resíduo gerado do que aquele que desconhece esses dados; o funcionário treinado para o correto descarte apresenta probabilidade quase que 2 vezes maior de proceder adequadamente do que o não treinado. 
Tabela 40 - Odds ratio, significância e intervalo de confiança $95 \%$ para as variáveis que compõem o modelo de regressão logística considerando o procedimento rotineiro de descarte dos resíduos gerados.

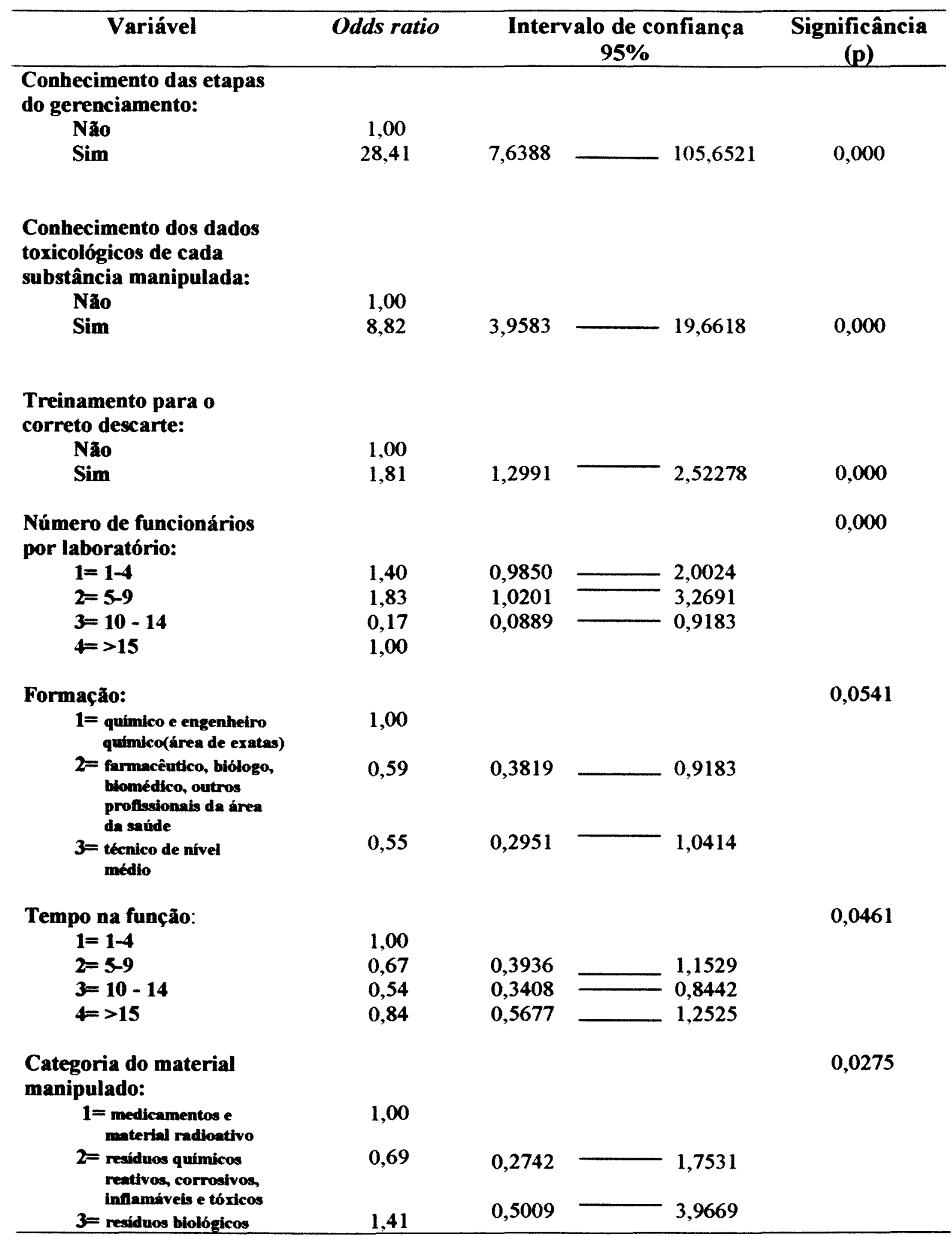


Tabela 41 - Odds ratio, significância e intervalo de confiança de $95 \%$ para as variáveis que compõem o modelo de regressão logística considerando o procedimento de descarte dos resíduos gerados adotado em situações de emergência.

\begin{tabular}{|c|c|c|c|c|}
\hline Variável & Odds ratio & \multicolumn{2}{|c|}{ Intervalo de confiança } & $\begin{array}{l}\text { Significância } \\
\text { (p) }\end{array}$ \\
\hline $\begin{array}{l}\text { Categoria do material } \\
\text { manipulado: }\end{array}$ & & & & 0,0000 \\
\hline $\begin{array}{c}1=\text { medicamentos e } \\
\text { material radioativo }\end{array}$ & 1,00 & & & \\
\hline $\begin{aligned} 2= & \text { residuos químicos } \\
& \text { reativos, corrosivos, } \\
& \text { inflamáveis e tóxicos }\end{aligned}$ & 0,18 & 0,0517 & 0,6479 & \\
\hline $3=$ residuos biológicos & 12,19 & 3,3144 & - 44,8493 & \\
\hline \multicolumn{5}{|l|}{$\begin{array}{l}\text { Conhecimento das etapas } \\
\text { do gerenciamento: }\end{array}$} \\
\hline $\begin{array}{l}\text { Nazo } \\
\text { Sim }\end{array}$ & $\begin{array}{c}1,00 \\
142,81\end{array}$ & 14,6029 & $-1396,535$ & 0,000 \\
\hline $\begin{array}{l}\text { Conhecimento dos dados } \\
\text { toxicológicos de cada } \\
\text { substância manipulada: }\end{array}$ & & & & 0,011 \\
\hline Nazo & 1,00 & & & \\
\hline Sim & 17,06 & 1,8992 & $-153,2427$ & \\
\hline Instituição: & & & & 0,011 \\
\hline $\mathbf{A}$ & 0,27 & 0,0754 & 0,9334 & \\
\hline B & 1,19 & 0,5038 & 2,8394 & \\
\hline C & 1,00 & & & \\
\hline Formação: & & & & 0,2148 \\
\hline $\begin{array}{l}\text { 1= quimico e Engenheiro } \\
\text { químico(área de exatas) }\end{array}$ & 1,00 & & & \\
\hline 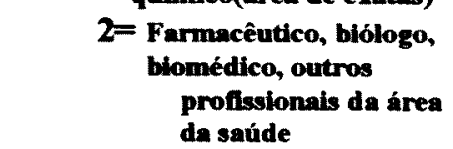 & 1,25 & 0,3993 & 3,9344 & \\
\hline $\begin{array}{c}3=\text { técnico de nível } \\
\text { médio }\end{array}$ & 2,55 & 0,6884 & 9,4250 & \\
\hline $\begin{array}{c}\text { Tempo de formado: } \\
1=1-4\end{array}$ & 1,00 & & & 0,0158 \\
\hline $2=5-9$ & 183 & 0.6801 & 4.9022 & \\
\hline $3=10-14$ & 0,65 & 0,2116 & 1,9841 & \\
\hline $4=>15$ & 0,43 & 0,1648 & 1,1303 & \\
\hline
\end{tabular}

Em situação de emergência, as variáveis independentes associadas ao correto procedimento de descarte são a categoria do material manipulado, conhecimento das etapas de gerenciamento, conhecimento dos dados toxicológicos de cada substância manipulada controladas pela Instituição de estudo, formação do funcionário e tempo de formado. A interpretação do modelo é igual à realizada para o modelo relativo ao descarte rotineiro de resíduos gerados em laboratório. 


\subsection{Discussão dos possíveis impactos sobre a saúde humana provocados pelos resíduos perigosos gerados nas instituições estudadas}

A Tabela A-33 do anexo 21, indicado pela cor roxa, apresenta os dados obtidos através do levantamento bibliográfico, enfocando cuidados na manipulação, padrões de segurança para o ambiente de trabalho, possiveis efeitos adversos e suas manifestações decorrentes da intoxicação aguda e crônica na exposição ocupacional aos resíduos perigosos produzidos nas instituições avaliadas.

A ocorrência da síndrome tóxica pode ser evitada com a observação dos padrões de segurança. Os limites de exposição, os niveis de risco mínimo e as doses diárias aceitáveis são determinados através das doses de referência. Para algumas das substâncias listadas na Tabela A-33, encontrou-se, na literatura consultada, a dose de referência estabelecida através de estudos com animais de experimentação. A Tabela A-34 ilustra o processo de obtenção dessas doses para tais toxicantes.

O nivel de risco mínimo (NRM) é uma estimativa da exposição humana diária a substâncias perigosas, presentes no meio ambiente, sem o risco considerável de se observar efeitos adversos durante um determinado tempo de exposição. A Agency for Toxic Substances and Disease Registry (ASTDR) usa a relação dose de nenhum efeito adverso observado (DNEAO) sobre os fatores de incerteza na dedução do NRM. Este é definido abaixo dos níveis capazes de promover um efeito nocivo na população suscetível à interação com determinada substância e é dependente do modelo matemático e do fator de incerteza utilizados, bem como dos objetivos das instituições que os adotam.

Os NRMs são estabelecidos para diferentes tempo e condições de exposição: aguda ( 1 - 14 dias), intermediária (15 - 364 dias) e crônica (365dias ou mais) e, para as vias de introdução oral e pulmonar. Geralmente baseados no efeito tóxico mais relevante para a população humana, efeitos irreversiveis - como dano renal e hepático irreversivel, malformações congênitas ou carcinomas - não são utilizados para fundamentar essa extrapolação. A título de exemplificação, a Tabela A-35, no 
anexo 21, apresenta os niveis de risco minimo para as substâncias perigosas utilizadas pelas Instituições de estudo e encontradas no documento da ATSDR (2000)

Cumpre ressaltar que a exposição a concentrações acima do NRM não leva obrigatoriamente à observação do efeito adverso (ATSDR, 2000; CHOU e WILLIAMS- JOHSON, 1998).

\subsection{Avaliação do envolvimento institucional em programa de gerenciamento de resíduos}

Tanto na Instituição A como na B, a preocupação com o meio ambiente e com a periculosidade dos reagentes envolvidos levaram a criação de uma comissão para gerenciá-los. Iniciaram praticamente do mesmo modo, solicitando a cada laboratório discriminar, em primeiro lugar, quais as substâncias ali manipuladas; e depois, as agruparam em combustiveis e não combustíveis, clorados e não clorados. A Instituição B ainda solicita a segregação de ácidos e bases fortes, metais pesados e citotóxicos.

A periodicidade do recolhimento dos residuos segregados é mensal na Instituição $B$ e sem periodicidade definida na Instituição $A$, até o momento da avaliação. Esse fato foi motivo de preocupação por vários dos entrevistados, tendo sido relatado a segregação de éter de petróleo por um dos laboratórios da Instituição A, o qual por não ter ocorrido a coleta, viu-se obrigado a descartá-lo na rede de esgoto.

Os resíduos coletados são armazenados, em ambas as Instituições, em local que não atende às especificações da ABNT NBR 12.809 (1993). Nesses locais também estão armazenados vários frascos não identificados encontrados quando da implantação do gerenciamento de residuos. 
A Instituição A tem enviado o material inflamável não clorado para ser incinerado em Taboão da Serra, São Paulo. A Instituição B aguardava, até o momento da coleta de dados, a construção de um incinerador no campus universitário, ou a liberação de verba para se proceder o tratamento extramuros.

A falta de verba e a falta de educação ambiental são as principais dificuldades encontradas por essas Instituições. Vários ciclos de palestras são anualmente ministrados na Instituição A no sentido de educar os seus funcionários, mediante adesão voluntária. A Instituição B confeccionou boletins e comunicados explicando as necessidades e a caracteristica do programa, além de promover dois dias de palestras e mesas redondas para discutir o assunto entre funcionários interessados.

O engajamento dos funcionários ao programa não está institucionalizado, dependendo do interesse e da iniciativa de cada um. Pode-se apreender, através das entrevistas realizadas, que alguns dos envolvidos reconhecem a não conformidade do descarte efetuado, porém relatam seu desconhecimento para modificá-lo. Não fazem menção em consultar a comissão de gerenciamento de resíduos, o que pode sugerir a falta de inter-relacionamento entre os funcionários e a referida comissão.

Dois dos entrevistados da Instituição B, acreditam que o programa precisa ser mais contundente exigindo a participação compulsória de pelo menos um funcionário de cada Laboratório. Em contrapartida um dos entrevistados da instituição A, afirma que: a adesão voluntária aos cursos e seminários promovidos favorece a conscientização sem a pressão da imposição pela diretoria, ainda que dessa forma não se possa garantir a uniformidade do conhecimento.

Observa-se que 48,8 \% dos funcionários da Instituição A, 44,5\% dos funcionários da Instituição B e 100,0 \% dos funcionários da Instituição C realizam, rotineiramente, o descarte incorreto de uma ou mais das substâncias ou materiais por eles manipulados. Em caso de derramamento dessas substâncias e fluidos biológicos, essas percentagens passam para $76,8 \%, 83,4 \%$ e $87,1 \%$, respectivamente, como demonstram as tabelas 42 e 43 . 
Tabela 42 - Característica do procedimento laboratorial de descarte, adotado em situação de rotina, segundo a Instituição de estudo

\begin{tabular}{|c|c|c|c|c|c|c|c|c|c|}
\hline \multirow{3}{*}{$\begin{array}{l}\text { Descarte } \\
\text { Situação de } \\
\text { rotina }\end{array}$} & \multicolumn{8}{|c|}{ Instituição } & \multirow{3}{*}{$x^{2}=132,7$} \\
\hline & \multicolumn{2}{|c|}{$\mathbf{A}$} & \multicolumn{2}{|c|}{ B } & \multicolumn{2}{|c|}{$\mathbf{C}$} & \multicolumn{2}{|c|}{ Total } & \\
\hline & $\mathbf{N}$ & $\%$ & $\mathbf{N}$ & $\%$ & $\mathbf{N}$ & $\%$ & $\mathbf{N}$ & $\%$ & \\
\hline \multirow[t]{2}{*}{ Correto } & 190 & 51,2 & 194 & 54,5 & 0 & 0 & 384 & 44,3 & \\
\hline & & & & & & & & & $p=0,000000$ \\
\hline Incorreto & 181 & 48,8 & 162 & 44,5 & 139 & 100,0 & 482 & 55,7 & \\
\hline Total & 371 & 100,0 & 356 & 100,0 & 139 & 100,0 & 866 & 100 & \\
\hline
\end{tabular}

Tabela 43 - Tipo de procedimento adotado quando do derramamento de resíduos perigosos ou infectantes, segundo a Instituição de estudo

\begin{tabular}{|c|c|c|c|c|c|c|c|c|c|}
\hline \multirow{3}{*}{$\begin{array}{l}\text { Descarte } \\
\text { Situação } \\
\text { emergência }\end{array}$} & \multicolumn{8}{|c|}{ Instituição } & \\
\hline & \multicolumn{2}{|r|}{$\overline{\mathbf{A}}$} & \multicolumn{2}{|c|}{$\mathbf{B}$} & \multicolumn{2}{|c|}{$\bar{C}$} & \multicolumn{2}{|c|}{ Total } & \\
\hline & $\mathbf{N}$ & $\%$ & $\mathbf{N}$ & $\%$ & $\mathbf{N}$ & $\%$ & $\mathbf{N}$ & $\%$ & \\
\hline Correto & 86 & 23,2 & 59 & 16,6 & 18 & 12,9 & 163 & 18,8 & $x^{2}=8,93$ \\
\hline Incorreto & 285 & 76,8 & 297 & 83,4 & 121 & 87,1 & 703 & 81,2 & $p=0,011514$ \\
\hline Total & 371 & 100,0 & 356 & 100,0 & 139 & 100,0 & 866 & 100,0 & \\
\hline
\end{tabular}

Na Instituição A, 36,7\% da população estudada afirma não haver recebido treinamento para o descarte correto das substâncias que manipula contra os $71,3 \%$ da Instituição B. E ainda, 53,3\% dos funcionários da instituição $A, 85,2 \%$ dos funcionários da Instituição B e 100,0\% dos funcionários da Instituição C entendem que um programa de treinamento para situações de emergência não existe em sua Instituição.

Nas Instituições A e B, o corpo de bombeiros ou a CIPA tem oferecido treinamento voltado, principalmente, para controle de incêndios. Da população 
estudada, $27,9 \%$ e $3,3 \%$ dos funcionários das Instituições A e B, respectivamente, relatam haver participado desses treinamentos

Em geral, equipamentos de proteção individual são utilizados pela maioria da população estudada. Determinados procedimentos analíticos, como a extração de gordura em Soxhlet, não são realizados em capela química. Reconhece-se a necessidade de óculos e proteção respiratória nesses casos, mas segundo um dos entrevistados da Instituição B: ninguém usa. Aqueles que trabalham com solventes, reconhecem a necessidade do uso de luvas especiais. Um dos entrevistados da Instituição B, afirma não haver verba para tal aquisição.

Vários laboratórios pertencentes a um dos departamentos da Instituição A não dispõem de capelas químicas. Muitos dos entrevistados pertencentes a esse departamento chamam a atenção para essa necessidade, o que implica num risco na manipulação de material corrosivo ou inflamável. Ressaltam ainda, a inexistência de lava - olhos em funcionamento e da dificuldade em se utilizar aventais de manga longa e sapatos fechados no verão, por não haver ar condicionado nesses laboratórios.

Neste departamento, os fluidos biológicos são a matriz analitica, existindo uma grande preocupação na adoção de procedimentos de segurança que minimizem os riscos biológicos decorrentes desta exposição. Todos esses laboratórios possuem capelas de fluxo laminar equipada com filtros HEPA - High efficency particulate and aerosols, de manutenção constante.

A manipulação de substâncias fora da capela ocorre mesmo nos Laboratórios que as possuem. Foi relatado por uma das funcionárias da Instituição B que pelo fato de existir uma única capela em seu laboratório, muitas vezes se manipula solventes fora dela. Cumpre ressaltar que as capelas quimicas de todas as três instituições estudadas não apresentam filtros. Tudo o que é evaporado, é liberado para o ar externo. As concentrações dessas emissões são desconhecidas podendo encontrar-se acima do recomendado. 
Algumas colocações feitas por docentes da Instituição B merecem ser transcritas ressaltando a dificuldade de percepção dos reais riscos pertinentes à matéria, bem como quanto a implementação do sistema de gerenciamento:

- todos estão conscientes dos n perigos da exposição, da necessidade do uso de máscaras, luvas, capelas, mas ainda não se sabe conduzir tudo porque falta infra-estrutura;

- o risco associado ao trabalho tem que ser avaliado considerando todo o resto. Neste país não se morre da exposição, e sim quando se vai ao cinema ou no semáforo. Fica muito caro elevar o nivel de um só aspecto.

- o custo (referindo-se ao custo da adoção de medidas de segurança e do tratamento de resíduos) está acima da exposição e da doença. O programa (referindo-se às medidas a serem adotadas) ainda fica muito a cargo de cada laboratório.

De toda a população estudada, somente os responsáveis por dois laboratórios pertencentes à Instituição $A$ possuem as fichas de segurança das substâncias manipuladas. Na Instituição B, nenhum dos docentes entrevistados possui as fichas de segurança dos diferentes produtos que manipula. No entanto, um deles relata recomendar a seus alunos de pós-graduação que procurem conhecer os efeitos tóxicos das substâncias que irão manipular.

Considerando as metodologias analíticas $\mathrm{e}$ as medidas de segurança necessárias, onze dos responsáveis pelos laboratórios da Instituição A tinham concluído os procedimentos operacionais padrão - POPs e oito declararam estar em fase de elaboração. Na Instituição B, somente um docente apresentava os POPs para as metodologias que executa e dois, afirmaram estar em fase de confecção.

$\mathrm{Na}$ validação de nova metodologia, a principal preocupação mencionada pelos entrevistados - respectivamente $40,4 \%$ dos responsáveis pelos laboratórios da Instituição A, 46,0\% dos docentes da Instituição B e apenas um dentre os três responsáveis por laboratórios entrevistados da Instituição C - reside na utilização de substâncias menos tóxicas. Foram ainda mencionados como de primordial atenção, 
os bons resultados analíticos, independente da toxicidade e periculosidade do resíduo gerado e a utilização de micro - métodos, como instrumento de minimização dos riscos.

A Instituição A restringiu o uso de solução sulfocrômica na lavagem de vidraria, no entanto, 10 dos 47 laboratórios avaliados relataram o uso de pequenas quantidades. $\mathrm{Na}$ Instituição $\mathrm{B}, 18$ dentre os 27 laboratórios estudados observaram o uso de pequenas quantidades desse material. Todos os laboratórios da Instituição $\mathrm{C}$ também empregam pequenos volumes de sulfocrômica na lavagem da vidraria.

Todas as Instituições avaliadas apresentam a aquisição centralizada de material. Vários dos laboratórios pertencentes às Instituições A e B já organizaram os seus almoxarifados internos e encaminharam os reagentes fora da validade para a comissão de gerenciamento de cada uma destas Instituições. Na Instituição $\mathrm{C}$, muitos reagentes fora da validade ainda se encontram em seu almoxarifado.

Quanto a importância da disposição adequada dos residuos gerados, a opinião dos analistas entrevistados nas Instituições A, B e C, respectivamente, encontra-se distribuída da seguinte forma: $35,1 \%, 23,1 \%$ e $52,0 \%$ entendem o correto descarte como medida de proteção para o analista e para o meio ambiente, $31,9 \%, 60,4 \%$ e $36,0 \%$ como proteção somente ao meio ambiente e $32,0 \%, 16,5 \%$ e $12,0 \%$ como proteção ao analista devido ao risco biológico ao qual está exposto. 


\section{DISCUSSÃO}

Nas três instituições avaliadas, poucas vezes o levantamento das substâncias e matrizes manipuladas e do conseqüente, resíduo gerado foi feito utilizando-se os procedimentos operacionais padrão - POPs. Em geral, pelo fato das instituições não serem ainda credenciadas e os Sistemas de Qualidade, tais como as Boas Práticas de Laboratório e ISOguia 25 estarem em fase de implantação, os POPs ainda estavam em fase de elaboração.

Em vários laboratórios, dependendo da característica e do fundamento dos métodos e técnicas empregadas, esse fato dificultou a compreensão dos procedimentos e da mistura e volume dos resíduos gerados nessas análises. $\mathrm{Na}$ tentativa de resgatar esses conhecimentos, após a tabulação dos dados coletados, retornou-se a esses laboratórios e entrevistou-se, novamente, seus funcionários procurando dirimir as dúvidas.

Pelas limitações intrínsecas ao instrumento de produção de informação adotado (entrevistas), os dados coletados dependem da qualidade das informações concedidas pelos entrevistados, da sua percepção quanto aos objetivos da pesquisa e de sua disponibilidade em relatar os seus procedimentos de rotina ou na inexistência desta, os empregados no mês anterior. Cumpre ressaltar que algumas vezes, a interação entrevistado-entrevistador ficou comprometida pela dificuldade de compreensão dos objetivos deste estudo por parte do entrevistado e/ou pela dificuldade do entrevistador em esclarecê-lo ou convencê-lo de suas necessidades. Assim sendo, os dados primários obtidos não representam o universo real dos resíduos gerados em cada uma da Instituições avaliadas, mas refletem com fidelidade o que foi transmitido durante as entrevistas

Para metodologias distantes da realidade analítica do pesquisador - como a biologia molecular - procurou-se o auxilio de docentes e analistas da referida área na tentativa de avaliar a compreensão dos procedimentos analíticos envolvidos e minimizar os vieses desta pesquisa. 
O procedimento de descarte dos resíduos gerados foi avaliado, como mencionado, segundo as exigências legais e os subsídios teóricos obtidos através da revisão bibliográfica realizada. A avaliação dos procedimentos adotados, em situação de rotina, estão devidamente relatados na sequiência, respectivamente para as Instituições A, B e C.

\section{Instituição A}

Com relação à Instituição A foram abordados os resíduos infectantes, inflamáveis, corrosivos, reativo, tóxicos, radioativos e não perigosos.

- Resíduos Infectantes: O gerenciamento de resíduos infectantes vem ocorrendo há dez anos nesta Instituição e como reflexo da estrutura implantada, procedese corretamente a inativação térmica ou química desses resíduos. A centralização da inativação térmica requer $o$ transporte dos residuos infectantes gerados em cada laboratório até este local, devendo-se observar as exigências das ABNT - NBR 12.810 (1993) para tanto. Foi relatado o uso de carrinhos nesse transporte e de EPIs pelo funcionário envolvido. Durante o período de estudo, não se presenciou, entretanto, a coleta e transporte desse material. Quanto às carcaças de animais, como a Instituição não dispõe de um incinerador, estas são devidamente acondicionadas e encaminhadas para incineração pela Prefeitura do município de São Paulo.

口 Resíduos inflamáveis: A segregação e reutilização de solventes são procedimentos constantes das normas estabelecidas pelo programa de gerenciamento de resíduos da instituição. Atendendo à essas normas, boa parte dos solventes gerados são segregados ou recuperados. No entanto, dependendo do volume utilizado e da característica do procedimento analítico (mistura com resíduos biológicos, por exemplo), outros procedimentos são adotados, a saber: evaporação em capela química sem filtros e descarte na rede de esgoto para os solventes mais polares, como álcoois e acetona - algumas vezes misturados a solventes mais apolares como o éter etílico - ou na mistura 
com resíduo biológico, após inativação do resíduo infectante com hipoclorito de sódio.

O formaldeído convertido a ácido fórmico durante o procedimento analítico pode ser descartado na rede de esgoto, entretanto, como o resíduo gerado nessa Instituição contém ácido acético, o pH da mistura deve ser verificado previamente ao descarte, procedendo a neutralização se necessário.

Os resíduos segregados são armazenados para posterior incineração. O local de armazenamento não atende às exigências legais apresentadas pela ABNTNBR 12.809 (1993).

Quanto à evaporação desses solventes em capelas químicas sem filtros é importante ressaltar a necessidade de se garantir que as concentrações emitidas não sejam elevadas. Em geral, a vazão das capelas químicas oferece uma dispersão elevada, emitindo concentrações da ordem de partes por trilhão. Contudo, considerando o número de laboratórios em cada instituição, as concentrações emitidas podem não ser tão irrelevantes. Desta forma, alguns autores têm recomendado o uso de lavadores de gases para neblinas ácidas e alcalinas, ou solventes bem polares e o uso de filtros de carvão ativado para os solventes clorados ou de lipossolubilidade elevada.

O custo desses equipamentos é, entretanto, elevado. Um lavador de gás custa em média, R\$ $10.000,00$ e ocupa uma área de $2,5 \times 1,20$, pesa 1 tonelada e meia e tem 3 metros de altura. Os filtros de carvão ativado apresentam um menor volume $1 \times 1 \times 1,20 \mathrm{~m}$ e menor custo inicial, R\$6.000,00. Possuem 2 a 3 elementos filtrantes, que saturam rapidamente em neblinas ácidas, e requerem substituição freqüente, no valor de $R \$ 1.000,00$ por elemento filtrante. Assim sendo, a alternativa mais adequada é adotar-se micro métodos, evaporando-se menor quantidade de solventes. 
No que tange a manipulação de misturas de resíduos químicos e biológicos, observa-se uma grande preocupação com a inativação dos resíduos biológicos, colocando-se em segundo plano o gerenciamento dos resíduos químicos. A diferença na percepção do procedimento correto de descarte a ser adotado, condicionada à categoria do material a ser manipulado, reforça a premissa da necessidade de se criar programas educacionais consistentes.

As substâncias sólidas classificadas como inflamáveis são descartadas na rede de esgoto, com exceção dos residuos contendo nitrato de amônia que são segregados para a comissão de descarte e o persulfato de amônia, o qual é descartado juntamente com o gel de acrilamida. $\mathrm{O}$ iodato de potássio durante o procedimento analítico é reduzido a iodeto, o qual poderia ser descartado diretamente na rede de esgoto. Entretanto, na mistura dos resíduos gerados nessa análise temos ácido sulfúrico, assim sendo, deve-se verificar o $\mathrm{pH}$ da mistura em questão, neutralizando-a, se necessário, antes do descarte. Quanto aos resíduos contendo permanganato de potássio e nitrito de sódio, recomenda-se a inativação química. Não foi referida qualquer determinação da Comissão de gerenciamento de residuos quanto ao descarte de resíduos contendo essas substâncias.

- Resíduos contendo substâncias reativas - Com exceção dos resíduos contendo 3-amino-propil)trietoxisilano, segregados para recolhimento pela Comissão de descartes, os demais resíduos contendo substâncias reativas são descartados na rede de esgoto. Resíduos perigosos devem ser segregados e tratados para posterior disposição. No caso do (3-amino-propil)trietoxisilano, o tratamento pode ser procedido no local de geração, visto ser facilmente hidrolisado em meio aquoso, permitindo o descarte na rede de esgoto após este procedimento.

O ácido pícrico, em função da sua reatividade (explosivo), deve ser tratado previamente como descrito na tabela A-30. Para a mistura de ácido pícrico com $\mathrm{NaOH}$, soro e tampão glicina, se o procedimento recomendado por ARMOUR (1996) for utilizado, será necessário observar o $\mathrm{pH}$ do resíduo 
alcalino após a acidificação. Como esse tratamento envolve acidificação, não há a necessidade de se proceder a inativação química da matriz biológica com hipoclorito. Quanto a mistura de resíduos - ácido pícrico, formol e etanol, o tratamento adequado é a incineração.

Quanto ao resíduo contendo anidrido acético por se tratar de uma mistura contendo clorofórmio, o tratamento recomendado é a incineração, não cabendo o tratamento químico descrito na Tabela A-30.

Os resíduos contendo íons cianeto devem ser tratados com hipoclorito de sódio para ocorrer a formação de íons cianato, estáveis e de menor periculosidade. Parte dos resíduos gerados nessa Instituição são tratados com hipoclorito, a única recomendação a ser feita é que se verifique se a quantidade de hipoclorito utilizada é suficiente para a conversão do íon cianeto a cianato

- Resíduos corrosivos - Dependendo do procedimento analítico onde a substância é utilizada e da composição da mistura onde se encontra, os resíduos contendo substâncias corrosivas são evaporados em capela química, segregados para posterior recolhimento pela comissão de gerenciamento, descartados na rede de esgoto ou autoclavados.

Verifica-se que o descarte na rede de esgoto é o procedimento mais empregado na Instituição $\mathrm{A}$, para as substâncias corrosivas. Para atender as exigências legais, todos os resíduos contendo substâncias corrosivas, dependendo do $\mathrm{pH}$ da mistura, deveriam ser neutralizados antes do seu descarte por essa via. Observou-se que essa conduta não está normatizada nessa instituição e que o descarte de resíduos corrosivos neutralizados é decorrente de metodologias titulométricas ácido-básicas.

Em geral, os ácidos e bases manipulados na Instituição são segregados quando a mistura de resíduos onde se encontram contém solventes 
inflamáveis ou clorados e metais, para posterior tratamento fora da unidade geradora. Porém, pode-se observar que essa conduta não foi totalmente incorporada pelos diferentes laboratórios da Instituição já que, por exemplo: $4,5 \%$ do volume total de ácido acético utilizado, em mistura contendo ácido sulfúrico, poderiam ser neutralizados e descartados na rede de esgoto, e são segregados; $1800 \mathrm{ml} / \mathrm{m}(62,3 \%$ do volume total) do resíduo contendo ácido acético em mistura ao clorofórmio, iodeto de potássio, amido e tiossulfato de sódio são descartados na rede de esgoto e deveriam ser segregados para posterior incineração devido a presença do hidrocarboneto clorado.

Quando o volume de resíduo gerado contendo substância corrosiva é pequeno e encontra-se misturado a hidrocarbonetos voláteis ou são componentes das formulações de agentes cromogênicos, estes são evaporados em capela química sem filtro especiais. Reitera-se as recomendações tecidas para os resíduos inflamáveis.

Ainda em função do pequeno volume gerado, alguns procedimentos de descarte normatizados pela comissão de gerenciamento podem ser modificados, como ocorre para o fenol ou para a mistura fenol:clorofórmio utilizada na biologia molecular e segregada na maioria dos laboratórios da Instituição. 1,5\% do volume total de fenol utilizado na instituição é autoclavado. Em virtude do caráter do resíduo gerado e da volatilidade do mesmo, este procedimento é inadequado, entretanto, os riscos decorrentes desta exposição são mínimos visto que menos de $1,5 \mathrm{ml}$ é autoclavado por vez.

口 Resíduos tóxicos - A maioria dos resíduos contendo solventes clorados são segregados. Como descrito nos parágrafos anteriores, esse procedimento não é institucionalizado, existindo ainda laboratórios que descartam resíduos contendo esses hidrocarbonetos na rede de esgoto, não atendendo, assim, às exigências legais. A segregação dos solventes inflamáveis e dos clorados, 
nem sempre é eficaz. Como se pode ver nos resultados, dependendo do laboratório onde são gerados, podem estar misturados com vários reativos, inclusive com metais. A justificativa para tal procedimento recai na falta de espaço para armazenamento no local de geração, na dificuldade em se conseguir um número maior de bombonas, e na falta de periodicidade na coleta dos resíduos gerados.

A segregação de resíduos contendo metais também não é realizada em sua totalidade. Quando sais metálicos são componentes das formulações de corantes são descartados na rede de esgoto sem prévia estabilização, como ocorre para o chumbo e a prata. Para os sais de mercúrio: $51,4 \%$ é segregado para posterior tratamento, $0,15 \%$ são estabilizados com ácido sulfidrico no próprio local de geração e o restante é descartado em saco plástico branco específico para RSS, o qual será posteriormente incinerado. A incineração de metais é, em geral, inadequada, uma vez que esse tratamento é ineficaz na destruição desses resíduos. Durante o processo de incineração, os metais são emitidos para o meio ambiente. A incineração de resíduos contendo certos metais, como o chumbo, só pode ser realizada quando a sua quantidade no resíduo for baixa, garantindo a emissão para o meio ambiente de concentrações inferiores às preconizadas.

Para o selenito de sódio, nenhum tratamento específico para o metal é adotado, por ser um componente de meio de cultura. Procede-se a inativação térmica objetivando reduzir a periculosidade do resíduo infectante. Sabe-se, no entanto, que o selenito de sódio se decompõe em contato com superfícies quentes ou na presença de fogo formando gases tóxicos (USDHHS - CHSI, 2000). Assim, após uma inativação química do meio de cultura, deve-se estabilizar o metal como descrito na Tabela A-30, separando-se a borra de metal estabilizado do restante do material, o qual pode ser descartado em saco plástico branco próprio para RSS. A borra deve ser encaminhada para o aterro industrial. 
O mesmo se dá com a azida sódica, presente em meios de cultura. Pode explodir com o aquecimento e portanto, a autoclavagem pode resultar em risco para o funcionário. Recomenda-se a inativação química e posterior, tratamento do resíduo contendo Azida sódica com descrito na Tabela A-31.

Para o ácido cacodílico, o descarte na rede de esgoto deste composto é inadequado. Como descrito na Tabela A-31, a incineração em temperaturas superiores a $1.100^{\circ} \mathrm{C}$ é recomendada.

Para as substâncias utilizadas como corantes ou reveladores, os laboratórios da instituição apresentam tratamento padronizado apenas para o brometo de etídio, utilizado em biologia molecular, adicionado ao gel de agarose ou aos tampões de corrida. Tratam esses resíduos de acordo com o procedimento descrito na literatura (SAMBROOK e col., 1989). Além do brometo de etídio (agente mutagênico), utilizam outras substâncias reconhecidamente carcinogênicas- diaminoazobenzidina, o-fenilenodiamina e auramina, entretanto, estas são descartadas na rede de esgoto, ainda que o volume utilizado por mês seja superior ao do brometo de etídio. Presume-se que a descrição de métodos de tratamento disponibilizadas em livros de biologia molecular tenha modificado a percepção somente para o brometo de etídio. Os resíduos de diaminoazobenzidina, o-fenilenodiamina e auramina, devem ser tratados como descrito na Tabela A-31, antes do seu descarte em rede de esgoto.

Quanto a acriflavina, a etapa de maior risco consiste na preparação do gel, que após a sua polimerização torna-se estável. A incineração é o tratamento adequado para esse resíduo. Com o acondicionamento dos géis de acrilamida em sacos plásticos específicos para os RSS, os quais serão incinerados pela prefeitura desta cidade, este resíduo finda por receber o correto tratamento.

Os residuos contendo brometo de cianogênio também recebem tratamento adequado, o que garante a minimização de sua periculosidade. 
a Resíduos radioativos- As substâncias radioativas utilizadas apresentam baixa atividade. Foi impossivel, entretanto, obter os valores corretos emitidos junto aos analistas ou ao fornecedor do Bactec (Becton \& Dickinson). Quanto ao acetato de uranila, o produto comercializado apresenta a composição isotópica de $\mathrm{U}^{238}$ - 99,6 - 99,7\% e $\mathrm{U}^{235}$ - 0,3 - 0,4\%. O Urânio natural apresenta $0,7 \%$ de $U^{235}$. A depleção do $U^{235}$ determina uma atividade de 0,51 $\mu \mathrm{Ci} / \mathrm{g}=1,887 \times 10^{4} \mathrm{~Bq} / \mathrm{g}$ no produto comercializado. Um material é considerado radioativo quando a sua atividade específica é maior que 74 Bq/g. (ELECTRON MICROSCOPY SCIENCES, 2000).

As recomendações do CNEN.NE 6.05 (1985) devem ser observadas, aguardando-se o decaimento em local adequado, para posterior disposição. PRÜSS e col. (1999) recomendam:

- a utilização de radionucleotídeos de meia-vida curta, substituindo-se, por exemplo, ${ }^{33} \mathrm{P}\left(\mathrm{t}_{1 / 2}=25\right.$ dias $)$ por ${ }^{32} \mathrm{P}\left(\mathrm{t}_{1 / 2}=14\right.$ dias $)$, ou ${ }^{32} \mathrm{~S}\left(\mathrm{t}_{1 / 2}=87\right.$ dias) por ${ }^{33} \mathrm{P}$ ou ${ }^{32} \mathrm{P}$;

- eliminar, sempre que possível, a etapa de fixação com metanol e ácido acético na coloração de géis de eletroforese contendo radionucleotídeos;

- remover os constituintes orgânicos da mistura através de resinas sintéticas ou de troca iônica, como amberlite ${ }^{\circledR}$ XAD e carvão ativado (menos eficiente). A solução aquosa deve ser manipulada como radioativa. A resina contendo os solventes deve ser disposta como residuo químico;

- uso de fluidos de cintilação não inflamáveis (fenilxililetano, diisopropilnaftaleno) em substituição aos inflamáveis (tolueno, xileno e pseudocumeno);

- separar uma autoclave para proceder a inativação térmica de resíduos que contenham em sua mistura substâncias radioativas.

Para os radionucleotídeos de meia vida longa como o urânio, segundo comunicação pessoal realizada por técnico do setor de proteção radiológica do Instituto de Pesquisas Energéticas e Nucleares - IPEN, esses resíduos devem ser encaminhados para este Instituto, onde serão encapsulados em 
concreto e guardados em depósito provisório localizado na referida instituição. Não há depósito definitivo para resíduos radioativos no Brasil.

- Resíduos não perigosos- Como relatado anteriormente, as substâncias listadas como não perigosas são aquelas que não apresentam propriedades inflamáveis, reativas, corrosivas ou tóxicas, segundo os parâmetros oferecidos pela ABNT - NBR 10.004 (1985). Entretanto, se a mistura onde se encontram apresentar uma substância perigosa ou infectante, esse resíduo deverá ser manipulado como perigoso.

Por exemplo, o resíduo contendo amido (não perigoso), tiossulfato de sódio (não perigoso), iodeto de potássio (não perigoso), ácido acético (corrosivo) e clorofórmio (tóxico), não deve ser descartado na rede de esgoto, pela presença das duas últimas substâncias. A incineração é o tratamento adequado pelo clorofórmio encontrar-se na mistura. Se este não estivesse presente, bastaria neutralizar o ácido acético contido na mistura para se proceder o descarte na rede de esgoto.

Observa-se, ainda, que muitas das substâncias classificadas como não perigosas apresentam dados de mutagenicidade relatados na literatura. A mutagenicidade não é um dos parâmetros considerados na avaliação da toxicidade de um resíduo, segundo a ABNT - NBR 10.004 (1985) ou Portaria CVS-01/2000. Entretanto, sabe-se que estes compostos mutagênicos, distribuidos no ecossistema, transferidos e acumulados através das cadeias tróficas, podem causar danos genéticos ou efeitos genotóxixos nos indivíduos ou populações expostos, aumentando a incidência de diversas patologias, inclusive o câncer nessas populações ou modificando a virulência de patógenos (UMBUZEIRO e ROUBICEK, in press)*.

* Umbuzeiro GA, Roubicek DA Genotoxicidade ambiental. In: Zagatto P, Bertoletti E. Ecotoxicologia Aquática : bases e aplicações. [In Press]. 
As ferramentas disponiveis para avaliar a detecção de mutágenos no meio ambiente e seus impactos sobre a saúde da população - avaliação do risco, ainda estão em discussão. Os vários testes propostos apresentam características diferentes, avaliando a capacidade de introduzir mutação em diferentes genes ou pares de base do DNA. Os resultados obtidos podem ser contraditórios ou de difícil interpretação. De qualquer forma, deve-se estar atento a essas considerações a fim de salvaguardar o meio ambiente e a saúde da população.

\section{Instituição B}

Com relação à Instituição $\mathrm{B}$ foram abordados os resíduos infectantes, inflamáveis, corrosivos, reativos, tóxicos, radioativos e não perigosos.

a Resíduos infectantes- Como relatado no item 7.2.3.2, os procedimentos de descarte adotados para esses resíduos não são uniformes nesta Instituição. Para atender às normas técnicas, todos os resíduos infectantes devem ser submetidos a inativação prévia ao descarte, o que não ocorre em alguns laboratórios.

- Resíduos inflamáveis - Dependendo da polaridade do solvente, de sua utilização no procedimento analítico e do volume gerado, estes podem ser segregados para posterior recolhimento pela comissão de gerenciamento, evaporados em capela química sem filtro ou descartados na rede de esgoto.

Em geral, quanto menor a polaridade do solvente inflamável utilizado maior a segregação, de 50,6\% do volume total gerado (éter etílico) a $100 \%$ (acetonitrila e heptano, por exemplo). A segregação diminui quando percentagem de reutilização é elevada, como para o éter de petróleo e etílico, ou quando o solvente utilizado é mais polar, como etanol e metanol. Neste 
caso, são segregados quando utilizados como fase móvel na técnica de cromatografia líquida de alta resolução, especialmente quando misturados a outros solventes mais apolares.

Os solventes mais polares são freqüentemente descartados na rede de esgoto. Segundo recomendação da USNIEHS (1998), esse procedimento pode ser adotado quando as concentrações desses solventes polares na mistura for inferior a $24 \%$. Assim sendo, a diluição desses resíduos deve ser efetuado antes do descarte pela via hídrica.

A PURDUE UNIVERSITY (1990) também estabelece que volumes inferiores a $50 \mathrm{ml}$ de substâncias inflamáveis ou combustiveis de baixa toxicidade e elevada polaridade - acetona, butanol, isobutanol, acetato de etila, etanol, isobutanol, isopropanol, metanol, propanol, podem ser descartados desta forma, desde que se proceda uma pré - diluição em ao menos 4 litros de água. Para misturas, a solubilidade de cada componente deve ser considerada antes da adoção deste procedimento de descarte. Soluções miscíveis com água, mas resistentes à biodegradação ou que contenham substâncias tóxicas não devem ser dispostas através da rede de esgoto.

Quanto à evaporação de substâncias inflamáveis em capelas químicas sem filtro e o descarte na rede de esgoto sem tratamento prévio, cabem as considerações já tecidas para a Instituição A.

- Resíduos Reativos - Excetuando-se o resíduo contendo cloreto de vanádio que se encontra segregado no local de geração, os agentes de derivatização, diazometano e trimetiliodosilano, e o cloreto de alumínio evaporados em capela, os demais residuos contendo substâncias reativas são descartados na rede de esgoto. 
Esses residuos deveriam ser tratados previamente ao descarte, como descrito na Tabela A-29, evitando risco para quem os recolhe e para o meio ambiente. A eficiência do tratamento deve ser comprovada antes do descarte, como mencionado anteriormente na Instituição A com referência à cloração dos sais de cianeto.

- Resíduos corrosivos - As substâncias de caráter ácido são, em geral, segregadas somente quando encontram-se misturadas a solventes orgânicos, 0 que representa em média $37,1 \%$ do volume total do residuo ácido gerado (de $13,2 \%$ para o ácido perclórico a $46,6 \%$ para o ácido acético), considerando os corrosivos líquidos; e de 83,8 a $100 \%$, para os sólidos (ácido oxálico, trifluoracético e fenol). Quanto aos álcalis, somente o hidróxido de amônia é segregado, $27,1 \%$ do total gerado.

O restante dos resíduos gerados são descartados, geralmente, sem neutralização na rede de esgoto ou evaporados em capelas quimicas sem filtros. Os poucos resíduos corrosivos descartados na rede de esgoto já neutralizados são provenientes de titulações ácido-básicas. Assim, verifica-se que a neutralização de residuos ácidos ou básicos ou o tratamento de outros resíduos corrosivos ainda não se encontra normatizada nesta Instituição.

口 Resíduos tóxicos- Resíduos contendo substâncias cloradas, como diclorometano e clorofórmio, outros substâncias orgânicas, como a dimetilformamida, e alguns sais metálicos são segregados para posterior recolhimento pela comissão de gerenciamento, quase que na totalidade dos residuos gerados excetuando-se os que contém sais de prata preferentemente dispostos na rede de esgoto. O descarte na rede de esgoto se dá quando os volumes gerados são pequenos. São, ainda, evaporados em capela química quando utilizados como agentes cromogênicos. Para esses resíduos vale o que foi discutido para a Instituição A. 
Quanto aos resíduos contendo brometo de etídio, observa-se a preocupação em tratá-los antes de seu descarte. Ao contrário da Instituição A, não existe um tratamento padronizado, diferindo de laboratório para laboratório. Dentre os tratamentos realizados verifica-se a inativação por hipoclorito de sódio, o que, como ressaltado na Tabela A- 31, gera compostos mutagênicos de maior potência que o precursor. Estas considerações são abordadas por SAMBROOK e col. (1989), compêndio de referência para os laboratórios que realizam Biologia Molecular e onde se discute a eficiência dos vários tratamentos para o brometo de etídio, os quais podem ser empregados no local de geração, evitando-se a segregação para posterior tratamento e os riscos decorrentes da adoção desse método.

Para os resíduos contendo auramina, diaminoazobenzidina, ofenilenodiamina, acrilamida, são pertinentes as observações feitas para a Instituição A.

Os resíduos contendo 2-mercaptoetanol também devem ser tratados antes de seu descarte na via hídrica, como relatado na Tabela A -31.

- Resíduos radioativos - O decaimento dos resíduos radioativos gerados é observado na Instituição. No entanto, não há um local adequado para o armazenamento desses resíduos durante esse período.

a Resíduos de medicamentos - A inativação de antineoplásicos atende as exigências legais e é realizada como descrito na literatura (HANSEL e col. 1997; PRÜSS e col., 1999).

- Resíduos não perigosos- As considerações feitas para a Instituição A também são aplicáveis para esta Instituição. 


\section{Instituição C}

Com relação à Instituição $\mathrm{C}$, estão abordados os residuos infectantes $\mathrm{e}$ especiais, sem subdivisões, por não haver um programa de gerenciamento institucionalizado.

- Resíduos infectantes - Até a finalização da coleta de dados somente um dos departamentos desta Instituição apresentava coleta de resíduos de serviço de saúde. Nos demais, o descarte de material biológico é feito e recolhido como resíduo comum, o que não atende as exigências legais.

Não obstante, mesmo no Laboratório pertencente à divisão onde existe uma coleta dos resíduos de serviço de saúde, não se procede a inativação do material biológico manipulado ou daquele não utilizado nas análises antes de seu descarte. Considerando que o destino dos RSS será a incineração efetuada pela prefeitura da cidade, a não inativação dos resíduos infectantes representa um risco tanto para aquele que recolhe esses residuos no local de geração como para aqueles que coletam os RSS gerados na Instituição até o incinerador. $O$ descarte na rede de esgoto de papa de tecidos e fluidos biológicos manipuladas ou não é inadequado.

- Resíduos especiais - Duas formas de descarte são adotadas pela Instituição: evaporação em capelas químicas ou via rede de esgoto. Os procedimentos adotados pela Instituição atendem às exigências legais. Os resíduos contendo substâncias inflamáveis, reativas, corrosivas e tóxicas devem ser tratados como descrito na Tabela A - 30 . 
Após as devidas explanações com relação aos procedimentos adotados nas Instituições $\mathrm{A}, \mathrm{B}$ e $\mathrm{C}$, verifica-se que pelo menos para os residuos especiais gerados em maior volume ou para as substâncias mais tóxicas, o procedimento adotado é correto nas Instituições onde o programa de gerenciamento já foi instituido. No entanto, torna- se evidente a necessidade de se criar mecanismos que propiciem a maior compreensão e conscientização dos envolvidos, quanto ao correto procedimento de descarte em situações de rotina e de emergência.

Os resultados apresentados refletem a falta de treinamento para o correto descarte relatada pelos funcionários das duas Instituições onde um programa já foi estabelecido, bem como, a falta de um programa de treinamento para situações de emergência devidamente formalizado. Pelas respostas oferecidas, percebe-se que esses treinamentos não abrangem o derramamento de substâncias, tendo sido relatado por vários dos entrevistados, diversos acidentes ocorridos pelo desconhecimento dos medidas a serem tomadas nessas situações.

$\mathrm{Na}$ lavagem de vidraria, mesmo que os volumes de solução sulfocrômica empregados sejam pequenos é inevitável o descarte de cromo na rede de esgoto durante esse procedimento. Recomenda-se proscrever o uso dessa solução substituindo-a por uma solução de hidróxido de potássio em álcool ou por produtos comerciais como o Alconox (PURDUE UNIVERSITY, 1990).

A centralização da aquisição de material a ser utilizado na Instituição é um importante fator na redução de custos. Permite programar as aquisições, evitandose grande quantidade de material não conforme em virtude da não utilização dentro do prazo de validade. Desta forma, cumpre-se o disposto na Portaria CVS1, de 18/01/2000, em que Os laboratórios Clínicos Autônomos e Unidade de Laboratórios Clínicos deverão desenvolver ações voltadas para o controle ..., dos prazos de validade e das condições de conservação, armazenamento e estocagem de produtos e artigos (sub-item IV.8.1.4.1) e Para efeitos desta Norma Técnica, é proibida a utilização de produtos e artigos cujos prazos de validade estejam expirados (sub-item IV.8.1.4.3). Estes conceitos são utilizados por diferentes 
Universidades e Instituições americanas (PURDUE UNIVERSITY, 1990; USEPA, 1990 a).

A manipulação adequada e o correto descarte dos resíduos gerados, além de proteger o meio ambiente e a saúde da coletividade, são medidas de segurança para o analista. Este axioma não está claro para a maior parte da população estudada, o que é corroborado pela ausência de fichas de segurança na maioria dos laboratórios avaliados. Os acidentes e situações de emergência parecem ser tratados como eventos de ocorrência impossível, apesar de terem sido relatados alguns incidentes nas três instituições estudadas.

Vários acidentes decorrentes da manipulação de material biológico foram descritos nos períodos de 1949 a 1979 e de 1960 a 1985, na Inglaterra e Estados Unidos. A maioria das infecções contraídas pelos analistas ingleses e americanos estavam relacionadas a Chlamydia spp, Brucella spp e Mycobacterium spp (SEWELL, 1995). Carvalho e Jales (1981) realizaram, em alguns laboratórios oficiais da rede de saúde da cidade de São Paulo, um levantamento dos casos de acidentes e infecções ali ocorridos. 171 casos foram informados sendo que 115 sofreram enfermidade e destes, 106 tiveram completa recuperação, 6 apresentaram incapacidade permanente em razão de acidentes com Trypanosoma cruzi, vírus da hepatite, blastomicose e picadas de animal e 3 foram a óbito, um por Clostridium tetani e dois por rickettisioses.

DUCREUX e AZOLOY (1997), citados por PELNIER e col. (1999), estimam que o risco de infecção pelo vírus da AIDS em decorrência de picada por agulha contaminada seja de $0,3 \%$ e de $0,05 \%$ após o contato cutâneo e de 5 a $40 \%$ pelo contato com o vírus da hepatite B.

O advento da epidemia de AIDS no início da década de 80 , associado ao recrudescimento da tuberculose, renovou o interesse em se estabelecer programas de segurança para os funcionários da saúde. As medidas adotadas diminuíram os riscos ocupacionais dessa exposição mas não os baniram (SEWELL, 1995). A 
análise das causas de acidentes revelaram a não observância das medidas de segurança como o uso de avental, luvas, máscaras, óculos e pipetas automáticas, além de se evitar a formação de aerossóis (PELNIER e col, 1999).

Segundo SEWELL (1995), analistas mais jovens, de 17 a 24 anos e do sexo masculino estão mais envolvidos em acidentes do que funcionários mais velhos, de 45 a 64 anos, e do sexo feminino. CARVALHO e JALES (1981) relatam que o contato com o material infeccioso através de seu derramamento, respingo ou aerossol foi o tipo de acidente mais freqüente na população, por eles, estudada.

Não se encontrou, na literatura consultada, relatos de acidentes envolvendo a manipulação de substâncias químicas em laboratório. Sabe-se, entretanto, que a manifestação do efeito adverso decorrente da interação entre um sistema biológico e uma ou mais substâncias químicas está relacionada às condições de exposição e pode ser minimizada através da adoção de medidas adequadas durante o manuseio e exposição a essas substâncias. O uso de equipamentos de proteção coletiva e individual torna-se imprescindivel para que os limites de exposição não sejam ultrapassados durante a realização das análises, evitando-se a observação de quadros de intoxicação aguda e crônica.

Nas Instituições estudadas, os procedimentos realizados sem equipamento de proteção individual ou utilizando equipamentos inadequados devem ser revistos; os níveis de exposição devem ser checados para se avaliar o seu impacto sobre a saúde do analista. A eficácia dos equipamentos de proteção individual ou coletivo também deve ser verificada e o necessário aporte de recursos deverá ser providenciado para garantir o correto funcionamento e a aquisição equipamentos adequados às substâncias manipuladas, como luvas específicas e filtros ou lavadores de gases para as capelas.

No ambiente ocupacional é mais fácil se estabelecer o binômio causa efeito e a sintomatologia decorrente da exposição aguda e crônica às substâncias 
quimicas. Na exposição ambiental, esse binômio e consequentemente, a avaliação de risco são dificeis de serem determinados em decorrência da complexidade dessa exposição pela concomitância de toxicantes presentes no ar, água, solo e alimentos e dos fatores de confusão: hábito de fumar, uso de álcool, uso médico ou não-médico de fármacos e drogas de abuso (MILLER, 1996; HANSEN e col., 1998).

O dano resultante da presença de substâncias perigosas em determinado local de disposição depende da extensão da contaminação, da possibilidade de contato com a população, das vias de introdução, do número de suscetíveis no entorno - crianças e grávidas, da toxicidade das substâncias aí presentes e da devida persistência no meio ambiente (ANDELMAN e UNDERHILL, 1987; JOHNSON, 1997). Substâncias de elevada persistência podem provocar efeitos nocivos mesmo quando presentes em baixas concentrações.

Dentre as dez substâncias mais freqüentemente encontradas em locais de disposição e liberadas para o meio ambiente tem-se os metais como chumbo, arsênico, mercúrio e cádmio e os solventes clorados, como o clorofórmio (JOHNSON, 1997). A população do entorno desses locais, apesar das limitações dos estudos epidemiológicos ai realizados, apresentou maior prevalência de anomalias cardíacas, cefaléia, fadiga, distúrbios neurológicos, câncer de esôfago, estômago, cólon, reto e bexiga, além de malformações congênitas - de pequenas a moderadas (SEVER, 1977 , JOHNSON, 1997).

Pode haver discrepância entre os achados decorrentes de estudos ocupacionais dos observados na população em geral. Por exemplo, o cromo hexavalente é responsável pela perfuração de septo nasal, ulcerações de pele e câncer pulmonar em trabalhadores expostos. Contrariamente, essas doenças não foram observadas na população residente nas imediações de áreas contaminadas. A forma química, a via de introdução e a concentração podem variar dependendo das condições do local de disposição e do comportamento da população do 
entorno, dificultando o estabelecimento do risco nessa exposição (ANDERSON e col., 1993; FAGLIANO e col., 1997).

O estudo realizado por FAGLIANO e col. (1997) na população do entorno de locais de disposição de cromo no estado de New Jersey-EUA, evidenciou, através da determinação de cromo urinário, exposição estatisticamente significativa em crianças de idade inferior a 6 anos e em alguns adultos, demonstrando a necessidade de se priorizar a vigilância epidemiológica e avaliação de risco nestes locais.

Não é só a população do entorno que se encontra exposta a substâncias perigosas. Os funcionários dos aterros sanitários e industriais também são população de risco. Associações positivas foram determinadas entre a exposição no local de trabalho e sérios problemas de saúde, incluindo alterações do humor ansiedade, depressão e irritabilidade; neurológicas - cefaléia, tontura e letargia; respiratórias - irritação de garganta, tosse e bronquite crônica; dermatológicas; problemas auditivos (GELBERG,1997).

A Agency for Toxic Substances and Disease Registry -ATSDR, através de seus assessores de saúde, procura identificar os contaminantes dos locais de disposição e os potenciais efeitos tóxicos decorrentes desta exposição. Utiliza, sempre que disponivel, os níveis de risco mínimo como um instrumento de triagem na priorização da intervenção nos diversos locais avaliados. Este instrumento pode também identificar quais os locais de disposição que não oferecem risco à saúde da população (ASTDR, 2000; CHOU e WILLIAMSJOHSON, 1998).

Como a maioria dos NRMs contém um certo grau de incerteza devido a falta de dados toxicológicos precisos que incluam a população suscetível crianças, idosos, grávidas e os comprometidos nutricional ou imunologicamente, a ATSDR adota uma postura conservadora e protetora, assumindo que o homem é 
mais sensivel que os animais aos efeitos das substâncias perigosas, particularmente os suscetíveis, revisando-os periódica e rigorosamente.

É necessário, portanto, para se avaliar o impacto ambiental dos residuos gerados pelas Instituições avaliadas e dispostos inadequadamente qualificar e quantificar as substâncias presentes nos efluentes dessas instituições, bem como determinar seu potencial genotóxico. Os testes de mutagenicidade em misturas complexas podem ser usados como controle de qualidade e monitorização ambiental (UMBUZEIRO e ROUBICEK, in press)* . Em geral, utiliza-se o teste de Ames devido a sua simplicidade e rapidez. Porém, como esse teste apresenta limitações - o benzeno, por exemplo, reconhecidamente mutagênico, apresenta teste de Ames negativo - sua combinação com análises químicas para caracterizar as classes de substâncias químicas presentes no efluente, assim como, os principais mutágenos da mistura é de grande auxílio. Deve-se observar, ainda, que numa mistura de resíduos, os efeitos mutagênicos das substâncias químicas podem ser antagonistas, aditivos, sinérgicos, intensificando ou reduzindo a resposta laboratorial (DE MARINI, 1991).

Para minimizar os impactos ambientais e sobre a saúde dos analistas, os resíduos gerados devem ser tratados, o que implica na destinação de verbas para sua execução. Com relação ao tratamento das frações levantadas nas Instituições de estudo, a quantidade mensal de resíduo a ser incinerado - solventes inflamáveis, solventes clorados, dimetilformamida e resíduos contendo fenol, acrilamida e ácido cacodílico, sem se considerar o peso de tampões e água presente nas misturas - é de aproximadamente $309 \mathrm{Kg} / \mathrm{m}$ para a Instituição A, $279 \mathrm{Kg} / \mathrm{m}$ para a Instituição B e de $29 \mathrm{Kg} / \mathrm{m}$ para a Instituição C.

* Umbuzeiro GA, Roubicek DA Genotoxicidade ambiental. In: Zagatto P, Bertoletti E. Ecotoxicologia Aquática : bases e aplicações. [In Press]. 
Quanto ao resíduos corrosivos, a Instituição A utiliza $13.850 \mathrm{ml} / \mathrm{m}$ de ácidos concentrados e $2,7 \mathrm{Kg} / \mathrm{m}$ de hidróxidos; na Instituição B são consumidos $32.300 \mathrm{ml} / \mathrm{m}$ de ácidos concentrados e $1,799 \mathrm{Kg} / \mathrm{m}$ de hidróxidos; a Instituição $\mathrm{C}$ emprega $1287 \mathrm{ml} / \mathrm{m}$ de ácidos concentrados e $0,160 \mathrm{Kg} / \mathrm{m}$ de hidróxidos em suas análises. A neutralização dos resíduos gerados não impõe ônus adicional para a Instituição desde que se segregue ácidos e hidróxidos já utilizados para este fim.

O resíduo corrosivo contendo cloreto de antimônio, gerado na Instituição A, apresenta uma mistura de anidrido acético e clorofórmio. Neste caso deve-se consultar a unidade de incineração e se verificar se a mistura pode ser incinerada, uma vez que o tratamento para o antimônio requer a fervura do resíduo com silicatos o que promoveria a evaporação do clorofórmio, exigindo capelas adequadas para esta manipulação.

O restante dos resíduos corrosivos gerados contém iodo - o qual durante a análise é convertido a iodeto ou é nebulizado em capela química e portanto, não requer ou não pode ser tratado- e peróxido de hidrogênio, cujo tratamento sairia em torno de US\$ 28,35/mês para a Instituição B e US\$ $15,75 /$ mês para a Instituição $C$. As soluções utilizadas são bastante diluídas, de concentrações inferiores à $5 \%$, o que reduz ainda mais o custo desse tratamento.

Algumas substâncias reativas como os silanos e o borohidreto de sódio são inativadas com água, não onerando a Instituição. Os demais resíduos reativos produzidos despenderiam, no seu tratamento, US\$ 0,73 na Instituição A, US\$ 21,02 na Instituição B e US\$ 0,06 na Instituição C.

$\mathrm{O}$ custo do tratamento dos resíduos tóxicos, excetuando-se os que devem ser incinerados, seria de US\$ 148,08 para a Instituição $A$, dos quais US\$ 110,30 empregados no tratamento de gel ou tampão contendo brometo de etídio; US\$ 114,31 para a Instituição B, dos quais US\$ 41,11 utilizados no tratamento de gel 
ou tampão contendo brometo de etídio e, finalmente, de US\$ 5,73 para a Instituição C, aproximadamente.

Estima-se que o custo total do tratamento de resíduos seja de USR\$ 486,30 para a Instituição $\mathrm{A}$, envolvendo a incineração de resíduos perigosos $\mathrm{e} o$ tratamento dos demais resíduos químicos gerados. Como o volume de resíduos a serem incinerados é situado entre 300 e $500 \mathrm{Kg} / \mathrm{mês}$, é aconselhável incinerá-los bimensalmente, possibilitando a redução do custo para US\$ 339,60 mensais. Para a Instituição B, o custo total estimado é de cerca de US\$ 485,70 mensais, sendo despendido com a incineração US\$ 306,60 mensais, deste que o encaminhamento para a unidade de tratamento seja bimensal. Com relação a Instituição $\mathrm{C}$, estimase que o custo mensal seja de cerca de US $\$ 78,00$, desde que se proceda a incineração semestralmente a um custo de US\$ 343,40 .

Cumpre ressaltar que os custos de cada tratamento foram estimados utilizando-se reagentes pro análise da Sygma-Aldrich. Este procedimento foi adotado pela dificuldade em se obter cotações sem que houvesse a real intenção da aquisição. Entretanto, para o tratamento dos resíduos, os reagentes utilizados não precisam ser de elevado grau de pureza podendo, portanto, ser adquiridos por menor custo.

De acordo com algumas experiências internacionais, o tratamento dos resíduos dentro da própria instituição geradora reduz os custos e garante o cumprimento das exigências legais, ainda que exija treinamento e pessoal capacitado para fazê-lo. A Universidade de Indiana, por exemplo, economizou perto de US\$ 120.000 dólares ao ano quando adotou esta medida (KAUFFMANN, 1990).

A recuperação de solventes é uma alternativa a ser considerada. A terceirização deste procedimento só compensa quando o volume gerado é grande. Exige-se em geral, volumes superiores a $3000 \mathrm{~L}$ e condicional à mistura de 
solventes. O custo é entorno de R\$1,20 por litro retornado, com recuperação de $60-70 \%$ do volume encaminhado à recuperação. Soma-se a esse montante, uma taxa fixa de cerca de $\mathrm{R} \$ 300,00$, relativa aos custos de transporte, certificado de transporte de resíduos perigosos fornecido pela Cetesb (CATRI) e incineração da fração não recuperada.

Considerando os aspectos abordados, faz-se mister a criação de um programa educacional institucionalizado para a capacitação do responsável pela Instituição de modo que as exigências legais sejam cumpridas e não se configure nenhuma ação ou omissão que possa enquadrá-lo na Lei de crimes ambientais.

O programa educacional deve oferecer subsídios para que cada laboratório da instituição tenha um gestor ambiental, o qual junto com o analista poderá avaliar a periculosidade dos resíduos gerados, reconhecendo cada etapa do procedimento analítico, bem como o fundamento do método em questão e consequentemente, os produtos e subprodutos gerados durante a execução da análise, e a eventual modificação/minimização da periculosidade do resíduo gerado.

A constituição do gestor ambiental permite ainda que, na medida do possível, os resíduos gerados sejam tratados no local de geração. É fato que alguns tratamentos implicam em procedimentos complexos que exigem treinamento do analista e uso de equipamentos de proteção específicos; para outros resíduos, os procedimentos são simples, como para os sais de cianeto ou para os silanos, por exemplo. Os binômios risco/beneficio e custo/benefício devem ser estudados pela comissão de gerenciamento de resíduos ao se construir o programa de gerenciamento a ser adotado pela Instituição.

Dos comentários realizados pelos diferentes entrevistados, observa-se a necessidade de se constituir um programa formal, apoiado pela diretoria da instituição, onde a comissão possa ser identificada como fonte de informação e diálogo quanto à disposição em situação de rotina e emergência. Os treinamentos 
devem ser periódicos, principalmente aqueles que abordam procedimentos em situações emergenciais, de modo a condicionar o individuo e permitir que as decisões corretas sejam tomadas em caso de acidente, antes que o medo bloqueie sua ação. Neste caso, além do gestor ambiental, é interessante que mais de um analista realize o treinamento para que na ausência do gestor e em situações de emergência se proceda adequadamente.

Os modelos de regressão logística desenvolvidos oferecem subsídios para a elaboração dos programas educacionais, os quais devem propiciar ao analista o conhecimento da estratégia e etapas do gerenciamento, oferecer fontes de informação para a obtenção dos dados toxicológicos e das propriedades físicoquimicas das substâncias por ele manipuladas e treinamento para as situações de emergência - derramamento, incêndio e explosão.

A International Chemical Workers Union (ICWU) desenvolveu um programa de treinamento, de 4 a 5 dias, dirigido aos funcionários que manipulam respondem pela destinação de substâncias perigosas. Para encorajar a participação e o intercâmbio das informações obtidas, recomenda que 3 a 4 participantes de cada setor realize concomitantemente o curso. $\mathrm{O}$ número máximo é de 24 alunos por classe para se promover discussões e garantir uma relação adequada entre instrutor e participante (McQUINSTON e col., 1992).

O programa acima tem dois objetivos interrelacionados: educação imediata e a longo prazo. O programa ensina o trabalhador aonde encontrar as respostas às suas perguntas e como utilizar e interpretar o achado. Aproximadamente $60 \%$ do curso ocorre em sala de aula e envolve pequenos grupos de pesquisa, resolução de problemas e exercícios, avaliação das próprias condições de trabalho e procedimentos, vídeos interativos, encenações e discussões. Treinos especificos envolvendo o uso de equipamentos de proteção individual, manipulação de contêineres, técnicas de contenção de derramamentos, simulação de vazamentos de tambores e válvulas preenchem os $40 \%$ restantes do curso. 
McQUINSTON e col. (1992) mencionam que baseado nas idéias do educador brasileiro Paulo Freire, o processo educacional envolve a parceria entre os participantes e o instrutor, o qual atua como fonte de referência e não como um perito. Nesta estrutura, os participantes são deliberadamente convidados a expor as suas experiências - situações reais por ele vividas ou de seu conhecimento - a discutir as dificuldades em se alterar o seu local de trabalho, e a desenvolver estratégias para um pensar crítico e ação social.

Para instrumentalizar a atuação a longo prazo do participante, emprega-se os cartões de risco. Este cartão consiste num sistema visual de avaliação dos procedimentos e programas desenvolvidos nas empresas ou instituições de origem: vermelho, corresponde às áreas que necessitam de aprimoramento e verde, quando se atua com segurança naquele aspecto. Várias questões são levantadas: pronta resposta nas situações de emergência, percepção e comunicação do perigo, programas para uso e manutenção de equipamentos de proteção individual e coletiva; identificação correta dos contêineres de resíduos perigosos; fichas de segurança acessiveis a todos os trabalhadores e treinamento mensal da equipe de emergência, dentre outros.

Como última atividade de cada sessão de treinamento, os participantes provenientes do mesmo local de trabalho, utilizando os cartões de riscos, avaliam o desempenho de sua empresa ou instituição, elegendo posteriormente, duas áreas vermelhas como alvo prioritário de modificações. As razões dessa escolha e a estratégia a ser utilizada para corrigir as situações selecionadas são discutidas e reelaboradas em classe ao final do curso.

Finalmente, é desejável que se conduza testes pré e pós-treinamento de modo a permitir os ajustes necessários. Desta forma, estarão sendo dadas as condições para o efetivo gerenciamento de resíduos, que é, definitivamente, uma questão de segurança para o analista, para o meio ambiente e para a população. 


\section{CONCLUSÕES}

9.1 A identificação dos tipos e quantidades dos resíduos produzidos pelas instituições estudadas permitiu caracterizar que resíduos infectantes e especiais são por elas gerados em situação de rotina. A Instituição A gera cerca de 6 toneladas mensais de resíduos infectantes, constituídos basicamente por fluidos biológicos, cultura de células e meios de cultura. Nas demais Instituições, o volume de resíduo infectante gerado é variável em função da rotina ou da etapa da pesquisa a ser executada, não havendo dados disponíveis para estimar o volume mensal gerado. Dentre os resíduos especiais, as principais substâncias inflamáveis presentes nos resíduos gerados são éter etílico e xileno na Instituição A; metanol, etanol, acetonitrila, éter etílico, éter de petróleo e hexano na Instituição B e éter etílico e metanol na Instituição C. As principais substâncias corrosivas são o ácido sulfúrico e o hidróxido de sódio para a Instituição A e o ácido clorídrico e o hidróxido de sódio, para as Instituições B e C. As principais substâncias reativas são o anidrido acético para as Instituições A e B e sais de cianeto, para a Instituição C, sendo gerados em volumes reduzidos nas três instituições. Para as substâncias químicas classificadas como tóxicas, o clorofórmio é o principal solvente clorado presente nos resíduos gerados. Dos sais metálicos, os sais de mercúrio são os mais utilizados nas Instituições A e C e os sais de cromo, na Instituição B.

9.2 A avaliação do nível de conhecimento do corpo funcional das Instituições estudadas quanto às providências a serem adotadas em situação de emergência evidenciou que, respectivamente, 76,8\%, 83,4\% e $87,1 \%$ dos funcionários avaliados nas Instituições A, B e C procedem inadequadamente na ocorrência de derramamento de resíduos, especialmente os químicos. Em nenhuma das Instituições estudadas existe um programa de treinamento para situações de emergência devidamente formalizado, no entendimento de $53,3 \%$ do corpo funcional da Instituição A, 85,2\% da Instituição B e 100,0\% do corpo funcional da Instituição C. Da população estudada, cerca de $28 \%$ 
dos funcionários da Instituição A e aproximadamente $3 \%$ dos funcionários da Instituição B relatam haver participado de treinamentos contra incêndio ou promovidos pela CIPA. Pelas respostas oferecidas percebe-se que esses treinamentos não abrangem o derramamento de substâncias químicas e que procedimentos de emergência só foram oferecidos para os residuos infectantes.

9.3 Com base nas exigências legais e no conhecimento do estado da arte observou-se que 48,8 \% dos funcionários da Instituição $A, 44,5 \%$ dos funcionários da Instituição B e 100,0 \% dos funcionários da Instituição C procedem incorretamente o descarte de uma ou mais das substâncias ou materiais por eles manipulados, em situação de rotina. Considerando os resíduos infectantes, os procedimentos adotados pela Instituição A estão corretos; na Instituição $\mathrm{B}$, a inativação prévia desses resíduos é realizada na maioria de seus laboratórios; na Instituição $\mathrm{C}$, o tratamento prévio não ocorre. Para os resíduos especiais gerados em maior volume ou para as substâncias mais tóxicas, o procedimento adotado é correto nas Instituições A e B, onde o programa de gerenciamento já foi instituído. No entanto, ainda se descarta inadequadamente vários resíduos contendo substâncias perigosas. Na Instituição $A, 36,7 \%$ da população estudada afirma não haver recebido treinamento para o correto descarte contra os $71,3 \%$ da Instituição B. Na Instituição $\mathrm{C}$, o descarte dos resíduos perigosos gerados não atende às exigências legais.

9.4 O modelo de regressão logística utilizado para verificar a percepção do corpo funcional demonstrou uma associação importante entre a disposição adequada dos resíduos rotineiramente gerados e o conhecimento das etapas do gerenciamento e dos dados toxicológicos de cada substância manipulada, o treinamento para o correto descarte e o número de funcionários em cada laboratório. Em situação de emergência, existe uma associação significativa entre o correto procedimento no descarte de resíduos e a categoria do material 
manipulado, o conhecimento das etapas de gerenciamento e dos dados toxicológicos de cada substância manipulada.

9.5 O conhecimento sistematizado das interações das substâncias químicas com o organismo e os respectivos reflexos sobre a saúde, possibilita destacar que expressão da toxicidade de uma substância química está relacionada às condições de exposição e pode ser minimizada através da adoção de medidas adequadas durante o manuseio e descarte destas. Assim, o uso de equipamentos de proteção coletiva e individual torna-se imprescindivel para reduzir a exposição durante a realização das análises. Da mesma forma, o tratamento dos resíduos gerados minimiza a periculosidade desses residuos. Diversos tratamentos químicos podem ser executados na própria instituição geradora, a baixos custos e com bom rendimento. Com a adoção das medidas evita-se a observação dos quadros de intoxicação aguda e crônica decorrentes tanto da exposição ocupacional como ambiental;

9.6 A implantação de programa de gerenciamento institucional passa pela necessidade imperiosa de decisão política da Instituição e respectivo rebatimento em seu orçamento, dando suporte ao controle de estoques e aquisição de insumos; à identificação e classificação dos resíduos gerados, à correta segregação, acondicionamento e armazenamento em local adequado; ao tratamento de residuos e efluentes, à existência de treinamento periódico do corpo funcional para a disposição rotineira e emergencial. 


\section{RECOMENDAÇÕES}

Todo o processo de elaboração do trabalho, conhecimento das experiências existentes, cotejamento com o estado da arte e a análise dos dados obtidos permitiram identificar alguns pontos mais significativos e meritórios de recomendações.

Recomenda-se que o programa de gerenciamento de resíduos de laboratório a ser adotado contenha elementos básicos para sua criação, destacando-se, entre outros, a atribuição de responsabilidades; o levantamento quali e quantitativo dos residuos produzidos; a segregação das frações infectantes, perigosas ou radioativas; o estabelecimento de regras internas para a manipulação desses resíduos, envolvendo o acondicionamento, freqüência de coleta, e etiquetas de identificação dentre outros; a avaliação e escolha das melhores opções de tratamento e disposição e construção de um local de armazenamento adequado, contemplando às exigências legais.

Do mesmo modo, a preocupação com o treinamento faz recomendar que seja instituído programa de treinamento enfocando a identificação e classificação dos resíduos gerados; a manipulação desses resíduos, abrangendo o acondicionamento e o armazenamento; medidas de segurança, incluindo uso de equipamentos de proteção individual, higiene pessoal, precauções contra incêndio, procedimentos a serem adotados em situação de emergência, fichas de segurança acessíveis aos analistas e os correspondentes procedimentos administrativos envolvendo licenças para transporte dos resíduos, registros, comunicação de acidentes, derramamentos e incêndios com periodicidade, ao menos bimensal, nos treinamentos das equipes de emergência.

Recomenda-se, ainda, a adoção de micro-métodos, para minimizar o volume de resíduos gerados e para reduzir os gastos com tratamento e disposição. Nesse sentido, a instituição de cooperativas para encaminhamento conjunto dos resíduos a serem tratados e conseqüente rateio dos custos, deve ser estimulada. 


\section{REFERÊNCIAS *}

[ABNT] Associação Brasileira de Normas Técnicas. Norma NBR 10.004. Resíduos sólidos: classificação. São Paulo; 1985.

[ABNT] Associação Brasileira de Normas Técnicas. Normas de gestão da qualidade e garantia da qualidade - Diretrizes para seleção e uso. NB-9000, ISO - 9000. São Paulo; 1990.

[ABNT] Associação Brasileira de Normas Técnicas. Norma NBR 12.807. Resíduos de serviço de saúde: terminologia. São Paulo; 1993.

[ABNT] Associação Brasileira de Normas Técnicas. Norma NBR 12.808. Resíduos de serviço de saúde : classificação. São Paulo; 1993.

[ABNT] Associação Brasileira de Normas Técnicas. Norma NBR 12.809. Manuseio de serviços de saúde: procedimento. São Paulo; 1993.

[ABNT] Associação Brasileira de Normas Técnicas. Norma NBR 12.810. Coleta de resíduos de serviços de saúde: procedimento. São Paulo; 1993.

[ACS] American Chemical Society Task Force on Laboratory Waste Management. Laboratory waste management: a guide book. Washington (DC): American Chemical Society; 1994.

American Conference of Governmental Industrial Hygienists. 1999 TLVs e BEIs: limites de exposição (TLVs) para substâncias químicas e agentes físicos e índice biológicos de exposição (BEIs). Trad. Associação Brasileira de Higienistas Ocupacionais. Campinas; 1999.

Andelman JB, Underhill, DW. Health effects from hazardous waste sites. Chelsea: Lewis Publisher; 1987.

*De acordo com Cuenca AMB, Noronha DP, Ferraz MLEF, Andrade MTD. Guia de apresentação de teses. São Paulo: Biblioteca/CIR - FSP; 1998. 
Andersen ME. Development of physiologically based pharmacokinetic and physiologically based pharmacodynamic models for applications in toxicology and risk assessment. Toxicol Lett. 1995; 79: 35-44.

Anderson RA, Colton T, Doull J, Marks JG, Smith RG, Bruce GM, et al. Designing a biological monitoring program to assess community exposure to chromium: conclusions of an expert panel. J Toxicol Environ Health 1993; 40: 555-83.

Armour MA. Hazardous laboratory chemicals: disposal guide. Boca Raton: CRC Press; 1996.

[ATSDR] Agency for Toxic Substances and Disease Registry. Minimum risk levels (MRLs) for hazardous substances. [monograph on line]. Atlanta; 2000. Available from <URL: http:// www.astdr.cdc.gov.mrls.htm. [2000 Mar 29].

Bernabei D, Lautenschlaeger L. Seguridad: manual para el laboratorio. $2^{*}$ ed. Darmstadt: Git Verlag; 1998.

Black H. Menace of microbes. [Forum] Environ Health Perspect [serial on line] 2000;108 (2). Available from<URL: http:// ehpnet1 niehs. nih.gov/docs/2000/1082/forum.htlm\#mer > [2000 Mar 05].

Boatrigh DT, Edwards AJ, Shaver KA. A comprehensive biomedical survey. J Environ Health $1993 ; 35(6): 19-26$.

Bove FJ. Public drinking water contamination and birthweight, prematurity, fetal deaths and birth defects Toxicol Ind Health 1996; 12: 255-66.

Brasil. Lei n. 9605, de 12/02/98. Dispõe sobre as sanções penais e administrativas derivadas de condutas e atividades lesivas ao meio ambiente, e dá outras providências. Diário Oficial da República Federativa do Brasil, Brasília, 13 fev 1998. V. 136, n. 31 , p. 1-30.

Brasil. Normas regulamentadoras aprovadas pela Portaria 3214, de 8 de junho de 1978, atualizadas até 18/7/1997. In: Segurança e Medicina do Trabalho. $38^{\circ}$ ed. São Paulo: Atlas; 1997. NR-15. 
Bretherick L. Bretherick's handbook of reactive chemical hazards. $2^{\mathrm{a}}$ ed. London: Butterwoths; 1990.

Burke EL. A survey of recent literature on medical waste. J Environ Health 1992; 34 (9): 11-6.

Bush OM, Kovaliczn RA, Santi V. Lixo hospitalar: normas de manuseio. Ponta Grossa: Universidade Estadual de Ponta Grossa; 1991.

Byrns $G$, Burke T. Medical waste management implications for small medical facilities. J Environ Health 1992; 33(3): 11-9.

Carvalho JPP, Jales LS. Acidentes envolvendo riscos biológicos e infecções associados a trabalhos de laboratório. Rev. Bras. Saúde Ocup. 1981; 35: 19- 24.

[CDC - WHO] Center for Disease Control and Prevention, World Health Organization. Epi Info 6. Version 6.04b [computer program] Atlanta; 1997.

Cha DK, Song JS, Sarr D. Treatment technologies. Water Environ Res 1997; 69: 676-89.

Chou $\mathrm{CH}$, Williams-Johnson $\mathrm{M}$ Health effects classification and its role in the derivation of minimal risks levels: neurological effects. Toxicol Ind Health 1998; 14: 455-71.

Circulo de Trabajo de Laga de la Republica Federal de Alemania. Instructivo sobre la minimizacion y eliminacion de desechos de instituciones publicas y privadas del sector salud Costa Rica; 1992.

[CNEN] Comissão Nacional de Energia Nuclear. Gerência de rejeitos radioativos em instalações radioativas. Rio de Janeiro; 1985. (CNEN.NE-6.05).

[CNEN] Comissão Nacional de Energia Nuclear. Diretrizes de radioproteção. Rio de Janeiro; 1988. (CNEN.NE-3.01). 
[CONAMA] Conselho Nacional do Meio Ambiente. Resolução n. ${ }^{\circ}$, de 05/08/1993: define os procedimentos mínimos para o gerenciamento dos resíduos sólidos oriundos de serviços de saúde, portos e aeroportos. [on line]. Disponivel em: http// www.mma.gov.br/port/conama/res/res93/res0593.html. [2000, maio 27].

Coggon D, Pannett B, Wield G. Upper aerodigestive cancer in battery manufacturers and steel workers exposed to mineral acid mists. Occup Environ Med 1996; 53:445-49.

Costello RG, Emery RJ. A program for reducing risk when releasing potentially hazardous assets. J Environ Health 1994; 59 (2): 12-6.

Cuthel TJ. Spills in laboratories. In: Hansen DJ (editor) The work environment: healthcare, laboratories and biosafety. Boca Raton: Lewis Publishers; 1993. v 2. p. $127-49$.

[CVS] Centro de Vigilância Sanitária do Estado de São Paulo. Portaria CVS -01, de 18/01/2000: dispõe sobre condições de funcionamento dos laboratórios de análises e pesquisas clínicas, patologia clínica e congêneres, dos postos de coleta descentralizados aos mesmos vinculados, regulamenta os procedimentos de coleta de material humano realizados nos domicílios dos cidadãos, disciplina o transporte de material humano e dá outras providências. Diário Oficial do Estado de São Paulo, São Paulo, 19 jan. 2000. Seção I, Suplemento.

DeMarini DM. Environmental mutagens/complex mixtures, In: Li AP, Heflich RH. Genetic toxicology. Boca Raton, CRC Press, 1991, p 285-302. Apud: Klaassen, CD, Amdur MO, Doull J. Casarett and Doull's Toxicology: the basic science of poisons. $5^{\text {th }}$. ed. New York: McGraw-Hill; 1996. p. 292-3.

Derelanko MJ; Hollinger MA. CRC handbook of Toxicology. Boca Raton: CRC Press; 1995.

De Rosa CT, Stevens Y, Johnson B. Role of risk assessment in Public Health practice Toxicol Ind Health 1998; 14: 389-412.

Electron Microscopy Sciences. Chemicals.[on line] Pennsylvania. Available from<URL: http://www.emsdiasum.com/sem/chemicals/tannics.html\#22400> [2000 Mar 05]. 
Fagliano JÁ, Savrin J, Udasin I, Gochfeld M Community exposure and medical screening near chromium waste sites in New Jersey Regul. Toxicol. Pharmacol 1997; 26: S13-22.

Farland W, Dourson $M$. Non cancer endpoints: approaches to quantitative risk assessment. In: Cothern CR. Comparative environmental risk assessment. Boca Raton, Lewis Publisher; 1993. p. 87- 106.

Faustman EM; Omenn GS. Risk Assessment In: Klaassen, CD, Amdur MO, Doull J. Casarett and Doull's Toxicology: the basic science of poisons. $5^{\text {th }}$. ed. New York: McGraw-Hill; 1996. p. 75-88

Fields WJ Jr, Smith RE, Tran-Saltzman K, Leutzinger, WP, Hodges W, Masih ST, Morrison AG. University of Missouri-Kansas City Chemical Management Plan [monograph on line]. Kansas City; 1996. Available from <URL: http:// www.epa.gov/rgytgrnj/specinit/p2/conference/field1.htm>. [2000 Mar 29].

Fischhoff B, Bostrom A, Quadrel MJ. Risk perception and communication. Annu Rev Public Health 1993; 14: 183-203.

Fleming DO, Richardson $\mathrm{JH}$, Aulis JJ, Vesley D. Laboratory safety: principles and practices $2^{\text {nd }}$ ed. Washington (DC): American Society of Microbiology; 1993.

Formaggia DM. Resíduos de serviço de saúde . Rev Limp Publica 1994; 26: 920.

Furs AK. CRC Handbook of Laboratory safety. $2^{\text {nd }}$ ed. London: CRC Press; 1993.

Gerba CP, Rose JB. Estimating viral disease risk from drinking water. In: Cothern CR. Comparative environmental risk assessment. Boca Raton, Lewis Publisher; 1993. p. 117 - 35.

Gerlberg KH. Health study of New York City department of sanitation landfill employees. J Occup Med 1997; 39: 1103-10. 
Gersberg RM, Korth KG, Rice LE. Chemical and microbial evaluation of in-situ bioremediation of hydrocarbons in anoxic ground water enriched with nutrients and nitrate. World J Microbiol Biotechnol 1995; 11: 549- 58.

Hall RM, Watson T, Schwartz RE, Bryson NS, Davis, Jr RC. RCRA hazardous waste handbook. $6^{\text {th }}$ ed. Rockville: Government Institutes; 1989.

Hansel S, Castegnaro M, Sportouch, MH, De Méo M, Milhavet JC, Laget M, Duménil G. Chemical degradation of wastes of antineoplastic agentes: cyclophosphamide, ifosfamide e melphalan. Int Arch Occup Environ Health 1997; 69: 109-14.

Hansen H, De Rosa CT, Pohl H, Fay M, Mumtaz MM. Public Health challenges posed by chemical mixtures. Environ Health Perspect 1998; 106 (suppl 6): 1271-80.

Hatfield TH, David HO. Measuring source reduction of laboratory hazardous wastes. J Environ Health 1993; 34(3): 5-10.

Hytonen M, Martimo KP, Estlander T, Tupasela O. Occupational IgE-mediated rhinitis caused by ninhydrin. Allergy 1996; 51: 114-6.

INMETRO. NIE-DINQP-093. Critérios para o credenciamento de laboratório de ensaio segundo os Princípios das Boas Práticas de Laboratório. Rio de Janeiro; 1998.

International Standard Organization General requirements for the competence of testing and calibration laboratories ( revision of guide 25). London; 1998. (ISO/IEC guide, 17025)

International Technical Information Institute Toxic and Hazardous Industrial Chemicals safety manual. Tokyo; 1977.

Johnson B. Hazardous waste : human health effects. Toxicol Ind Health 1997; 13: 121-143.

Kaufmann J A. Waste disposal in academic institutions. $2^{\text {nd }}$ ed. Chelsea: Lewis Publishers;1990. 
Kriegman-King MR, Reinhard M. Transformation of carbon tetrachloride in the presence of sulfite, biotin and vermiculite. Environ Sci Techno. 1992; 26: 2198206.

Lauwerys $\mathrm{R}$, Bernard A, Roels $\mathrm{H}$, Buchet JP. Heath risk assessment of long-term exposure to non-genotoxic chemicals: application of biological indices. Toxicol Lett 1995; 77: 39-44.

Leite EMA. Solventes orgânicos. In: Oga S. Fundamentos de Toxicologia. São Paulo, Atheneu; 1996 .p. 187-229.

Lepera JS. Agentes metemoglobinizantes. In: Oga S. Fundamentos de Toxicologia. São Paulo, Atheneu; 1996 . p. 174-86.

Lewis RJ. Sax's dangerous properties of industrial materials. $8^{\text {th }}$. ed. New York: Van Nostrand Reinhold; 1992

Lowry LK. Role of biomarkers of exposure in the assessment of health risks. Toxicol Lett 1995; 77: 31-38.

Lunn G, Sansone EB. Destruction of hazardous chemicals in the laboratory. $2^{\text {nd }}$ ed. New York, John Wiley \& Sons; 1994.

Macgregor DG, Fleming R. Risk perception and symptom reporting. Risk Anal 1996; 16: $773-783$.

Marchese J. Medical waste disposal. In: Hansen DJ, editor The work environment: healthcare, laboratories and biosafety. Boca Raton: Lewis Publishers; 1993. v. 2, p. 151-68.

McQuiston TH, Coleman P, Wallerstein NB, Marcus AC, Morawetz JS, Ortlieb DW. Hazardous waste worker education. J Occup Med 1992; 34: 1410 - 26.

Merck Index: an encyclopedia of chemicals, drugs and biologicals. $12^{\text {th }} \mathrm{ed}$. Whitehouse Station: Merck \& Co.; 1996.

Merck International. Safety data sheets: ChemCAT [CD ROM]. Darmastad; 1998. 
Michigan State University. Office of Radiation, Chemical and Biological Safety. MSU biohazardous waste management plan. Michigan; 1999a. Available from <URL: http:/ www.orcbs.msu.edu/biological/biolsaf.htm > [2000 Jun 07].

Michigan State University. Office of Radiation, Chemical and Biological Safety. Radiation Safety Program Michigan, 1999 b. Available from <URL: http:// www.orcbs.msu.edu/radiation/rad saf.htm $>$ [2000 Jun 07].

Miller AB. Review of extant community-based epidemiologic studies on health effects of hazardous waste. Toxicol Ind Health 1996; 12: 225-33.

Morgan MG. Risk analysis and management. Sci Am 1993; 269: 24 - 30.

Nardocci A.C. Risco como instrumento de gestão ambiental. São Paulo; 1999. [Tese de Doutorado - Faculdade de Saúde Pública da USP].

[NRC] National Research Council. Committee on Environmental Epidemiology. Environmental epidemiology: public health and hazardous waste. Washington (DC): National Academy Press; 1991.

[NRC] National Research Council. Committee on Hazardous Substance in the Laboratory. Prudent practices in the laboratory: handling and disposal of chemicals. Washington (DC): National Academy Press; 1995.

Nava C. Worldwide overview of hazardous waste. Toxicol Ind Health 1996; 12: 127-38.

Neil N., Malmforms T., Slovic P. Intutitive toxicology: expert and lay judgments of chemical risks. Toxicol Pathol 1994: 22: $198-201$.

Oga, S. Fundamentos de toxicologia. São Paulo: Atheneu ; 1996

Oleckno WA. Guidelines for improving risk communication in environmental health. J Environ Health 1993; 36: 20-6. 
Pelnier I, Prevosto JM, Dusseau JY, Cheminel V, Renard C, Thefenne H, Thual A, Chaulet JF. Hygiène et securité au laboratoire: exemples dáctions menées dans le cadre dúme démarche dássurance qualité. Ann Biol Clin 1999; 57: 619 - 26.

Phifer RW, McTigue WR. Handbook of hazardous waste management for small quantity generators. Chelsea: Lewis Publishers; 1988.

Picot A, Grenouillet $P$. Safety in the chemistry and biochemistry laboratory. New York: Wiley-VCHH; 1995.

Pinholster G. Biomedical Research goes green [Forum] Env Health Perspect [serial on line] 2000; 108 (2). Available from<URL: http:// www. ehpnet 1.niehs.nih.gov/docs/2000/108-2/forum.htlm\#mer> [2000 Mar 05].

Pleus RC, Kathryn EK. Health effects of hazardous waste incineration facilities: Five case studies. Toxicol Ind. Health 1996; 12: 277-288.

Poirier MC, Beland FA. Determination of carcinogen-induced macromolecular adducts in animals and humans. Prog Exp Tumor Res 1987; 31: 1-10.

Prüss A, Giroult E, Rushbrook $P$. Safe management of wastes from health-care activities. Geneva: WHO; 1999.

Purdue University Chemical Management Committee. Purdue University Guidelines for handling and disposal of chemicals. Indiana, 1990.

Quigley DR. Handbook of emergency chemical management. Boca Raton: CRC Press; 1994.

Quillardet P, Hofnung $\mathrm{M}$ Ethidium bromide and safety - readers suggest alternative solutions Trends Genetic 1988; 4: 89.

Renwick AG. Data-derived safety factors for the evaluation of food aditives and environmental contaminants. Food Addit Contam 1993; 10: 275 - 305.

Risso WM. Gerenciamento de resíduos de serviços de saúde: a caracterização como instrumento básico para abordagem do problema. São Paulo; 1993. [Dissertação de Mestrado - Faculdade de Saúde Pública da USP]. 
Salgado, PET. Toxicologia dos metais. In: Oga S. Fundamentos de Toxicologia. São Paulo: Atheneu; 1996. p. 153-72.

Sambrook J, Fritsch EF Maniatis T. Molecular cloning: a laboratory manual. $2^{\text {th }}$ ed. Plainview: Cshl; 1989.

Sever LE. Environmental contamination and health effects: what is the evidence? Toxicol Ind Health 1997; 13: 145-61.

Sewell DL. Laboratory-associated infections and biosafety. Clin Microbiol Rev 1995; 8: 389- 405 .

Shukla Y, Anthony M, Gupta KP, Mehrotra NK. Tumor promoting activity of ninhidrin on mouse skin. Food Chem Toxicol 1994; 32 (7): 651-4.

Silverman GS. Control of hazardous waste at a small quantity generating university. J Environ Health 1992; 55(2):29-34.

Sokolowska J, Tyszka T. Perception and acceptance of technological environmental risks : why are poor countries less concerned? Risk Anal 1995: 15: $733-43$.

[SRA] Society for Risk Analysis. Glossary of risk analysis terms. McLean; 1999 Available from <URL: http://www. sra.org/gloss3.htm $>$ [2000 Nov 01].

Stata Corporation. Intercooled Stata- Statistics Data Analysis, versão 6.0. College Station; 1999.

Stricoff RS, Walters, DB. Handbook of laboratory health and safety. $2^{\text {th }}$ ed. New York: John Wiley \& Sons; 1995.

Sygma-Aldrich Química Brasil. Aldrich: catalog of handbook of fine chemicals 1998-1999. São Paulo: Aldrich Chemical.; 1998.

Tomes CPS TM System. Toxicology, Occupational Medicine and Environmental series. [CD Rom]. Micromedex, 1987-1999. 
[USDOE] US Department of Energy. Office of Environmental Management. Office of Technology Development. Flameless thermal oxidation. Savannah; 1995. Available from <URL: http:// www.em.doe gov/plumesfa/intech/flo/index.html $>$ [2000 Mar 07].

[USDHHS] U.S. Department of Health and Human Service. National Toxicology Program. $9^{\text {th }}$ Report on Carcinogens. North Carolina; 1998. Available from <URL: http://ehis.niehs.nih.gov/roc/toc9.html. [2000 May 20].

[USDHHS - CHSI] U.S. Department of Health and Human Service. National Toxicology Program. Chemical Health \& Safety Information. North Carolina; 2000. Available from <URL: http://ntp-server.niehs.nih.gov/Main_Pages/ChemHS.html. [2000 Mar 10].

[USEPA] U.S. Environmental Protection Agency Guide for infectious waste management. Report. Washington; 1986.

[USEPA] U.S. Environmental Protection Agency. Guides to pollution prevention: research and educational institutions. Report. Cincinnati; 1990 a.

[USEPA] U.S. Environmental Protection Agency. Guides to pollution prevention: selected hospital waste streams; Report. Cincinnati; 1990 b.

[USEPA] U.S. Environmental Protection Agency. Risk characterization: Practical guidance for National Center for Environmental Assessment. Washington, US EPA; 1996. In: World Health Organization Principles for the assessment of risks to human health from exposure to chemicals. Geneva, 1999. (Environmental Health Criteria 210).

[USEPA] U.S. Environmental Protection Agency and US Department of Energy. Labs for the $21^{\text {st }}$ century. [on-line]. Available from <URL: http:// www.epa.gov/21 centurylabs/index. html $>$ [2000 Mar 05].

[US NAS] National Academy of Science (1983) National Research Council, Committee on Institutional. Means for Assessment of Risks To Public Health: Risk Assessment in the Federal Government: Managing the process. Washington, DC, National Academy, Press, p 1-50. apud: World Health Organization Principles for the assessment of risks to human health from exposure to chemicals. Geneva, 1999. (Environmental. Health Criteria, 210). 
[USNIEHS] U S National Institute of Environmental Health Science. Health and safety waste manual [monograph on line]. USA: NIEHS; 1998. Available from

$<$ URL: http:// www.niehs. nih.gov/odshsb/wasteman/home.htlm >[2000 Mar 05].

Wada S, Ichikawa H, Tatsumi K. Removal of phenols from wastewater by soluble and immobilized tyrosinase. Biotechnol Bioeng 1993; 42: 854-58.

Watts RJ, Nubbe, ME, Hess, TF, Teel, AL, Jones, AP. Assessment, management and minimization. Water Environ Res 1997; 69: 669-675.

Wyes HW. Hazardous waste: its impact on human health in europe Toxicol Ind Health 1997; 13 : 109-19.

World Health Organization. International Programme on chemical safety - IPCS. Assessing human health risks of chemicals: derivation of guidance values for health-based exposure limits. Geneva, 1994. (Environmental. Health Criteria, 170).

World Health Organization. International Programme on chemical safety - IPCS.

Principles for evaluating chemical effects on the aged population. Geneva; 1993. (Environmental Health Criteria, 144).

World Health Organization. International Programme on chemical safety - IPCS. Principles for the assessment of risks to human health from exposure to chemicals. Geneva, 1999. (Environmental. Health, Criteria 210).

Yang RSH, El-Masri HÁ, Thomas RS, Constan AA, Tessari JD. The application of physiologically based pharmacokinetic/phamaocodynamic (PBPK/PD) modeling for exploring risk assessment approaches of chemical mistures. Toxicol Lett 1995; 79: 193-200.

Zilli M, Converti A, Lodi A Phenol removal from gases with a biological filter by Pseudomonas putida. Biotechnol Bioeng 1993; 41: 693-99. 


\section{ANEXO 1}

- Caracterização de resíduos químicos não listados

- Concentração máxima de alguns constituintes no lixiviado 


\section{Caracterização de resíduos químicos não listados na NBR 10.004}

Segundo a Norma, são considerados resíduos:

\section{1. inflamáveis:}

a) líquidos que apresentam ponto de fulgor inferior a $60^{\circ} \mathrm{C}$, excetuando-se as soluções aquosas com menos de $24 \%$ de álcool em volume;

b) não líquidos capazes de, nas CNTP, produzir fogo por fricção, absorção de umidade ou por alterações químicas espontâneas e, quando inflamada, queimar vigorosa e persistentemente, dificultando a extinção do fogo;

c) oxidantes definidos como substâncias que podem liberar oxigênio e, como resultado, estimular a combustão e aumentar a intensidade do fogo em outro material.

2. corrosivos:

a) soluções aquosas que apresentem $\mathrm{pH} \leq 2$ ou $\mathrm{pH} \geq 12,5$;

b) líquidos que corroam o aço ou corroer o aço (SAE 1020) a uma razão de $6,35 \mathrm{~mm}$ ao ano, a uma temperatura de $55^{\circ} \mathrm{C}$;

\section{3. reativos :}

a) os que são normalmente instáveis e reagem de forma violenta e imediata, sem detonar;

b) os que reagem violentamente com água ou formam com ela misturas potencialmente explosivas;

c) os que geram gases, vapores e fumos tóxicos em quantidades suficientes para provocar dano à saúde ou ao meio ambiente, quando misturados com água;

d) os que apresentam ânions cianeto ou sulfeto em sua constituição, os quais por reação, podem liberar gases, vapores ou fumos tóxicos em quantidades suficientes para provocar dano à saúde ou ao meio ambiente;

e) os capazes de produzir reação explosiva e detonante sob ação de forte estímulo, ação catalítica ou da temperatura em ambientes confinados;

f) os capazes de produzir, prontamente, reação ou decomposição detonante ou explosiva nas CNTP;

h) os explosivos. 


\section{4. tóxicos}

a) os que apresentam, quando testados, $\mathrm{DL}_{50}$ (oral, ratos) $<50 \mathrm{mg} / \mathrm{Kg}$ ou $\mathrm{CL}_{50}$ (via pulmonar, ratos) $<2 \mathrm{mg} / \mathrm{L}$ ou ainda, $\mathrm{DL}_{50}$ (via dérmica, coelhos) $<200 \mathrm{mg} / \mathrm{Kg}$;

b) aqueles cujo extrato obtido por lixiviação contiver qualquer um dos contaminantes da tabela abaixo. O procedimento de lixiviação para caracterizar a toxicidade consiste na extração do resíduo em fase aquosa, em $\mathrm{pH} \leq 5,0$, assim obtido pela adição de ácido acético. $\mathrm{O}$ extrato é analisado, quantificando-se diversas substâncias inorgânicas e orgânicas. O resultado obtido é comparado com os limites máximos apresentados no anexo G, Listagem 7 da NBR 10.004 .

Se sabemos que o resíduo não contém nenhum deste compostos então o teste não precisa ser realizado. 
Tabela A-1 - Limites máximos permitidos no extrato obtido por lixiviação do resíduo estudado

\begin{tabular}{|c|c|c|}
\hline \multirow{2}{*}{ Constituinte } & \multicolumn{2}{|c|}{$\begin{array}{c}\text { Concentração máxima } \\
\text { no lixiviado }(\mathrm{mg} / \mathrm{L})\end{array}$} \\
\hline & $\mathbf{E P A}^{\mathbf{a}}$ & NBR 10.004 \\
\hline Aldrin & - & 0,003 \\
\hline Arsênico & 5,0 & 5,0 \\
\hline Bário & 100,0 & 100,0 \\
\hline Benzeno & 0,5 & - \\
\hline Cádmio & 1,0 & 0,5 \\
\hline Chumbo & 5,0 & 5,0 \\
\hline Clordano & 0,03 & 0,03 \\
\hline Cloreto de vinila & 0,2 & 一 \\
\hline Clorobenzeno & 100,0 & - \\
\hline Clorofórmio & 6 & - \\
\hline Cresol & 200,0 & 一 \\
\hline Cromo & 5,0 & 5,0 \\
\hline 1,2-dicloretano & 0,5 & - \\
\hline 1,4-diclorobenzeno & 7,5 & - \\
\hline DDT & - & 0,1 \\
\hline 2,4-D & 10,0 & 10,0 \\
\hline Dieldrin & - & 0,003 \\
\hline 2,4-dinitrotolueno & 0,13 & - \\
\hline Endrin & 0,02 & 0,02 \\
\hline Epóxi-heptacloro & 0,01 & - \\
\hline Fluoreto & 150,0 & 一 \\
\hline Heptacloro & 0,008 & 0,01 \\
\hline Hexacloretano & 3 & - \\
\hline Hexaclorobenzeno & 0,13 & 0,001 \\
\hline Hexaclorobutadieno & 0,5 & - \\
\hline Lindano & 0,4 & 0,3 \\
\hline
\end{tabular}


Cont. Tabela A-1

\begin{tabular}{|c|c|c|}
\hline \multirow{2}{*}{ Constituinte } & \multicolumn{2}{|c|}{$\begin{array}{c}\text { Concentração máxima } \\
\text { no lixiviado }(\mathrm{mg} / \mathrm{L}) \\
\end{array}$} \\
\hline & EPA $^{a}$ & NBR 10.004 \\
\hline m-cresol & 200 & - \\
\hline Mercúrio & 0,2 & 一 \\
\hline Metil etil cetona & 200 & - \\
\hline Metoxicloro & 10,0 & 3,0 \\
\hline Nitrobenzeno & 2,0 & - \\
\hline o-cresol & 200 & - \\
\hline p-cresol & 200 & - \\
\hline Pentaclorofenol & 100 & 1,0 \\
\hline Piridina & 5,0 & - \\
\hline Prata & 5,0 & 5,0 \\
\hline Selênio & 1,0 & 1,0 \\
\hline Tetracloretileno & 0,7 & - \\
\hline tetracloreto de carbono & 0,5 & - \\
\hline Toxafeno & 0,5 & 0,5 \\
\hline Tricloretileno & 0,5 & - \\
\hline $2,4,5-\mathrm{T}$ & & 0,2 \\
\hline 2,4,5-TP(silvex) & 1,0 & 3,0 \\
\hline 2,4,5-triclorofenol & 400 & - \\
\hline 2,4,6-triclorofenol & 2,0 & - \\
\hline
\end{tabular}

Fonte :a: 40 CFR 261.25 citada pelo American Checimal Society Task Force on Laboratory Waste Management, 1994. b: ABNT-NBR- 10004 - Anexo G, listagem n. ${ }^{0} 7$. 


\section{ANEXO 2}

- Protocolo para identificação de substâncias químicas desconhecidas 
I aueıa A-L - rrotocolo para ıentılıcaçao de substäncias quimicas desconhecidas.

TESTE PROCEDIMENTO

reatividade com água adicionar uma pequena quantidade de amostra à água. Observar aparecimento de chama ou decomposição violenta, evolução de gás ou liberação de calor.

cianeto

sulfeto

pH

oxidantes

oxidante forte

peróxidos

redutor

inflamabilidade

solubilidade em água

halogênio

Fonte: ACS, 1994 misturar $2 \mathrm{ml}$ da amostra a $1 \mathrm{ml}$ de água destilada $+1 \mathrm{ml} \mathrm{de} \mathrm{NaOH} 10 \%+1 \mathrm{ml} \mathrm{de} \mathrm{FeSO}_{4} .10 \%+\mathrm{FeCl}_{3} 5 \%$. Acidificar a mistura com $\mathrm{H}_{2} \mathrm{SO} 4$ concentrado. $\mathrm{O}$ desenvolvimento de cor azul indicada a presença de cianeto. Este teste só deve ser realizado se o residuo apresentar $\mathrm{pH}>10$

adicionar 2 gotas de HCL $3 \mathrm{M}$ a 3 gotas do residuo e segurar uma tira de papel embebida em solução de acetato de chumbo sobre a mistura. O desenvolvimento de cor preta no papel indica sulfetos.

verificar o pH da solução ou do líquido em questão.

0 umedecer papel de amido iodetado primeiramente em HCL $1 \mathrm{~N}$ e depois, no residuo. O desenvolvimento de cor roxa indica substância oxidante.

- adicionar 0,1 a $0,2 \mathrm{~g}$ de $\mathrm{KI}$ ou $\mathrm{NaI}$ a $1 \mathrm{ml}$ de uma solução acídica $10 \%$ do residuo. o desenvolvimento de cor castanha indica a positividade.

adicionar uma quantidade pequena do resíduo a igual volume de $\mathrm{MgCl}_{2} \mathrm{e}$ água suficiente para dissolvê-los. Cor preta indica positividade.

D umedecer papel de amido iodetado em HCL $1 \mathrm{~N}$ e então, no resíduo. Deixar evaporar o solvente e adicionar uma gota de água. O desenvolvimento de cor escura indica a presença de hidroperóxidos.

e adicionar $\mathrm{l}$ ml de uma solução saturada de $\mathrm{KI}$ a $9 \mathrm{ml}$ de solventes, após agitação, o desenvolvimento de cor amarela intensa indica a formação de mais de $0,005 \%$ de peróxido

- umedecer fita 2,6-dicloroindofenol em água e, então, no resíduo. A descoloração da fita indica a positividade do teste

(2) utilizar uma fita de azul de metileno e proceder como descrito para redutor

- mergulhar um bastão de cerâmica no resíduo, deixar escorrer e aplicar e retirar um fósforo ou outra fonte de chama. Uma chama de aproximadamente 1,8 $\mathrm{cm}$ indica um resíduo inflamável. Uma chama menor que $1,8 \mathrm{~cm}$ indica um resíduo combustivel mais não característicamente inflamável.

- Colocar uma pequena porção da amostra $(<5 \mathrm{ml})$ num suporte de alumínio. Aplicar uma fonte de ignição por $30 \mathrm{~s}$. Se o material entrar em combustão, apresenta ponto de fulgor $<60^{\circ} \mathrm{C}$. Se não houver ignição, aplique a fonte por $1 \mathrm{~s}$, se o material queimar, é combustivel, ponto de fulgor entre 60 e $93{ }^{\circ} \mathrm{C}$

após testar a reatividade do residuo em água, misturar $\mathrm{lg}$ da amostra a $10 \mathrm{ml}$ de água. Observar o residuo e estime a solubilidade (insolúvel, parcialmente solúvel, solúvel). Se insolúvel, verifique a densidade. Liquidos orgânicos não halogenados são menos densos que a água.

aquecer um pedaço de fio de cobre sobre uma chama até que fique vermelho; limpar com água destilada. Mergulhar na amostra e aquecer na chama. A cor verde indica a positividade. 


\section{ANEXO3}

- Fluxograma para a caracterizaç̃o de substâncias químicas desconhecidas 


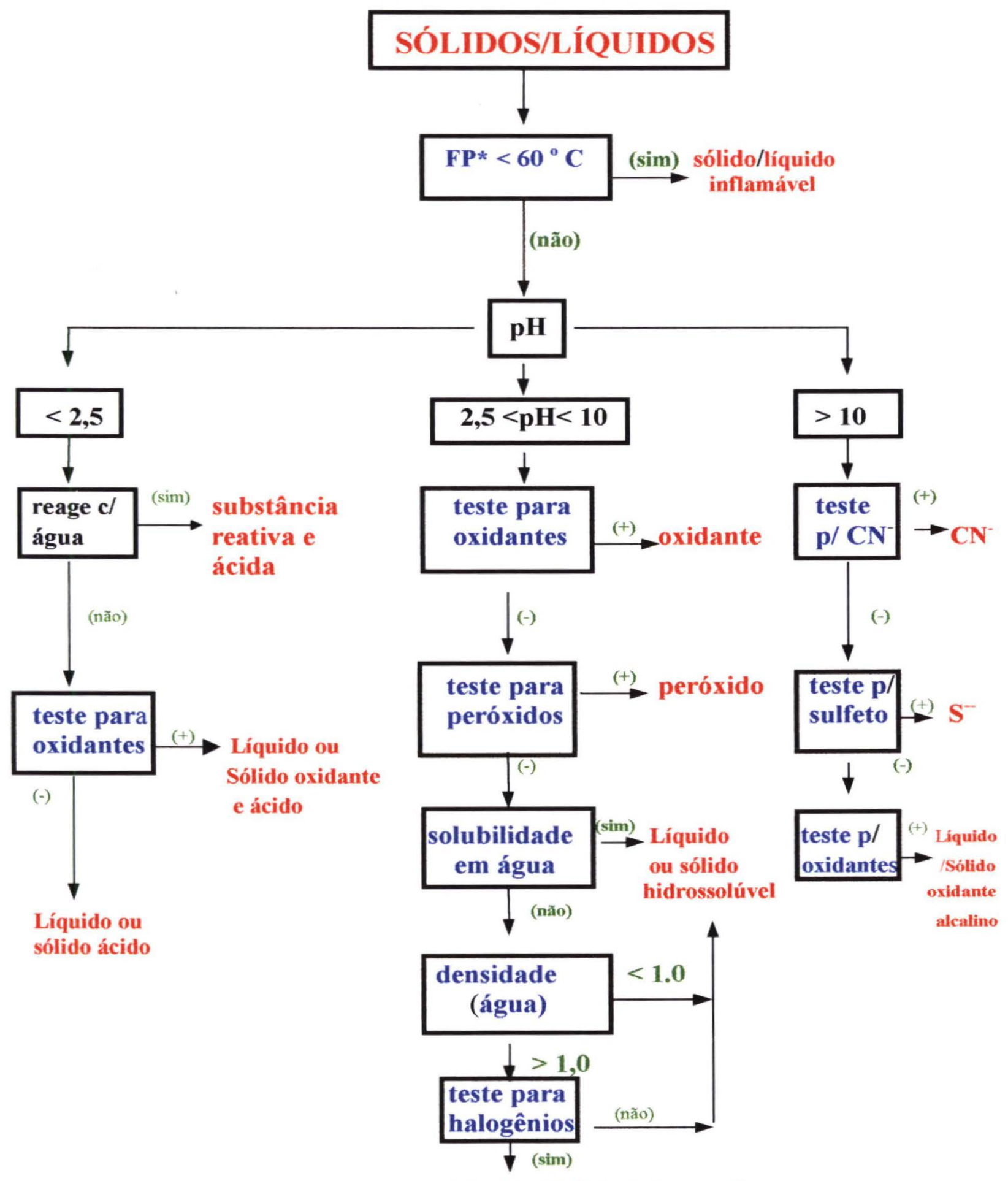

Líquido/ Sólido halogenado

Figura A-1 -Fluxograma para a caracterização de substâncias químicas desconhecidas. Fonte: National Research Council, 1995; modificado. *FP= ponto de fulgor 
Maria de Fátima Menezes Pedrozo

A10

ANEXO 4

- Tratamentos adotados para diferentes categorias de Resíduos de Serviço de Saúde. 
Tabela A-3 - Tratamentos adequados para as diferentes categorias de Resíduos de Serviço de Saúde.

\begin{tabular}{|c|c|c|c|c|c|c|}
\hline \multirow[b]{2}{*}{ Tecnologia ou método } & \multicolumn{6}{|c|}{ Categoria de resíduos } \\
\hline & $\begin{array}{c}\text { Infectantes } \\
\text { ripos A.1, A.2, e A.5* }\end{array}$ & $\begin{array}{c}\text { Infectantes } \\
\text { Tipos A.3 e A.5 }\end{array}$ & $\begin{array}{c}\text { Infectante } \\
\text { Tipo A.4 }\end{array}$ & $\begin{array}{c}\text { Farmacêutico } \\
\text { Tipo B.2 }\end{array}$ & $\begin{array}{c}\text { Químico perigoso } \\
\text { Tipo B.3 }\end{array}$ & $\begin{array}{c}\text { Radioativo } \\
\text { Tipo B.1 }\end{array}$ \\
\hline Forno rotativo & Sim & Sim & Sim & Sim & Sim & $\begin{array}{l}\text { Residuos de baixa } \\
\text { atividade }\end{array}$ \\
\hline Incinerador Pirolítico ${ }^{2}$ & Sim & Sim & Sim & $\begin{array}{l}\text { Pequenas } \\
\text { quantidades }\end{array}$ & $\begin{array}{l}\text { Pequenas } \\
\text { quantidades }\end{array}$ & $\begin{array}{l}\text { Resíduos de baixa } \\
\text { atividade }\end{array}$ \\
\hline $\begin{array}{l}\text { Incinerador de câmara } \\
\text { fixa }{ }^{3}\end{array}$ & Sim & Sim & Sim & Não & Não & $\begin{array}{l}\text { Residuos de baixa } \\
\text { atividade }\end{array}$ \\
\hline Desinfecção química & Sim & Não & Sim & Não & Não & Não \\
\hline Autoclavagem & Sim & Não & Sim & Não & Não & Não \\
\hline Estabilização & Não & Não & Não & Sim & Sim (metais) & Não \\
\hline Encapsulação ${ }^{4}$ & Não & Não & Sim & Sim & Não & Não \\
\hline Outros métodos & & & & $\begin{array}{l}\text { Devolver ao } \\
\text { fabricante }\end{array}$ & $\begin{array}{l}\text { Reações químicas } \\
\text { especificas }\end{array}$ & $\begin{array}{l}\text { Aguardar } 0 \\
\text { decaimento }\end{array}$ \\
\hline
\end{tabular}

Fonte: PRÜSS e col. (1999), adaptado

* Segundo classificação da ABNT- NBR 12.808, 1993

1- temperatura de incineração $1200-1600{ }^{\circ} \mathrm{C}$. Capacidade disponivel de 0.5 a 3 toneladas/h. Custo do equipamento e operacional elevados. Residuos e sub produtos de incineração altamente corrosivos, e a tubulação refratária exige manutenção freqüente.)

2- temperatura de incineração $800-900^{\circ} \mathrm{C}$. Capacidade disponivel de $200 \mathrm{Kg} / \mathrm{dia}$ a 10 toneladas $/ \mathrm{d}$.

3- temperatura de incineração $300-400{ }^{\circ} \mathrm{C}$. Capacidade disponivel de 100 a $200 \mathrm{Kg} / \mathrm{d}$.

4- resíduo misturado à argila, cimento, areia betuminosa, espuma plástica e após a secagem deste meio, os conteineres são selados e dispostos em aterro sanitário. 


\section{ANEXO 5}

- Algumas opçōes de tratamento de Resíduos de Serviço de Saúde - Vantagens e desvantagens 


\section{Método empregado}

Forno rotativo

Incinerador pirolítico

Incinerador de câmara fixa

Autoclavagem

Encapsulamento

Simples, baixo custo e segura

Custo relativamente baixo químicos e farmacêuticos farmacêuticos químicos são de baixo custo. pequenos.

Estabilizacão

\section{Desvantagens}

Alto investimento e custo

Adequado para os resíduos infectantes, para a maioria do

Eficiência de desinfeção elevada; adequado para todos os resíduos infectantes e para a maioria dos químicos e

Destruição incompleta de fármacos citotóxicos. Investimento e custo operacional relativamente alto.

Eficiência de desinfeção boa. Redução drástica do volume e peso dos resíduos. Resíduos podem ser dispostos no aterro sanitário. Custos de investimento e operacional relativamente baixos

Eficiência elevada na desinfeção quando realizada em boas condições de operação. Alguns desinfetantes

Custo do investimento e operacional relativamente

Fonte: PRUSS e col. (1999), adaptado
Emissões significativas de poluentes para a atmosfera. Necessidade de se remover periodicamente a escória e fuligem. Ineficiente na destruição de citotóxicos e algumas substâncias químicas.

Inadequado para fármacos e substâncias químicas. Requer pessoal treinado para o processo. Algumas substâncias utilizadas no processo são perigosas.

Inadequado para resíduos químicos, farmacêuticos, restos de animais, peças anatômicas e resíduos não permeáveis ao calor. Operação requer pessoal treinado.

Recomendado para material perfuro-cortante.

Requer técnico habilitado e uso de EPI 


\section{ANEXO 6}

- Utilização e eficácia de diferentes descontaminantes em laboratório 
Tabela A-5 - Utilização e eficácia dos diferentes descontaminantes em laboratórios clínicos e de pesquisa

\begin{tabular}{|c|c|c|c|c|c|c|c|c|c|c|c|c|c|c|c|c|}
\hline \multirow[b]{2}{*}{ Descontaminante } & \multicolumn{4}{|c|}{ Parâmetros utilizados } & \multicolumn{5}{|c|}{ Eficácia } & \multicolumn{7}{|c|}{ Características relevantes } \\
\hline & 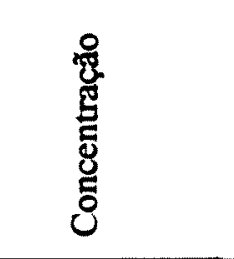 & 总 & 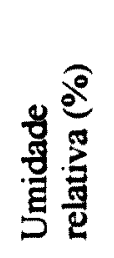 & 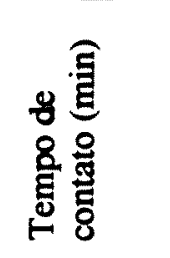 & 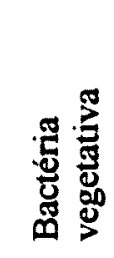 & 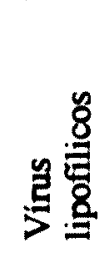 & 을 & 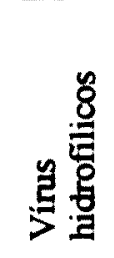 & 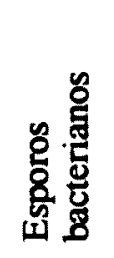 & 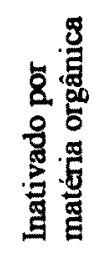 & 颍 & 旡 & 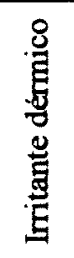 & 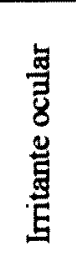 & 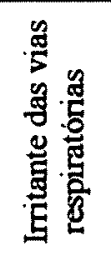 & 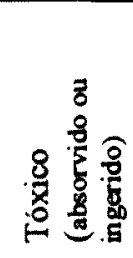 \\
\hline $\begin{array}{l}\text { Autoclave } \\
\qquad 1,05 \mathrm{Kg} / \mathrm{cm}^{2}\end{array}$ & Vapor saturado & 121 & & $50-90$ & + & + & + & + & + & & & & & & & \\
\hline $1,90 \mathrm{Kg} / \mathrm{cm}^{2}$ & Vapor saturado & 132 & & $10-20$ & + & + & + & + & + & & & & & & & \\
\hline Estufa & & $160-180$ & & $180-240$ & + & + & + & \pm & + & & & & & & & \\
\hline Incinerador & & $649-926$ & & $1-60 *$ & + & + & + & + & + & & & & & & & \\
\hline Radiação UV (253,7 nm) & $40 \mu \mathrm{W} / \mathrm{cm}^{2}$ & & & $10-30$ & + & & + & \pm & & + & & & + & + & & \\
\hline Óxido de etileno & $400-800 \mathrm{mg} / 1$ & $35-60$ & $30-60$ & $105-240$ & + & + & + & + & + & + & & + & & + & + & + \\
\hline $\begin{array}{l}\text { Composto de amônio } \\
\text { quatemário }\end{array}$ & $0,1-0,2 \%$ & $4-50$ & $<30$ & $8-60$ & + & + & + & + & + & + & & + & + & + & + & \\
\hline Compostos fenólicos & $0,2-3 \%$ & & & $10-30$ & + & + & + & \pm & & \pm & + & + & + & + & \pm & + \\
\hline $\begin{array}{l}\text { Alcool etílico ou } \\
\text { propílico }\end{array}$ & $70-85 \%$ & & & $10-30$ & + & + & + & \pm & & + & & & & + & & + \\
\hline Formaldeido $^{b}$ & $4-8 \%$ & & & $10-30$ & + & + & + & + & \pm & & + & & + & + & + & + \\
\hline Glutaraldeído & $2 \%$ & & & $10-600$ & + & + & + & + & + & & + & & + & + & + & + \\
\hline Peróxido de hidrogênio & $6 \%$ & & & $10-600$ & + & + & + & + & + & & + & + & + & + & & \\
\hline $\begin{array}{l}\text { Composto a base de } \\
\text { cloro }\end{array}$ & $0,01-5 \%$ & & & $10-30$ & + & + & + & + & \pm & + & \pm & + & + & + & + & + \\
\hline
\end{tabular}




\section{ANEXO 7}

- Incompatibilidade de substâncias químicas 


\begin{tabular}{|c|c|c|}
\hline número & Grupo químico & $\begin{array}{l}\text { Incompatível com os grupos } \\
\text { químicos representados pelos } \\
\text { números listados na primeira } \\
\text { coluna }\end{array}$ \\
\hline 1 & Ácidos inorgânicos & $\begin{array}{l}2,3,4,5,6,7,8,10,11,13,14,16- \\
19,21,22,23\end{array}$ \\
\hline 2 & Ácidos orgânicos & $1,3,4,7,14,16-19,22$ \\
\hline 3 & Cáusticos & $1,2,5,7,8,13-18,20,22,23$ \\
\hline 4 & Aminas e aminas alifáticas & $1,2,5,7,8,13-18,23$ \\
\hline 5 & Compostos halogenados & $1,3,4,11,14,17$ \\
\hline 6 & Álcoois, glicóis e éteres glicólicos & $1,7,14,16,20,23$ \\
\hline 7 & Aldeídos & $1,2,3,4,6,8,15-17,19,20,23$ \\
\hline 8 & Cetonas & $1,3,4,7,19,20$ \\
\hline 9 & Hidrocarbonetos saturados & 20 \\
\hline 10 & Hidrocarbonetos aromáticos & 1,20 \\
\hline 11 & Olefinas & $1,5,20$ \\
\hline 12 & Óleos derivados do petróleo & 20 \\
\hline 13 & Esteres & $1,3,4,19,20$ \\
\hline 14 & Monômeros, esteres polimerizáveis & $1,2,3,4,5,6,15,16,19-21,23$ \\
\hline 15 & Fenóis & $3,4,7,14,16,19,20$ \\
\hline 16 & Alquil óxidos & $1,2,3,4,6,7,14,15,17-19,23$ \\
\hline 17 & Cianidrinas & $1,2,3,4,5,7,16,19,23$ \\
\hline 18 & Nitrilas & $1,2,3,4,16,23$ \\
\hline 19 & Amônia & $1,2,7,8,13-17,20,23$ \\
\hline 20 & Halogênios & $3,6-15,19,21,22$ \\
\hline 21 & Éteres & $1,14,20$ \\
\hline 22 & Fósforo elementar & $1,2,3,20$ \\
\hline 23 & Anidridos ácidos & $1,3,4,6,7,14,16-19$ \\
\hline
\end{tabular}

Fonte: J. Hazardous Materials, 1:334, 1975 citado, como mencionado, por FURS, 1993. 


\section{ANEXO 8}

- Exemplos de reações entre resíduos incompatíveis 
Exemplos de resíduos potencialmente incompativeis. Estes resíduos quando misturados com outros materiais ou residuos podem produzir calor ou pressão, fogo ou explosão, reaçðes violentas. fumos. pós neblinas ou gases tóxicos, ou ainda. fumos ou gases inflamáveis (ACS, 1994).

Tabela A-7- Geração de calor ou reações violentas como resultado da mistura das substâncias listadas e identificadas como grupol-A com as do grupo 1-B.

\begin{tabular}{ll}
\hline grupo 1-A & grupo 1-B \\
\hline Resíduo de acetileno, & resíduo ácido, ácido ou água, \\
líquidos alcalinos cáusticos, & ácido de bateria, produtos químicos de limpeza \\
produto de limpeza alcalino, & eletrólito ácido, liquido ácido de gravação ou \\
liquido alcalino corrosivo, & solvente, resíduo de banho de ácido e outros \\
fluido de bateria alcalino corrosivo, & ácidos, corrosivos \\
resíduo aquoso cáustico, & \\
resíduo de cal e outros alcalis corrosivos & \\
\hline
\end{tabular}

Fonte : ACS, 1994.

Tabela A-8 - Explosão, fogo, geração de gás inflamável (hidrogênio) como conseqüências da mistura de materiais dos grupos 2-A com 2-B.

grupo 2-A grupo 2-B

alumínio, berilio, cádmio, lítio, magnésio, qualquer residuo listado nos grupos 1-A e 1-B.

potássio, sódio, pó de zinco, outros metais

reativos e hidretos metálicos

Tabela A-9 - Geração de gás cianídrico e sulfúrico como conseqüência da interação do grupo 3-A com 3-B.

\begin{tabular}{ll}
\hline grupo 3-A & Grupo 3-B \\
\hline $\begin{array}{l}\text { soluções já utilizadas contendo } \\
\text { cianeto e sulfeto }\end{array}$ & resíduos do grupo 1-B e ácidos em geral \\
\hline
\end{tabular}

Tabela A-10 - Explosão, fogo, geração de calor ou de gases inflamáveis ou tóxicos como conseqüência da interação entre os materiais do grupo 4-A com 4-B.

\begin{tabular}{ll}
\hline grupo 4-A & grupo-4B \\
\hline Alcoóis e água & qualquer residuo concentrado dos grupos 1-A e \\
& $1-\mathrm{B}$, cálcio, lítio, potássio, hidretos metálicos, \\
& $\mathrm{SO}_{2} \mathrm{Cl}_{2}, \quad \mathrm{SOCl}_{2}, \quad \mathrm{PCl}_{3}, \mathrm{CH}_{3} \mathrm{SiCl}_{3} \quad$ e outros \\
& residuos reativos com água \\
\hline
\end{tabular}


Tabela A-11 - Explosão, fogo e reações violentas como conseqüência da mistura de materiais listados no grupo 5-A com 5-B.

grupo 5-A grupo 5-B

Álcoois, aldeídos, hidrocarbonetos halogenados, resíduos dos grupos 1-A, 1-B e 2-A hidrocarbonetos nitrados, hidrocarbonetos

insaturados, outros compostos orgânicos reativos e solventes

Tabela A-12 - Explosão, fogo, reaç̃̃es violentas como conseqüência da reação entre substâncias do grupo 6-A com 6-B.

\begin{tabular}{ll}
\hline grupo 6-A & grupo 6-B \\
\hline Cloratos, cloro, ácidos minerais concentrados, & ácido acético, e outros ácidos orgânicos, \\
ácido cròmio, hipoclorito, fumos de ácido & cloretos, resíduos do grupo 2-A, resíduos do \\
nítrico, percloratos, permanganatos, peróxidos, & do grupo 2-A, resíduos grupo 4-A, outros \\
outros oxidantes fortes & resíduos combustiveis e inflamáveis \\
\hline
\end{tabular}

Fonte: ACS, 1994 


\section{ANEXO 9}

- Segregação de substâncias químicas de acordo com a classificação 


\section{Classificação das Substâncias químicas}

\section{Explosivas}

1.1. Com perigo de explosão em massa

1.2. Com perigo de projeção

1.3. Com perigo de incêndio, predominantemente

1.4. Sem deslocamento significativo de ar

1.5. Agentes detonadores

1.6. Substâncias detonantes de grande sensibilidades

2.1. Gases inflamáveis

2.2 Gases não inflamáveis

2.3 Gases tóxicos

3 Líquidas inflamáveis

4.1 Sólidas inflamáveis

4.2 Espontaneamente combustiveis

4.3 Perigo no contato com umidade

5.1 Substâncias oxidantes

5.2 Peróxidos orgânicos

6.1 Tóxicas

6.2 Agente infectante

7 Radioativas

8 Corrosivas

9 Outras menos perigosas

Exemplos de separação

\section{INDICAÇÕES}

A. LONGE DE: significa que devem estar separados de maneira que os materiais incompatíveis não possam atuar uns sobre os outros de forma perigosa em caso de acidente, mas podem ser colocados no mesmo compartimento.

B. SEPARADO DE: devem estar separados no mesmo compartimento

C. SEPARADO por um compartimento: exige-se uma separação longitudinal ou vertical constituida por um compartimento intermediário completo.

D. Separado longitudinalmente por compartimento intermediário grande ou frasco

$X$. não se recomenda separação especial.

\begin{tabular}{|c|l|l|c|l|c|}
\hline $\mathbf{N}^{\bullet}$ & \multicolumn{1}{|c|}{ classe } & + & $\mathbf{N}^{\bullet}$ & \multicolumn{1}{c|}{ classe } & Tipo de separação \\
\hline 4.1 & $\begin{array}{l}\text { Sólido } \\
\text { inflamável }\end{array}$ & + & 1 & Explosivo & $\mathbf{D}$ \\
\hline 3 & $\begin{array}{l}\text { Líquido } \\
\text { inflamável }\end{array}$ & + & 5.2 & Peróxido orgânico & $\mathbf{C}$ \\
\hline 6.1 & Tóxico & + & 1 & explosivo & $\mathbf{B}$ \\
\hline 4.1 & $\begin{array}{l}\text { Sólido } \\
\text { inflamável }\end{array}$ & + & $\mathbf{8}$ & Corrosivo & $\mathbf{A}$ \\
\hline
\end{tabular}

Fonte: BERNABEI e LAUTENSCHLAEGER, 1998.
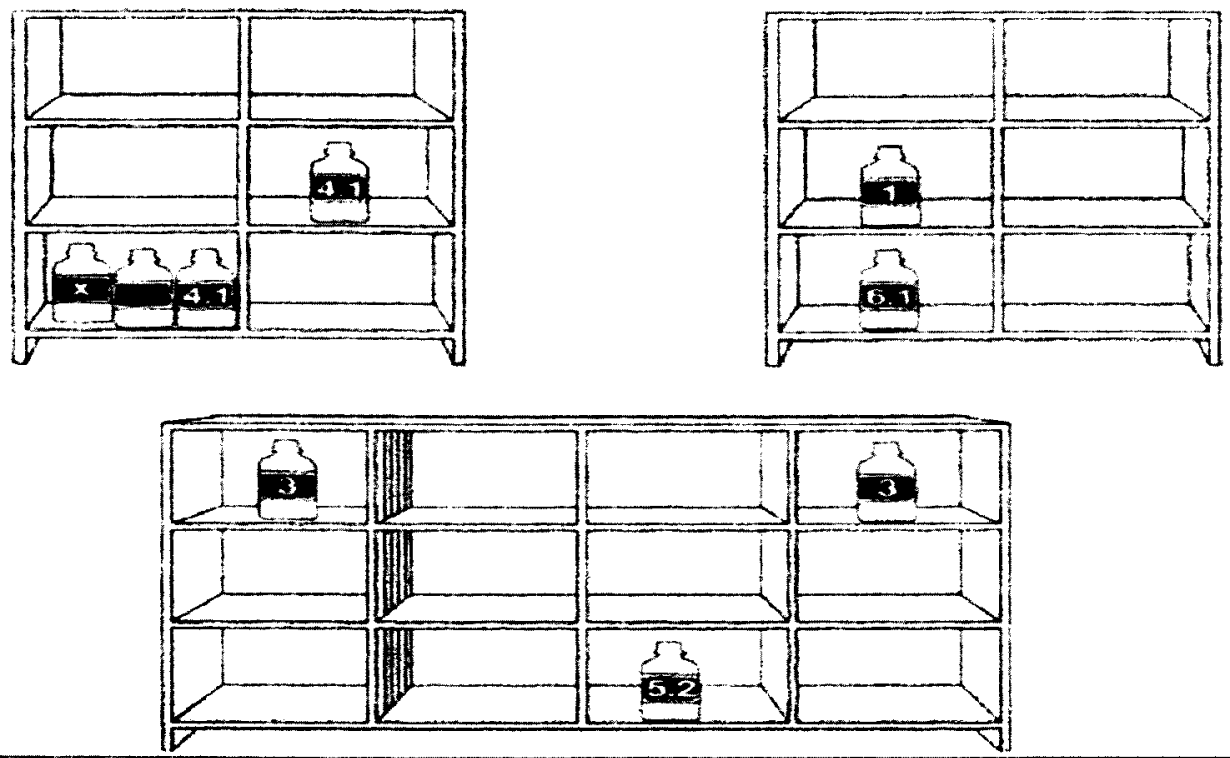
Quadro A-1 -Segregação de substâncias perigosas. requisitos a serem observados dependendo da classificação da substância.

\begin{tabular}{|c|c|c|c|c|c|c|c|c|c|c|c|c|c|c|c|c|c|}
\hline classe & \begin{tabular}{|l|}
1.1 \\
1.2 \\
1.5 \\
\end{tabular} & 1.3 & $\begin{array}{l}1.4 \\
1.6 \\
\end{array}$ & 2.1 & 2.2 & 2.3 & 3 & 4.1 & 4.2 & 4.3 & 5.1 & 5.2 & 6.1 & 6.2 & 7 & 8 & 9 \\
\hline Explosivos 1.1, 1.2, 1.5 & * & * & * & $\mathrm{D}$ & B & B & $\mathrm{D}$ & D & D & D & D & $\mathrm{D}$ & B & D & B & D & $\mathrm{x}$ \\
\hline Explosivos 1.3 & * & * & * & D & B & B & D & C & C & D & D & D & B & D & B & B & $\mathrm{X}$ \\
\hline Explosivos 1.4, 1.6 & * & * & * & $\mathrm{B}$ & $\mathrm{A}$ & A & B & B & B & B & B & B & $\mathrm{X}$ & D & B & $\mathrm{B}$ & $\mathrm{X}$ \\
\hline Gases Inflamáveis 2.1 & $\mathrm{D}$ & D & B & $\mathrm{X}$ & $\mathrm{X}$ & $\mathrm{X}$ & $\mathrm{B}$ & $\bar{A}$ & B & $\mathrm{X}$ & B & B & $\mathrm{X}$ & D & B & A & $\mathrm{X}$ \\
\hline $\begin{array}{l}\text { Gases não tóxicos, não } \\
\text { inflamáveis }\end{array}$ & B & B & A & $\mathrm{X}$ & $\mathrm{X}$ & $\mathrm{X}$ & $A$ & $\mathrm{X}$ & A & $\mathrm{X}$ & $\mathrm{X}$ & $A$ & $\mathrm{X}$ & B & $\mathrm{A}$ & $\mathrm{X}$ & $\mathrm{X}$ \\
\hline Gases tóxicos 2.3 & $\mathrm{~B}$ & $\mathrm{~B}$ & $\mathbf{A}$ & $\mathrm{X}$ & $\mathbf{X}$ & $\mathrm{X}$ & B & $\mathrm{X}$ & B & $\mathrm{X}$ & $\mathrm{X}$ & B & $\mathrm{X}$ & B & $\mathrm{A}$ & $\mathrm{X}$ & $\mathrm{X}$ \\
\hline Líquidos inflamáveis 3 & $\mathrm{D}$ & D & $\mathrm{B}$ & B & $\mathrm{A}$ & B & $\mathrm{X}$ & $\mathrm{X}$ & $\mathrm{B}$ & $\mathrm{A}$ & $\mathrm{B}$ & B & $\mathrm{X}$ & $\mathrm{C}$ & $\mathrm{B}$ & $\mathrm{X}$ & $\mathrm{X}$ \\
\hline Sólidos inflamáveis 4.1 & D & C & B & A & $\mathrm{X}$ & $\mathrm{X}$ & $\mathrm{X}$ & $\mathrm{X}$ & A & $\mathrm{X}$ & A & B & $\mathrm{X}$ & $\mathrm{C}$ & B & A & $\mathrm{X}$ \\
\hline $\begin{array}{l}\text { Substâncias de combustão } \\
\text { espontânea } 4.2\end{array}$ & D & $\mathrm{C}$ & B & $B$ & $\mathrm{~A}$ & B & $B$ & $\mathrm{~A}$ & $\mathrm{X}$ & $\bar{A}$ & B & B & A & $\mathrm{C}$ & B & A & $\mathrm{X}$ \\
\hline $\begin{array}{l}\text { Substâncias perigosas quando } \\
\text { em contato com umidade } 4.3\end{array}$ & D & D & B & $\mathrm{X}$ & $\mathrm{X}$ & $\mathrm{X}$ & A & $\mathrm{X}$ & A & $\mathrm{X}$ & B & $\mathrm{B}$ & $\mathrm{X}$ & B & B & $A$ & $\mathrm{X}$ \\
\hline Substâncias oxidantes 5.1 & D & D & B & B & $\mathrm{X}$ & $\mathrm{X}$ & B & A & B & B & $\mathrm{X}$ & B & A & $\mathrm{C}$ & A & B & $\mathrm{X}$ \\
\hline Peróxidos orgânicos 5.2 & D & $\mathrm{D}$ & $\mathrm{B}$ & B & $\mathrm{A}$ & B & $\mathrm{B}$ & $\mathrm{B}$ & $\mathrm{B}$ & $\mathrm{B}$ & B & $\mathrm{X}$ & A & $\mathrm{C}$ & B & $\mathrm{B}$ & \\
\hline Substâncias tóxicas 6.1 & B & B & $\mathrm{X}$ & $\mathrm{X}$ & $\mathrm{X}$ & $\mathrm{X}$ & $\mathrm{X}$ & $\mathrm{X}$ & A & $\mathrm{X}$ & A & A & $\mathrm{X}$ & A & $\mathrm{X}$ & $\mathrm{X}$ & $\mathrm{X}$ \\
\hline Material infectante 6.2 & D & D & $\mathrm{D}$ & D & B & B & C & $\mathrm{C}$ & C & B & $\mathrm{C}$ & $\mathrm{C}$ & A & $\mathrm{X}$ & $\mathrm{C}$ & C & $\mathrm{X}$ \\
\hline Material radioativo 7 & $\mathrm{~B}$ & $\mathrm{~B}$ & B & B & $\mathrm{A}$ & $\mathrm{A}$ & B & $\mathrm{B}$ & B & $\mathrm{B}$ & $\mathrm{A}$ & B & $\mathrm{X}$ & $\mathrm{C}$ & $\mathrm{X}$ & $\mathrm{B}$ & $\mathrm{X}$ \\
\hline Corrosivos 8 & D & B & B & A & $\mathrm{X}$ & $\mathrm{XB}$ & $\mathrm{X}$ & A & $\mathrm{A}$ & $\mathrm{A}$ & $\mathrm{B}$ & B & $\mathrm{X}$ & $\mathrm{C}$ & B & $\mathrm{X}$ & $\mathrm{X}$ \\
\hline Outros menos perigosos & $\mathrm{X}$ & $\mathrm{X}$ & $\mathrm{X}$ & $\mathrm{X}$ & $\mathrm{X}$ & $\mathrm{XB}$ & $\mathrm{X}$ & $\mathrm{X}$ & $\mathrm{X}$ & $\mathrm{X}$ & $\mathrm{X}$ & $\mathrm{X}$ & $\mathrm{X}$ & $\mathrm{X}$ & $\mathrm{X}$ & $\mathrm{X}$ & $\mathrm{X}$ \\
\hline
\end{tabular}

Fonte: 49 CFR 176.83 citado por ACS, 1994. 


\section{ANEXO 10}

- Roteiro de entrevista com membro da Comissão de gerenciamento de resíduos 
Roteiro de entrevista com membro da Comissão de gerenciamento de resíduos
ID: Instituição $A \square$
Instituição B $\square$
Instituição C $\square$

\section{Características da Instituição}

Atividade desenvolvida: $\quad$ Ensino/Pesquisa $\square$

Análise/Pesquisa $\square$

Número de laboratórios

Número de funcionários

Nível técnico

Nivel superior

Nivel administrativo

Linhas de pesquisa

Análises realizada

Comissão de Descartes:

Número de componentes

Formação dos componentes

Início da implantação do Programa

Fatores que levaram a sua implantação 
Dificuldades encontradas

Necessidade de treinamento

Quantos foram realizados?

Qual foi a abordagem?

Confecção de Manuais

Na implantação do programa foram encontrados frascos sem rótulo?

Qual a conduta adotada?

Características do gerenciamento:

1)como se procede a identificação e classificação dos resíduos?

2) Como se procede a segregação e acondicionamento dos resíduos perigosos?

2.1) Cada residuo é acondicionado separadamente? (exemplos)

2.2) Mantém-se registros dos resíduos gerados desde o local de geração até a destinação final dos mesmos? 
3) Há um local de armazenamento dos resíduos? Qual a sua característica?

4) Como os resíduos são transportados do local de geração ao local de armazenamento?

5) Como os resíduos são transportados do local de armazenamento ao local de disposição?

6) Freqüência do transporte interno e externo

7) Trata-se resíduos na Instituição? Quais? Tipo de Tratamento? Local de tratamento

8) Foi desenvolvido algum tipo de rótulo para classificação e disposição do resíduos?

9) Foram adotados procedimentos de segurança, específicos para o manuseio de resíduos?

10) Como lidam com incompatibilidades e extravasamento de resíduos, reagentes e materiais biológicos? 
11) Como lidam com situações de emergência (explosões, incêndios)?

12) Encontram-se disponíveis em cada laboratório as fichas de segurança de cada substância utilizada?

13) Foi adotada alguma política de minimização dos resíduos?

14) A aquisição das substâncias químicas utilizadas é centralizada ou é realizada diretamente por cada laboratório?

14.1) Existe algum programa de controle de estoque e monitorização das aquisições?

15) Antes da validação de uma nova metodologia, algum procedimento ou consulta à Comissão deve ser realizado?

16) Resíduos perigosos gerados / tratamento/disposição adotados

\begin{tabular}{|l|l|l|l|l|}
\hline Residuo & $\begin{array}{c}\text { Estado } \\
\text { fisico }\end{array}$ & $\begin{array}{c}\text { Quantidade } \\
\text { /mês }\end{array}$ & Tratamento & Disposição \\
\hline & & & & \\
\hline & & & & \\
\hline & & & & \\
\hline & & & & \\
\hline & & & & \\
\hline & & & & \\
\hline & & & & \\
\hline & & & & \\
\hline & & & & \\
\hline & & & & \\
\hline
\end{tabular}




\section{ANEXO 11}

- Roteiro de entrevista com o responsável pelo laboratório 


\section{Roteiro de entrevista com o responsável pelo laboratório}

ID: Instituição A $\square$

InstituiçãoB

InstituiçãoC

Número de funcionários

Nível técnico

Nível superior

Nível administrativo

Responsável : Formação:

Tempo na função:

Tempo de formado:

Sexo:

Idade:

1) Que tipo de análises são realizadas? Qual o número de análises realizadas?

2) Quais os resíduos gerados? Quantidade (Quadro)

3) Quais os cuidados no descarte deste resíduos? Por que? Oferece risco na exposição? (quadro)

4) Na sua opinião, qual a importância do gerenciamento de resíduos de laboratório?

5) A implantação do gerenciamento de resíduos:

a) exigiu treinamento dos seus funcionários?

b) dificultou ou interferiu na condução das análises?

c) Foi motivo de queixa?

6) Como se processa a aquisição de reagentes? Adquiri-se quantidades mínimas? 
7) O que se faz com materiais fora do prazo de validade?

8) Como se procede a lavagem da vidraria utilizada?

9) Na escolha da metodologia, para uma nova análise, leva-se em consideração os reagentes e volumes utilizados pensando no risco da exposição e resíduos gerados ?

10) Quando uma nova metotodologia é validada, existe algum tipo de treinamento? Qual?

11) As substâncias utilizadas são identificadas e classificadas para que o correto descarte de seus resíduos seja adotado?

12) Existe algum norma a ser seguida em situações de emergência (incêndio, explosões, derramamento de resíduos, falta de luz, etc)?

12.1) Os funcionários receberam algum treinamento ou curso para cumprimento dessas normas?

13) O laboratório dispõe das fichas de segurança de cada produto utilizado?

13.1) Quem é o responsável pela guarda das fichas de segurança?

14) Para a realização das análises, quais os procedimentos de segurança requeridos?

15) Estes procedimentos encontram-se por escrito? 
Quadro referente ao roteiro de entrevista com o responsável pelo laboratório

\begin{tabular}{|c|c|c|c|c|c|}
\hline $\begin{array}{l}\text { Resíduo gerado/ } \\
\text { Substância manipulada }\end{array}$ & \begin{tabular}{|l|} 
quantidade \\
/mês
\end{tabular} & $\begin{array}{l}\text { Estado } \\
\text { físico }\end{array}$ & cuidados & risco na exposição & descarte \\
\hline & & & & & \\
\hline & & & & & \\
\hline & & & & & \\
\hline & & & & & \\
\hline & & & & & \\
\hline & & & & & \\
\hline & & & & & \\
\hline & & & & & \\
\hline & & & & & \\
\hline & & & & & \\
\hline & & & & & \\
\hline & & & & & \\
\hline & & & & & \\
\hline
\end{tabular}




\section{ANEXO 12}

- Roteiro de entrevista com os técnicos e analistas 


\section{Roteiro de entrevista com os técnicos/analistas de laboratório}

$\begin{array}{lll}\text { ID: } \quad \text { Instituição A } & \text { Instituição B } \\ \text { Nivel : } & \text { técnico } \square & \text { Instituição } C \square \\ \text { Formação } & & \text { tempo de formado: } \\ \text { tempo na função: } & \text { número de análises realizadas: } \\ \text { Sexo: } & \text { Idade: }\end{array}$

1) Tipos de análise que realiza

2) Substâncias que manipula (Quadro)

3) Alguma delas é: (Quadro)

- explosiva

- inflamável

- corrosiva

- reativa

- oferece risco significativo de exposição

Quais efeitos pode provocar? (Quadro abaixo)

4) A manipulação destas substâncias requer algum cuidado especial? (Quadro abaixo)

5) No término da análise, como descarta o material utilizado? (Quadro abaixo)

5.1) Na sua opinião, o descarte realizado atende às exigências legais?

5.2) Deveria ser modificado? Como?

6) Você acha que o procedimento de descarte adotado é complicado?

7) Você acha o correto descarte necessário? Por que?

8) Como descarta soluções/reagentes que utiliza e estão fora da validade? 
8.1) Nos casos de derramamento de soluções/reagentes que utiliza, qual é o procedimento de descarte adotado?

9) Recebeu algum treinamento para a manipulação e descarte das substâncias que utiliza?

10) Existe um programa ou procedimento a ser adotado em situações de emergência? 10.1) Se sim, você realizou algum treinamento?

10.2) Em situações de emergência ( falta de luz, derramamento de substância, explosão, incêndio), quais medidas devem ser tomadas, considerando as análises que você realiza?

11) Existe alguma dificuldade/pressão na realização do seu trabalho (pressão, complexidade da análise, risco de contaminação, risco de explosão, incêndio, rapidez na liberação do resultado, etc.) ?

12) A implantação do gerenciamento de residuos dificultou/dificultaria ou interferiu/interferiria na execução de seu trabalho? 
Dados referentes às questões $2,3,4 e 5$ do roteiro de entrevista com técnicos e analistas de laboratório

\begin{tabular}{|c|c|c|c|c|c|}
\hline Substância & quantidade/mês & $\begin{array}{l}\text { Característica } \\
\text { da substância }\end{array}$ & Cuidados na manipulação & Efeitos tóxicos & $\begin{array}{l}\text { descarte } \\
\end{array}$ \\
\hline & & & & & \\
\hline & & & & & \\
\hline & & & & & \\
\hline & & & & & \\
\hline & & & & & \\
\hline & & & & & \\
\hline & & & & & \\
\hline & & & & & \\
\hline & & & & & \\
\hline & & & & & \\
\hline & & & & & \\
\hline & & & & & \\
\hline & & & & & \\
\hline & & & & & \\
\hline & & & & & \\
\hline
\end{tabular}


ANEXO 13

- Questionário para técnicos e analistas de laboratório 


\section{Questionário para técnicos/analistas de laboratório}

ID: $\quad$ Instituição A $\quad$ Instituição B $\quad$ Instituição

C

Nivel : técnico

Formação:

tempo na função:

Sexo: idade: $\square$ F

$\mathbf{M}$ superior $\square$

Tempo de formado:

Laboratório a que pertence:

1) Tipos de análise que realiza

2) Recebeu algum treinamento para a manipulação e descarte das substâncias que utiliza?

3) Existe um programa ou procedimento a ser adotado em situações de emergência?

3.1) Se sim, você realizou algum treinamento?

4) Em situações de emergência ( falta de luz, explosão, incêndio), quais medidas devem ser tomadas, considerando as análises que você realiza?

5) Existe alguma dificuldade/pressão na realização do seu trabalho (pressão, complexidade da análise, risco de contaminação, risco de explosão, incêndio, rapidez na liberação do resultado, etc.)?

6) Utilizando o quadro que se encontra no verso, liste, por gentileza, as substâncias que manipula, bem como a matriz onde a análise é realizada, especificando se alguma(s) delas é (são):

- Explosiva (EX), inflamável (IN), corrosiva(CR) ou reativa (RE)?

- Oferece risco significativo de exposição? De que tipo?

- Quais efeitos tóxicos pode $(\mathrm{m})$ provocar?

- A manipulação destas substâncias requer algum cuidado especial? 
7) Qual a importância de se proceder o correto descarte das substâncias manipuladas?

7.1) Na sua opinião, o descarte das substâncias utilizadas na análise atende às exigências Legais?

7.2.) Deveria ser modificado? Como?

8) A implantação do gerenciamento de resíduos dificultou/dificultaria ou interferiu/interferiria na execução de seu trabalho?

Quadro referente à pergunta número 6 .

\begin{tabular}{|c|c|c|c|c|}
\hline $\begin{array}{l}\text { Substância } \\
\text { manipulada }\end{array}$ & $\begin{array}{l}\text { Característica } \\
\text { da substância } \\
\text { (EX, IN, CR, RE) }\end{array}$ & $\begin{array}{c}\text { Risco na } \\
\text { exposição }\end{array}$ & Efeito Tóxico & $\begin{array}{l}\text { Cuidados na } \\
\text { manipulação }\end{array}$ \\
\hline & & & & \\
\hline & & & & \\
\hline & & & & \\
\hline & & & & \\
\hline & & & & \\
\hline & & & & \\
\hline & & & & \\
\hline & & & & \\
\hline & & & & \\
\hline & & & & \\
\hline & & & & \\
\hline & & & & \\
\hline & & & & \\
\hline
\end{tabular}

Obrigado pela atenção!

Nota: Se o espaço destinado à resposta de cada pergunta for insuficiente, por favor, utilize uma folha a parte. 


\section{ANEXO 14}

- Termo de consentimento 


\section{Termo de consentimento}

Trata-se de uma pesquisa qualitativa, desenvolvida pela doutoranda da Faculdade de Saúde Pública /USP, Maria de Fátima Pedrozo, sob Orientação do Prof. Dr. Arlindo Phillipi Junior, com o intuito de avaliar os procedimentos adotados no descarte de materiais, reagentes e soluções utilizados em laboratórios, em situação de rotina e emergência. Cumpre ressaltar que, tanto o nome da Instituição como o dos entrevistados permanecerão sob sigilo.

EU, tendo sido esclarecido da finalidade desta pesquisa e do sigilo das informaçðes aqui oferecidas, respondo voluntariamente às questões que me serão feitas.

São Paulo, / 1999. 


\section{ANEXO 15}

- Resíduos contendo substâncias inflamáveis gerados pelas Instituiçōes avaliadas 
Tabela A-13- Residuos contendo substâncias classificadas como inflamáveis gerados pela Instituição A e descarte adotado.

\begin{tabular}{|c|c|c|}
\hline Substância & Volume & Descarte adotado \\
\hline Acetato de etila & $6.100 \mathrm{ml} / \mathrm{m}$ & $\begin{array}{l}5.300 \mathrm{ml} / \mathrm{m} \text { - segregados para a comissão de descarte sendo } 5000 \mathrm{ml} / \mathrm{m} \mathrm{em} \text { mistura ao sulfato de cobre ou amônia e } 300 \mathrm{ml} / \mathrm{m} \\
\text { em mistura ao tolueno e ácido fórmico; } 120 \mathrm{ml} / \mathrm{m} \text { segregado } \mathrm{em} \text { mistura a acetonitrila e água }(70: 10: 30 \text { de acetato de etila); } \\
680 \mathrm{ml} / \mathrm{m} \text { - evaporados em capela química em mistura ao metanol e hidróxido de amônia. }\end{array}$ \\
\hline Acetona & $8.300 \mathrm{ml} / \mathrm{m}$ & $\begin{array}{l}4.450 \mathrm{ml} / \mathrm{m} \text { segregados para a comissão sendo que } 500 \mathrm{ml} / \mathrm{m} \mathrm{em} \text { mistura com agua, } 350 \mathrm{ml} / \mathrm{m} \text { em mistura com resíduos de } \\
\text { praguicidas organofosforados, clorados e cumarinicos, } 100 \mathrm{ml} / \mathrm{m} \mathrm{em} \text { mistura com o cloroformio; } 600 \mathrm{ml} / \mathrm{m} \mathrm{são} \mathrm{reutilizados} \\
\text { Restante descartado na rede de esgoto sendo que } 1.300 \mathrm{ml} / \mathrm{m} \text { dilujdos com hipoclorito e destes } 100 \mathrm{ml} / \mathrm{m} \text { são ainda } \\
\text { autoclavados antes do descarte. }\end{array}$ \\
\hline Acetonitrila & $12.000 \mathrm{ml} / \mathrm{m}$ & $\begin{array}{l}\text { Segregados para a comissão sendo que } 9.400 \mathrm{ml} / \mathrm{m} \text { em mistura com metanol , } 1.020 \mathrm{ml} / \mathrm{m} \text { em mistura com tampão fosfato, dos } \\
\text { quais } 200 \mathrm{ml} / \mathrm{m} \text { recolhidos em frasco único com mistura de solventes clorados e não clorados, dietilditiocarbamato de prata, 1- } \\
\text { naftol; } 950 \mathrm{ml} / \mathrm{m} \text { em mistura com acetato de etila e água, } 40 \mathrm{ml} / \mathrm{m} \text { em mistura com água e } 60 \mathrm{ml} / \mathrm{m} \text { segregados em frasco único } \\
\text { em mistura com ciclohexano, metanol, dietilditiocarbamato de prata em piridina e l-naftol. }\end{array}$ \\
\hline Álcool isoamílico & $4 \mathrm{ml} / \mathrm{m}$ & $\begin{array}{l}\text { Cerca de } 1 \mathrm{ml} / \mathrm{m} \text { descartado em saco autoclavável em mistura ao clorofórmio e depois, descartado como RSS; } \\
\text { Restante segregado em mistura ao fenol e clorofórmio. }\end{array}$ \\
\hline Benzeno & $7 \mathrm{ml} / \mathrm{m}$ & Utilizado para ressuspender extratos e evaporado em capela química \\
\hline Butanol & $1.150 \mathrm{ml} / \mathrm{m}$ & $\begin{array}{l}450 \mathrm{ml} / \mathrm{m} \text { segregados em mistura ao etanol, água e hidróxido de amônia; } \\
\text { Restante descartado na rede de esgoto, sendo que } 500 \mathrm{ml} / \mathrm{m} \text { em mistura com metanol, ferricianeto de potássio. }\end{array}$ \\
\hline Ciclohexano & $1.100 \mathrm{ml} / \mathrm{m}$ & $\begin{array}{l}600 \mathrm{ml} / \mathrm{m} \text { evaporados em capela em mistura ao tolueno e dietilamina; } \\
\text { Restante segregado em frasco único, misturados ao acetato de etila ácido acético, hidróxido de amônia, metanol, l-naftol e } \\
\text { dietilcarbamato de prata em piridina. }\end{array}$ \\
\hline Dietilamina & $80 \mathrm{ml} / \mathrm{m}$ & Evaporados em capela em mistura com ciclohexano e tolueno. \\
\hline $\begin{array}{l}\text { Dissulfeto de } \\
\text { carbono }\end{array}$ & $100 \mathrm{ml} / \mathrm{m}$ & Segregados \\
\hline
\end{tabular}


Cont. Tabela A-13

\begin{tabular}{|c|c|c|}
\hline Substância & Volume & Descarte adotado \\
\hline Etanol & $\begin{array}{l}\text { a. } 43.600 \\
\mathrm{ml} / \mathrm{m} \mathrm{p.a} \text {. } \\
\text { b. } 330 \mathrm{ml} / \mathrm{m} \\
\text { (comercial) }\end{array}$ & $\begin{array}{l}\text { a. } 384 \mathrm{ml} / \mathrm{m} \text { segregados, sendo } 150 \mathrm{ml} / \mathrm{m} \text { em mistura com ácido cloridrico e soda, } 225 \mathrm{ml} / \mathrm{m} \text { em mistura com butanol, água e } \\
\text { hidróxido de amônia, } 9 \mathrm{ml} / \mathrm{m} \text { em mistura com ácido pícrico e formol } \\
430 \mathrm{ml} / \mathrm{m} \text { evaporados em capela (solução aquosa } 50 \% \text { ou } 70 \%) ; 45 \mathrm{ml} / \mathrm{m} \text { autoclavado e descartado como RSS; } \\
\text { Restante descartado na rede de esgoto em diferentes diluições }(60,70,78,80,95 \% \text { ) sendo que } 7.500 \mathrm{ml} / \mathrm{m} \text { em mistura com } \\
\text { glicerina e } \mathrm{KOH} 30 \%, 840 \mathrm{ml} / \mathrm{m} \text { em mistura com acetona e; } 2.500 \mathrm{ml} / \mathrm{m} \text { em mistura com éter etílico; } 120 \mathrm{ml} / \mathrm{m} \text { em mistura } \\
\text { comácido acético; } 350 \mathrm{ml} / \mathrm{m} \mathrm{em} \mathrm{mistura} \mathrm{com} \mathrm{cloreto} \mathrm{férrico,} 2,2 \text {-bipirideno e EDTA; } \\
\text { b. } 330 \mathrm{ml} / \mathrm{m} \text { do comercial é destilado com NaOH e óxido de magnésio, e então, utilizado e descartado na rede de esgoto. }\end{array}$ \\
\hline Éter de petróleo & $\begin{array}{l}22.250 \mathrm{a} \\
27.250 \mathrm{ml} / \mathrm{m}\end{array}$ & $6.000 \mathrm{ml} / \mathrm{m}$ segregados; $5.000 \mathrm{ml} / \mathrm{m}$ reutilizados; restante evaporado em capela química \\
\hline Éter etílico & $132.500 \mathrm{ml} / \mathrm{m}$ & $\begin{array}{l}6.000 \mathrm{ml} / \mathrm{m} \text { - reutilizados (só se perde pela volatilização); } 64.000 \mathrm{ml} / \mathrm{m} \text { segregados; } \\
700 \mathrm{ml} / \mathrm{m} \text { descartados na rede de esgoto em mistura com formaldeído e fezes diluídos em hipoclorito; } \\
\text { Restante é evaporado em capela química. }\end{array}$ \\
\hline Formaldeido & $\begin{array}{l}792 \mathrm{ml} / \mathrm{m} \\
\text { (solução } 37 \% \text { ) }\end{array}$ & $\begin{array}{l}\text { Rede de esgoto sendo que } 784 \mathrm{ml} / \mathrm{m} \text { em mistura com éter e fezes; } 4 \mathrm{ml} / \mathrm{m} \text { oxidado a ácido fórmico e descartado em mistura ao } \\
\text { ácido acético, } 2 \mathrm{ml} / \mathrm{m} \mathrm{em} \mathrm{mistura} \mathrm{ao} \mathrm{NaOH} \text { e água; } 1 \mathrm{ml} / \mathrm{m} \text { segregado em mistura ao etanol e ácido pícrico. }\end{array}$ \\
\hline Heptano & $8.015 \mathrm{ml} / \mathrm{m}$ & $15 \mathrm{ml} / \mathrm{m}$ rede de esgoto em mistura com óleo mineral; Restante recuperado e reutilizado. \\
\hline Hexano & $10.500 \mathrm{ml} / \mathrm{m}$ & Cerca de $500 \mathrm{ml} / \mathrm{m}$ descartado na rede de esgoto; o restante segregado. \\
\hline Iodato de potássio & $1,3 \mathrm{~g} / \mathrm{m}$ & Rede de esgoto reduzido a iodeto em mistura com ácido sulfúrico, vitamina $\mathrm{C}$ oxidada, amido. \\
\hline Isopropanol & $30.700 \mathrm{ml} / \mathrm{m}$ & Rede de esgoto \\
\hline Metanol & $24.100 \mathrm{ml} / \mathrm{m}$ & $\begin{array}{l}\text { Cerca de } 15.800 \mathrm{ml} / \mathrm{m} \text { descartados na rede de esgoto sendo que } 400 \mathrm{ml} / \mathrm{m} \text { (solução diluída } 20 \% \text { ) em mistura ao ácido sulfúrico } \\
2 \% \text { ), } 3600 \mathrm{ml} / \mathrm{m} \text { em mistura com ácido acético e água, cerca de } 500 \mathrm{ml} / \mathrm{m} \text { em mistura ao ácido acético e glicerina, } 100 \mathrm{ml} / \mathrm{m} \\
\text { em mistura ao ácido sulfúrico, hidróxido de sódio, ferricianeto de potássio, } 1600 \mathrm{ml} / \mathrm{m} \text { diluído com água antes do descarte; } \\
\text { cerca de } 85 \mathrm{ml} / \mathrm{m} \text { evaporados em capela em mistura ao anisaldeído e ácidos acético e sulfúrico, cerca de } 80 \mathrm{ml} / \mathrm{m} \text { em mistura } \\
\text { ao acetato de etila e hidróxido de amônia evaporados em capela; }\end{array}$ \\
\hline
\end{tabular}


Cont. Tabela A-13

\begin{tabular}{lll}
\hline Substância & Volume & Descarte adotado \\
\hline Metanol & cerca de $7.900 \mathrm{ml} / \mathrm{m}$ segregados sendo $4.600 \mathrm{ml} / \mathrm{m}$ em mistura a acetonitrila, $2000 \mathrm{ml} / \mathrm{m}$ em mistura ao hidróxido de amônia \\
& $5 \%$, cerca de $130 \mathrm{ml} / \mathrm{m}$ em mistura ao tampáo fosfato, $100 \mathrm{ml} / \mathrm{m}$ em mistura com ácido sulfúrico, butanol, ferricianeto de \\
& potássio e hidróxido de sódio; outros $100 \mathrm{ml} / \mathrm{m}$ em mistura ao clorofórmio; cerca de $40 \mathrm{ml} / \mathrm{m}$ em mistura com água, $530 \mathrm{ml} / \mathrm{m}$ \\
em mistura com hidróxido de sódio $0,05 \mathrm{M}$, sulfato de tetrabutilamônio, acetonitrila em frasco único contendo solventes \\
clorados e não clorados, dietilditiocarbamato de prata, ácidos hidróxidos, 1 - naftol.
\end{tabular}

\section{Metiletilcetona $\quad 500 \mathrm{ml} / \mathrm{m} \quad$ Reutilizados várias vezes e depois segregado}

Metilisobutilcetona $1000 \mathrm{ml} / \mathrm{m}$ Segregados em mistura com matriz biológica (sangue) e pirrolidinaditiocarbamato de amônia.

Nitrato de amônia $1,25 \mathrm{~g} / \mathrm{m}$

Nitrito de sódio $\quad 0,062 \mathrm{~g} / \mathrm{m}$

Segregados para comissão em mistura ao cloreto de cobalto, tiocianato de potássio e tensoativo não iônico

\section{Permanganato de $2,8 \mathrm{~g} / \mathrm{m}$ potássio}

Piridina a. $600 \mathrm{ml} / \mathrm{m} \quad \begin{aligned} & \text { a. Segregados sendo que } 100 \mathrm{ml} / \mathrm{m} \text { em mistura ao dietilditiocarbamato de prata complexado com arsênico, aguardando decisão } \\ & \text { da comissão; Restante em frasco único contendo solventes clorados e não clorados, 1-naftol, ácidos, bases, dietilditiocarbamato. }\end{aligned}$ b. $20 \mathrm{ml} / \mathrm{sem} *$ b. segregados com outros solventes.

Tolueno $\quad 750 \mathrm{ml} / \mathrm{m} \quad 30 \mathrm{ml} / \mathrm{m}$ descartados na rede de esgoto em mistura com acetato de cobre e cuproína e $120 \mathrm{ml} / \mathrm{m}$ evaporados em capela em mistura com ciclohexano e dietilamina; $600 \mathrm{ml} / \mathrm{m}$ segregados em mistura ao acetato de etila e ácido fórmico.

Xileno $\quad 100.400 \mathrm{ml} / \mathrm{m} \quad 400 \mathrm{ml} / \mathrm{m}$ evaporados; Restante segregado (xilol) para a comissão de descarte

Nota: $\mathrm{ml} / \mathrm{m}=$ mililitro por mès e $\mathrm{g} / \mathrm{m}=$ gramas por mês; * utilizado uma única vez no semestre 
Tabela A-14- Residuos contendo substâncias classificadas como inflamáveis gerados pela Instituição B e descarte adotado.

\begin{tabular}{|c|c|c|}
\hline Substância & Volume & Descarte adotado \\
\hline Acetaldeído & $0,4 \mathrm{ml} / \mathrm{m}$ & Descartado na rede de esgoto em mistura com ácido sulfúrico, acético, difenilamina. \\
\hline Acetato de butila & $128 \mathrm{ml} / \mathrm{m}$ & Segregado em mistura ao butanol \\
\hline Acetato de etila & $9.800 \mathrm{ml} / \mathrm{m}$ & $\begin{array}{l}870 \mathrm{ml} / \mathrm{m} \text { - rede esgoto em mistura com hexano ou com urina tampão acetato, acetoacetato de etila; } 90 \mathrm{ml} / \mathrm{m} \text { - evaporados em } \\
\text { capela; } 8.840 \mathrm{ml} / \mathrm{m} \text { - segregados para a comissão a maior parte em mistura com clorofórmio, metanol, dimetilformamida, água, } \\
\text { ciclohexano. }\end{array}$ \\
\hline Acetona & $4.500 \mathrm{ml} / \mathrm{m}$ & $\begin{array}{l}1.100 \mathrm{ml} / \mathrm{m} \text { separados para a comissão, destes cerca de } 90 \mathrm{ml} \text { misturados ao clorofórmio e } 100 \mathrm{ml} \text { misturados ao clorofórmio e } \\
\text { isopropanol; Restante descartado na rede de esgoto. }\end{array}$ \\
\hline Acetonitrila & $27.500 \mathrm{ml} / \mathrm{m}$ & $\begin{array}{l}\text { Segregados para a comissão de descarte, destes } 24.000 \mathrm{ml} / \mathrm{m} \text { misturados à água, metanol, ácidos. Fosfórico ou tampão } \\
\text { trietanolamina, tetrahidrofurano, } 1.150 \mathrm{ml} / \mathrm{m} \text { misturados ao metanol e diclorometano, } 350 \mathrm{ml} / \mathrm{m} \text { em mistura ao clorofórmio e } \\
\text { metanol e } 270 \mathrm{ml} / \mathrm{m} \text { misturados ao ácido acético } 0,1 \% \text {. }\end{array}$ \\
\hline Álcool isoamílico & a. $64,5 \mathrm{ml} / \mathrm{m}$ & $\begin{array}{l}16 \mathrm{ml} / \mathrm{m} \text { segregados em mistura ao fenol e cloroformio; } 8,5 \mathrm{ml} / \mathrm{m} \text { descartados na rede de esgoto em mistura ao ácido } \\
\text { sulfanílico e } 40 \mathrm{ml} / \mathrm{m} \mathrm{em} \text { mistura com cloridrato de hidroxilamina }\end{array}$ \\
\hline & b. $10 \mathrm{ml} / \mathrm{a}$ & $10 \mathrm{ml} / \mathrm{a}$ - descartados na rede de esgoto em mistura com leite e ácido. \\
\hline Benzeno & $1000 \mathrm{ml} / \mathrm{m}$ & Menos de $20 \mathrm{ml} / \mathrm{m}$ evaporados na capela; Restante segregados para a Comissão de descarte \\
\hline Brometo de alila & $17,3 \mathrm{ml} / \mathrm{m}$ & Utilizado na reação de sintese, os subprodutos são descartados na rede de esgoto \\
\hline Butanol & $380 \mathrm{ml} / \mathrm{m}$ & $\begin{array}{l}30 \mathrm{~mL} / \mathrm{m} \text { - rede de esgoto em mistura com ácido Tiobarbitúrico e homogenato de tecido; } \\
\text { Restante segregados para a comissão em mistura com ácidos acético, acetona, água e acetato de butila, heptano. }\end{array}$ \\
\hline Ciclohexano & $750 \mathrm{ml} / \mathrm{m}$ & $\begin{array}{l}75 \mathrm{ml} / \mathrm{m} \text { descartados na rede de esgoto junto com NaCL e matriz biológica (sangue ou plasma) } \\
\text { Restante segregados sendo que cerca de } 500 \mathrm{ml} \text { misturado ao acetato de etila, } \mathrm{NH} 4 \mathrm{OH} \text {, etanol. }\end{array}$ \\
\hline Dietilamina & $240 \mathrm{ml} / \mathrm{m}$ & $\begin{array}{l}200 \mathrm{ml} / \mathrm{m} \text { - evaporados na capela } \\
40 \mathrm{ml} / \mathrm{m} \text { - segregados misturado ao hexano, isopropanol e ácido acético }\end{array}$ \\
\hline
\end{tabular}


Cont. Tabela A-14

\begin{tabular}{|c|c|c|}
\hline Substância & Volume & Descarte adotado \\
\hline Disobutilamina & $2 \mathrm{ml} / \mathrm{m}$ & Utilizado em síntese química \\
\hline Etanol & $30.900 \mathrm{ml} / \mathrm{m}$ & $\begin{array}{l}5000 \mathrm{ml} / \mathrm{m} \text { evaporados em capela; } \\
\text { restante descartado na rede de esgoto ou utilizado para limpeza de bancadas }\end{array}$ \\
\hline Éter de petróleo & $21.250 \mathrm{ml} / \mathrm{m}$ & $\begin{array}{l}12.000 \mathrm{ml} / \mathrm{m} \text { reutilizados; } 3500 \mathrm{ml} / \mathrm{m} \text { descartado na rede de esgoto; } 2000 \mathrm{ml} / \mathrm{m} \text { concentrados no rotavapor-parte vai para rede } \\
\text { de esgoto; restante segregado. }\end{array}$ \\
\hline Éter etilico & $26.100 \mathrm{ml} / \mathrm{m}$ & $\begin{array}{l}7000 \mathrm{ml} / \mathrm{m} \text { - reutilizados; } 2000 \mathrm{ml} / \mathrm{m} \text { - utilizados para anestesiar animais (evaporados); } 400 \mathrm{ml} / \mathrm{m} \text { evaporados em capela; } 3000 \\
\mathrm{ml} / \mathrm{m} \text { - concentrados no rotavapor, parte vai para a rede de esgoto; } 500 \mathrm{ml} / \mathrm{m} \text { descartados na rede de esgoto; restante segregado. }\end{array}$ \\
\hline Formaldeído & $505 \mathrm{ml} / \mathrm{m}$ & $\begin{array}{l}200 \mathrm{ml} / \mathrm{m} \text { evaporados em capela; } 5 \mathrm{ml} / \mathrm{m} \text { descartados na rede de esgoto misturados a } 35 \mathrm{ml} / \mathrm{m} \text { de metanol; } \\
300 \mathrm{ml} / \mathrm{m} \text { - diluídos } 10 \% \text { e utilizados em assepsia. }\end{array}$ \\
\hline Heptano & $530 \mathrm{ml} / \mathrm{m}$ & Segregados sendo que $220 \mathrm{ml} / \mathrm{m}$ em mistura com acetato de etila e $110 \mathrm{ml} / \mathrm{m}$ em mistura com butanol e ácido acético. \\
\hline Hexano & $25.900 \mathrm{ml} / \mathrm{m}$ & $\begin{array}{l}\text { Cerca de } 980 \mathrm{ml} / \mathrm{m} \text { - evaporados em capela;1 } 20 \mathrm{ml} / \mathrm{m} \text { evaporados no rotavapor; } \\
100 \mathrm{~mL} / \mathrm{m} \text { descartados na rede de esgoto com } 10 \mathrm{ml} \text { de ácido clorídrico } 1 \mathrm{M} ; 4000 \mathrm{ml} / \mathrm{m} \text { descartados na rede de esgoto em } \\
\text { mistura com o acetato de etila; restante segregado sendo } 250 \mathrm{ml} / \mathrm{m} \text { misturados com éter, } 9000 \text { ml } / \mathrm{m} \text { misturados com } \\
\text { isopropanol, ácido acético, água e dietilamina, } 2.500 \mathrm{ml} / \mathrm{m} \text { misturados com isopropanol, } 125 \mathrm{ml} / \mathrm{mm} \text { misturados com éter etilico } \\
\text { e acetonitrila e } 1000 \mathrm{ml} / \mathrm{m} \text { misturados ao metanol. }\end{array}$ \\
\hline Isopropanol & $4.100 \mathrm{ml} / \mathrm{m}$ & $\begin{array}{l}\text { Cerca de } 50 \mathrm{ml} / \mathrm{m} \text { descartados na rede de esgoto, destes } 30 \mathrm{ml} \text { misturados ao clorofórmio; Cerca de } 30 \mathrm{ml} / \mathrm{m} \text { autoclavados e } \\
\text { descartados como RSS; restante segregado misturado ao hexano, água, ácido acético e dietilamina. }\end{array}$ \\
\hline Metanol & $55.700 \mathrm{ml} / \mathrm{m}$ & $\begin{array}{l}4.200 \mathrm{ml} / \mathrm{m} \text { descartados na rede de esgoto; cerca de } 330 \mathrm{ml} / \mathrm{m} \text { evaporados em capela; } 600 \mathrm{ml} / \mathrm{m} \text { concentrados no rotavapor, } \\
\text { perda, devido ao vácuo, para rede de esgoto; r estante segregado sendo } 12.600 \mathrm{ml} / \mathrm{m} \text { misturados a } 1.400 \mathrm{ml} \text { de água; } 12.000 \\
\mathrm{ml} / \mathrm{m} \text { em mistura com água, acetonitrila, ácido fosfórico; } 2000 \mathrm{ml} / \mathrm{m} \text { em mistura com clorofórmio e acetato de etila; cerca de } \\
600 \mathrm{ml} / \mathrm{m} \text { em mistura com } \mathrm{KCL} ; 1000 \mathrm{ml} / \mathrm{m} \text { em mistura com acetato de lítio } 20 \mathrm{mM} ; 1.875 \mathrm{ml} / \mathrm{a} \text { rede de esgoto em mistura } \\
\text { com sulfato de cobre } 10 \% \text {. }\end{array}$ \\
\hline Metilisobutilcetona & $85 \mathrm{ml} / \mathrm{m}^{*}$ & Segregados \\
\hline
\end{tabular}

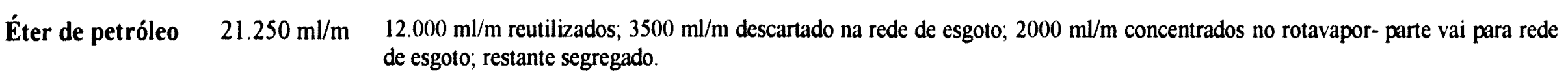

Éter etilico $\quad 26.100 \mathrm{ml} / \mathrm{m} \quad 7000 \mathrm{ml} / \mathrm{m}$ - reutilizados; $2000 \mathrm{ml} / \mathrm{m}$ - utilizados para anestesiar animais (evaporados); $400 \mathrm{ml} / \mathrm{m}$ evaporados em capela; 3000 $\mathrm{ml} / \mathrm{m}$ - concentrados no rotavapor, parte vai para a rede de esgoto; $500 \mathrm{ml} / \mathrm{m}$ descartados na rede de esgoto; restante segregado.

$200 \mathrm{ml} / \mathrm{m}$ evaporados em capela; $5 \mathrm{ml} / \mathrm{m}$ descartados na rede de esgoto misturados a $35 \mathrm{ml} / \mathrm{m}$ de metanol;

$/ \mathrm{m}$ - diluidos $10 \%$ e utilizados em assepsia.

Heptano

$530 \mathrm{ml} / \mathrm{m}$

Cerca de $980 \mathrm{ml} / \mathrm{m}$ - evaporados em capela; $120 \mathrm{ml} / \mathrm{m}$ evaporados no rotavapor; isopropanol, ácido acético, água e dietilamina, $2.500 \mathrm{ml} / \mathrm{m}$ misturados com isopropanol, $125 \mathrm{ml} / \mathrm{m}$ misturados com éter etilico e acetonitrila e $1000 \mathrm{ml} / \mathrm{m}$ misturados ao metanol.

descartados como RSS; restante segregado misturado ao hexano, água, ácido acético e dietilamina.

perda, devido ao vácuo, para rede de esgoto; $r$ estante segregado sendo $12.600 \mathrm{ml} / \mathrm{m}$ misturados a $1.400 \mathrm{ml}$ de água; 12.000 $\mathrm{ml} / \mathrm{m}$ em mistura com água, acetonitrila, ácido fosfórico; $2000 \mathrm{ml} / \mathrm{m}$ em mistura com clorofórmio e acetato de etila; cerca de $600 \mathrm{ml} / \mathrm{m}$ em mistura com KCL; $1000 \mathrm{ml} / \mathrm{m}$ em mistura com acetato de lítio $20 \mathrm{mM} ; 1.875 \mathrm{ml} / \mathrm{a}$ rede de esgoto em mistura sulfato de cobre $10 \%$ 
Cont. Tabela A-14

\section{Substância}

Volume

\section{Descarte adotado}

Piridina $\quad 300 \mathrm{ml} / \mathrm{a} \quad 150 \mathrm{ml}$ - descartados com hipoclorito; $150 \mathrm{ml}$ descartados em mistura ao dietilditiocarbamato de prata.

Tetrahidrofurano $4.000 \mathrm{ml} / \mathrm{m} \quad 500 \mathrm{~mL} / \mathrm{m}$ descartados na rede de esgoto; Restante segregado sendo $3000 \mathrm{ml} / \mathrm{m}$ misturados à acetonitrila e tampão trietanolamina.

Tolueno $\quad 4.400 \mathrm{ml} / \mathrm{m} \quad 500 \mathrm{ml} / \mathrm{m}$ descartados na rede de esgoto; restante é segregado, maior parte misturado a solventes não clorados.

Trietilamina $\quad 7.500 \mathrm{ml} / \mathrm{m} \quad$ Segregados em mistura com tetracloreto e diclorometano.

Xileno $\quad 1000 \mathrm{ml} / \mathrm{m} \quad$ Segregados para a comissão de descarte

Nota: $\mathrm{ml} / \mathrm{m}$ = mililitro por mês e $\mathrm{g} / \mathrm{m}=$ gramas por mês; * uso realizado uma vez ao ano, durante aula prática para a graduaçăo. 
Tabela A-15 - Residuos contendo substâncias classificadas como inflamáveis gerados pela Instituição $\mathrm{C}$ e descarte adotado.

\begin{tabular}{|c|c|c|}
\hline Substância & Volume & Descarte adotado \\
\hline Acetona & $1100 \mathrm{ml} / \mathrm{m}$ & Rede de esgoto sendo $1.000 \mathrm{ml} / \mathrm{m}$ em mistura ao clorofórmio \\
\hline Alcool isoamílico & $2 \mathrm{ml} / \mathrm{m}$ & Rede de esgoto em mistura ao clorofórmio \\
\hline Benzeno & $40 \mathrm{ml} / \mathrm{m}$ & Rede de esgoto \\
\hline Ciclohexano & $450 \mathrm{ml} / \mathrm{m}$ & Rede de esgoto em mistura com dietilamina e tolueno \\
\hline Clorobutano & $180 \mathrm{ml} / \mathrm{m}$ & $20 \mathrm{ml} / \mathrm{m}$ - Rede de esgoto em mistura com a solução de ácido sulfúrico $0,5 \mathrm{~N} ;$ restante evaporado \\
\hline Dietilamina & $60 \mathrm{ml} / \mathrm{m}$ & Rede de esgoto em mistura com ciclohexano e tolueno. \\
\hline Etanol & $2.800 \mathrm{ml} / \mathrm{m}$ & $\begin{array}{l}100 \mathrm{ml} / \mathrm{m} \text { em mistura ao clorofórmio, evaporados fora da capela; restante rede de esgoto sendo } 200 \mathrm{ml} / \mathrm{m} \mathrm{em} \text { mistura ao ácido } \\
\text { acético } 0,5 \% \text { e } 600 \mathrm{ml} / \mathrm{m} \mathrm{em} \text { mistura a anestésico local (pó). }\end{array}$ \\
\hline Éter de petróleo & 300 a $600 \mathrm{ml} / \mathrm{m}$ & Evaporados. \\
\hline Éter etílico & $12.000 \mathrm{ml} / \mathrm{m}$ & Evaporados em mistura ao clorofórmio. \\
\hline Formaldeído & $2 \mathrm{ml} / \mathrm{m}$ & Rede de esgoto como ácido fórmico e em mistura ao hidróxido de sódio. \\
\hline $\begin{array}{l}\text { Gasolina, álcool } \\
\text { combustivel } \\
\text { Hexann }\end{array}$ & NE & Restante do material descartado na rede de esgoto \\
\hline Isopropanol & $\begin{array}{l}\text { 2. } 000 \mathrm{ml} / \mathrm{m} \\
520 \mathrm{ml} / \mathrm{m}\end{array}$ & $\begin{array}{l}1.200 \mathrm{ml} / \mathrm{m} \text { - rede de esgoto; o restante evaporado em capela química; } \\
500 \mathrm{ml} / \mathrm{m} \text { evaporados; restante descartado na rede de esgoto. }\end{array}$ \\
\hline Metanol & 5. $050 \mathrm{ml} / \mathrm{m}$ & Rede de esgoto sendo $5000 \mathrm{ml}$ em mistura com clorofórmio. \\
\hline Nitrito de sódio & $2,5 \mathrm{~g} / \mathrm{m}$ & Nebulizados em capela em mistura com a p-nitroanilina e ácido clorídrico. Restante da solução descartada na rede de esgoto. \\
\hline
\end{tabular}


Cont. Tabela A-15

Substância

Volume

Descarte adotado

Piridina $\quad 45 \mathrm{ml} / \mathrm{m}$

Rede de esgoto em mistura com ácido barbitúrico, ácido cloridrico e cloramina T.

Tetracloreto de $\quad 100 \mathrm{ml} / \mathrm{m} \quad$ Rede de esgoto.

carbono

Tetrahidrofurano $100 \mathrm{ml} / \mathrm{m} \quad$ Rede de esgoto.

Tolueno $650 \mathrm{ml} / \mathrm{m} \quad$ Rede de esgoto sendo $560 \mathrm{ml} \mathrm{em}$ mistura ao clorofórmio e $90 \mathrm{ml} \mathrm{em}$ mistura ao ciclohexano e dietilamina

Xileno $\quad 40 \mathrm{ml} / \mathrm{m} \quad$ Rede de esgoto

Nota: $m / m=$ mililitro por mês $\mathrm{e} g / m=$ gramas por mês; $\mathrm{NE}=$ nåa especificado 


\section{ANEXO 16}

- Resíduos contendo substâncias corrosivas gerados pelas Instituições avaliadas 
Tabela A-16 - Resíduos contendo substâncias classificadas como corrosivas gerados pela Instituição A e o descarte adotado

\begin{tabular}{|c|c|c|}
\hline Substância & Volume & Descarte adotado \\
\hline Ácido acético & $\begin{array}{l}3.265 \mathrm{ml} / \mathrm{m} \\
\text { (concentrado) }\end{array}$ & $\begin{array}{l}\text { Rede de esgoto- cerca de } 1800 \mathrm{ml} / \mathrm{m} \text { em mistura com o clorofórmio, ácido acético, iodeto de potássio, amido e tiossulfato de } \\
\text { sódio; cerca de } 420 \mathrm{ml} \text { do concentrado (soluçðes diluidas } 5 \mathrm{a} 7 \% \text { ) em mistura de iodeto de potássio, ácido acético e tiossulfato } \\
\text { de sódio; } 400 \mathrm{ml} / \mathrm{m} \text { em mistura ao metanol e água; } 50 \mathrm{ml} / \mathrm{m} \text { do concentrado em mistura ao ponceau; } 60 \mathrm{ml} / \mathrm{m} \text { em mistura com } \\
\text { formaldeido oxidado à ácido fórmico na reação; } 85 \mathrm{ml} / \mathrm{m} \text { em mistura ao metanol e glicerina; Nebulizados em capela: cerca de } \\
10 \mathrm{ml} / \mathrm{m} \text { em mistura ao anisaldeído, metanol e ácido sulfúrico e cerca de } 35 \mathrm{ml} / \mathrm{m} \text { em mistura com iodo, iodeto de potássio e } \\
\text { ácido sulfúrico e nitrato de bismuto; Segregados cerca de } 165 \mathrm{ml} \text { do concentrado sendo } 130 \mathrm{ml} \mathrm{em} \mathrm{mistura} \mathrm{ao} \mathrm{ácido} \mathrm{sulfúrico,} \\
30 \mathrm{ml} \text { em mistura ao anidrido acético, ácido sulfúrico e clorofórmio e } 5 \mathrm{ml} \text { em mistura ao ciclohexano e acetato de etila; Cerca } \\
\text { de } 240 \mathrm{~mL} / \mathrm{m} \text { evaporado em capela química em mistura com o etanol. }\end{array}$ \\
\hline Ácido clorídrico & $\begin{array}{l}3.800 \mathrm{ml} / \mathrm{m} \\
\text { (concentrado) }\end{array}$ & $\begin{array}{l}\text { Cerca de } 48 \mathrm{~mL} / \mathrm{m} \text { do concentrado (equivalente a } 900 \mathrm{ml} / \mathrm{m} \text { de solução } 1 \mathrm{~N} \text { ) segregados em mistura com metais; Restante } \\
\text { descartado na rede de esgoto sendo cerca de } 180 \mathrm{ml} / \mathrm{m} \text { do concentrado (solução } 2 \mathrm{~N} \text { ) em mistura com soro, ácido tioglicólico e } \\
\text { ácido tricloracético, } 4 \mathrm{ml} / \mathrm{m} \text { do concentrado (soluçðes diluidas }=0,1 \mathrm{~N} \text { ) em mistura com o princípio ativo de medicamentos; } 22 \\
\mathrm{ml} / \mathrm{m} \text { em mistura com agentes cromogênicos diluidos com hipoclorito; } 500 \mathrm{ml} / \mathrm{m} \text { descartados na rede de esgoto sem } \\
\text { neutralização, manipulado sob exaustão; } 2.100 \mathrm{ml} / \mathrm{m} \text { neutralizados (titulaçăo ácido-base) a maior parte em mistura com oxido } \\
\text { cuproso }\end{array}$ \\
\hline Ácido fórmico & $100 \mathrm{~mL} / \mathrm{m}$ & Segregado em mistura ao tolueno e acetato de etila. \\
\hline Ácido fosfórico & $\begin{array}{l}4 \mathrm{ml} / \mathrm{m} \\
\text { (concentrado) }\end{array}$ & Segregado em mistura a sulfanilamida, naftilenodiamina e água. \\
\hline $\begin{array}{l}\text { Ácido } \\
\text { metafosfórico }\end{array}$ & $15 \mathrm{ml} / \mathrm{m}$ & Rede de esgoto em mistura a suco de frutas e ácido sulfúrico \\
\hline Ácido nítrico & $55 \mathrm{~mL} / \mathrm{m}$ & $\begin{array}{l}38 \mathrm{ml} / \mathrm{m} \text { (cerca de } 900 \mathrm{ml} / \mathrm{m} \text { de uma solução } 1 \mathrm{~N} \text { ) segregados em mistura a metais; } \\
\text { Restante descartado na rede de esgoto em mistura com urina e cloreto estanoso (análise de mercúrio). }\end{array}$ \\
\hline Ácido perclórico & $35 \mathrm{~mL} / \mathrm{a}^{*}$ & Rede de esgoto \\
\hline
\end{tabular}


Cont. Tabela A-16

\section{Substância} Ácido sulfúrico

\section{Volume}

$6.100 \mathrm{ml} / \mathrm{m}$ (concentrado)

Cerca de $20 \mathrm{~mL} / \mathrm{m}$ segregados em mistura ao fenol e hidroxido de sodio e aq com iodo, iodeto de potássio e ácido acético e nitrato de bismuto; $6020 \mathrm{ml} / \mathrm{m}$ descartados na rede de esgoto sendo cerca de $40 \mathrm{ml} / \mathrm{m}$ em mistura ao reagente cromogênico e diluído em hipoclorito (soluçðes $0,1 \mathrm{M}, 0,5$ a $2 \mathrm{~N}$ ); cerca de $24 \mathrm{ml} / \mathrm{m}$ com grande volume de água (hidrólise ácida - determinação vitaminas); $1 \mathrm{ml} / \mathrm{m}$ em mistura com butanol; metanol, hidróxido de sódio e ferricianeto de potássio; cerca de $5 \mathrm{ml} / \mathrm{m}$ em mistura ao anisaldeído, metanol e ácido acético, restante é descartado neutralizado na rede de esgoto (titulação ácido-base)

\begin{abstract}
Ácido tioglicólico $360 \mathrm{~mL} / \mathrm{m}$
Ácido

$1.202 \mathrm{~g} / \mathrm{m}$

tricloracético

$\begin{array}{ll}\begin{array}{l}\text { Cloreto de } \\ \text { antimônio }\end{array} & 87,5 \mathrm{~g} / \mathrm{m} \\ \text { Fenol } & 716 \mathrm{ml} / \mathrm{m}\end{array}$

Rede de esgoto em mistura com soro, ácido tricloracético e ácido cloridrico, diluídos com hipoclorito.

Rede de esgoto, sendo $1.200 \mathrm{~g} / \mathrm{m}$ em mistura com ácido tioglicólico e ácido clorídrico e soro- inavados com hipoclorito e 2 $\mathrm{g} / \mathrm{m}$ em mistura ao ponceau e água.

Rede de esgoto em mistura com anidrido acético, clorofórmio .

$11 \mathrm{ml} / \mathrm{m}$ autoclavado em mistura ao clorofórmio e descartado como RSS; $483 \mathrm{ml} / \mathrm{m}$ segregados em mistura com clorofórmio e álcool isoamílico; cerca de $2 \mathrm{~mL} / \mathrm{m}(2 \mathrm{~g} / \mathrm{m})$, usado no preparo de ácido disulfonico e segregado com ácido sulfúrico; cerca de $220 \mathrm{ml} / \mathrm{m}$ (equivalente a $235,8 \mathrm{~g} / \mathrm{m}$ ) utilizados como anti-séptico, e em corantes e descartados na rede de esgoto.
\end{abstract}

Hidróxido de amônia

$215 \mathrm{ml} / \mathrm{m}$

Hidróxido de cálcio

Hidróxido de potássio

$450 \mathrm{~g} / \mathrm{m}$

Hidróxido de sódio
$25 \mathrm{ml} / \mathrm{m}$ evaporados em capela em mistura ao acetato de etila e metanol; restante segregado sendo $90 \mathrm{ml} / \mathrm{m}$ em mistura ao butanol, etanol e água e $100 \mathrm{ml} / \mathrm{m}$ em mistura ao metanol.

Utilizado na determinação de nicotinamida em cereais - etapa de hidrólise. O hidrolisado reage com bromocianogênio, ácido sulfanílico e ácido clorídrico - inativação com hipoclorito e descarte rede de esgoto.

Fase aquosa - rede de esgoto em mistura com etanol, glicerina e vitaminas A, $\beta$-caroteno e $\mathrm{E}$.

Cerca de $57,64 \mathrm{~g} / \mathrm{m}$ segregados sendo $12 \mathrm{~g} / \mathrm{m}$ em mistura com iodeto de mercúrio e iodeto de potássio, $9,6 \mathrm{~g} / \mathrm{m}$ com ácido disulfônico e água , $36 \mathrm{~g} / \mathrm{m}$ em mistura com metais e cerca de $0,04 \mathrm{mg} / \mathrm{m}$ em mistura com o metanol; $1825 \mathrm{~g} / \mathrm{m}$ utilizados na determinação de protídeos (titulação ácido - base) descartado na rede de esgoto, neutralizado, em mistura ao óxido cuproso; 
Cont. Tabela A-16

Substância

Volume

Hidróxido de

sódio

lodo

$11 \mathrm{~g} / \mathrm{m}$

Persulfato de

$0,12 \mathrm{~g} / \mathrm{m}$

amônia

\section{Descarte adotado}

Cerca de $110,78 \mathrm{~g} / \mathrm{m}$ descartados na rede de esgoto sendo $60 \mathrm{~g} / \mathrm{m} \mathrm{em}$ mistura com formaldeído, $30 \mathrm{~g} / \mathrm{m}$ em mistura com butanol, metanol e ácido sulfúrico, $15 \mathrm{~g} / \mathrm{m}$ em mistura ao metanol, ferricianeto de potássio e ácido sulfúrico, $3,2 \mathrm{~g} / \mathrm{m} \mathrm{em}$ mistura p-nitrofenilhidrazina e diluído com hipoclorito de sódio, $2,5 \mathrm{~g} / \mathrm{m}$ descartados com grande volume de água(utilizados na destilação de etanol comercial); $80 \mathrm{mg} / \mathrm{m}$ descartados neutralizados na rede de esgoto em mistura ao cloridrato de hidroxilamina, azul de bromofenol; restante utilizado para solubilização de princípios ativos, basificação ou neutralização de soluções e meios de cultura.

Nebulizados em capela química em mistura com ácido acético e sulfúrico, iodeto de potássio e nitrato de bismuto, restante descartado na rede de esgoto em mistura ao iodeto de potássio.

RSS junto com o gel de acrilamida 
Tabela A-17 - Residuos contendo substâncias classificadas como corrosivos gerados pela Instituição B e descarte adotado.

\begin{tabular}{lll}
\hline Substância & Volume & Descarte adotado \\
\hline Ácido acético & $\begin{array}{l}2.350 \mathrm{ml} / \mathrm{m} \\
\text { concentrado }\end{array}$ & $\begin{array}{l}1090 \mathrm{ml} / \mathrm{m} \text { segregados sendo } 40 \mathrm{ml} / \mathrm{m} \mathrm{misturado} \mathrm{ao} \mathrm{n-hexano,} \mathrm{isopropanol,} \mathrm{dietilamina} \mathrm{e} \mathrm{água} \mathrm{e} \mathrm{o} \mathrm{restante} \mathrm{misturado} \mathrm{aos} \mathrm{solventes} \\
\text { extratores; } 80 \mathrm{ml} / \mathrm{m} \text { do concentrado }=200 \mathrm{ml} / \mathrm{m} \text { solução } 10 \% \text { - neutralizado antes descarte na rede de esgoto; restante descartado na } \\
\text { rede de esgoto sendo que cerca de } 65 \mathrm{~mL} / \mathrm{m} \mathrm{da} \mathrm{solução} \mathrm{concentrada} \mathrm{=} \mathrm{solução} 7 \% \mathrm{em} \mathrm{metanol;} 50 \mathrm{ml} / \mathrm{m} \mathrm{descartado} \mathrm{misturado} \mathrm{ao} \mathrm{fenol} \\
\text { e ácido sulfúrrico }\end{array}$
\end{tabular}

Ácido clorídrico $\begin{aligned} & 10.900 \mathrm{ml} / \mathrm{m} \\ & \text { concentrado }\end{aligned}$

Ácido fórmico $\quad 800 \mathrm{~mL} / \mathrm{m}$

concentrado

Ácido fosfórico

$650 \mathrm{ml} / \mathrm{m}$

$150 \mathrm{mg} / \mathrm{m}$ (a) a. Rede de esgoto em mistura com urina, etanol, ácido clorídrico e água

Ácido

fosfotungstico (a)

e ácido tungstico (b)

Ácido nítrico

$6,8 \mathrm{mg} / \mathrm{m} \mathrm{(b)}$

écido sulfúrico.

$4.000 \mathrm{ml} / \mathrm{m}$ segregados; $36,5 \mathrm{ml} / \mathrm{m}$ da solução concentrada (equivalente a $5.000 \mathrm{ml} / \mathrm{m}$ solução $0, \mathrm{IN}$ ) descartados na rede de esgoto com medicamentos solubilizados; $10 \mathrm{ml} / \mathrm{m}$ descartado na rede de esgoto misturado ao ácido tiobarbitúrico, butanol e homogenato de tecido; $120 \mathrm{ml} / \mathrm{m}$ descartado na rede de esgoto misturados à matriz biológica (urina); restante descartado neutralizado.

$350 \mathrm{~mL} / \mathrm{m}$ segregados, parte misturada à solventes; $250 \mathrm{~mL} / \mathrm{m}$ nebulizados com reveladores na capela; $200 \mathrm{~mL} / \mathrm{m}$ descartados na rede de esgoto.

a. $12,2 \mathrm{l} / \mathrm{m}$
b. $2 \mathrm{ml} / \mathrm{a}^{*}$

a. $225 \mathrm{ml} / \mathrm{m}$ neutralizados antes do descarte na rede de esgoto. Restante descartados na rede de esgoto diluidos com bastante água

b. $2 \mathrm{ml} / \mathrm{a}$

Ácido oxálico $\quad 105 \mathrm{~g} / \mathrm{m}$

Ácido perclórico $\quad 760 \mathrm{ml} / \mathrm{m}$

Ácido periódico $\quad 0,5 \mathrm{~g} / \mathrm{a}^{*}$

Ácido sulfúrico

$4.430 \mathrm{ml} / \mathrm{m}$

concentrado b. $2 \mathrm{~mL} /$ ano da solução concentrada $=270 \mathrm{~mL} /$ ano solução $\mathrm{HNO}_{3} 1,5 \%$ descartada na rede de esgoto misturada à urina e $\mathrm{SnCl}_{2}$

$100 \mathrm{~g} / \mathrm{m}$ segregados; $5 \mathrm{~g} / \mathrm{m}$ nebulizados em capela em mistura com ácido bórico

Cerca de $100 \mathrm{~mL} / \mathrm{m}$ segregados misturados ao metanol e hexano; $80 \mathrm{ml} / \mathrm{m}$ descartado na rede de esgoto bem diluído com água; restante neutralizado e descartado na rede de esgoto.

Descartado na rede de esgoto corante.

$2.030 \mathrm{ml} / \mathrm{m}$ segregados, parte misturado à solventes ou fenol, destes, $7,0 \mathrm{ml} / \mathrm{m}$ do ácido concentrado (equivalente a $2.500 \mathrm{ml} / \mathrm{m}$ de uma soluçào $0,1 \mathrm{~N}$ ); restante descartado na rede de esgoto sendo que cerca de $1.350 \mathrm{ml} / \mathrm{m}$ descartados após titulação ácido-base (neutralizado); cerca de 10 $\mathrm{mL} / \mathrm{m}$ descartados misturados ao ácido sulfanilico, acetaldeído, difenilamina; outros $10 \mathrm{~mL} / \mathrm{m}$ descartados misturados ao etanol e leite; cerca de $8,5 \mathrm{ml} / \mathrm{m}$ da solução concentrada (equivalente a $80 \mathrm{ml} / \mathrm{m}$ soluçå $\mathrm{H}_{2} \mathrm{SO}_{4} 4 \mathrm{~N}$ ) descartados juntamente com agente cromogênico e hipoclorito. 
Cont. Tabela A-17

\begin{tabular}{|c|c|c|}
\hline Substância & Volume & Descarte adotado \\
\hline $\begin{array}{l}\text { Ácido } \\
\text { Tricloracético }\end{array}$ & $40 \mathrm{~g} / \mathrm{m}$ & Descartados na rede de esgoto com bastante água, sendo que $5 \mathrm{~g} / \mathrm{m}$ em mistura a tampões fosfato \\
\hline $\begin{array}{l}\text { Ácido } \\
\text { trifluoracético }\end{array}$ & $9,9 \mathrm{~g} / \mathrm{m}$ & $8,3 \mathrm{~g} / \mathrm{m}$ segregados em mistura com acetonitrila e água; $1,6 \mathrm{~g} / \mathrm{m}$ - neutralização prévia ao descarte na rede de esgoto. \\
\hline Fenol & $2.500 \mathrm{ml} / \mathrm{m}^{* *}$ & $\begin{array}{l}\text { Segregados em mistura com ácido sulfúrico }(1.200 \mathrm{ml} / \mathrm{m} \text { soluçăo } 5 \%) \text { e com clorofórmio, e o restante com álcool iso - amílico ; } 32 \\
\mathrm{ml} / \mathrm{m} \text { autoclavado e descartado com RSS. }\end{array}$ \\
\hline $\begin{array}{l}\text { Hidróxido de } \\
\text { amônia }\end{array}$ & $\begin{array}{l}36,9 \mathrm{ml} / \mathrm{m} \\
\text { concentrado }\end{array}$ & $\begin{array}{l}11 \mathrm{~mL} / \mathrm{m} \text { segregados para a comissão, destes } 1 \mathrm{~mL} / \mathrm{m} \text { da solução concentrado (equivalente a } 200 \mathrm{ml} / \mathrm{m} \mathrm{NH} \mathrm{OH}_{0} 0,5 \% \text { ) segregado sem } \\
\text { mistura com o metanol; } 0,9 \mathrm{~mL} / \mathrm{m} \text { soluçăo concentrada (equivalente a } 24 \mathrm{ml} / \mathrm{m} \mathrm{NH} \mathrm{H}_{4} \mathrm{OH} 1 \mathrm{M} \text { ) descartados na rede de esgoto, neutralizados, } \\
\text { em mistura ao dimetilsulfóxido, borohidreto de sódio, ácido acético anidrido acético; restante descartado na rede de esgoto, diluído, } \\
\text { juntamente com a matriz. }\end{array}$ \\
\hline \multirow[t]{2}{*}{$\begin{array}{l}\text { Hidróxido de } \\
\text { potássio }\end{array}$} & a. $460 \mathrm{~g} / \mathrm{m}$ & $\begin{array}{l}\text { a. } 56 \mathrm{~g} / \mathrm{m} \text { (equivalente a } 1 \mathrm{~L} \text { de soluça } \mathrm{KOH} \mathrm{IN} \text { ) nebulizados em capela química (revelador); } 150 \mathrm{~g} / \mathrm{m} \text { (equivalente a } 500 \mathrm{~m} / \mathrm{m} \text { de soluçăo } \mathrm{KOH} \\
30 \% \text { ) descartados na rede de esgoto misturados a amostra de tecido, e sulfato de sódio; restante descartado neutralizado na rede de } \\
\text { esgoto. }\end{array}$ \\
\hline & b. $32,76 \mathrm{~g} / \mathrm{ano}$ & $\begin{array}{l}\text { b. } 32,76 \text { g/ano ( equivalente a } 75 \mathrm{ml} / \text { ano de soluça } \mathrm{KOH} 7,8 \mathrm{~N} \text { ) descartados "aos poucos" na rede de esgoto juntamente com amostra de } \\
\text { urina e um pouco de piridina. }\end{array}$ \\
\hline $\begin{array}{l}\text { Hidróxido de } \\
\text { sódio }\end{array}$ & $1306 \mathrm{~g} / \mathrm{m}$ & $\begin{array}{l}\text { Cerca de } 48 \mathrm{~g} / \mathrm{m} \text { (equivalente a } 5.500 \mathrm{ml} / \mathrm{m} \text { de solução } \mathrm{NaOH} 200 \mathrm{mM} \text { e } 5.500 \mathrm{~m} / \mathrm{m} \text { de } \mathrm{NaOH} 18 \mathrm{mM} \text { ) segregados para a comissão; restante } \\
\text { descartado na rede de esgoto neutralizado em mistura a restos de solventes (éter, etanol), fenol } 5 \% \text { e precursores de síntese. }\end{array}$ \\
\hline Iodo & $148,5 \mathrm{~g} / \mathrm{m}$ & $\begin{array}{l}24,4 \mathrm{~g} / \mathrm{m} \text { nebulizados em capela, componente do revelador Dragendorff iodado composto por } \mathrm{H}_{2} \mathrm{SO}_{4} 10 \% \text {, nitrato de bismuto, iodeto } \\
\text { de potássio e iodo; } 4,5 \mathrm{~g} / \mathrm{m} \text { utilizados na assepsia de bancadas e frascos em mistura com etanol (soluçães } 0,5 \mathrm{e} 2 \% \text { ); restante } \\
\text { descartado na rede de esgoto sendo } 5,0 \mathrm{~g} / \mathrm{m} \text { reduzidos a iodeto previamente e } 4,5 \mathrm{~g} / \mathrm{m} \text { utilizados como corante. }\end{array}$ \\
\hline $\begin{array}{l}\text { Peróxido de } \\
\text { hidrogênio }\end{array}$ & $\begin{array}{l}45 \mathrm{ml} / \mathrm{m} \\
\text { concentrado }\end{array}$ & Descartados na rede de esgoto em mistura com as matrizes utilizadas, por exemplo, leite \\
\hline $\begin{array}{l}\text { Persulfato de } \\
\text { amônia }\end{array}$ & $2,6 \mathrm{~g} / \mathrm{m}$ & Constituinte do gel acrilamida \\
\hline
\end{tabular}

amônia

Nota: * $\mathrm{ml} / \mathrm{a}$ ou g/a $=$ utilizados uma vez ao ano em aulas práticas para a graduaçà; ${ }^{* *}$ considerando $1.200 \mathrm{ml}$ de uma soluçà aquosa $5 \% ; \mathrm{ml} / \mathrm{m}=\mathrm{mililitro} \mathrm{por} \mathrm{mês} \mathrm{e} \mathrm{g/m=} \mathrm{gramas} \mathrm{por} \mathrm{mês}$ 
Tabela A-18- Residuos contendo substâncias classificadas corrosivas gerados pela Instituição C e descarte adotado

\begin{tabular}{|c|c|c|}
\hline Substância & Volume & Descarte adotado \\
\hline Ácido acético & $22 \mathrm{ml} / \mathrm{m}^{*}$ & $\begin{array}{l}\text { Rede de esgoto em mistura com sangue sendo } 10 \mathrm{ml} / \mathrm{m} \text { misturados também ao acetato de chumbo e } 9,5 \mathrm{ml} / \mathrm{m} \text { em mistura ao etanol } \\
10 \% \text {. }\end{array}$ \\
\hline Ácido clorídrico & $610 \mathrm{ml} / \mathrm{m}^{*}$ & $\begin{array}{l}\text { Rede de esgoto sendo que } 500 \mathrm{ml} / \mathrm{m} \mathrm{em} \mathrm{mistura} \mathrm{com} \mathrm{matriz} \mathrm{biológica;} 100 \mathrm{ml} / \mathrm{m} \text { em mistura com a vanilina e etanol; } 4 \mathrm{ml} / \mathrm{m} \\
\text { em mistura com o tiocianato de cobalto; } 6 \mathrm{ml} / \mathrm{m} \mathrm{em} \mathrm{mistura} \mathrm{ao} \mathrm{ácido} \mathrm{barbitúrico} \mathrm{e} \mathrm{piridina}\end{array}$ \\
\hline Ácido nítrico & $250 \mathrm{ml} / \mathrm{m}^{*}$ & $\begin{array}{l}150 \mathrm{ml} / \mathrm{m} \text { descartado nas rede de esgoto diluídos } 1: 2 \mathrm{com} \text { água } ; 100 \mathrm{ml} / \mathrm{m} \text { nebulizados em capela juntamente com o dicromato } \\
\text { de potássio, ácido sulfúrico e ácido perclórico. }\end{array}$ \\
\hline Ácido perclórico & $100 \mathrm{ml} / \mathrm{m}^{*}$ & Nebulizados juntamente com o dicromato de potássio, ácido sulfúrico e ácido nítrico \\
\hline Ácido sulfúrico & $300 \mathrm{ml} / \mathrm{m}^{*}$ & $\begin{array}{l}\text { Rede de esgoto juntamente com material biológico (diluído) e com clorobutano; } 100 \mathrm{ml} / \mathrm{m} \text { nebulizados juntamente com o } \\
\text { dicromato de potássio, ácido perclórico e ácido nitrico }\end{array}$ \\
\hline Fenol & $10 \mathrm{ml} / \mathrm{m}$ & Rede de esgoto em mistura ao clorofórmio e álcool isoamílico \\
\hline $\begin{array}{l}\text { Hidróxido de } \\
\text { amônia }\end{array}$ & $100 \mathrm{ml} / \mathrm{m}^{*}$ & Rede de esgoto juntamente com o material biológico \\
\hline $\begin{array}{l}\text { Hidróxido de } \\
\text { potássio }\end{array}$ & $10 \mathrm{~g} / \mathrm{m}$ & Rede de esgoto \\
\hline $\begin{array}{l}\text { Hidróxido de } \\
\text { sódio }\end{array}$ & $60 \mathrm{~g} / \mathrm{m}$ & Rede de esgoto sendo que $57 \mathrm{~g} / \mathrm{m}$ em mistura ao ácido fórmico. \\
\hline Iodo & $12 \mathrm{~g} / \mathrm{m}$ & Nebulizados em capela em mistura com ácido acético, nitrato de bismuto, iodeto de potássio e ácido sulfúrico. \\
\hline $\begin{array}{l}\text { Peróxido de } \\
\text { hidrogênio }\end{array}$ & $25 \mathrm{ml} / \mathrm{m}$ & Descartados como resíduo sólido juntamente com tubo de reação contendo a matriz biológica, em saco de lixo comum. \\
\hline $\begin{array}{l}\text { Persulfato de } \\
\text { amônia }\end{array}$ & $0,425 \mathrm{~g} / \mathrm{m}$ & Constituinte do gel de acrilamida. Em geral, o gel é arquivado, quando não, descartado em saco plástico comum \\
\hline
\end{tabular}
amônia

Nota: $\mathrm{m} / \mathrm{m}=$ mililitro por mès e $\mathrm{g} / \mathrm{m}=$ gramas por mês; * volume expresso em relaçăo à substância concentrada 


\section{ANEXO 17}

- Resíduos contendo substâncias reativas gerados pelas Instituições avaliadas 
Tabela A-19 - Residuos contendo substâncias classificadas como reativas gerados na Instituição A e o descarte adotado

\begin{tabular}{|c|c|c|}
\hline Substância & Volume & Descarte adotado \\
\hline Ácido pícrico & $1,2 \mathrm{~g} / \mathrm{m}$ & $\begin{array}{l}0,6 \mathrm{~g} / \mathrm{m} \text { descartados em rede de esgoto em mistura com soro e tampões glicina em } \mathrm{NaOH} \text { diluidos com hipoclorito; } \\
\text { restante segregado em mistura com formol e etanol. }\end{array}$ \\
\hline $\begin{array}{l}\text { (3-amino- } \\
\text { propil)trietoxisilano }\end{array}$ & $16 \mathrm{~g} / \mathrm{m}$ & Segregados (solução em acetona) \\
\hline Anidrido acético & $10 \mathrm{ml} / \mathrm{m}$ & Rede de esgoto em mistura ao cloreto de antimônio e clorofórmio. \\
\hline Sais de cianeto & $\begin{array}{l}0,085 \text { a } 0,230 \mathrm{~g} / \mathrm{m} \\
\text { de CN }\end{array}$ & $\begin{array}{l}\text { Rede de esgoto sendo cerca de } 25 \mathrm{mg} / \mathrm{m} \text { em mistura ao tampão fosfato, soro, ferricianeto de potássio, ácido acético, } \\
\text { diluídos com hipoclorito de sódio e o restante em mistura ao soro, lisante e } \mathrm{KCN} \text { diluídos com hipoclorito }\end{array}$ \\
\hline
\end{tabular}

Nota: $\mathbf{m l} / \mathbf{m}=$ mililitro por mès e $\mathrm{g} / \mathrm{m}=$ gramas por mès 
Tabela A-20 - contendo substâncias classificadas como reativas gerados pela Instituição B e descarte adotado.

\begin{tabular}{|c|c|c|}
\hline Substância & Volume & Descarte adotado \\
\hline Ácido pícrico & $1,68 \mathrm{~g} / \mathrm{m}$ & Rede de esgoto em mistura com soro, hidróxido de sódio sendo $0,36 \mathrm{~g} / \mathrm{m}$ diluído com hipoclorito. \\
\hline Anidrido acético & $315 \mathrm{ml} / \mathrm{m}$ & Descartados na rede de esgoto sendo que $240 \mathrm{ml} / \mathrm{m}$ em mistura com dimetilsulfóxido, borohidreto de sódio, $\mathrm{NH}_{4} \mathrm{OH}$ e ácido acético. \\
\hline $\begin{array}{l}\text { Borohidreto de } \\
\text { sódio }\end{array}$ & $4,8 \mathrm{~g} / \mathrm{m}$ & Rede de esgoto em mistura com hidróxido de amônia, ácido acético, dimetilsulfóxido, anidrido acético. \\
\hline Cloreto de alumínio & $36,5 \mathrm{~g} / \mathrm{m}$ & $\begin{array}{l}36,0 \mathrm{~g} / \mathrm{m} \text { (equivalente a } 300 \mathrm{ml} / \mathrm{m} \text { soluça } 3 \% \mathrm{em} \text { metanol) nebulizados em capela; } 0,5 \mathrm{~g} / \mathrm{m} \text { descartado na rede de esgoto ou em saco plástico } \\
\text { branco como RSS. }\end{array}$ \\
\hline Cloreto de tionila & $170 \mathrm{ml} / \mathrm{m}$ & $160 \mathrm{ml} / \mathrm{m}$ utilizado como substrato de sintese e o restante segregado em mistura a ciprofoxacina, dimetilformamida. \\
\hline Cloreto de vanádio & $5 \mathrm{ml} / \mathrm{m}^{* *}$ & Segregados no laboratório misturado à amostra (soro ou plasma) \\
\hline Diazometano & $5 \mathrm{ml} / \mathrm{m}$ & Evaporados em capela \\
\hline Magnésio metálico & $25,3 \mathrm{~g} / \mathrm{m}$ & Descartados na rede de esgoto ou como resíduo sólido juntamente com fragmentos de vegetais analisados \\
\hline Sais de cianeto & $\begin{array}{l}\text { a. } 0,3 \mathrm{~g} / \mathrm{m} \\
\text { de } \mathrm{NaCN} \\
9 \text { a } 15 \mathrm{~g} \\
\text { de } \mathrm{KCN} \\
\text { b. } 200 \mathrm{mg} / \mathrm{a}^{*} \\
\text { de } \mathrm{NaCN}\end{array}$ & $\begin{array}{l}\text { a. } 0,3 \mathrm{~g} / \mathrm{m} \text { descartado na rede de esgoto. } \\
9 \text { a } 15 \mathrm{~g} / \mathrm{m} \text { (equivalente a } 6 \mathrm{l} / \mathrm{m} \text { de soluçăo } 0,15 \text { a } 0,25 \% \text { em sal de amônio quaternário) descartados na rede de esgoto; } \\
\text { b. } 200 \mathrm{mg} / \mathrm{a} \text { descartados na rede de esgoto em mistura à matriz (soro) diluidos com hipoclorito }\end{array}$ \\
\hline Sódio metálico & $4 \mathrm{~g} / \mathrm{m}$ & Utilizado em sínteses \\
\hline $\begin{array}{l}\text { Trimetiliodosilano + } \\
\text { n-metil-n (trimetilsilil } \\
\text { fuoroacetamida) }\end{array}$ & $\begin{array}{l}5 \mathrm{ml}+0,02 \\
\mathrm{ml} / \mathrm{m}\end{array}$ & Evaporados em capela \\
\hline
\end{tabular}


Tabela A - 21- Resíduos contendo substâncias classificadas como reativas gerados pela Instituição C e descarte adotado

Substância

Volume

\section{Descarte realizado}

Cianeto de sódio $0,018 \mathrm{~g} / \mathrm{m}$ Rede de esgoto complexado ao ácido barbitúrico em piridina. Soluções vencidas também sæao descartadas na rede de esgoto,

Nota: $g / m=$ gramas por mês

sem inativação prévia 


\section{ANEXO 18}

- Resíduos contendo substâncias tóxicas gerados pelas

Instituições avaliadas 
Tabela A-22 - Resíduos contendo substâncias classificadas como tóxicas gerados na Instituição A e o descarte adotado.

\begin{tabular}{|c|c|c|}
\hline Substância & Volume & Descarte adotado \\
\hline Ácido cacodílico & $0,83 \mathrm{~g} / \mathrm{m}$ & Rede de esgoto, descartado solução de glutaraldeído em tampão cacodilato fosfato \\
\hline Ácido ósmico & $0,3 \mathrm{~g} / \mathrm{m}$ & Segregado ( equivalente a $30 \mathrm{ml} / \mathrm{m}$ de solução $1 \%$ ) \\
\hline Ácido sulfanílico & $1,25 \mathrm{~g} / \mathrm{m}$ & $\begin{array}{l}1,2 \mathrm{~g} / \mathrm{m} \text { descartado na rede de esgoto em mistura com bromocianogênio, ácido cloridrico e hidróxido de cálcio, inativados com } \\
\text { hipoclorito de sódio; restante segregado em frasco único em mistura com } 1 \text { - naftol, hidróxido de amônia, solventes clorados e não } \\
\text { clorados. }\end{array}$ \\
\hline Ácido sulfídrico & $800 \mathrm{ml} / \mathrm{m}$ & Rede de esgoto após precipitar metais. \\
\hline Acrilamida & $\begin{array}{l}165,6 \mathrm{~g} \text { a } 360 \mathrm{~g} \\
\text { acrilamida e } \\
4,4 \mathrm{~g} \mathrm{a} 9,6 \mathrm{~g} / \mathrm{m} \\
\text { bis-acrilamida }\end{array}$ & Descartados em saco plástico branco como RSS, uma parte é autoclavada antes da disposição. \\
\hline Auramina & $6,5 \mathrm{~g} / \mathrm{m}$ & $\begin{array}{l}\text { Rede de esgoto sendo } 0,5 \mathrm{~g} / \mathrm{m} \text { em mistura com fenol, etanol e agua e o restante em mistura ao etanol }(600 \mathrm{~mL} / \mathrm{m} \text { de uma soluçăo } 1 \% \text { em } \\
\text { etanol } 95 \% \text { ) }\end{array}$ \\
\hline Azida sódica & $\begin{array}{l}\text { a. } 1,0 \mathrm{~g} / \mathrm{m} \\
\text { b. } 0,04 \mathrm{~g} / \mathrm{m} \\
\text { c. } N E\end{array}$ & $\begin{array}{l}\text { a. Componente do ágar azida juntamente com bactotryptose, bactobeef extract, } \mathrm{NaCL} \text {, bacto ágar - autoclavado e descartado como } \\
\text { RSS } \\
\text { b. Solução em tampão fosfato não descartada - conservante de amostra } \\
\text { c. Conservante de Kits, nas concentraç̃es de } 0,01 \text { a } 0,1 \% \text {, descartado na rede de esgoto. }\end{array}$ \\
\hline Brometo de etídio & $\begin{array}{l}\text { Cerca de } \\
0,0013 \mathrm{~g} / \mathrm{m} \\
(0,0001 \mathrm{~g} / \mathrm{m} \text { no gel } \\
\text { de agarose e } 0,0012 \\
\mathrm{~g} / \mathrm{m} \text { em água para } \\
\text { corar) }\end{array}$ & $\begin{array}{l}\text { Inativação padronizada com } \mathrm{KMnO}_{4} 0,5 \mathrm{M}, \mathrm{HCL} 2,5 \mathrm{~N} \mathrm{e} \mathrm{NaOH} 2,5 \mathrm{~N} \text { para posterior descarte na rede de esgoto, como } \\
\text { descrito por SAMBROOK e col. (1989). }\end{array}$ \\
\hline Bromocianogênio & $80 \mathrm{ml} / \mathrm{m}$ & Solução inativada com hipoclorito até pH 13 e descartada na rede de esgoto \\
\hline Cádmio metálico & $100 \mathrm{~g} / \mathrm{m}$ & Estocado, aguardando decisão da comissão de descarte. \\
\hline
\end{tabular}

Ácido sulfanílico $\quad 1,25 \mathrm{~g} / \mathrm{m}$ hipoclorito de sódio; restante segregado em frasco único em mistura com 1 - naftol, hidróxido de amônia, solventes clorados e não Rede de esgoto após precipitar metais

Acrilamida acrilamida e $4,4 \mathrm{~g}$ a $9,6 \mathrm{~g} / \mathrm{m}$

Rede de esgoto sendo $0,5 \mathrm{~g} / \mathrm{m}$ em mistura com fenol, etanol e água e o restante em mistura ao etanol $(600 \mathrm{~mL} / \mathrm{m}$ de uma soluçăa $1 \%$ em

b. Solução em tampão fosfato não descartada - conservante de amostra

Inativação padronizada com $\mathrm{KMnO}_{4} 0,5 \mathrm{M}, \mathrm{HCL} 2,5 \mathrm{~N} \mathrm{e} \mathrm{NaOH}$ 2,5 $\mathrm{N}$ para posterior descarte na rede de esgoto, como

Estocado, aguardando decisão da comissão de descarte 
Cont. Tabela A - 22

\begin{tabular}{|c|c|c|}
\hline Substância & Volume & Descarte adotado \\
\hline Cloreto estanoso & $13 \mathrm{~g} / \mathrm{m}$ & $\begin{array}{l}\text { Rede de esgoto sendo que } 12 \mathrm{~g} / \mathrm{m} \text { em mistura com ácido clorídrico, iodeto de potássio e } 1 \mathrm{~g} / \mathrm{m} \text { em mistura aos ácidos nítrico, } \\
\text { urina contendo sais de mercúrio a serem analisados. }\end{array}$ \\
\hline Clorofórmio & $27.900 \mathrm{ml} / \mathrm{m}$ & $\begin{array}{l}450 \mathrm{ml} / \mathrm{m} \text { recuperados e reutilizados; } 12.000 \mathrm{ml} / \mathrm{m} \text { guardados para recuperação porém a seção foi inativada. Estão aguardando } \\
\text { instruçðes da comissão de gerenciamento; } 3.500 \mathrm{ml} / \mathrm{m} \text { evaporados em capela química; Cerca de } 33 \mathrm{ml} / \mathrm{m} \text { autoclavados em mistura ao } \\
\text { fenol e álcool isoamílico e descartados como RSS; Cerca de } 950 \mathrm{~mL} / \mathrm{m} \text { descartados na rede de esgoto em mistura com ácido acético e } \\
\text { iodeto de potássio, amido e tiossulfato de sódio ou em mistura com o anidrido acético e cloreto de antimônio. O restante é segregado } \\
\text { sendo que } 35 \mathrm{~mL} / \mathrm{m} \text { segregados em frasco único em mistura com solventes não halogenados, piridina, dietiliditiocarbamato de prata, } \\
1 \text {-naftol e cerca de } 175 \mathrm{ml} / \mathrm{m} \text { em mistura ao fenol ( } 450 \mathrm{ml}) \text { e álcool isoamílico ( } 4 \mathrm{ml}) \text {. }\end{array}$ \\
\hline
\end{tabular}

Dimetilaminoazo $\quad 0,0165 \mathrm{~g} / \mathrm{m} \quad$ Rede de esgoto em mistura com ácido sulfúrico e hipoclorito de sódio

\section{Benzeno}

\section{Diclorometano $\quad 6.500 \mathrm{ml} / \mathrm{m} \quad$ Segregados}

Fenolftaleína $^{1}$ NE Indicador $* *$

1-naftol $\quad 0,052 \mathrm{~g} / \mathrm{m}$

$0,032 \mathrm{~g} / \mathrm{m}$ segregado em mistura com solventes, dietilditocarbamato de prata; o restante é autoclavado com o meio de cultura e descartado como RSS

o-fenilenodiamina $1,7 \mathrm{~g} / \mathrm{m}$

Rede de esgoto em mistura com tampões citrato, fosfatos, ácidos cloridrico ou sulfúrico diluído com hipoclorito

Sal de arsênico $\quad 0,00025 \mathrm{~g} / \mathrm{m} \quad$ Segregado complexado ao dietilditiocarbamato de prata em piridina

Sais de chumbo (citrato, óxido e

a. 0,02184

a. quando utilizado como corante descartado na rede de esgoto

nitrato de chumbo)

$\mathrm{g} / \mathrm{m}$

b. $0,5 \mathrm{~g} / \mathrm{a}$

Restante segregados com metilisobutilcetona e com o material biológico; Soluções - estoque vencidas também são segregadas para serem tratadas com $\mathrm{H}_{2} \mathrm{~S}$.

(óxido)

b. Nebulizado em capela (uso eventual)

Sais de mercúrio $\quad 6,61 \mathrm{~g} / \mathrm{m}(\mathrm{Hg}) \quad 3,2 \mathrm{~g} / \mathrm{m}$ (solução de brometo de mercúrio $5 \%$ ) utilizados para embeber tiras de papel e descartadas como resíduo sólido em saco plástico branco; restante segregado para a comissão sendo $3,0 \mathrm{~g} / \mathrm{m}$ em mistura com carbonato, iodeto de potássio e $\mathrm{NaOH}$; $0,4 \mathrm{~g} / \mathrm{m}$ revelador de gelatinase; $0,01 \mathrm{~g} / \mathrm{m}$ (soluç̧̋es-estoque vencidas) segregadas para serem tratadas com $\mathrm{H}_{2} \mathrm{~S}$. Quando 0 analito é o mercúrio presente no material biológico (urina)é descartado na rede de esgoto com o cloreto estanoso e o ácido nítrico, juntamente com a matriz biológica. 
Cont. Tabela A - 22

\begin{tabular}{lll}
\hline Substância & Volume & \multicolumn{1}{c}{ Descarte adotado } \\
\hline Sais de prata & $2,97 \mathrm{~g} / \mathrm{m}(\mathrm{Ag})$ & $\begin{array}{l}2,65 \mathrm{~g} / \mathrm{m} \text { descartados na rede de esgoto (solução 0,2 e } 0,17 \% \text { de nitrato de prata); } \\
0,32 \mathrm{~g} / \mathrm{m} \text { segregados com dietilditiocarbamato de prata em piridina sendo } 0,1 \mathrm{~g} / \mathrm{m} \text { segregados em frasco único em mistura a } \\
\text { solventes clorados e não clorados, ácidos, hidróxidos e 1-naftol e o restante guardado no laboratório em separado, à espera de } \\
\text { instruççes da comissão de descarte (parte desta solução está complexada ao arsênio). }\end{array}$
\end{tabular}

Selenito de sódio $\quad 16 \mathrm{~g} / \mathrm{m} \quad$ Componente de meio de cultura juntamente com tryptona, lactose e fosfato de sódio,- autoclavado e descartado como RSS Nota: $\mathrm{ml} / \mathrm{m}=$ mililitro por mês; $g / m=$ grama por mês; $g / a=$ grama por ano; $N E=$ Não especificado; ${ }^{* *}=$ suspeito de ser carcinogênico para o homem; $1=$ USDHHS, 1998 
Tabela A-23 - Resíduos contendo substâncias classificadas como tóxicas gerados pela Instituição B e descarte adotado

\begin{tabular}{|c|c|c|}
\hline Substância & Volume & Descarte adotado \\
\hline $\begin{array}{l}\text { 2-acetilamino } \\
\text { fluoreno }\end{array}$ & $\mathrm{lg} / \mathrm{m}$ & $\begin{array}{l}\text { Utilizado na experimentaçåo com animais. Seringas, cânulas, frascos lavados com acetona e permanganato de potássio, } \\
\text { descartados na rede de esgoto }\end{array}$ \\
\hline Ácido orótico & $17,5 \mathrm{~g} / \mathrm{m}$ & Reage com sulfadoxina e sulfametoxazol. O produto da síntese é guardado para purificação e teste. \\
\hline Ácido sulfanílico & $\begin{array}{l}\text { a. } 0,03 \mathrm{~g} / \mathrm{m} \\
\text { b. } 0,75 \mathrm{~g} / \mathrm{a}\end{array}$ & $\begin{array}{l}\text { a. Rede de esgoto sendo que } 0,02 \mathrm{~g} / \mathrm{m} \text { descartado em mistura ao álcool isoamilico e } 0,01 \mathrm{~g} / \mathrm{m} \text { em mistura ao ácido acético } 30 \% \text {. } \\
\text { b. } 0,75 \mathrm{~g} / \text { a descartado na rede de esgoto em mistura com } 1 \text {-naftol e hidróxido de amônia } 10 \% \text {. }\end{array}$ \\
\hline Acriflavina & $20 \mathrm{mg} / \mathrm{m}$ & Componente de Meio de cultura, autoclavado e descartado como RSS \\
\hline Acrilamida & $\begin{array}{l}371 \mathrm{~g} \text { a } 792 \mathrm{~g} / \mathrm{m} \\
* \text { e } 9,9 \text { a } 21 \mathrm{~g} / \mathrm{m} \\
\text { bisacrilamida* }\end{array}$ & $\begin{array}{l}\text { Descartado após polimerização como RSS; } \\
3000 \mathrm{ml} / \mathrm{m} \text { de gel de acrilamida marcado com } \mathrm{P}^{32} \text {, aguarda-se o decaimento, em bombonas de plástico que permanecem no } \\
\text { proprio laboratório, para depois descartá-lo como RSS. }\end{array}$ \\
\hline $\begin{array}{l}\text { Arseniato de } \\
\text { sódio }\end{array}$ & $\begin{array}{l}7,1 \mathrm{~g} \mathrm{de} \\
\text { arsênico/m }\end{array}$ & Segregados em meio ácido \\
\hline Auramina & $0,0044 \mathrm{~g} / \mathrm{m}$ & Descartado na rede de esgoto $(4 \mathrm{ml} / \mathrm{m}$ de uma solução $0,11 \%$ de auramina em etanol $95 \%$ e fenol $3 \%$ ) \\
\hline Brometo de etídio & $\begin{array}{l}0,000205 \mathrm{~g} \mathrm{em} \\
5.400 \mathrm{ml} / \mathrm{m} \text { de } \\
\text { gel de agarose e } \\
\text { em } 700 \mathrm{ml} / \mathrm{m} \mathrm{de} \\
\text { tampão }\end{array}$ & $\begin{array}{l}1.780 \mathrm{ml} / \mathrm{m} \text { de gel agarose } \mathrm{c} / \text { brometo inativado com hipoclorito; } \\
120 \mathrm{~mL} / \mathrm{m} \text { do gel inativado com } \mathrm{KMnO}_{4} 0,5 \mathrm{M}, \mathrm{HCL} 2,5 \mathrm{~N} \text { e } \mathrm{NaOH} 2,5 \mathrm{~N} \text { para posterior descarte na rede de esgoto } \\
3.500 \mathrm{ml} / \mathrm{m} \text { segregados; } \\
700 \mathrm{~mL} / \mathrm{m} \text { filtrado sobre carvão ativado e o carvão descartado como RSS.. }\end{array}$ \\
\hline Cloreto estanoso & $11,1 \mathrm{~g} / \mathrm{a} \mathrm{Sn}$ & $\begin{array}{l}4,67 \mathrm{~g} / \mathrm{a} \text { (equivalente a uma soluça } \mathrm{Sn} \mathrm{Cl}, 5 \% \text { em HCL } 10 \% \text { ) descartados na rede de esgoto em mistura com urina; e } 6,43 \mathrm{~g} / \mathrm{a} \text { (equivalente a } \\
\text { uma soluça } \mathrm{SnCl}_{2} .2 \mathrm{H}_{2} \mathrm{O} 40 \% \mathrm{em} \mathrm{HCL} \text { conc.) descartados na rede de esgoto em mistura com } \mathrm{KI} \text {, zinco em pó (parcial ou totalmente } \\
\text { consumido na reaçáo) }\end{array}$ \\
\hline
\end{tabular}




\begin{tabular}{|c|c|c|}
\hline Substância & Volume & Descarte adotado \\
\hline Clorofórmio & $16.320 \mathrm{ml} / \mathrm{m}$ & $\begin{array}{l}95 \mathrm{ml} / \mathrm{m} \text { descartado na rede de esgoto, destes } 30 \mathrm{ml} / \mathrm{m} \text { juntamente com iodeto de potássio e tiossulfato de sódio; } 1700 \mathrm{~mL} / \mathrm{m} \\
\text { concentrados em rotavapor, uma parte pequena vai para a rede de esgoto; } 31 \mathrm{ml} / \mathrm{m} \text { autoclavados juntamente com } 1 \mathrm{ml} \text { de } \\
\text { álcool isoamilico e descartados como } \mathrm{RSS} ; 450 \mathrm{ml} / \mathrm{m} \text { evaporados em capela ; restante segregado sendo que } 20 \mathrm{ml} / \mathrm{m} \\
\text { segregados em mistura com } 1 \mathrm{ml} \text { de álcool isoamilico; } 1,200 \mathrm{ml} / \mathrm{m} \text { separados para a comissão em mistura com leite e } \\
\text { dodecilsulfato de sódio; } 700 \mathrm{ml} / \mathrm{m} \text { segregados em mistura a acetona e isopropanol e } 120 \mathrm{ml} / \mathrm{m} \text { segregados misturado a acetona; } \\
12.000 \mathrm{ml} / \mathrm{m} \text { separados para a comissão em mistura com acetato de etila e metanol; cerca de } 800 \mathrm{ml} / \mathrm{m} \mathrm{misturados} \mathrm{a} 400 \mathrm{ml} / \mathrm{m} \\
\text { de metanol. }\end{array}$ \\
\hline
\end{tabular}

Dimetilaminoazo $\quad 0,00125 \mathrm{~g} / \mathrm{m} \quad$ Descartados na rede de esgoto com ácido sulfúrico diluidos no hipoclorito.

\section{Benzeno}

\section{Diclorometano $\quad 19.400 \mathrm{ml} / \mathrm{m}$}

$500 \mathrm{~mL} / \mathrm{m}$ descartados com a matriz biológica (urina), diluidos com hipoclorito na rede de esgoto; cerca de $2.000 \mathrm{ml} / \mathrm{m}$ evaporados em capela; cerca de $300 \mathrm{ml} / \mathrm{m}$ concentrados no rotavapor * (10L/estudo); restante segregado sendo $170 \mathrm{ml} / \mathrm{m}$ misturados ao metanol e a acetonitrila.

Dietilnitrosamina $\underset{\text { em solufio fisiologica }}{\mathrm{lg} / \mathrm{m}}$ Utilizado em estudo experimental, residuo e seringa descartados como RSS

Difenilamina $\quad 2,4 \mathrm{~g} / \mathrm{m} \quad$ Descartados na rede de esgoto em mistura com ácido sulfúrico, acético e acetaldeído

Dimetilformamida $1.500 \mathrm{ml} / \mathrm{m} \quad$ Segregados sendo que $1 ., 350 \mathrm{ml} / \mathrm{m} \mathrm{em}$ mistura com ácidos e metanol, acetato de etila

Fenolftaleína $\quad 2-3 \mathrm{~mL} / \mathrm{m} \quad$ Indicador - rede de esgoto em mistura com óleos, bases e ácidos ou leite e hidróxidos

Fluoreto de $\quad 0,4 \mathrm{~g} /$ ano $\quad$ Solução etanólica descartada na rede de esgoto diluida em hipoclorito

fenilmetilsulfonio

(PMSF

lodeto de cádmio $750 \mathrm{mg} / \mathrm{m}$ nebulizados em capela química (revelador) $-15 \mathrm{~mL} / \mathrm{m}$ de solução $5 \%$ em ninhidrina $1 \%$ em etanol - 
Cont. Tabela A-23

\begin{tabular}{|c|c|c|}
\hline Substância & Volume & Descarte adotado \\
\hline Naftol & $\begin{array}{l}\text { a. } 55 \mathrm{mg} / \mathrm{m} \\
\text { b. } 0,6 \mathrm{~g} / \mathrm{a}\end{array}$ & $\begin{array}{l}\text { a. } 55 \mathrm{mg} / \mathrm{m} \text { (soluç̧es em acido acético e etanol } 95 \% \text { ), utilizadas em testes bioquímicos para identificação de microorganismos } \\
\text { autoclavados e descartados como RSS } \\
\text { b. } 0,6 \mathrm{~g} / \mathrm{a} \text { descartado na rede de esgoto em mistura com ácido sulfanílico e hidróxido de amônia } 10 \% \text {. }\end{array}$ \\
\hline Ninhidrina & $38,04 \mathrm{~g} / \mathrm{m}$ & $\begin{array}{l}38 \mathrm{~g} / \mathrm{m} \text { descartado na- rede de esgoto em mistura com dimetilsulfóxido, água, acetato de lítio e ácido acético; } 0,04 \mathrm{~g} / \mathrm{m} \\
\text { (equivalente a } 1 \mathrm{~m} / \mathrm{m} \text { ) autoclavado em mistura com acetona e butanol e descartado como RSS. }\end{array}$ \\
\hline o-fenilenodiamina & 0,04 a $0,08 \mathrm{~g} / \mathrm{m}$ & Descartado na rede de esgoto misturado ao ácido sulfúrico e diluído com hipoclorito \\
\hline $\begin{array}{l}\text { Sais de chumbo } \\
\star \star \star\end{array}$ & $\begin{array}{l}12,25 \mathrm{~g} \text { de } \\
\mathrm{Pb} / \mathrm{m}\end{array}$ & $\begin{array}{l}0,0056 \mathrm{mg} / \mathrm{m} \text { segregado em mistura com tampão acetato, tioacetamida e glicerina } \\
\text { restante descartado na rede de esgoto ou no saco plástico juntamente com a matriz analisada. }\end{array}$ \\
\hline Sais de cromo & $\begin{array}{l}\text { a. } 325,8 \mathrm{~g} / \mathrm{m} \mathrm{de} \\
\mathrm{Cr} \\
\text { b. } 4,16 \mathrm{~g} / \text { ano }\end{array}$ & $\begin{array}{l}\text { a. Segregados sendo que } 16,9 \mathrm{~g} / \mathrm{m} \text { segregado em mistura ao sulfato de ferro e amônia e ácido sulfúrico e } 308,9 \mathrm{~g} / \mathrm{m} \text { equivalente a } \\
1500 \mathrm{ml} / \mathrm{m} \text { de solução de dicromato de potássio } 0,7 \mathrm{~N} \text {; } \\
\text { b. } 4,16 \mathrm{~g} \text { /ano (equivalente a de tríxxido de cromo) descartados na rede de esgoto em mistura com hidróxido de potássio } \\
7,8 \mathrm{~N} \text {, piridina, urina diluidos numa solução de hipoclorito. }\end{array}$ \\
\hline Sais de mercúrio & $\begin{array}{l}\text { a. } 90 \mathrm{~g} / \mathrm{m} \text { de } \\
\mathrm{Hg} \\
\text { b. } 4,8 \mathrm{~g} / \mathrm{ano}\end{array}$ & $\begin{array}{l}\text { a. Segregados sendo que } 70 \mathrm{~g} / \mathrm{m} \mathrm{na} \mathrm{forma} \mathrm{de} \mathrm{acetato} \mathrm{de} \mathrm{mercúrio}(350 \mathrm{~m} / \mathrm{m} \text { de soluçăo } 0,1 \mathrm{~N} \text { ) e } 20 \mathrm{~g} / \mathrm{m} \text { na forma de iodeto mercúrico } \\
(100 \mathrm{ml} / \mathrm{m} \text { solução } 1 \mathrm{~N}) \\
\text { b. } 4,4 \mathrm{~g} / \text { ano }(6 \mathrm{~g} \text { de cloreto de mercúrio) descartados na rede de esgoto em mistura com nitrato férrico, ácido clorídrico; e soro } \\
\text { (volume da mistura equivalente a } 180 \mathrm{ml} / \text { ano) e } 0,4 \mathrm{~g} / \text { ano (equivalente a uma solução } \mathrm{HgNO}_{3} 0,1 \% \text { ) nebulizados em capela. }\end{array}$ \\
\hline Sais de prata & $\begin{array}{l}\text { a. } 13,9 \mathrm{~g} \mathrm{de} \\
\mathrm{Ag} / \mathrm{m}\left(\mathrm{Ag} \mathrm{NO}_{3}\right) \\
\text { (nitrato de prata) } \\
\text { b. } 0,75 \mathrm{~g} \mathrm{Ag} / \mathrm{ano})\end{array}$ & $\begin{array}{l}\text { a. } 10,373 \mathrm{~g} / \mathrm{m} \text { descartados na rede de esgoto sendo que } 9,6 \mathrm{~g} / \mathrm{m} \text { (equivalente a } 75,8 \mathrm{ml} \text { solução de } \mathrm{AgNO}_{3} 5 \% \text { ) descartados misturados a } 25 \\
\mathrm{ml} \mathrm{NH} \mathrm{NH}_{4} \mathrm{OH} \text { concentrado, } 180 \mathrm{ml} \text { de } \mathrm{NaOH} 0,1 \mathrm{~N} \text { e } 1715 \mathrm{ml} \text { de água; } 0,77 \mathrm{~g} / \mathrm{m} \text { (equivalentes a } 720 \mathrm{ml} / \mathrm{m} \text { de solução } 0,17 \% \text { ) descartados } \\
\text { misturados ao hidróxido de sódio; } 0,003 \mathrm{~g} / \mathrm{m} \text { equivalentes a } 100 \mathrm{ml} / \mathrm{m} \text { de solução de AgNO } \mathrm{A}_{3} 0,05 \% \text {; restante é segregado. } \\
\text { b. dietilditiocarbamato de } \mathrm{Ag} \text { (equivalente a } 150 \mathrm{ml} / \text { ano de solução } 0,5 \% \mathrm{em} \text { piridina) descartado na rede de esgoto. }\end{array}$ \\
\hline $\begin{array}{l}\text { Tetracloreto de } \\
\text { carbono }\end{array}$ & $60 \mathrm{ml} / \mathrm{m}$ & Segregados em mistura com a trietilamina \\
\hline Tioacetamida & $0,240 \mathrm{~g} / \mathrm{m}$ & Segregados em mistura com nitrato de chumbo, tampão acetato e glicerina ( $56: 28: 28: 6$ de tioacetamida) $-6 \mathrm{~mL} / \mathrm{m}$ solução $4 \%$ \\
\hline
\end{tabular}


Tabela A - 24 - Residuos contendo substâncias classificadas como tóxicas geradas pela Instituição C e descarte adotado

\begin{tabular}{|c|c|c|}
\hline Substância & Volume & Descarte adotado \\
\hline Acetato de chumbo & $\mathrm{lg} / \mathrm{m}$ & Rede de esgoto em mistura ao ácido acético e sangue. \\
\hline $\begin{array}{l}\text { Acrilamida } \\
\text { /bisacrilamida }\end{array}$ & $\begin{array}{l}117,3 \text { a } 255 \mathrm{~g} / \mathrm{m} \\
\text { acrilamida e } 3,1 \text { a } 6,8 \\
\mathrm{~g} \text { m de bisacrilamida }\end{array}$ & Arquivado. \\
\hline Benzidina & $25 \mathrm{~g} / \mathrm{m}$ & $\begin{array}{l}\text { Descartados com resíduos sólidos em saco plástico comum, juntamente com tubo de ensaio onde se procedeu a reação } \\
\text { contendo sangue peróxido de hidrogênio e ácido acético. }\end{array}$ \\
\hline Clorofórmio & $31.380 \mathrm{ml} / \mathrm{m}$ & $\begin{array}{l}18.100 \mathrm{ml} / \mathrm{m} \text { evaporados em capela em mistura com éter etílico, } 4.000 \mathrm{ml} / \mathrm{m} \text { evaporados em capela em mistura ao a } \\
\text { isopropanol;; restante descartado na rede de esgoto sendo que } 5.000 \mathrm{ml} / \mathrm{m} \text { em mistura ao metanol; } 4.000 \mathrm{ml} / \mathrm{m} \mathrm{em} \text { mistura à } \\
\text { acetona } 240 \mathrm{ml} / \mathrm{m} \text { em mistura ao tolueno e cerca de } 40 \mathrm{ml} / \mathrm{m} \mathrm{em} \mathrm{mistura} \mathrm{ao} \mathrm{álcool} \mathrm{isoamilico} \mathrm{e} \mathrm{iodeto} \mathrm{de} \mathrm{sódio.}\end{array}$ \\
\hline Diclorometano & $10 \mathrm{ml} / \mathrm{m}$ & Rede de esgoto \\
\hline Fenolftaleína & $0,25 \mathrm{~g} / \mathrm{m}$ & $\begin{array}{l}\text { Descartado como residuo sólido, em saco plástico comum, juntamente com o tubo de ensaio onde se procedeu a reação } \\
\text { contendo sangue }\end{array}$ \\
\hline Nitrato de prata & $4,2 \mathrm{~g} / \mathrm{m}$ & Rede de esgoto \\
\hline Sais de mercúrio & $15,3 \mathrm{~g} / \mathrm{m} \mathrm{de} \mathrm{Hg}$ & Nebulizados em capela com água e ácido sulfúrico \\
\hline $\begin{array}{l}\text { Soluções padrão } \\
\text { de metais* }\end{array}$ & $\begin{array}{l}0,001 \text { a } 0,003 \mathrm{~g} / \mathrm{m} \\
\text { de cada metal }\end{array}$ & Descarta-se na rede de esgoto as soluçðes estoque vencidas e os resíduos provenientes das análises. \\
\hline
\end{tabular}


ANEXO 19

- Resíduos contendo substâncias não perigosas gerados pelas Instituições avaliadas 
Tabela A-25 - Residuos contendo substâncias classificadas como não perigosas gerados na Instituição A e o descarte adotado.

\begin{tabular}{|c|c|c|}
\hline Substância & Volume & Descarte \\
\hline $\begin{array}{l}\alpha \text {-amilase; protease; } \\
\text { amiloglicosidade }\end{array}$ & $\mathrm{NE}$ & Rede de esgoto - análise de fibras (hidrólise enzimática) \\
\hline Acetato de cobre & $0,43 \mathrm{~g} / \mathrm{m}$ & Rede de esgoto em mistura com álcool isoamílico, cuproína em tolueno, tampło acetato, diluídos em álcool comercial. \\
\hline Acetato de zinco ${ }^{3}$ & $3,6 \mathrm{~g} / \mathrm{m}$ & Utilizado para precipitar proteina de embutidos, descartado na rede de esgoto $\mathrm{em}$ mistura com o ferricianeto de potássio- \\
\hline Ácido bórico & $\begin{array}{l}\text { cerca de } 3.300 \\
\mathrm{~g} / \mathrm{m}\end{array}$ & $\begin{array}{l}\text { Cerca de } 3000 \mathrm{~g} / \mathrm{m} \text { utilizado como componente do tampão de corrida para o gel de agarose, se misturado ao brometo de } \\
\text { etídio, tratado com como descrito por SAMBROOK e col (1989); restante descartado na rede de esgoto, } 0,3 \mathrm{~g} / \mathrm{m} \text { utilizado } \\
\text { em titulação ácido-base, descartado neutralizado na rede de esgoto. }\end{array}$ \\
\hline Ácido cloroplatínico & $0,75 \mathrm{~g} / \mathrm{m}$ & Nebulizados em capela em mistura ao iodeto de potássio (solução aquosa) \\
\hline Amido & $4 \mathrm{~g} / \mathrm{m}$ & Rede de esgoto em mistura ao clorofórmio, ácido acético, iodeto de potássio, tiossulfato de sódio. \\
\hline 4-aminoantipirina ${ }^{1}$ & $0,022 \mathrm{~g} / \mathrm{m}$ & $\begin{array}{l}\text { Segregados (complexo aminopirina-fenol), diluidos com tampào cloreto de potássio, ácido bórico e } \mathrm{NaOH} \text { - pH 7,97 e em } \\
\text { mistura com hexacianeto ferroso III ; o restante descartado na rede de esgoto em mistura a colesterol esterase, colesterol } \\
\text { oxidase, peroxidase, glicerol fosfato oxidas e diluidos com hipoclorito. }\end{array}$ \\
\hline Anisaldeído ${ }^{1}$ & $0,5 \mathrm{ml} / \mathrm{m}$ & Nebulizado em capela química em mistura com ácidos acético e sulfúrico e metanol \\
\hline $\begin{array}{l}\text { Batofenantrolina } \\
1\end{array}$ & $0,300 \mathrm{~g} / \mathrm{m}$ & Descartado na rede de esgoto diluídos com hipoclorito (utilizado na determinação de transferrina) \\
\hline 2,2'-bipirideno ${ }^{1}$ & $0,300 \mathrm{~g} / \mathrm{m}$ & Rede de esgoto em mistura com cloreto férrico, etanol e EDTA. \\
\hline Brometo de dimidio & $0,7 \mathrm{~g} / \mathrm{m}$ & Segregado ou evaporado em mistura ao clorofórmio e ao dissulfine blue \\
\hline $\begin{array}{l}\text { Brometo de } \\
\text { hexadeciltrimetil } \\
\text { Amónia }\end{array}$ & $1,3 \mathrm{~g} / \mathrm{m}$ & Solução 5\% em NaCL 5M - autoclavados e descartado scomo RSS. \\
\hline $\begin{array}{l}\text { Carbonato de } \\
\text { magnésio }\end{array}$ & $60 \mathrm{~g} / \mathrm{m}$ & Clarificante - filtrado e residuo - RSS \\
\hline
\end{tabular}


Cont. Tabela A- 25

\begin{tabular}{|c|c|c|}
\hline Substância & Volume & Descarte \\
\hline Carbonato de sódio & $500 \mathrm{~g} / \mathrm{m}$ & Rede de esgoto \\
\hline Citrato de amônia & $20 \mathrm{~g} / \mathrm{m}$ & Segregados em mistura ao hidróxido de amônia e água \\
\hline Citrato de sódio & $12 \mathrm{~g} / \mathrm{m}$ & $\begin{array}{l}\text { Solução amoniacal segregada em frasco único em mistura com solventes, hidróxidos, ácidos , dietilditiocarbamato de } \\
\text { prata e 1-naftol. }\end{array}$ \\
\hline Cloreto de cobalto ${ }^{1}$ & $\begin{array}{l}\text { Cerca de } \\
0,078 \mathrm{~g} / \mathrm{m}\end{array}$ & Segregado em mistura ao nitrato de amônia, tiocianato de potássio e tensoativo não iônico. \\
\hline Cloreto de magnésio & $\begin{array}{l}\text { a. } 7,1 \mathrm{~g} / \mathrm{m} \\
\text { b. } 0,0095 \mathrm{~g} / \mathrm{m}\end{array}$ & $\begin{array}{l}\text { a. Rede de esgoto em mistura com sulfato de extran, soro, diluídos com hipoclorito. } \\
\text { b. Rede de esgoto em mistura com hemolisado, NADP, EDTA e tampão tris-HCL diluídos em hipoclorito }\end{array}$ \\
\hline $\begin{array}{l}\text { Cloreto de } \\
\text { naftilenodiamina }\end{array}$ & $0,165 \mathrm{~g} / \mathrm{m}$ & $\begin{array}{l}0,125 \mathrm{~g} / \mathrm{m} \text { descartados na rede de esgoto em mistura com cloreto de amônia e desproteinizado de carne ou salsicha; } 0,04 \\
\mathrm{~g} / \mathrm{m} \text { segregados em mistura à água, sulfanilamida, ácido fosfórico. }\end{array}$ \\
\hline Cloreto férrico & $0,125 \mathrm{~g} / \mathrm{m}$ & Rede de esgoto em mistura ao etanol, EDTA, 2,2' bipirideno \\
\hline $\begin{array}{l}\text { Cloridrato de } \\
\text { hidroxilamina }\end{array}$ & $5,6 \mathrm{~g} / \mathrm{m}$ & $\begin{array}{l}\text { Rede de esgoto sendo que } 3,6 \mathrm{~g} / \mathrm{m} \text { em mistura com glutaraldeído, azul de bromo fenol (solução neutralizada) e o restante } \\
\text { em mistura com ácido clorídrico, água, tampão acetato, fenantrolina. }\end{array}$ \\
\hline 4-clorofenol ${ }^{1}$ & $0,076 \mathrm{~g} / \mathrm{m}$ & Rede de esgoto (solução $0,5 \mathrm{mg} / \mathrm{ml} \mathrm{em} \mathrm{tampão} \mathrm{tris.}$ \\
\hline 4-cloronaftol ${ }^{1}$ & $0,176 \mathrm{~g} / \mathrm{m}$ & Rede de esgoto com hipoclorito \\
\hline Cuproína ${ }^{1}$ & $0,12 \mathrm{~g} / \mathrm{m}$ & $\begin{array}{l}\text { Solução } 0,4 \% \text { em tolueno descartada na rede de esgoto em mistura com acetato de cobre em álcool isoamilico e tampão } \\
\text { acetato, diluídos em etanol comercial. }\end{array}$ \\
\hline Dicloridrina & $2-3 \mathrm{ml} / \mathrm{m}$ & Rede de esgoto em mistura com glicerol \\
\hline $\begin{array}{l}\text { 2,6-dicloroquinona } \\
\text { clorimida }\end{array}$ & $20 \mathrm{~g} / \mathrm{m}$ & Rede de esgoto em mistura com tampão cloreto de amônia, isopropanol, vitamina B6. \\
\hline
\end{tabular}


Cont. Tabela A- 25

\begin{tabular}{|c|c|c|}
\hline Substância & Volume & Descarte \\
\hline Dimetilsulfóxido ${ }^{1}$ & $55 \mathrm{a} 155 \mathrm{ml} / \mathrm{m}$ & Concentrados em capela química, a maior parte em mistura com éter etílico ou de petróleo. \\
\hline Dióxido de titânio ${ }^{1}$ & $\begin{array}{l}\text { Cerca de } \\
5,5 \mathrm{~g} / \mathrm{m}\end{array}$ & $\begin{array}{l}\text { Rede de esgoto em mistura com sulfato de cobre e sulfato de potássio. (Catalisador utilizado na digestão ácida de } \\
\text { alimentos- determinação de protídeos) }\end{array}$ \\
\hline Dissulfine blue ${ }^{2}$ & $0,35 \mathrm{~g} / \mathrm{m}$ & Segregados ou evaporados em capela em mistura com brometo de dimidium e clorofórmio. \\
\hline $\begin{array}{l}\text { Dodecilsulfato de } \\
\text { sódio }\end{array}$ & $25,2 \mathrm{~g} / \mathrm{m}$ & $\begin{array}{l}1,2 \mathrm{~g} / \mathrm{m} \text { evaporados em capela; } 21,6 \mathrm{~g} / \mathrm{m} \text { descartados na rede de esgoto; } 2,4 \mathrm{~g} / \mathrm{m} \text { descartados no saco plástico branco } \\
\text { como RSS (componente do gel de acrilamida) }\end{array}$ \\
\hline EDTA sódico ${ }^{1}$ & $\begin{array}{l}\text { a. } 0,038 \mathrm{~g} / \mathrm{m} \\
\text { b. } 330 \mathrm{~g} / \mathrm{m}\end{array}$ & $\begin{array}{l}\text { a. Rede de esgoto em mistura com hemolisado, Tampão Tris- HCL, cloreto de magnésio e NADP diluídos com hipoclorito. } \\
\text { b. Tampão de corrida para o gel de agarose ( descarte na rede de esgoto se não contiver brometo de etídio) }\end{array}$ \\
\hline $\begin{array}{l}\text { Ferricianeto de } \\
\text { potássio }^{1}\end{array}$ & $1,82 \mathrm{~g} / \mathrm{m}$ & $\begin{array}{l}1,96 \mathrm{~g} / \mathrm{m} \text { descartados na rede de esgoto sendo que } 1,8 \mathrm{~g} / \mathrm{m} \text { utilizados para precipitar proteina de embutidose descartados } \\
\text { em mistura com o acetato de zinco, } 0,16 \mathrm{~g} / \mathrm{m} \text { em mistura com cianeto de sódio, tampão e sangue total, diluídos com } \\
\text { hipoclorito; } 0,02 \mathrm{~g} / \mathrm{m} \text { segregado em mistura com } 4 \text {-aminopirina e fenol. }\end{array}$ \\
\hline Fluoresceína ${ }^{1}$ & $\begin{array}{l}\text { a. } \lg / \mathrm{m} \\
\text { b. NE }\end{array}$ & $\begin{array}{l}\text { a. Rede de esgoto em mistura às amostras de vitamina B2 } \\
\text { b. utilizado em imunofluorescência }\end{array}$ \\
\hline $\begin{array}{l}\text { Fosfotungstato de } \\
\text { potássio }\end{array}$ & $0,02 \mathrm{~g} / \mathrm{m}$ & Rede de esgoto descarte de soluçð̄es; reativo descartado com o material analisado em saco plástico branco como RSS \\
\hline Glicerina $^{1}$ & $1500 \mathrm{ml} / \mathrm{m}$ & Rede de esgoto sendo que $6 \mathrm{ml} / \mathrm{m}$ em mistura com metanol, ácido acético, e o restante com etanol e $\mathrm{KOH}$ \\
\hline Glicina & $288 \mathrm{~g} / \mathrm{m}$ & Rede de esgoto em mistura ao tampão de corrida do gel de acrilamida \\
\hline Glicose & $0,025 \mathrm{~g} / \mathrm{m}$ & Rede de esgoto em mistura com nitrito de sódio, azul de metileno, e sangue diluídos em hipoclorito. \\
\hline Iodeto de potássio ${ }^{1}$ & $41 \mathrm{~g} / \mathrm{m}$ & $\begin{array}{l}29 \mathrm{~g} / \mathrm{m} \text { nebulizados em capela sendo } 15 \mathrm{~g} / \mathrm{m} \text { em mistura ao ácido cloroplatínico e o restante em mistura com ácido acético, } \\
\text { sulfúrico, iodo e nitrato de bismuto; } 9 \mathrm{~g} / \mathrm{m} \text { descartados na rede de esgoto sendo } 1 \mathrm{~g} / \mathrm{m} \text { em mistura com clorofórmio, ácido } \\
\text { acético, tiossulfato de sódio e amido e } 8 \mathrm{~g} / \mathrm{m} \text { em mistura com iodo e água; } 3 \mathrm{~g} / \mathrm{m} \text { segregados em mistura a iodeto de } \\
\text { mercúrio e } \mathrm{NaOH} \text {. }\end{array}$ \\
\hline
\end{tabular}


Cont. Tabela A- 25

\begin{tabular}{|c|c|c|}
\hline Substância & Volume & Descarte \\
\hline $\begin{array}{l}\text { Monohidrato de } \\
\text { fenantrolina }^{1}\end{array}$ & $0,040 \mathrm{~g} / \mathrm{m}$ & Rede de esgoto em mistura com a hidroxilamina, ácido cloridrico e tampðo acetato. \\
\hline Nitrato de bismuto & $0,59 \mathrm{~g} / \mathrm{m}$ & Nebulizado em capela em mistura com iodo, iodeto de potássio e ácidos acético e sulfúrico. \\
\hline Óxido de magnésio ${ }^{1}$ & $0,5 \mathrm{~g} / \mathrm{m}$ & Rede de esgoto em mistura com etanol comercial e $\mathrm{NaOH}$; descartado com grande volume de água. \\
\hline $\begin{array}{l}\text { Pirrolidinaditio } \\
\text { carbamato de } \\
\text { amônio }^{1}\end{array}$ & $0,4 \mathrm{~g} / \mathrm{m}$ & Segregado em mistura a metilisobutilcetona e sangue. \\
\hline $\begin{array}{l}\text { p-nitrofenil } \\
\text { hidrazina }^{1}\end{array}$ & $0,04 \mathrm{mg} / \mathrm{m}$ & Rede de esgoto em mistura com $\mathrm{NaOH}$ e diluida em hipoclorito. \\
\hline Polietilenoglicol $^{1}$ & $15 \mathrm{~g} / \mathrm{m}$ & Nebulizados em capela - solução etanólica \\
\hline Resorcina $^{1}$ & $0,1 \mathrm{~g} / \mathrm{m}$ & Rede de esgoto \\
\hline $\begin{array}{l}\text { Rnase, proteinase e } \\
\text { lisozima (concentraşăo } \\
\text { Năo especificada) }\end{array}$ & 2 a $4 \mathrm{ml} / \mathrm{m}$ & Tampão de lise- rede de esgoto \\
\hline Sulfanilamida ${ }^{1}$ & $0,6 \mathrm{~g} / \mathrm{m}$ & $\begin{array}{l}0,4 \mathrm{~g} / \mathrm{m} \text { segregado em mistura ao ácido fosfórico, naftilenodiamina e água e } 0,2 \mathrm{~g} / \mathrm{m} \text { descartado na rede de esgoto em } \\
\text { mistura com naftilenodiamina, tampão e cloreto de amônia. }\end{array}$ \\
\hline Sulfato de cobre ${ }^{1}$ & $\begin{array}{l}\text { Cerca de } 63 \\
\mathrm{~g} / \mathrm{m}\end{array}$ & $\begin{array}{l}\text { Rede de esgoto como óxido cuproso em mistura com o tartarato de sódio e potássio }(8,7 \mathrm{~g} / \mathrm{m}) \text {; catalisador - na digestão } \\
\text { ácida de alimentos- determinação de protídeos em mistura com dióxido de titânio e sulfato de potássio. }\end{array}$ \\
\hline Sulfato de potássio ${ }^{1}$ & $\begin{array}{l}\text { Cerca de } 540 \\
\mathrm{~g} / \mathrm{m}\end{array}$ & $\begin{array}{l}\text { Catalisador na disgestão ácida para quantificação de protídeos em alimentos em mistura com o sulfato de cobre e dióxido } \\
\text { de titânio }\end{array}$ \\
\hline Sulfito de sódio ${ }^{1}$ & $2,5 \mathrm{~g} / \mathrm{m}$ & Rede de esgoto neutralizado (titulação de formol). \\
\hline
\end{tabular}


Cont. Tabela A- 25

\begin{tabular}{|c|c|c|}
\hline Substância & Volume & Descarte \\
\hline $\begin{array}{l}\text { Tampão acetato de } \\
\text { amônia }\end{array}$ & $200 \mathrm{ml} / \mathrm{m}$ & Rede de esgoto em mistura com água, hidroxilamina e fenantrolina \\
\hline $\begin{array}{l}\text { Tampão acetato de } \\
\text { sódio/ ácido acético }\end{array}$ & $10 \mathrm{ml} / \mathrm{m}$ & Rede de esgoto em mistura com cuproina e acetato de cobre. \\
\hline Tampão barbital & $50 \mathrm{~g} / \mathrm{m}$ & Reaproveitado várias vezes e depois descartado na rede de esgoto diluido em hipoclorito \\
\hline $\begin{array}{l}\text { Tampåo de corrida } \\
\text { acrilamida (trisma, } \\
\text { glicina, SDS, agua) }\end{array}$ & $\begin{array}{l}\text { Cerca de } \\
20.000 \mathrm{ml} / \mathrm{m}\end{array}$ & Rede de esgoto sem inativação \\
\hline $\begin{array}{l}\text { Tampåo de lavagem } \\
\text { - tecnica ELISA (fosfnto } \\
\text { ou citrato ou PBS) }\end{array}$ & $\begin{array}{l}\text { Cerca de } \\
6.400 \mathrm{ml} / \mathrm{m}\end{array}$ & $1.300 \mathrm{ml} / \mathrm{m}$ descartados na rede de esgoto sem inativaçăo, restante inativado com hipoclorito antes do descarte \\
\hline $\begin{array}{l}\text { Tampão PBS }\left(\mathrm{NaCl}_{h}\right. \\
\left.\mathrm{Na}_{2} \mathrm{HPO}_{4} \text { e } \mathrm{NaH}_{3} \mathrm{PO}_{4}\right)\end{array}$ & NE & $\begin{array}{l}\text { Tampåo utilizado em etapas de lavagem nos métodos imunológicos, em geral, inativado com hipoclorito e descartado na } \\
\text { rede de esgoto. }\end{array}$ \\
\hline $\begin{array}{l}\text { Tampão soda, } \\
\text { cloreto de potássio, } \\
\text { ácido bórico }\end{array}$ & $50 \mathrm{ml} / \mathrm{m}$ & Segregados ou evaporados em mistura ao clorofórmio \\
\hline $\begin{array}{l}\text { Tampåo TBE (tris, } \\
\text { EDTA, ácido bórico) }\end{array}$ & $22.600 \mathrm{ml} / \mathrm{m}$ & $\begin{array}{l}4.000 \mathrm{ml} / \mathrm{m} \text { inativados como descrito por SAMBROOK e col. (1989); restante descartado na rede de esgoto sem } \\
\text { inativação. }\end{array}$ \\
\hline $\begin{array}{l}\text { Tartarato de sódio e } \\
\text { potássio }\end{array}$ & $43 \mathrm{~g} / \mathrm{m}$ & Rede de esgoto em mistura com óxido cuproso. \\
\hline $\begin{array}{l}\text { Temed-N,N,N',N'- } \\
\text { tetrametil- 1,2- } \\
\text { etanodiamina }\end{array}$ & $2,4 \mathrm{ml}$ & Descartado como RSS - juntamente com o gel de acrilamida \\
\hline
\end{tabular}

Tampão acetato de $10 \mathrm{ml} / \mathrm{m}$ Rede de esgoto em mistura com cuproina e acetato de cobre.

Reaproveitado várias vezes e depois descartado na rede de esgoto diluido em hipoclorito

Tampão de corrida Cerca de

Rede de esgoto sem inativação

Tampåo de lavagem Cerca de - tecnica ELISA (fosfato $6.400 \mathrm{ml} / \mathrm{m}$

Tampão PBS ( $\mathrm{NaCl}_{n} \quad \mathrm{NE}$

$50 \mathrm{ml} / \mathrm{m}$

cloreto de potássio,

Tampão TBE (tris, $\quad 22.600 \mathrm{ml} / \mathrm{m}$

etanodiamina 
Cont. Tabela A- 25

\begin{tabular}{|c|c|c|}
\hline Substância & Volume & Descarte \\
\hline $\begin{array}{l}\text { Tetrabutilamônio } \\
\text { hidrogeno sulfato } \\
\mathbf{0 , 0 1} \mathbf{M}\end{array}$ & $325 \mathrm{ml} / \mathrm{m}$ & $\begin{array}{l}\text { Segregados em frasco único em mistura com metanol e outros solventes clorados e não clorados, dietilditiocarbamato de } \\
\text { prata, tampóes e 1-naftol. }\end{array}$ \\
\hline $\begin{array}{l}\text { 3,3',5,5'-Tetrametil } \\
\text { benzidina (TMB) }\end{array}$ & $102 \mathrm{mg} / \mathrm{m}$ & $\begin{array}{l}\text { Rede de esgoto em mistura com peróxido de hidrogênio e ácido sulfúrico } 2 \mathrm{~N} \text { diluídos em hipoclorito. (concentração da } \\
\text { solução não especificada nas bulas dos KITS, quantidade extrapolada a partir de solução preparada em laboratório na } \\
\text { concentração de } 25 \mathrm{mM} \text { em dimetilsulfóxido) }\end{array}$ \\
\hline $\begin{array}{l}\text { Tiocianato de } \\
\text { potássio }^{1}\end{array}$ & $1,65 \mathrm{~g} / \mathrm{m}$ & Segregados em mistura ao nitrato de amônia, cloreto de cobalto e tensoativo não iônico. \\
\hline $\begin{array}{l}\text { Tiocianato de } \\
\text { guanidina } 5 \mathbf{M}^{1}\end{array}$ & $5.400 \mathrm{ml} / \mathrm{m}$ & Filtrados sobre dióxido de silício - em mistura com triton X-100 e Tris HCL, descartados na rede de esgoto \\
\hline $\begin{array}{l}\text { Tiossulfato de sódio } \\
0,01 \text { N e } 0,1 \mathrm{~N}\end{array}$ & $\begin{array}{l}\text { Cerca de } 3,5 \\
\mathrm{~g} / \mathrm{m}\end{array}$ & $\begin{array}{l}\text { Rede de esgoto em mistura com amido óleo, clorofórmio e ácido acético glacial (Titulação para determinar o índice de } \\
\text { iodo) }\end{array}$ \\
\hline Trisma base & $\begin{array}{l}\text { Cerca de } 470 \\
\mathrm{~g} / \mathrm{m}\end{array}$ & $\begin{array}{l}\text { Rede de esgoto cerca de } 10 \mathrm{~g} / \mathrm{m} \text {; componente do gel de acrilamida, Tampöes de corrida e de amostra do gel de acrilamida } \\
\text { e agarose, descartados juntamente a esses componentes }\end{array}$ \\
\hline
\end{tabular}

Nota: $\mathrm{NE}=$ não especificado; 1 - dados de mutagenicidade relatados; 2-Carcinogenicidade questionada em animais de experimentação; 3-teratogênico experimental 
Tabela A-26 - Residuos contendo substâncias classificadas como não perigosas gerados pela Instituição B e classificados não perigosos

\begin{tabular}{|c|c|c|}
\hline Substância & Volume & Descarte realizado \\
\hline $\begin{array}{l}\text { Acetato de cobre } \\
3 \%\end{array}$ & $0,25 \mathrm{~g} / \mathrm{m}$ & Rede de esgoto ou como RSS \\
\hline $\begin{array}{l}\text { Acetato de lítio } \\
\text { Acetato de lítio } 20 \\
\mathbf{m M}\end{array}$ & $\begin{array}{l}14 \mathrm{~g} / \mathrm{m} \\
1.000 \mathrm{ml} / \mathrm{m}\end{array}$ & $\begin{array}{l}\text { Rede de esgoto em mistura ao DMSO, ninhidrina e ácido acético. } \\
\text { Segregados pelo fato da solução ser em metanol }\end{array}$ \\
\hline $\begin{array}{l}\text { Acetato de sódio } \\
2 \mathbf{M}^{1}\end{array}$ & $30 \mathrm{ml} / \mathrm{m}$ & Descartados na rede de esgoto com ferrosina \\
\hline Acetato de zinco ${ }^{1}$ & $13,2 \mathrm{~g} / \mathrm{a}$ & Descartados na rede de esgoto em mistura com ácido acético. \\
\hline $\begin{array}{l}\text { Acetoacetato de } \\
\text { etila }\end{array}$ & $180 \mathrm{ml} / \mathrm{a}$ & Descartados na rede de esgoto \\
\hline Äcido bórico & $\begin{array}{l}\text { Cerca de } 1380 \\
\mathrm{~g} / \mathrm{m}\end{array}$ & Descartados na rede de esgoto, solução saturada e componente do tampão de corrida do gel de agarose. \\
\hline Ácido cítrico & $100 \mathrm{~g} / \mathrm{m}$ & Segregados \\
\hline $\begin{array}{l}\text { Ácido indolacético } \\
0,1 \mathrm{mM} \text { em água' }\end{array}$ & $500 \mathrm{ml} / \mathrm{m}$ & Rede de esgoto em mistura com fragmentos de fruta e manitol \\
\hline Ácido linoleico & $\begin{array}{l}4.000 \mathrm{ml} / \mathrm{m} \\
\text { solução } 10 \%\end{array}$ & Rede de esgoto em mistura com tampão citrato. \\
\hline $\begin{array}{l}\text { Ácido } \\
\text { tiobarbitúrico }\end{array}$ & $0,77 \mathrm{~g} / \mathrm{m}$ & $\begin{array}{l}\text { Rede de esgoto sendo } 0,67 \mathrm{~g} / \mathrm{m} \text { em mistura com acido tricloracético, água e } 0,1 \mathrm{~g} / \mathrm{m} \text { de uma solução alcalina em mistura } \\
\text { com butanol e ácido. }\end{array}$ \\
\hline Alfa amilase & $2 \mathrm{ml} / \mathrm{m}$ & Rede de esgoto em mistura com tampão e etanol (análise de fibras). \\
\hline Amido 0,5\% & $4,0 \mathrm{~mL} / \mathrm{m}$ & Rede de esgoto em mistura com tiossulfato, lodeto de potássio. \\
\hline
\end{tabular}


Cont. Tabela A- 26

\begin{tabular}{|c|c|c|}
\hline Substância & Volume & Descarte \\
\hline 4-aminoantipirina ${ }^{1}$ & $\begin{array}{l}\text { a. } 0,036 \mathrm{~g} / \mathrm{m} \\
\text { b. } 0,0125 \mathrm{~g} / \mathrm{m}\end{array}$ & $\begin{array}{l}\text { a. Descartado na rede de esgoto em mistura com plasma, 4-clorofenol e enzimas } \\
\text { b. Rede de esgoto em mistura com soro e colesterol oxidase, peroxidase, ácido 2-hidroxi-fenil-acético, ferricianeto de potássio. }\end{array}$ \\
\hline Anisaldeído ${ }^{1}$ & $4 \mathrm{ml} / \mathrm{m}$ & Nebulizados em capela em mistura com metanol, ácidos acético e sulfúrico \\
\hline $\begin{array}{l}\text { Bicarbonato de } \\
\text { sódio }\end{array}$ & $5,0 \mathrm{~g} / \mathrm{m}$ & Rede de esgoto \\
\hline $\begin{array}{l}\text { Brometo de } \\
\text { potássio }^{1}\end{array}$ & $208 \mathrm{~g} / \mathrm{m}$ & Rede de esgoto \\
\hline $\begin{array}{l}\text { Carbonato de } \\
\text { potássio }\end{array}$ & $1,2 \mathrm{~g} / \mathrm{m}$ & Rede de esgoto \\
\hline Carbonato de sódio & $71,2 \mathrm{~g} / \mathrm{m}$ & Rede de esgoto \\
\hline Citrato de sódio & $40 \mathrm{~g} / \mathrm{m}$ & Rede de esgoto - Fase móvel em mistura com HCL (tampão citrato) \\
\hline Cloreto de amônia & NE & Rede de esgoto \\
\hline Cloreto de cálcio $^{1}$ & $120 \mathrm{~g} / \mathrm{m}$ & Rede de esgoto \\
\hline $\begin{array}{l}\text { Cloreto de } \\
\text { magnésio }\end{array}$ & $10 \mathrm{~g} /$ semestre & Rede de esgoto \\
\hline Cloreto de potássio ${ }^{1}$ & $30 \mathrm{~g} / \mathrm{m}$ & Rede de esgoto \\
\hline Cloreto de sódio ${ }^{1}$ & $0,4 \mathrm{~g} / \mathrm{m}$ & Rede de esgoto com a fase aquosa das reaç̃es \\
\hline Cloreto férrico $^{1}$ & $64,5 \mathrm{~g} / \mathrm{m}$ & $\begin{array}{l}\text { Soluçð̃es } 2,5 \text { e } 10 \% \text {-nebulizadas na capela e o restante das soluçð̃es descartado na rede de esgoto e } 0,4 \mathrm{~g} / \mathrm{m} \text { descartado } \\
\text { na rede de esgoto em mistura com ácido fosfórico, tiosemicarbazida e diacetilmonoxima e soro. }\end{array}$ \\
\hline
\end{tabular}


Cont. Tabela A- 26

\begin{tabular}{|c|c|c|}
\hline Substância & Volume & Descarte \\
\hline $\begin{array}{l}\text { Cloridrato de } \\
\text { Hidroxilamina }\end{array}$ & $0,027 \mathrm{~g} / \mathrm{m}$ & Rede esgoto em mistura com álcool isoamílico \\
\hline 4-clorofenol ${ }^{1}$ & $0,274 \mathrm{~g} / \mathrm{m}$ & Descartado na rede de esgoto em mistura com plasma, 4-aminoantipírina e enzimas (KIT triglicérides) \\
\hline 4-cloronaftol & $32 \mathrm{mg} / \mathrm{m}$ & Rede de esgoto diluido com hipoclorito em mistura com ácido sulfúrico $4 \mathrm{~N}^{*}$ \\
\hline $\begin{array}{l}\text { Colato de sódio } \\
4 \%\end{array}$ & $12 \mathrm{ml} / \mathrm{m}$ & Rede de esgoto em mistura ao sulfato de cobre, homogenato de tecido, água e ácido sulfúrico. \\
\hline $\begin{array}{l}\text { Difenilboriloxietil } \\
\text { Amina }\end{array}$ & $8 \mathrm{~g} / \mathrm{m}$ & Nebulizados em capela- solução metanólica \\
\hline $\begin{array}{l}\text { Dihidrogeno fosfato } \\
\text { de potássio }\end{array}$ & $1.500 \mathrm{~g} / \mathrm{m}$ & Descartados na rede de esgoto \\
\hline $\begin{array}{l}\text { p-dimetilamino } \\
\text { benzaldeído }^{1}\end{array}$ & $1 \mathrm{~g} / \mathrm{m}$ & Rede de esgoto. \\
\hline Dimetilsulfóxido $^{1}$ & $1.550 \mathrm{ml} / \mathrm{m}$ & Rede de esgoto, sendo $1.500 \mathrm{ml} / \mathrm{m}$ em mistura com ninhidrina, acetato de lítio e ácido acético \\
\hline $\begin{array}{l}\text { Dodecilsulfato de } \\
\text { sódio ou lauril } \\
\text { sulfato de sódio }\end{array}$ & $40,2 \mathrm{~g} / \mathrm{m}$ & $\begin{array}{l}5,2 \mathrm{~g} / \mathrm{m} \text { descartado como RSS com gel de acrilamida, } \\
\text { Restante no tampão de corrida, descartado como o tampão ou diretamente na rede de esgoto }\end{array}$ \\
\hline EDTA $^{1}$ & $\begin{array}{l}\text { Cerca de } 1500 \\
\mathrm{~g} / \mathrm{m}\end{array}$ & Rede de esgoto, a maior parte componente do tampão de corrida do gel de agarose \\
\hline $\begin{array}{l}\text { Ferricianeto de } \\
\text { potássio }^{1}\end{array}$ & $8,7 \mathrm{~g} / \mathrm{a}$ & Rede de esgoto com mistura de desproteinizantes ou em mistura com hemolisado diluido com hipoclorito \\
\hline Glicerina $^{1}$ & $\begin{array}{l}\text { Solução aquosa } \\
85 \%=28 \mathrm{~m} / \mathrm{m}\end{array}$ & segregados em mistura com nitrato de chumbo, tampão acetato, tioacetamida. \\
\hline
\end{tabular}


Cont. Tabela A- 26

\begin{tabular}{|c|c|c|}
\hline Substância & Volume & Descarte \\
\hline Glicina & $800 \mathrm{~g} / \mathrm{m}$ & Rede de esgoto - tampło de corrida do gel de acrilamida e tampão de transferência \\
\hline Glicose & $4 \mathrm{~g} / \mathrm{m}$ & Rede de esgoto \\
\hline Glicose oxidase & $\begin{array}{l}20 \mathrm{ml} / \mathrm{s}^{*} \\
\text { (concentracio no } \\
\text { especificada) }\end{array}$ & Rede de esgoto \\
\hline Hexoquinase & $\begin{array}{l}200 \mu \mathrm{L} / \mathrm{s} \\
\text { (concentraçà nåo } \\
\text { especificada) }\end{array}$ & Rede de esgoto \\
\hline $\begin{array}{l}\text { Hidróxido de } \\
\text { trimetilfenilamônio }\end{array}$ & $0,263 \mathrm{~g} / \mathrm{m}$ & Rede de esgoto em mistura com urina e plasma, diluídos em hipoclorito. \\
\hline lodeto de potássio ${ }^{1}$ & $\begin{array}{l}\text { a. } 48,8 \mathrm{~g} / \mathrm{m} \\
\text { b. } 9 \mathrm{~g} / \mathrm{a}\end{array}$ & $\begin{array}{l}\text { a. } 48,8 \mathrm{~g} / \mathrm{m} \text { nebulizado em capela em mistura com iodo e nitrato de bismuto } \\
\text { b. } 9 \mathrm{~g} / \text { a descarto na rede de esgoto em mistura com } \mathrm{HCL}\end{array}$ \\
\hline Manitol $120 \mathrm{mM}$ & $500 \mathrm{ml} / \mathrm{m}$ & Junto com ácido indolacético \\
\hline Nitrato de bismuto & $20,7 \mathrm{~g} / \mathrm{m}$ & Nebulizados em capela em mistura a iodo e iodeto de potássio em ácido acético \\
\hline $\begin{array}{l}\text { Nitrato de magnésio } \\
\text { hexahidratado }\end{array}$ & $90 \mathrm{~g} / \mathrm{a}$ & Calcinados com a matriz peixe \\
\hline Ortofenantrolina ${ }^{1}$ & $0,19 \mathrm{~g} / \mathrm{m}$ & Indicador - rede de esgoto em mistura com dicromato de potássio, ácido sulfúrico e sulfato de ferro e amônia. \\
\hline Óxido de alumínio - & $80 \mathrm{~g} / \mathrm{m}$ & Sínteses \\
\hline
\end{tabular}


Cont. Tabela A- 26

\begin{tabular}{|c|c|c|}
\hline Substância & Volume & Descarte \\
\hline Oxido de magnésio & $90 \mathrm{~g} / \mathrm{a}$ & Calcinados com a matriz - peixe \\
\hline Pepsina & $40 \mathrm{~g} / \mathrm{m}$ & Rede de esgoto com os restos de frutas, proteases, etc. \\
\hline Peptona & $0,5 \mathrm{~g} / \mathrm{s}^{*}$ & Rede de esgoto com os restos de frutas, proteases, etc. \\
\hline Peroxidase & $20 \mathrm{ml} / \mathrm{s}^{*}$ & Rede de esgoto com os restos de frutas \\
\hline $\begin{array}{l}\text { Polietilenoglicol - } \\
400^{1}\end{array}$ & $40 \mathrm{~g} / \mathrm{m}$ & Nebulizados em capela - solução etanólica \\
\hline Polivinilpirrolidona & $0,4 \mathrm{~g} / \mathrm{se}$ & Rede de esgoto juntamente com os restos de frutas, pepsina, protease, etc ${ }^{3}$ \\
\hline $\begin{array}{l}\text { Reativo } 1 \text { - } \\
\text { fenilfosfato } \\
\text { dissódico, } \\
\text { carbonato de } \\
\text { bicarbonato de } \\
\text { sódio }\end{array}$ & $100 \mathrm{ml} / \mathrm{a}$ & Leite + reativo 1 e reativo 2 descartados na rede de esgoto \\
\hline $\begin{array}{l}\text { Reativo } 2 \\
\text { dicloroquina } \\
\text { cloroimida } 1 \mathrm{mg} / \mathrm{ml} \\
\text { em etanol }\end{array}$ & $5 \mathrm{ml} / \mathrm{a}$ & Leite + reativo $1+$ reativo 2 descartados na rede de esgoto \\
\hline Resorcina $^{1}$ & $26,2 \mathrm{~g} / \mathrm{m}$ & $\begin{array}{l}15 \mathrm{~g} / \mathrm{m} \text { nebulizados em capela } \\
1,2 \mathrm{~g} / \mathrm{m} \text { rede de esgoto em mistura com sulfato de cobre e ácido n-acetilneurâmico }\end{array}$ \\
\hline Sulfato de amônia & $20 \mathrm{~g} / \mathrm{s}$ & Rede de esgoto \\
\hline Sulfato de cobre' & $\begin{array}{l}\text { a. } 52,2 \mathrm{~g} / \mathrm{m} \\
\text { b. } 375 \mathrm{~g} / \mathrm{a}\end{array}$ & $\begin{array}{l}10,9 \mathrm{~g} / \mathrm{m} \text { descartados na rede de esgoto - resíduo praticamente neutro. } \\
\text { Restante descartado na rede de esgoto em mistura com colato de sódio, } \mathrm{NaOH} \text { ou com tartarato de sódio e potássio e } \\
\text { amostra diluidos em hipoclorito. } \\
375 \mathrm{~g} \text { g (equivalentes a } 3.750 \mathrm{ml} / \mathrm{a} \text { de um solução } 10 \% \text { ) descartados na rede de esgoto, metade em mistura com metanol. }\end{array}$ \\
\hline & & 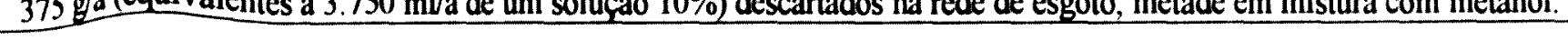 \\
\hline
\end{tabular}


Cont. Tabela A- 26

\begin{tabular}{|c|c|c|}
\hline Substância & Volume & Descarte \\
\hline $\begin{array}{l}\text { Sulfato de ferro e } \\
\text { amônia }\end{array}$ & $135 \mathrm{~g} / \mathrm{m}$ & Segregado em mistura ao dicromato de potássio, ácido sulfúrico e ortofenantrolina \\
\hline $\begin{array}{l}\text { Sulfato de } \\
\text { magnésio }\end{array}$ & $20 \mathrm{~g} /$ semestre & Rede de esgoto \\
\hline Sulfato de potássio & $318,9 \mathrm{~g} / \mathrm{m}$ & Descartados na rede de esgoto \\
\hline Sulfato de sódio ${ }^{1}$ & $5 \mathrm{~g} / \mathrm{m}$ & Rede de esgoto \\
\hline Sulfato de zinco' & $\mathrm{lg} / \mathrm{m}$ & Rede de esgoto ${ }^{3}$ \\
\hline Sulfato ferroso ${ }^{1}$ & $150 \mathrm{~g} / \mathrm{m}$ & Rede de esgoto \\
\hline $\begin{array}{l}\text { Sulfonato de } \\
\text { diclorofenol }\end{array}$ & $176 \mathrm{ml} / \mathrm{m}$ & Rede de esgoto em mistura com aminopirina, enzimas e plasma \\
\hline $\begin{array}{l}\text { Tampão acetato } \\
\text { pH } 4,6-5,6\end{array}$ & $\begin{array}{l}31,5 \mathrm{~mL} / \mathrm{m} / \\
560 \mathrm{ml} / \mathrm{a}\end{array}$ & $\begin{array}{l}28 \mathrm{~mL} / \mathrm{m} \text { em mistura com nitrato de chumbo, tioacetamida e glicerina segregado. Restante, rede de esgoto com fase } \\
\text { aquosa das reaçð̋es e matrizes. }\end{array}$ \\
\hline $\begin{array}{l}\text { Tampão de corrida } \\
\text { acrilamida (trisma, } \\
\text { glicina, SDS, água) }\end{array}$ & $35.000 \mathrm{ml} / \mathrm{m}$ & Rede de esgoto \\
\hline $\begin{array}{l}\text { Tampão fosfato } \\
\text { mono e dihidratado }\end{array}$ & $1.420 \mathrm{ml} / \mathrm{m}$ & $\begin{array}{l}\text { Rede de esgoto sendo } 1.000 \mathrm{ml} / \mathrm{m} \mathrm{em} \text { mistura com enzimas, hidróxido e ácido e etanol e o restante com a fase aquosa } \\
\text { das reaçðes. }\end{array}$ \\
\hline Tampão PBS & NE & Rede de esgoto \\
\hline $\begin{array}{l}\text { Tampão TBE (Irts } \\
\text { EDTA, acidos, borico) } \\
\text { Ou TPE - gel agarose }\end{array}$ & $\begin{array}{l}10.000 \mathrm{ml} / \mathrm{m} \\
\text { considerando } \\
\text { reutilização }\end{array}$ & Rede de esgoto \\
\hline
\end{tabular}


Cont. Tabela A- 26

\begin{tabular}{|c|c|c|}
\hline Substância & Volume & Descarte \\
\hline $\begin{array}{l}\text { Tampão tris, l- } \\
\text { alanina, LDH, NADH, } \\
\text { Oxoglutarato, L- } \\
\text { aspartato }(K I T)\end{array}$ & $\mathrm{NE}$ & Rede de esgoto \\
\hline $\begin{array}{l}\text { Tartarato de sódio e } \\
\text { potássio }\end{array}$ & $0,6 \mathrm{~g} / \mathrm{m}$ & Rede de esgoto \\
\hline $\begin{array}{l}\text { Temed-N,N,N',N'- } \\
\text { tetrametil- 1,2- } \\
\text { etanodiamina }\end{array}$ & $5,2 \mathrm{~mL} / \mathrm{m}$ & RSS- componente do gel de acrilamida \\
\hline $\begin{array}{l}\text { Tetrametilbenzidina } \\
\text { (TMB }\end{array}$ & $\begin{array}{l}0,04 \text { a } 0,08 \\
g / m\end{array}$ & Rede de esgoto diluído com hipoclorito em mistura com ácido sulfúrico \\
\hline Tiosemicarbazida $^{1}$ & $0,017 \mathrm{~g} / \mathrm{m}$ & Rede de esgoto em mistura com cloreto férrico e ácido fosfórico e diacetilmonoxima ( KIT uréia) ${ }^{2}$ \\
\hline $\begin{array}{l}\text { Tiossulfato de sódio } \\
0,01 \text { N e } 0,1 \text { N }\end{array}$ & $\begin{array}{l}1000 \mathrm{ml} / \mathrm{m} \\
(0.1 \mathrm{~N}) \mathrm{e} 100 \\
\mathrm{ml} / \mathrm{a}(0,01 \mathrm{~N})\end{array}$ & Rede de esgoto com iodeto \\
\hline Trietanolamina & $40 \mathrm{ml} / \mathrm{m}$ & tampão trietanolamina ( $4 \mathrm{ml}: 2 \mathrm{~L} \mathrm{H}_{2} \mathrm{O}$ ), Segregado em mistura com acetonitrila, tetrahidrofurano \\
\hline Trisma base & $2965 \mathrm{~g} / \mathrm{m}$ & Rede de esgoto - tampães de corrida dos géis de agarose e acrilamida, tampão de amostra e tampão de transferência \\
\hline Vanilina & $\begin{array}{l}\text { a. } 6 \mathrm{~g} / \mathrm{m} \\
\text { b. } 147 \mathrm{mg} / \mathrm{m} \\
\text { c. } 1 \mathrm{~g} / \mathrm{a}\end{array}$ & $\begin{array}{l}\text { a. } 6 \mathrm{~g} / \mathrm{m} \text { Nebulizado na capela ( solução etanólica) } \\
\text { b. } 147 \mathrm{mg} / \mathrm{m} \text { - rede de esgoto em mistura com soro, ácido fosfórico e sulfúrico (cerca de } 4,5 \mathrm{ml} \text { de soro e } 105 \mathrm{ml} \text { de solução) } \\
\text { c. } 1 \mathrm{~g} / \mathrm{a} \text { - rede de esgoto em mistura ao clorofórmio ( } 50 \mathrm{~mL} \text { de cada) }\end{array}$ \\
\hline
\end{tabular}


Tabela A -27 - Resíduos contendo substâncias classificadas como não perigosas gerados pela Instituição $\mathrm{C}$ e classificados não perigosos

\begin{tabular}{|c|c|c|}
\hline Substância & Volume & Descarte realizado \\
\hline Ácido barbitúrico & $9 \mathrm{~g} / \mathrm{m}$ & Rede de esgoto em mistura com piridina e cloramina $\mathrm{T}$ \\
\hline $\begin{array}{l}\text { Ácido } \\
\text { cloroplatínico }{ }^{1}\end{array}$ & $2,1 \mathrm{~g} / \mathrm{m}$ & Nebulizados em capela (solução aquosa $2,5 \mathrm{mg} / \mathrm{ml}$ )juntamente com iodeto de potássio \\
\hline $\begin{array}{l}\text { Ácido tartárico e } \\
\text { tartarato de sódio }\end{array}$ & 45 e $57 \mathrm{~g} / \mathrm{m}$ & Rede de esgoto (solução aquosa) \\
\hline $\begin{array}{l}\text { Anti- } \\
\text { gamaglobulina } \\
\text { humana }\end{array}$ & $K i t-\mathrm{NE}$ & Descartado em saco plástico comum juntamente com o tubo de reação contendo o material biológico. \\
\hline Cloramina t & $0,125 \mathrm{~g} / \mathrm{m}$ & Rede de esgoto em mistura com piridina, ácido cloridrico e ácido barbitúrico \\
\hline Cloreto de amônia & $50 \mathrm{~g} / \mathrm{m}$ & Rede de esgoto solução em hidróxido de amônia \\
\hline Cloreto de cobalto $^{1}$ & $3,4 \mathrm{~g} / \mathrm{m}$ & Rede de esgoto em mistura com o tiocianato de amônia (solução aquosa), ácido clorídrico $0,1 \mathrm{~N}$ e anestésico local (pó) \\
\hline Cloreto de sódio ${ }^{1}$ & $250 \mathrm{~g} / \mathrm{m}$ & Descarta como resíduo sólido em saco plástico para RSS \\
\hline Cloreto férrico $^{1}$ & $10 \mathrm{~g} / \mathrm{m}$ & $\begin{array}{l}\text { Nebulizados em capela (solução } 5 \% \\
\text { ) }\end{array}$ \\
\hline $\begin{array}{l}\text { Dodecilsulfato de } \\
\text { sódio }^{1}\end{array}$ & $21,7 \mathrm{~g} / \mathrm{m}$ & $\begin{array}{l}20 \mathrm{~g} / \mathrm{m} \text { - Rede de esgoto - componente do tampão de corrida e tampão de amostra do gel de acrilamida - restante arquivado } \\
\text { com o gel (componente do gel de acrilamida) }\end{array}$ \\
\hline Glicina & $288 \mathrm{~g} / \mathrm{m}$ & Rede de esgoto, componente do tampão de corrida do gel de acrilamida \\
\hline Iodeto de potássio ${ }^{1}$ & $24 \mathrm{~g} / \mathrm{m}$ & Nebulizados em mistura ao iodo, ácido acético, nitrato de bismuto e ácido sulfúrico \\
\hline Iodeto de sódio ${ }^{1}$ & $18 \mathrm{~g} / \mathrm{m}$ & Rede de esgoto em mistura com clorofórmio e álcool isoamílico \\
\hline Nitrato de bismuto & $1 \mathrm{~g} / \mathrm{m}$ & Nebulizado em mistura ao iodo, ácido acético, iodeto de potássio e ácido sulfúrico \\
\hline
\end{tabular}


Cont. Tabela A-27

\begin{tabular}{|c|c|c|}
\hline Substância & Volume & Descarte realizado \\
\hline $\begin{array}{l}\text { p-dimetilamino } \\
\text { benzaldeído }^{\prime}\end{array}$ & $0,25 \mathrm{~g} / \mathrm{m}$ & $0,05 \mathrm{~g} / \mathrm{m}$ nebulizado em capela (solução etanólica), restante descartado na rede de esgoto. \\
\hline p-nitroanilina ${ }^{1}$ & $2,8 \mathrm{~g} / \mathrm{m}$ & Parte nebulizada em capela em mistura ao nitrito de sódio e ácido clorídrico, restante rede de esgoto \\
\hline $\begin{array}{l}\text { Rodizonato de } \\
\text { sódio }\end{array}$ & $50 \mathrm{~g} / \mathrm{m}$ & Solução aquosa descartada na rede de esgoto \\
\hline Sulfato de sódio ${ }^{1}$ & $1.500 \mathrm{~g} / \mathrm{m}$ & Descarte como residuo sólido em saco plástico branco próprio para RSS \\
\hline Tampão citrato & a. $20 \mathrm{ml} / \mathrm{m}$ & a. Rede de esgoto em mistura ao material biológico e a timolftaleina \\
\hline $\begin{array}{l}\text { Tampão tris, } \\
\text { glicina, SDS }\end{array}$ & $\begin{array}{l}\text { b. } 20.000 \\
\mathrm{ml} / \mathrm{m}\end{array}$ & b. Rede de esgoto ( solução aquosa) \\
\hline Timolftaleína & $0,15 \mathrm{~g} / \mathrm{m}$ & Rede de esgoto em mistura ao material biológico e ao tampão citrato \\
\hline $\begin{array}{l}\text { Tiocianato de } \\
\text { amônia }\end{array}$ & $2,2 \mathrm{~g} / \mathrm{m}$ & Rede de esgoto em mistura com o cloreto de cobalto (solução aquosa), ácido clorídrico $0,1 \mathrm{~N}$ e anestésico local (pó) \\
\hline Trizma & $\begin{array}{l}\text { Cerca de } 62 \\
\mathrm{~g} / \mathrm{m}\end{array}$ & Rede de esgoto -componente do tampão de corrida e tampão de amostra \\
\hline Vanilina $^{1}$ & $50 \mathrm{~g} / \mathrm{m}$ & Rede de esgoto em mistura com ácido clorídrico concentrado e etanol. \\
\hline
\end{tabular}

Nota: $\mathrm{NE}=$ Não especificado, $\mathrm{l}=$ dados de mutagenicidade relatados; $\mathrm{g} / \mathrm{m}=$ grama por $\mathrm{mês} ; \mathrm{ml} / \mathrm{m}=$ mililitro por $\mathrm{mês}$ 
ANEXO 20

- Estado da Arte quanto ao tratamento e disposição de resíduos 
Tabela A-28 - Tratamento, disposição, incompatibilidade e procedimentos a serem adotados em situações de emergência para as substâncias inflamáveis levantadas.

\begin{tabular}{|c|c|c|c|c|}
\hline Substância & Tratamento/disposição & Custo* & Incompatibilidade & $\begin{array}{l}\text { Característica relevante da substância / } \\
\text { Procedimentos em situações de emergência }\end{array}$ \\
\hline $\begin{array}{l}\text { Acetaldeído } \\
\text { CAS }^{275-07-0}\end{array}$ & Incineração ${ }^{6}$ & $\begin{array}{l}\text { la } 250 \mathrm{Kg}= \\
\text { US } \$ 343,40^{*}\end{array}$ & $\begin{array}{l}\text { Oxidantes fortes, ácidos, } \\
\text { bases, álcoois, amônia, } \\
\text { aminas, fenóis, cetonas, ácido } \\
\text { cianidrico e ácido sulfidrico. } \\
\text { Forma peróxidos em contato } \\
\text { com o ar }{ }^{9}\end{array}$ & $\begin{array}{l}\text { - } \mathrm{FP}-40^{\circ} \mathrm{C}^{11} \\
\text { - Incêndio }-\mathrm{CO}_{2} \text {, pó químico, água } \\
\text { - Derramamento - adsorver com areia, vermiculite, } \\
\text { sulfato de sódio } 6,11\end{array}$ \\
\hline $\begin{array}{l}\text { Acetato de butila } \\
\text { CAS 123-86-4 }\end{array}$ & Incineração ${ }^{11}$ & $\begin{array}{l}\text { l a } 250 \mathrm{Kg}= \\
\text { US\$ } 343,40^{*}\end{array}$ & $\begin{array}{l}\text { Nitratos, ácidos fortes, } \\
\text { bases fortes, oxidantes } \\
\text { fortes }{ }^{11}\end{array}$ & $\begin{array}{ll}\text { - } & \text { FP } 22^{\circ} \mathrm{C}^{11} \\
\text { - Incêndio }-\mathrm{CO}_{2} \text {, pó químico, água } \\
\text { - }\end{array}$ \\
\hline $\begin{array}{l}\text { Acetato de etila } \\
\text { CAS 141-78-6 }\end{array}$ & $\begin{array}{l}\text { Incineração em forno rotatório - } 820 \\
\text { a } 1600{ }^{\circ} \mathrm{C} \text { ou incinerador de injeção } \\
\text { líquida } 450-1600{ }^{\circ} \mathrm{C}^{6,11}\end{array}$ & $\begin{array}{l}\text { l a } 250 \mathrm{Kg}= \\
\text { US } \$ 343,40^{*}\end{array}$ & $\begin{array}{l}\text { Metais alcalinos, fluoretos, } \\
\text { hidretos, agentes oxidantes } \\
\text { fortes }^{2}\end{array}$ & $\begin{array}{l}\text { - } \mathrm{FP}-7.2^{\circ} \mathrm{C}^{10} \\
\text { - Incêndios pequenos }-\mathrm{CO}_{2} \text {, pó químico, água, espuma } \\
\text { - Derramamento - absorver com papel, areia }{ }^{11}\end{array}$ \\
\hline $\begin{array}{l}\text { Acetona } \\
\text { CAS 67-64-1 }\end{array}$ & Incineração ${ }^{6}$ & $\begin{array}{l}\text { l a } 250 \mathrm{Kg}= \\
\text { US\$ } 343,40^{*}\end{array}$ & $\begin{array}{l}\text { Ácidos, agentes oxidantes, } \\
\text { metais, bromofórmio, } \\
\text { clorofórmio e alcalis com } \\
\text { formação 1,1,1-tricloro-2- } \\
\text { hidroxi-2-metilpropano } 2,11\end{array}$ & $\begin{array}{l}\text { - } \mathrm{FP}--20^{\circ} \mathrm{C}^{2} \\
\text { - Incêndio - pó químico, } \mathrm{CO}_{2} \text {, água, espuma } \\
\text { - Derramamento- adsorver com areia, terra seca }{ }^{11}\end{array}$ \\
\hline $\begin{array}{l}\text { Acetonitrila } \\
\text { CAS 75-05-8 }\end{array}$ & $\begin{array}{l}\text { 1. } 50 \mathrm{ml} \text { de solução aquosa de } \\
\text { acetonitrila } 10 \mathrm{mg} / \mathrm{ml}+50 \mathrm{ml} \\
\mathrm{KOH} 1 \mathrm{M}+5 \mathrm{~g} \text { liga Ni-AL. } \\
\text { Reagir por } 12 \mathrm{~h} \text {, filtrar, } \\
\text { neutralizar o filtrado e descartá- } \\
\text { lo na rede de esgoto }\end{array}$ & $\begin{array}{l}\text { 1. US\$ } 0,14 \\
\text { /mg }\end{array}$ & $\begin{array}{l}\text { Oxidantes fortes, ácido } \\
\text { nítrico, percloratos, ácido } \\
\text { sulfúrico, ácido } \\
\text { clorosulfônico }^{11}\end{array}$ & $\begin{array}{l}\text { - } \mathrm{FP}-12,8^{\circ} \mathrm{C}^{10} \\
\text { - Incêndio - pó químico, } \mathrm{CO}_{2} \text {, água } \\
\text { - Derramamento- adsorver com areia ou papel ou } \\
\text { adicionar excesso solução } \mathrm{NaOH} \text { e } \mathrm{CaCl}_{2} \mathrm{O}_{2}{ }^{6}\end{array}$ \\
\hline
\end{tabular}


Cont. Tabela A-28

\begin{tabular}{|c|c|c|c|c|}
\hline Substância & Tratamento/disposição & Custo $^{*}$ & Incompatibilidade & $\begin{array}{l}\text { Característica relevante da substância / } \\
\text { Procedimentos em situações de emergência }\end{array}$ \\
\hline $\begin{array}{l}\text { Acetonitrila } \\
\text { CAS 75-05-8 }\end{array}$ & $\begin{array}{l}\text { 2. }+\mathrm{NaOH} \text { em excesso }+\mathrm{CaCl}_{2} \mathrm{O}_{2} . \\
\text { Após } 24 \mathrm{~h} \text {, desprezar na rede de } \\
\text { esgoto } \\
\text { 3. Incineração }\end{array}$ & $\begin{array}{l}\text { 2. US\$ } \\
0,046 / \mathrm{mg} \\
\text { (soluçðes 2M) } \\
\text { 3. } 1 \text { a } 250 \mathrm{Kg}= \\
\text { US\$ } 343,40\end{array}$ & & \\
\hline $\begin{array}{l}\text { Álcool isoamílico } \\
\text { CAS 123-51-3 }\end{array}$ & Incineração ${ }^{11}$ & $\begin{array}{l}\text { la } 250 \mathrm{KG}= \\
\text { US\$343,40 }\end{array}$ & Agentes oxidantes ${ }^{8}$ & $\begin{array}{l}\text { - } \mathrm{FP} 45^{\circ} \mathrm{C}^{9} \\
\text { - Incêndio: } \mathrm{CO}_{2} \text {, pó químico, água }{ }^{11} \\
\text { - Derramamento: adsorver com areia, incinerar }\end{array}$ \\
\hline $\begin{array}{l}\text { Benzeno } \\
\text { CAS 71-43-2 }\end{array}$ & $\begin{array}{l}\text { 1. Bio-remediação (aqüífero) }+ \\
\text { fosfato de amônia (nutriente) }+ \\
\mathrm{KNO}_{3} \text { (aceptor elétrons) }+ \\
\text { microflora presente - eficiência } \\
78 \text { a } 99 \%{ }^{5} \\
\text { 2. Incineração }\end{array}$ & $\begin{array}{l}\text { 1. } \mathrm{NC}^{\mathrm{b}} \\
\text { 2. } 1 \text { a } 250 \mathrm{Kg}= \\
\text { US\$ } 343,40\end{array}$ & $\begin{array}{l}\text { Oxidantes fortes, } \\
\text { percloratos, vários sais de } \\
\text { fluoreto e ácido nítrico } 11\end{array}$ & $\begin{array}{l}\text { - } \mathrm{FP}-11^{\circ} \mathrm{C}^{11} \\
\text { - Incêndio - pó, } \mathrm{CO}_{2} \text {, água, espuma } \\
\text { - Derramamento - adsorver com areia ou mistura } 1: 1: 1 \\
\text { de } \mathrm{Na}_{2} \mathrm{CO}_{3} \text { ou } \mathrm{Ca} \mathrm{CO} \text {, bentonita e areia - incinerar }\end{array}$ \\
\hline $\begin{array}{l}\text { Brometo de alila } \\
\text { CAS 106-95-6 }\end{array}$ & Incineração ${ }^{11}$ & $\begin{array}{l}1 \text { a } 250 \mathrm{Kg}= \\
\text { US\$343, } 40\end{array}$ & Agentes oxidantes ${ }^{8}$ & $\begin{array}{l}\text { - } \mathrm{FP}-2^{\circ} \mathrm{C}^{9} \\
\text { - Incêndio: } \mathrm{CO}_{2} \text {, pó químico, água }{ }^{11} \\
\text { - Derramamento: adsorver com areia, incinerar }{ }^{6,8}\end{array}$ \\
\hline $\begin{array}{l}\text { Butanol } \\
\text { CAS 71-36-3 }\end{array}$ & Incineração 6,11 & $\begin{array}{l}1 \mathrm{a} 250 \mathrm{Kg}= \\
\text { US\$343, } 40\end{array}$ & $\begin{array}{l}\text { Oxidantes fortes, ácidos } \\
\text { minerais fortes, metais } \\
\text { alquilados e halogênios }\end{array}$ & $\begin{array}{l}\text { - } \mathrm{FP} 36-38^{\circ} \mathrm{C}^{10} \\
\text { - Incêndio - pó, } \mathrm{CO}_{2} \text {, água, } \\
\text { - Derramamento - adsorver com areia, vermiculite, } \\
\text { papel }^{6,11}\end{array}$ \\
\hline $\begin{array}{l}\text { Ciclohexano } \\
\text { CAS 110-82-7 }\end{array}$ & Incineração ${ }^{6,11}$ & $\begin{array}{l}1 \text { a } 250 \mathrm{Kg}= \\
\text { US\$343, 40 }\end{array}$ & Materiais oxidantes ${ }^{\prime \prime}$ & $\begin{array}{l}\text { - } \mathrm{FP}-20^{\circ} \mathrm{C}^{6} \\
\text { - Incêndio - pó, } \mathrm{CO}_{2} \text {, água } \\
\text { - Derramamento - adsorver com areia, vermiculite, } \\
\text { papel }{ }^{6,11}\end{array}$ \\
\hline
\end{tabular}


Cont. Tabela A-28

\begin{tabular}{|c|c|c|c|c|}
\hline Substância & Tratamento/disposição & Custo* & Incompatibilidade & $\begin{array}{l}\text { Característica relevante da substância / } \\
\text { Procedimentos em situações de emergência }\end{array}$ \\
\hline $\begin{array}{l}\text { Clorobutano } \\
\text { CAS 109-69-3 }\end{array}$ & Incineração & $\begin{array}{l}\text { l a } 250 \mathrm{Kg}= \\
\mathrm{US} \$ 343,40\end{array}$ & Oxidantes $^{8}$ & $\begin{array}{l}\text { FP }-10^{\circ} \mathrm{C}^{8} \\
\text { - Incêndio: água e pó químico } \\
\text { - Derramamento: adsorver com areia, vermiculite, } \\
\text { papel e incinerar }{ }^{11}\end{array}$ \\
\hline $\begin{array}{l}\text { Dietilamina } \\
\text { CAS } 109-89-7\end{array}$ & $\begin{array}{l}\text { 1. adicionar hidrogenosulfato de } \\
\text { sódio, aspergir água e neutralizar. } \\
\text { Desprezar na rede de esgoto. }{ }^{6} \\
\text { 2. incineração }{ }^{6,11}\end{array}$ & $\begin{array}{l}\text { 1. US\$ } 0,3 / 100 \\
\mathrm{ml}^{9} \\
\text { 2. Até } 250 \mathrm{~kg}= \\
\text { US\$ } 343,40\end{array}$ & $\begin{array}{l}\text { Oxidantes, ácidos fortes e } \\
\text { nitrato de celulose }\end{array}$ & $\begin{array}{l}\text { - FP - } 17.8^{\circ} \mathrm{C}^{11} \\
\text { - Incêndio - pó, } \mathrm{CO}_{2} \text {, água } \\
\text { Derramamento - absorver com areia, vermiculite, e } \\
\text { pequenos volumes com papel evaporando-0 na capela } \\
\text { química }{ }^{11} \text { ou colocar bissulfato de sódio e aspergir água }\end{array}$ \\
\hline $\begin{array}{l}\text { Diisobutilamina } \\
\text { CAS 110-96-3 }\end{array}$ & Incineração ${ }^{6}$ & $\begin{array}{l}\text { Até } 250 \mathrm{~kg}= \\
\text { US\$ } 343,40\end{array}$ & $\begin{array}{l}\text { Alumínio, cobre, zinco, } \\
\text { mercúrio } 11\end{array}$ & $\begin{array}{l}\text { - FP } 29,4^{\circ} \mathrm{C} \text {, corrosivo } \\
\text { - Incêndio: } \mathrm{CO}^{2}, \text { pó, água } \\
\text { - Derramamento: adsorver com areia ou terra seca e } \\
\text { incinerar }\end{array}$ \\
\hline $\begin{array}{l}\text { Dissulfeto de } \\
\text { carbono } \\
\text { CAS 75-15-0 }\end{array}$ & $\begin{array}{l}\text { 1. Para cada } 3 \text { ml de solução utilizar, } \\
670 \mathrm{ml} \text { de hipoclorito de sódio } \\
2 \% \text { ou uma solução aquosa } 0,25 \% \\
\text { de hipoclorito de cálcio. A adição } \\
\text { deve ser gota a gota, evitando-se } \\
\text { o aquecimento da vidraria. } \\
\text { Quando todo o volume foi } \\
\text { adicionado, continue misturando } \\
\text { por mais } 2 \text { horas ou até a } \\
\text { obtenção de uma solução clara e } \\
\text { homogênea. Descarte na rede de } \\
\text { esgoto }{ }^{1} \text {; } \\
\text { Quantidades grandes podem ser } \\
\text { recuperadas por destilação }{ }^{1} \text {; } \\
\text { 3. Incineração }\end{array}$ & $\begin{array}{l}\text { 1. US\$ } 0,11 \\
/ \mathrm{ml}^{9}\end{array}$ & $\begin{array}{l}\text { Ar, poeira, halogênios, } \\
\text { amina, azidas, metais e } \\
\text { oxidantes }\end{array}$ & $\begin{array}{l}\text { - } \quad \text { FP }-30{ }^{\circ} \mathrm{C}^{11} \\
\text { - Incêndio: água, } \mathrm{CO}_{2} \text { e pó químico } \\
\text { - } \\
\text { Derramamento: adsorver com areia, vermiculite, } \\
\text { papel e incinerar }\end{array}$ \\
\hline
\end{tabular}


Cont. Tabela A-28

\begin{tabular}{|c|c|c|c|c|}
\hline Substância & Tratamento/disposição & Custo $^{*}$ & Incompatibilidade & $\begin{array}{l}\text { Característica relevante da substância / } \\
\text { Procedimentos em situacões de emergência }\end{array}$ \\
\hline $\begin{array}{l}\text { Etanol } \\
\text { CAS 64-17-5 }\end{array}$ & $\begin{array}{l}\text { 1. concentraçð̃es inferiores a } 24 \% \\
\text { podem ser descartadas na rede } \\
\text { de esgoto }{ }^{4} \\
\text { 2. } \\
\text { concentraçðes superiores a } 24 \% \\
\text { - incineração }{ }^{4}\end{array}$ & $\begin{array}{l}\text { 2. Até } 250 \mathrm{Kg} \\
=\text { US\$ } 343,40\end{array}$ & $\begin{array}{l}\text { Oxidantes fortes, } \\
\text { pentafluoreto de bromo, } \\
\text { brometo de acetila, cloreto } \\
\text { de acetila, platina e sódio } \\
2,11\end{array}$ & $\begin{array}{l}\text { - } \mathrm{FP} 12,2^{\circ} \mathrm{C}^{11} \\
\text { - Incêndio - } \mathrm{CO}_{2} \text {, pó, e água } \\
\text { - Derramamento - adsorver com areia, ou papel }\end{array}$ \\
\hline $\begin{array}{l}\text { Éter de petróleo } \\
\text { CAS 8032-32-4 }\end{array}$ & Incineração $^{6}$ & $\begin{array}{l}\text { Até } 250 \mathrm{Kg}= \\
\text { US } \$ 343,40\end{array}$ & $\begin{array}{l}\text { Oxidantes como cloro, } \\
\text { bromo e flúor } 2,11\end{array}$ & $\begin{array}{l}\text { - } \mathrm{FP} \sim-40^{\circ} \mathrm{C}^{10} \\
\text { - Incêndio }-\mathrm{CO}_{2} \text {, pó químico } \\
\text { - } \quad \text { Derramamento - adsorver com areia }\end{array}$ \\
\hline $\begin{array}{l}\text { Éter etilico } \\
\text { CAS 60-29-7 }\end{array}$ & 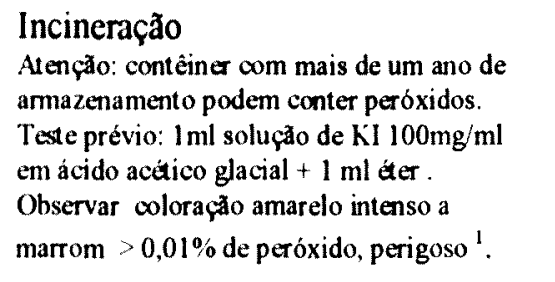 & $\begin{array}{l}\text { Até } 250 \mathrm{Kg}= \\
\text { US\$343, } 40\end{array}$ & $\begin{array}{l}\text { Oxidantes, halogênios, } \\
\text { enxofre e compostos de } \\
\text { enxofre. Forma peróxidos } \\
\text { sob influência do ar e luz } \\
\text { especialmente quando se } \\
\text { tenta evaporar à secura. }{ }^{* *}\end{array}$ & $\begin{array}{l}\text { - } \mathrm{FP}-45^{\circ} \mathrm{C} \\
\text { - Incêndio - } \mathrm{CO}_{2}, \mathrm{pó} \text {, água } \\
\text { - Derramamento - adsorver com areia ou mistura } 1: 1: 1 \\
{ }_{11} \mathrm{Na}_{2} \mathrm{CO}_{3} \text { ou } \mathrm{Ca} \mathrm{CO}_{3} \text {, bentonita e areia - incinerar }\end{array}$ \\
\hline $\begin{array}{l}\text { Heptano } \\
\text { CAS 142-82-5 }\end{array}$ & Incineração ${ }^{6,11}$ & $\begin{array}{l}\text { Até } 250 \mathrm{Kg}= \\
\text { US\$ } 343,40\end{array}$ & Oxidantes fortes ${ }^{2,11}$ & $\begin{array}{l}\text { - } \mathrm{FP}-4^{\circ} \mathrm{C}^{2} \\
\text { - Incêndio - } \mathrm{CO}_{2} \text {, pó químico, água } \\
\text { - Derramamento - adsorver com areia, vermiculite, } \\
\text { papel (este só se o volume for pequeno) }\end{array}$ \\
\hline $\begin{array}{l}\text { Hexano } \\
\text { CAS 110-54-3 }\end{array}$ & Incineraçãa ${ }^{11}$ & $\begin{array}{l}\text { Até } 250 \mathrm{Kg}= \\
\text { US\$ } 343,40\end{array}$ & $\begin{array}{l}\text { Oxidantes fortes (cloro, } \\
\text { bromo, iodo), tetróxido de } \\
\text { nitrogênio } 2,11\end{array}$ & $\begin{array}{l}\text { - } \quad \mathrm{FP}-30^{\circ} \mathrm{C} \\
\text { - Incêndio - } \mathrm{CO}_{2} \text {, pó químico, água } \\
\text { - } \quad \text { Derramamento - adsorver com areia, vermiculite }{ }^{11}\end{array}$ \\
\hline $\begin{array}{l}\text { Isopropanol } \\
\text { CAS 71-23-8 }\end{array}$ & Incineração " & $\begin{array}{l}\text { Até } 250 \mathrm{Kg}= \\
\text { US } \$ 343,40\end{array}$ & $\begin{array}{l}\text { Acetaldeído, cloro, óxido } \\
\text { de etileno, cromatos, ácido } \\
\text { perclórico, halogênios e } \\
\text { oxidantes. (Reage com o ar } \\
\text { formando peróxidos) }\end{array}$ & $\begin{array}{l}\text { - } \mathrm{FP} 11,7^{\circ} \mathrm{C}^{10} \\
\text { - Incêndio - } \mathrm{CO}_{2} \text {, pó químico, água } \\
\text { - } \quad \text { Derramamento - adsorver com areia, vermiculite }\end{array}$ \\
\hline
\end{tabular}


Cont. Tabela A-28

\begin{tabular}{|c|c|c|c|c|}
\hline Substância & Tratamento/disposição & Custo & Incompatibilidade & $\begin{array}{l}\text { Característica relevante da substância / } \\
\text { Procedimentos em situações de emergência }\end{array}$ \\
\hline $\begin{array}{l}\text { Metanol } \\
\text { CAS 67-56-1 }\end{array}$ & Incineração & $\begin{array}{l}\text { Até } 250 \mathrm{Kg}= \\
\text { US\$ } 343,40\end{array}$ & $\begin{array}{l}\text { Ácidos fortes, oxidantes } \\
\text { fortes, cáusticos, aminas } \\
\text { alifáticas, anidrido crômico, } \\
\text { perclorato de chumbo, } \\
\text { ácido perclórico, } \\
\text { clorofórmio }+\mathrm{NaOH}^{11}\end{array}$ & $\begin{array}{l}\text { - } \quad \text { FP } 12^{\circ} \mathrm{C}^{11} \\
\text { - Incêndio - } \mathrm{CO}_{2}, \text { pó químico, água } \\
\text { - Derramamento - adsorver com areia, vermiculite }\end{array}$ \\
\hline $\begin{array}{l}\text { Metilisobutilcetona } \\
\text { CAS 108-10-1 }\end{array}$ & Incineração ${ }^{11}$ & $\begin{array}{l}\text { Até } 250 \mathrm{Kg}= \\
\text { US\$ } 343,40\end{array}$ & $\begin{array}{l}\text { Oxidantes. Quando } \\
\text { aquecido explode }\end{array}$ & $\begin{array}{l}\text { - } \mathrm{FP} 25^{\circ} \mathrm{C}^{11} \\
\text { - Incêndio - } \mathrm{CO}_{2} \text {, pó químico, água } \\
\text { - Derramamento - adsorver com areia, vermiculite }\end{array}$ \\
\hline $\begin{array}{l}\text { Nitrito de sódio } \\
\text { CAS 7632-00-0 }\end{array}$ & $\begin{array}{l}\text { 1. Se o residuos for sólido, } \\
\text { adicionar água ( } 30-50 \mathrm{ml} / \mathrm{g} \text {.) } \\
\text { Então, gentilmente, adicionar } \\
\text { solução de bissulfito de sódio } \\
10 \%,(50 \text { a } 75 \mathrm{ml} / \mathrm{g} \text { ). Quando a } \\
\text { reação estiver completada, } \\
\text { neutralize com carbonato de } \\
\text { sódio e descarte na rede de } \\
\text { esgoto } \\
\text { 2. Em solução aquosa, adicionar } \\
\text { hidróxido de amônia } 50 \% \text { e } \\
\text { acidificar a pH } 1 \text { com } \mathrm{HCL}^{1} \text {. }\end{array}$ & $\begin{array}{l}\text { 2. US\$ } \\
0,018 / \mathrm{ml}^{9}\end{array}$ & $\begin{array}{l}\text { Acetanilida, antipirina, sais } \\
\text { de mercúrio, hidrazinas, } \\
\text { tiocianatos, permanganato, } \\
\text { sulfitos, hipofosfitos e } \\
\text { iodeto. Reage em contato } \\
\text { com celulose, lítio e } \\
\text { potássio +amônia. } \\
\text { Decompde-se em contato } \\
\text { com ácidos (mesmo os } \\
\text { fracos), com liberação de } \\
\mathrm{N}_{2} \mathrm{O}_{3}{ }^{3}\end{array}$ & $\begin{array}{l}\text { - Oxidante forte } \\
\text { - Incêndio: } \mathrm{CO}_{2}, \text { po químico } \\
\text { - Derramamento: proceda como descrito no item } \\
\text { tratamento }\end{array}$ \\
\hline $\begin{array}{l}\text { Permanganato } \\
\text { de potássio } \\
\text { CAS } 7722-64-7\end{array}$ & $\begin{array}{l}\text { Adicionar bissulfito de sódio (solução } \\
\text { concentrada) e até que a cor magenta } \\
\text { desapareça, após acidificaçãa com } \\
\mathrm{H}_{2} \mathrm{SO}_{4} 3 \mathrm{M} \text {. Neutralize com carbonato de } \\
\text { sódio se necessário. Descarte na rede de } \\
\text { esgoto } \\
1,111\end{array}$ & $\begin{array}{l}\text { US\$ } 5,34 / \\
100 \mathrm{ml} \mathrm{de} \\
\text { solução }\end{array}$ & $\begin{array}{l}\text { Ácido acético, anidrido } \\
\text { acético, acetona, álcoois e } \\
\text { ácido nitrico, nitrato de } \\
\text { amônia, formaldeido, glicerol, } \\
\text { ácido cloridrico, peróxido de } \\
\text { hidrogênio, hidroxilamina, } \\
\text { áido sulfúrico concentrado }\end{array}$ & $\begin{array}{l}\text { - Oxidante forte, inflamável através de reaçðes } \\
\text { químicas }{ }^{8} \\
\text { - Incêndio: água } \\
\text { - Derramamento: adsorver com areia ou mistura de } \\
\text { carbonato de sódio:betonita:areia }(1: 1: 1) \text { e tratar com } \\
\text { descrito anteriormente }\end{array}$ \\
\hline
\end{tabular}


Cont. Tabela A-28

\begin{tabular}{|c|c|c|c|c|}
\hline Substância & Tratamento/disposição & Custo* & Incompatibilidade & $\begin{array}{l}\text { Característica relevante da substância / } \\
\text { Procedimentos em situações de emergência }\end{array}$ \\
\hline $\begin{array}{l}\text { Tetrahidrofurano } \\
\text { CAS 109-99-9 }\end{array}$ & Incineração" & $\begin{array}{l}\text { Até } 250 \mathrm{Kg}= \\
\text { US\$ } 343,40\end{array}$ & $\begin{array}{l}\text { Oxidantes fortes. Explosivo } \\
\text { com lítio e alumínio. } \\
\text { Peróxidos podem se formar } \\
\text { em contato com o ar }\end{array}$ & $\begin{array}{l}\text { - } \mathrm{FP}-17,2^{\circ} \mathrm{C}^{11} \\
\text { - } \\
\text { - } \\
\text { Derramaiomamento - adsorver com areia, vermiculite, } \\
\text { papel }^{11}\end{array}$ \\
\hline $\begin{array}{l}\text { Tolueno } \\
\text { CAS 108-88-3 }\end{array}$ & $\begin{array}{l}\text { 1. Incineração } \\
2 . \text { Bio-remediação (aqüífero) -+ } \\
\text { fosfato de amônia (nutriente) }+ \\
\mathrm{KNO}_{3} \text { (aceptor elétrons) }+ \\
\text { microflora presente - eficiência } 78 \text { a } \\
99 \%\end{array}$ & $\begin{array}{l}\text { 1. Até } 250 \mathrm{Kg} \\
=\mathrm{US} \$ 343,40 \\
\text { 2. NC }\end{array}$ & $\begin{array}{l}\text { Oxidantes, ácido nítrico, } \\
\text { trifluoreto de boro, } \\
\text { tetróxido de nitrogênio, } \\
\text { trinitrometano }\end{array}$ & $\begin{array}{l}\text { - } \mathrm{FP} 4,4^{\circ} \mathrm{C}^{11} \\
\text { - Incêndio }-\mathrm{CO}_{2} \text {, pó químico, água } \\
\text { - Derramamento - adsorver com areia, vermiculite, } \\
\text { papel }\end{array}$ \\
\hline $\begin{array}{l}\text { Trietilamina } \\
\text { CAS 121-44-8 }\end{array}$ & Incineração ${ }^{11}$ & $\begin{array}{l}\text { Até } 250 \mathrm{Kg}= \\
\text { US } \$ 343,40\end{array}$ & $\begin{array}{l}\text { Tetróxido de nitrogênio e } \\
\text { oxidantes }{ }^{8}\end{array}$ & $\begin{array}{ll}\text { - } & \mathrm{FP}-6^{\circ} \mathrm{C}^{9} \\
\text { - } & \text { Incêndio: } \mathrm{CO}_{2} \text {, pó químico } \\
\text { - } & \text { Derramamento: adsorver com areia, incinerar } \\
& 6,8\end{array}$ \\
\hline $\begin{array}{l}\text { Xileno } \\
\text { CAS 106-42-3 }\end{array}$ & $\begin{array}{l}\text { 1. Incineração } \\
\text { 2. Bio-remediação (aqüífero) - }+ \\
\text { fosfato de amônia (nutriente) }+\mathrm{KNO}_{3} \\
\text { (aceptor elétrons) + microflora presente - } \\
\text { eficiência } 78 \text { a } 99 \%{ }^{5}\end{array}$ & $\begin{array}{l}\text { 1. Até } 250 \mathrm{Kg} \\
\text { US } \$ 343,40 \\
\text { 2. NC }\end{array}$ & $\begin{array}{l}\text { Ácido acético, ácido nítrico, } \\
\text { oxidantes fortes } "\end{array}$ & $\begin{array}{l}\text { - } \\
\text { - } \\
\text { - Incêndio } 29^{\circ} \mathrm{C}^{11} \\
\text { - } \mathrm{CO}_{2} \text {, pó químico, água } \\
\text { papel }{ }^{11}\end{array}$ \\
\hline
\end{tabular}

Nota: $\mathrm{FP}=$ ponto de fulgor, $\mathrm{NC}=\mathrm{Na}$ calculado, $\mathrm{CAS}=$ número de registro no Chemical abstrac;; ${ }^{*}$ Custo estimado do tratamento; ${ }^{* *}$ procedimento para remocào dos peroxidos com sulfato ferroso $5 \%$ ligeiramente acidificado com bissulfato de sódio ou soluçăo Metabissulfito de sódio $50 \%$ na proporçåo $1: 5$ de áter ${ }^{1,8,11}$. Custo* estimado utilizando reagentes p.a Syma - Aldrich, Referencias: $1=$

ARMOUR, 1996; 2 = MERCK INTERNATIONAL - Chem Cat, 1998; 3 = USDHHS - CHSI, 2000; 4 = FIELDS e col., 1996; 5 = GERSBERG, 1995; $6=$ INTERNATIONAL. TECHNICAL INFORMATION INSTITUTE, 1977; $7=$ LUNN \& SANSONE, 1994; 8= LEWIS, 1992; 9= SYGMA-ALDRICH, 1999; $10=$ MERCK INDEX, 1996; $11=$ TOMES CPS, $1987-1999$. 
Tabela A -29 - Tratamento, disposição, incompatibilidade e procedimentos a serem adotados em situações de emergência para as substâncias corrosivas levantadas.

\begin{tabular}{|c|c|c|c|c|}
\hline Substância & Tratamento/disposição & Custo* & Incompatibilidade & $\begin{array}{l}\text { Característica relevante da substância / } \\
\text { Procedimento em situações de emergência }\end{array}$ \\
\hline $\begin{array}{l}\text { Ácido acético } \\
\text { CAS 64-19-7 }\end{array}$ & Neutralizar com $\mathrm{NaOH} 5 \%$ ou $\mathrm{Na}_{2} \mathrm{CO}_{3}^{1,6}$ & $\begin{array}{l}\text { US\$ } 0,0024 / \mathrm{ml} \\
\text { de } \mathrm{NaOH} 5 \%{ }^{\text {utilizado }}{ }^{9}\end{array}$ & $\begin{array}{l}\text { Acetaldeido, anidrido acético, } \\
\text { carbonatos, oxidos, hidróxidos, } \\
\text { fosfatos, ácidos crômico, ácido } \\
\text { nitrico, peróxido de sódio. Em } \\
\text { contato com a água libera vapores }\end{array}$ & $\begin{array}{l}\text { - } \mathrm{FP} 43^{\circ} \mathrm{C} \text {, inflamável e corrosivo } \\
\text { - } \quad \text { Incêndio - } \mathrm{CO}_{2} \text {, água } \\
\text { - } \quad \text { Derramamento adsorver com areia, } \\
\text { vermiculite } \mathrm{T} \text {, ou mistura } 1: 1: 1 \text { de } \mathrm{Na}_{2} \mathrm{CO}_{3} \text { ou } \\
\mathrm{Ca} \mathrm{CO}_{3} \text {, bentonita e areia }\end{array}$ \\
\hline $\begin{array}{l}\text { Ácido clorídrico } \\
\text { CAS 7647-01-0 }\end{array}$ & Neutralizar com $\mathrm{NaOH}$ ou $\mathrm{Na}_{2} \mathrm{CO}_{3}$ & $\begin{array}{l}\text { US\$ } 0,049 / \mathrm{g} \text { de } \\
\text { carbonato } \\
\text { utilizado }\end{array}$ & $\begin{array}{l}\text { Alcalis, aminas, cobre, } \\
\text { formaldeído, permanganato } \\
\text { de potássio, anidrido acético, } \\
\text { tetracloreto de carbono }+ \\
\text { álcool. }\end{array}$ & $\begin{array}{l}\text { - Incêndio - } \mathrm{CO}_{2} \text {, pó químico, } \\
\text { - Derramamento - cobrir com soda ou carbonato } \\
\text { de sódio }{ }^{6}\end{array}$ \\
\hline $\begin{array}{l}\text { Ácido fórmico } \\
\text { CAS 64-18-6 }\end{array}$ & $\begin{array}{l}\text { 1. Neutralizar com } \mathrm{NaOH} \text { ou } \mathrm{Na}_{2} \mathrm{CO}_{3} \\
\text { 2. Incineração }{ }^{6}\end{array}$ & $\begin{array}{l}\text { US } \$ 0,049 / \mathrm{g} \text { de } \\
\text { carbonato } \\
\text { utilizado }^{9}\end{array}$ & $\begin{array}{l}\text { Oxidantes fortes, cáusticos, } \\
\text { ácido sulfúrico }\end{array}$ & $\begin{array}{l}\text { - } \mathrm{FP} 69^{\circ} \mathrm{C} \text {, } \\
\text { - Incêndio - } \mathrm{CO}_{2} \text {, pó químico, água } \\
\text { - Derramamento - cobrir com soda ou carbonato } \\
\text { de sódio }{ }^{6}\end{array}$ \\
\hline $\begin{array}{l}\text { Ácido fosfórico } \\
\text { CAS 7664-38-2 }\end{array}$ & Neutralizar com $\mathrm{NaOH}$ ou $\mathrm{Na}_{2} \mathrm{CO}_{3}{ }^{1}$ & $\begin{array}{l}\text { US\$ } 0,049 / \mathrm{g} \text { de } \\
\text { carbonato } \\
\text { utilizado }^{9}\end{array}$ & $\begin{array}{l}\text { Bases, oxidos metálicos, } \\
\text { metais e ligas metálicas }\end{array}$ & $\begin{array}{l}\text { - Incêndio - água } \\
\text { - Derramamento - cobrir com soda ou carbonato } \\
\text { de sódio }{ }^{6}\end{array}$ \\
\hline $\begin{array}{l}\text { Ácido nítrico } \\
\text { CAS } 7697-37-2\end{array}$ & Neutralizar com $\mathrm{NaOH}$ ou $\mathrm{Na}_{2} \mathrm{CO}_{3}{ }^{6}$ & $\begin{array}{l}\text { US } \$ 0,049 / \mathrm{g} \text { de } \\
\text { carbonato } \\
\text { utilizado }^{9}\end{array}$ & $\begin{array}{l}\text { Substâncias orgânicas nitradas } \\
\text { e combustiveis, oxidantes, } \\
\text { solventes orgânicos, alcoóis, } \\
\text { cetonas, aldeídos, anidridos, } \\
\text { aminas, anilina, nitrilas, } \\
\text { metais, metais alcalinos, } \\
\text { amônia, alcalis, hidretos, } \\
\text { compostos halogenados, } \\
\text { peróxido de hidrogênio, } \\
\text { fosfitos }^{3}\end{array}$ & $\begin{array}{l}\text { - Incêndio - } \mathrm{CO}_{2} \text {, água, espuma }{ }^{3,8} \\
\text { - Derramamento - cobrir com soda ou carbonato } \\
\text { de sódio }{ }^{6}\end{array}$ \\
\hline
\end{tabular}


Cont. Tabela A-29

\begin{tabular}{|c|c|c|c|c|}
\hline Substância & Tratamento/disposição & Custo* & Incompatibilidade & $\begin{array}{l}\text { Característica relevante da substância / } \\
\text { Procedimento em situações de emergência }\end{array}$ \\
\hline $\begin{array}{l}\text { Ácido oxálico } \\
\text { CAS 144-62-7 }\end{array}$ & $\begin{array}{l}\text { Para cada } 5 \mathrm{~g} \text { de ácido oxálico adicionar } 25 \\
\mathrm{ml} \text { de } \mathrm{H}_{2} \mathrm{SO}_{4} \text { concentrado. Aquecer a } \\
\text { mistura a } 80-100^{\circ} \mathrm{C} \text { por } 30 \text { minutos. } \\
\text { Neutralizar com carbonato de sódio }\end{array}$ & $\begin{array}{l}\text { US\$ } 0,052 / g \text { de } \\
\text { acido oxálico }+ \\
\text { US\$ } 0,049 \text { por } \mathrm{g} \\
\text { de carbonato } \\
\text { utilizado }^{9}\end{array}$ & $\begin{array}{l}\text { Prata, cloreto de sódio }+ \\
\text { água }\end{array}$ & $\begin{array}{l}\text { - Incêndio - } \mathrm{CO}_{2} \text {, pó químico, água } \\
\text { - Derramamento - cobrir com carbonato de } \\
\text { sódio, areia e betonita }(1: 1: 1) \text { e neutralizar } \\
\text { com carbonato de sódio se necessário }\end{array}$ \\
\hline $\begin{array}{l}\text { Ácido perclórico } \\
\text { CAS 7601-90-3 }\end{array}$ & $\begin{array}{l}\text { 1. neutralizar com } \mathrm{NaOH} \text {, diluindo } \\
\text { primeiramente a solução ácida para } \\
\text { concentrações inferiores a } 0,1 \%\end{array}$ & $\begin{array}{l}\text { US\$ } 0,049 / \mathrm{g} \text { de } \\
\mathrm{NaOH} \text { utilizado }\end{array}$ & $\begin{array}{l}\text { Oxidantes fortes (explosão), } \\
\text { nitrilas, alcoóis, ácidos, } \\
\text { anidridos, éteres, } \\
\text { halogênios, sulfóxidos, } \\
\text { hidrocarbonetos } \\
\text { halogenados, cetonas, } \\
\text { iodetos } 8,11\end{array}$ & $\begin{array}{l}\text { - Incêndio - água } \\
\text { - Derramamento - cobrir com agentes redutores } \\
\text { (sais de ferro ou bissulfitos), neutralizar com } \\
\text { soda } 6\end{array}$ \\
\hline $\begin{array}{l}\text { Ácido periódico } \\
\text { CAS } 10450-60-9\end{array}$ & $\begin{array}{l}\text { Nenhuma referência encontrada na } \\
\text { literatura. }\end{array}$ & & $\begin{array}{l}\text { Dimetilsulfóxido e } \\
\text { hidróxido de } \\
\text { tetraetilamônio } 8,11\end{array}$ & - Incêndio - pó químico, água ${ }^{11}$ \\
\hline $\begin{array}{l}\text { Ácido sulfúrico } \\
\text { CAS 7664-93-9 }\end{array}$ & Neutralizar com $\mathrm{NaOH}$ ou $\mathrm{Na}_{2} \mathrm{CO}_{3}{ }^{6}$ & $\begin{array}{l}\text { US\$ } 0,049 / \mathrm{g} \mathrm{de} \\
\mathrm{NaOH} \text { utilizado }\end{array}$ & $\begin{array}{l}\text { Anidrido acético, acetona, } \\
\text { dicromato de potássio, } \\
\text { acetonitrila, acrilonitrila, } \\
\text { álcool-água, peróxido de } \\
\text { hidrogênio, picratos, ácido } \\
\text { perclórico, ácido nítrico, } \\
\text { metais, permanganato de } \\
\text { potássio, piridina, estireno, } \\
\text { água }{ }^{11}\end{array}$ & $\begin{array}{l}\text { - Incêndio- } \mathrm{CO}_{2} \text {, pó químico } \\
\text { - Derramamento: cobrir com soda ou } \mathrm{Na}_{2} \mathrm{CO}_{3}{ }^{6}\end{array}$ \\
\hline $\begin{array}{l}\text { Ácido } \\
\text { Tricloracético } \\
\text { CAS 76-03-9 }\end{array}$ & Neutralizar com carbonato de sódio 6 & $\begin{array}{l}\text { US\$ } 0,049 / \mathrm{g} \text { de } \\
\text { carbonato } \\
\text { empregado }^{9}\end{array}$ & $\begin{array}{l}\text { Quando aquecido } \\
\text { decompóem-se em } \\
\text { cloroformio e carbonato de } \\
\text { sódio } 6.8\end{array}$ & $\begin{array}{l}\text { - Incêndio - } \mathrm{CO}_{2} \text {, pó químico, água } \\
\text { - Derramamento - cobrir com soda ou carbonato } \\
\text { de sódio }{ }^{6}\end{array}$ \\
\hline
\end{tabular}


Cont. Tabela A- 29

\begin{tabular}{|c|c|c|c|c|}
\hline Substância & Tratamento/disposição & Custo* & Incompatibilidade & $\begin{array}{l}\text { Característica relevante da substância / } \\
\text { Procedimento em situações de emergência }\end{array}$ \\
\hline $\begin{array}{l}\text { Ácido } \\
\text { trifluoracético } \\
\text { CAS 76-05-1 }\end{array}$ & Incinerar dissolvido em solvente inflamável & $\begin{array}{l}\text { Vide custos para } \\
\text { inflamáveis }\end{array}$ & $\begin{array}{l}\text { Dimetilsulfóxido e hidreto } \\
\text { de alumínio e lítio. Reage } \\
\text { rapidamente com o ar }\end{array}$ & $\begin{array}{l}\text { - Incêndio - } \mathrm{CO}_{2} \text {, pó químico, água } \\
\text { - Derramamento - cobrir com soda ou carbonato } \\
\text { de sódio e incinerar }{ }^{1}\end{array}$ \\
\hline $\begin{array}{l}\text { Cloreto de } \\
\text { antimônio } \\
\text { CAS 10025-91-9 }\end{array}$ & $\begin{array}{l}\text { Adicionar } 4 \mathrm{~g} \text { de silicato de sódio para cada } \\
\text { grama de sal de antimônio. Leve a fervura, } \\
\text { resfrie. Filtre o precipitado. Descarte } 0 \\
\text { filtrado na rede de esgoto e disponha o } \\
\text { resíduo em aterro industrial }{ }^{1}\end{array}$ & $\begin{array}{l}\text { US\$ } 0,25 / \mathrm{g} \text { de } \\
\text { cloreto de } \\
\text { antimônio } 9\end{array}$ & $\begin{array}{l}\text { Alumínio, potássio, sódio, } \\
\text { ácido perclórico, oxidantes } \\
\text { fortes, ácidos fortes e } \\
\text { metais. Reage } \\
\text { violentamente com a água } \\
\text { formando ácido cloridrico }\end{array}$ & $\begin{array}{l}\text { - Incêndio - pó químico, } \mathrm{CO}_{2} \mathrm{~T} \\
\text { - Derramamento: adsorver com areia, } \\
\text { vermiculite e tratar como descrito no item } \\
\text { precedente. }\end{array}$ \\
\hline \multirow[t]{2}{*}{$\begin{array}{l}\text { Fenol **} \\
\text { CAS 108-95-2 }\end{array}$} & $\begin{array}{l}\text { 1. solução fenol } 63 \mathrm{mg} / \mathrm{mL}+2,35 \mathrm{~g} \\
\mathrm{FeSO}_{4} .7 \mathrm{H}_{2} \mathrm{O} \text {. Ajustar pH } 5-6 \mathrm{com} \\
\mathrm{H}_{2} \mathrm{SO}_{4} .+41 \mathrm{ml} \mathrm{H}_{2} \mathrm{O}_{2} 30 \% \text {, } \\
\text { lentamente. Reação exotérmica. Deixar } \\
12 \text { horas em repouso, descartar na rede } \\
\text { de esgoto. } \\
\text { 2. Bioremediação: a. coluna empacotada } \\
\text { com pérola de vidro e Pseudomonas } \\
\text { putida como microflora, converte } 93 \text { a } \\
99,6 \% \text { do fenol } 12 \text { b. remoção de } \\
\text { efluentes industriais empregando- se } \\
\text { uma enzima imobilizada, tirosinase de } \\
\text { cogumelo. O processo remove 100\% } \\
\text { do fenol em } 2 \text { horas e é eficaz para } \\
\text { vários compostos fenólicos substituídos } \\
\text { 13. }\end{array}$ & \multirow[t]{2}{*}{$\begin{array}{l}\text { US\$ } 1,87 / \mathrm{ml} \text { de } \\
\text { fenol (solução } 63 \\
\mathrm{mg} / \mathrm{ml})^{9}\end{array}$} & \multirow[t]{2}{*}{$\begin{array}{l}\text { Nitrobenzeno, cloreto de } \\
\text { alumínio, nitrito de sódio, } \\
\text { nitrato de sódio/ácido } \\
\text { trifluoracético }\end{array}$} & \multirow[t]{2}{*}{$\begin{array}{l}\text { - Incêndio: } \mathrm{CO}_{2} \text {, água } \\
\text { - Derramamento: cobrir com areia }{ }^{11}\end{array}$} \\
\hline & 3. Incineração & & & \\
\hline
\end{tabular}


Cont. Tabela A- 29

\begin{tabular}{|c|c|c|c|c|}
\hline Substância & Tratamento/disposição & Custo* & Incompatibilidade & $\begin{array}{l}\text { Característica relevante da substância / } \\
\text { Procedimento em situações de emergência }\end{array}$ \\
\hline $\begin{array}{l}\text { Hidróxido de } \\
\text { amônia } \\
\text { CAS 1336-21-6 }\end{array}$ & Neutralizado com $\mathrm{HCL}^{1,6}$ & $\begin{array}{l}\text { US\$ } 0,09 / \mathrm{ml} \mathrm{de} \\
\text { ácido } \\
\text { concentrado } \\
\text { utilizado } 9\end{array}$ & $\begin{array}{l}\text { Acroleína, ácido acrílico, } \\
\text { ácido clorosulfônico, ácido } \\
\text { clorídrico, ácido fluorídrico, } \\
\text { ácido nítrico, halogênios, } \\
\text { nitrato de prata, oxidos de } \\
\text { prata, permanganato de } \\
\text { potássio e ácido sulfúrico }\end{array}$ & $\begin{array}{l}\text { - Incêndio: } \mathrm{CO} 2 \text {, água, pó químico } \\
\text { - derramamento: adsorver com uma mistura } \\
\text { 1:1:1 de } \mathrm{Na}_{2} \mathrm{CO}_{3} \text { ou } \mathrm{Ca} \mathrm{CO}_{3} \text {, bentonita e areia. } \\
\text { Neutralizar com } \mathrm{HCL}^{1,6}\end{array}$ \\
\hline $\begin{array}{l}\text { Hidróxido de } \\
\text { potássio } \\
\text { CAS 1310-58-3 }\end{array}$ & Neutralizado com $\mathrm{HCL}^{6}$ & $\begin{array}{l}\text { US } \$ 0,09 / \mathrm{ml} \mathrm{de} \\
\text { ácido } \\
\text { concentrado } \\
\text { utilizado }^{9}\end{array}$ & $\begin{array}{l}\text { Água, metais, } \\
\text { hidrocarbonetos } \\
\text { halogenados, anidrido } \\
\text { maleico }^{2,8} \text {. }\end{array}$ & $\begin{array}{l}\text { Incêndio }-\mathrm{CO}_{2} \text {, água, pó químico } \\
\text { - Derramamento - sólido: coletar com escova e pá, } \\
\text { transferindo para um recipiente onde possa ser } \\
\text { diluído com água e neutralizado com HCL } 6 \mathrm{M} \text {; } \\
\text { Solução: neutralizar com } \mathrm{HCL}^{6}\end{array}$ \\
\hline $\begin{array}{l}\text { Hidróxido de } \\
\text { sódio } \\
\text { CAS 1310-73-2 }\end{array}$ & Neutralizado com $\mathrm{HCL}^{1,6}$ & $\begin{array}{l}\text { US } \$ 0,09 / \mathrm{ml} \mathrm{de} \\
\text { ácido } \\
\text { concentrado } \\
\text { utilizado }{ }^{9}\end{array}$ & $\begin{array}{l}\text { Água, ácidos, líquidos } \\
\text { inflamáveis, nitrometano, } \\
\text { hidrocarbonetos } \\
\text { halogenados, metais como } \\
\text { alumínio, zinco e estanho }\end{array}$ & $\begin{array}{l}\text { - Incêndio - } \mathrm{CO}_{2} \text {, água, pó químico } \\
\text { - Derramamento - sólido: coletar com escova e pá, } \\
\text { transferindo para um recipiente onde possa ser } \\
\text { diluído com água e neutralizado com HCL } 6 \mathrm{M} \text {; } \\
\text { Solução: neutralizar com } \mathrm{HCL}^{1,6}\end{array}$ \\
\hline $\begin{array}{l}\text { lodo } \\
\text { CAS 7553-56-2 }\end{array}$ & $\begin{array}{l}\text { 1. Para } 5 \mathrm{~g} \text { de iodo, adicionar } 300 \mathrm{ml} \text { de } \\
\text { solução de tiossulfato de sódio } 4 \% \mathrm{e} \\
1,0 \mathrm{~g} \text { de carbonato de sódio. Misturar e } \\
\text { neutralizar com carbonato de sódio ou } \\
\mathrm{HCL} \text { diluído. Descartar na rede de } \\
\text { esgoto } \\
\text { 2. Reduzir o iodo com agentes redutores } \\
\text { (bissulfitos, ou sais de ferro com } \\
\mathrm{H}_{2} \mathrm{SO}_{4} 3 \mathrm{M} \text { ) }\end{array}$ & $\begin{array}{l}\text { 1. US\$ } 0,103 / \mathrm{g} \\
\text { de iodo } 9\end{array}$ & $\begin{array}{l}\text { Potássio, sódio, fósforo, } \\
\text { lítio, zinco, acetileno, } \\
\text { acetaldeído, cloro líquido, } \\
\text { etanol, butadieno, amônia, } \\
\text { materiais orgânicos e } \\
\text { oxidantes }\end{array}$ & $\begin{array}{l}\text { - oxidante forte e corrosivo } \\
\text { - Incêndio - pó químico, } \mathrm{CO}_{2} \text {, água } \\
\text { - Derramaneto - adsorver e colocar excesso de } \\
\text { metabissulfito de sódio ou tiossulfato de sódio } \\
1,6\end{array}$ \\
\hline
\end{tabular}


Cont. Tabela A- 29

\begin{tabular}{|c|c|c|c|c|}
\hline Substância & Tratamento/disposição & Custo & Incompatibilidade & $\begin{array}{l}\text { Característica relevante da substância / } \\
\text { Procedimento em situações de emergência }\end{array}$ \\
\hline $\begin{array}{l}\text { Peróxido de } \\
\text { hidrogênio } \\
\text { CAS 7722-84-1 }\end{array}$ & $\begin{array}{l}\text { Adicionar à solução de peróxido } \\
\text { diluída (5\%), uma solução de } \\
\text { metabissulfito de sódio } 50 \% \text { (em } \\
\text { excesso). A reação é exotérmica. } \\
\text { Neutralizar e descatar na rede de } \\
\text { esgoto }{ }^{\text {' }}\end{array}$ & $\begin{array}{l}\text { US\$ } 0,63 / \mathrm{ml} \mathrm{de} \\
\text { solução de } \mathrm{H}_{2} \mathrm{O}_{2} \text {, } \\
\text { utilizando-se o } \\
\text { dobro de } \\
\text { metabissulfito de } \\
\text { sódio }\end{array}$ & $\begin{array}{l}\text { Oxidantes, ferro, cobre, } \\
\text { bronze, cromo, zinco, } \\
\text { chumbo, prata, magnésio, } \\
\text { ácidos orgânicos, cetonas. } \\
\text { Contato com material } \\
\text { combustível resulta em } \\
\text { combustão espontânea }^{6,11}\end{array}$ & 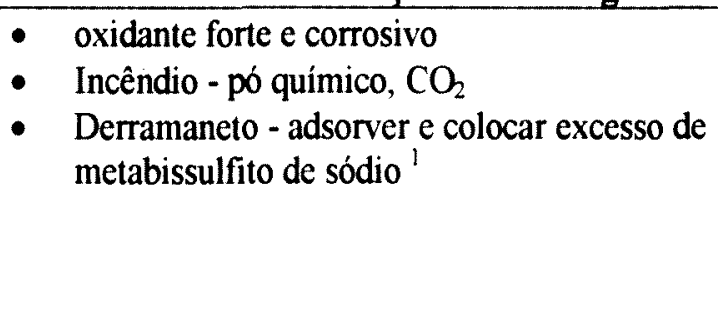 \\
\hline
\end{tabular}

2000: 4 = FIELDS e col 1996; 5 = GERSBERG, 1995; 6 = INTERNo como extremamente perigoso 1 = ARMOUR, 1996; 2 = MERCK INTERNATIONAL - Che 8

ALDRICH, 1999; 10= MERCK INDEX, 1996; 11 = TOMES CPS, 1987 - 1999; 12=ZILLI e col., 1993; 13= WADA e col., 1993 
Tabela A-30 - Tratamento e disposição, incompatibilidade e procedimentos a serem adotados em situações de emergência para as substâncias reativas levantadas.

\begin{tabular}{|c|c|c|c|c|}
\hline Substância & Tratamento/disposiçăo & Custo* & Incompatibilidade & $\begin{array}{l}\text { Característica relevante da substância / } \\
\text { Procedimento em situações de emergência }\end{array}$ \\
\hline $\begin{array}{l}\text { (3-amino propil) } \\
\text { trietoxi silano } \\
\text { CAS } 919-30-2\end{array}$ & $\begin{array}{l}\text { Hidrolisar com água, adicionando } \\
\text { cuidadosamente. Neutralizar se } \\
\text { necessário (procedimento adotado para } \\
\text { todos os silanos) }{ }^{1}\end{array}$ & & Ácidos ${ }^{\top}$ & $\begin{array}{l}\text { - FP } 93{ }^{\circ} \mathrm{C} \text {, irritante } \\
\text { - Incêndio: pó químico, } \mathrm{CO}_{2}{ }^{2} \\
\text { - Derramamento: adsorver com areia e proceder } \\
\text { hidrólise cuidadosamente }\end{array}$ \\
\hline $\begin{array}{l}\text { Ácido pícrico } \\
\text { CAS 88-89-1 }\end{array}$ & $\begin{array}{l}\text { 1. Acidificar a solução de ácido } \\
\text { pícrico com HCL concentrado, } \\
\text { adicionar estanho metálico. Deixar } \\
\text { reagir. Após } 14 \text { dias, todo o ácido } \\
\text { picrico estará reduzido } \\
\text { 2. Para } 1 \mathrm{~g} \text { de ácido picrico adicionar } \\
\mathrm{NaOH} 5,2 \mathrm{mg} / \mathrm{ml} \mathrm{e} 2,7 \mathrm{~g} \text { de sulfito } \\
\text { de sódio. Quando a reação estiver } \\
\text { completada, descarte a mistura com } \\
\text { o residuos perigosos " } \\
\text { 3. Incineração "I }\end{array}$ & $\begin{array}{l}\text { 2.US\$ } 0,078 / \mathrm{g} \\
\text { de ácido } \\
\text { pícrico }\end{array}$ & $\begin{array}{l}\text { Metais pesados, oxidantes, } \\
\text { amônia, albumina. Picratos } \\
\text { são mais sensíveis ao choque, } \\
\text { friç̧ão e aquecimento }{ }^{11}\end{array}$ & $\begin{array}{l}\text { - Incêndio: } \mathrm{CO}_{2} \text {, pó químico, água }{ }^{11} \\
\text { - Derramamento: adsorver com areia, incinerar }{ }^{6,8}\end{array}$ \\
\hline $\begin{array}{l}\text { Anidrido } \\
\text { acético } \\
\text { CAS 108-24-7 }\end{array}$ & $\begin{array}{l}\text { Adicionar a cada } 5 \mathrm{ml} \text { de anidrido, } \\
60 \mathrm{ml} \text { de } \mathrm{NaOH} 2,5 \mathrm{M} \text {. Manter por } \\
12 \text { horas sob agitação, evitando que } \\
\text { a temperatura da reação aumente } \\
\text { muito. Neutralizar com HCL } 2 \mathrm{M} \mathrm{e} \\
\text { descartar na rede de esgoto }^{1}\end{array}$ & US\$ $0,052 / \mathrm{ml}^{9}$ & $\begin{array}{l}\text { Ácidos fortes, água, peróxido } \\
\text { de hidrogênio, aminas, bases } \\
\text { fortes, alcoóis } 1,11\end{array}$ & $\begin{array}{l}\text { - } \mathrm{FP} 54{ }^{\circ} \mathrm{C} \text {, corrosivo } \\
\text { - Incêndio - } \mathrm{CO}_{2} \text {, pó químico } \\
\text { - Derramamento: adsorver com areia, mistura } 1: 1: 1 \mathrm{de} \\
\mathrm{Na}_{2} \mathrm{CO}_{3} \text { ou } \mathrm{Ca} \mathrm{CO}_{3} \text {, bentonita e areia } 1,11\end{array}$ \\
\hline $\begin{array}{l}\text { Boridreto de } \\
\text { sódio } \\
\text { CAS 16940-66-2 }\end{array}$ & $\begin{array}{l}\text { Em capela química, adicionar um } \\
\text { volume de água de modo a obter uma } \\
\text { soluçãa de boridreto de concentração } \\
\text { inferior a } 3 \% \text {. Sob atmosfera de } \\
\text { nitrogênio, adicionar ácido acético } \\
\text { diluído gota a gota até neutralização }{ }^{\text {. }} \text {. }\end{array}$ & & $\begin{array}{l}\text { Ácidos, alcalis e cloreto de } \\
\text { alumínio. Reage com a água } \\
\text { liberando hidrogênio }\end{array}$ & $\begin{array}{l}\text { - Incêndio: pó químico }{ }^{11} \\
\text { - Derramamento: adsorver e adicionar bastante água }{ }^{1}\end{array}$ \\
\hline
\end{tabular}


Cont. Tabela A-30

\begin{tabular}{|c|c|c|c|c|}
\hline Substância & Tratamento/disposiçăo & Custo* & Incompatibilidade & $\begin{array}{l}\text { Característica relevante da substância / } \\
\text { Procedimento em situacoóes de emergência }\end{array}$ \\
\hline $\begin{array}{l}\text { Cloreto de } \\
\text { alumínio } \\
\text { CAS 7446-70-0 }\end{array}$ & $\begin{array}{l}\text { Adicionar excesso de carbonato de } \\
\text { sódio. Neutralize se necessário e } \\
\text { descarte na rede de esgoto }{ }^{1}\end{array}$ & $\begin{array}{l}\text { US\$ } 0,078 / \mathrm{g} \text { de } \\
\text { carbonato } \\
\text { utilizado }^{9}\end{array}$ & $\begin{array}{l}\text { Bases fortes, alcoóis, } \\
\text { nitrobenzeno, anilina, amônia } \\
\text { borohidreto de sódio. Reage } \\
\text { violentamente com a água } \\
\text { formando HCL }{ }^{11}\end{array}$ & $\begin{array}{l}\text { - Incêndio - } \mathrm{CO}_{2} \text {, pó químico } \\
\text { - Derramamento: adsorver com areia ou mistura 1:1:1 } \\
\text { de } \mathrm{Na}_{2} \mathrm{CO}_{3} \text { ou } \mathrm{Ca} \mathrm{CO}_{3} \text {, bentonita e areia }\end{array}$ \\
\hline $\begin{array}{l}\text { Cloreto de } \\
\text { tionila } \\
\text { CAS } 7719-09-7\end{array}$ & $\begin{array}{l}\text { Adicionar bicarbonato de sódio. } \\
\text { Misturar e neutralizar }{ }^{6}\end{array}$ & $\begin{array}{l}\text { US } \$ 0,03 / \mathrm{g} \mathrm{de} \\
\text { bicarbonato } \\
\text { utilizado }^{9}\end{array}$ & $\begin{array}{l}\text { Água, amônia e formaldeido. } \\
\text { Chem cat. Reage } \\
\text { violentamente com a água } \\
\text { formando } \mathrm{SO}_{2}, \mathrm{HCL}\end{array}$ & $\begin{array}{l}\text { - Incêndio }-\mathrm{CO}_{2} \text {, pó químico } \\
\text { - Derramamento: adsorver com areia }{ }^{11} \text { ou } \mathrm{Na}_{2} \mathrm{CO}_{3}{ }^{1}\end{array}$ \\
\hline $\begin{array}{l}\text { Cloreto de } \\
\text { vanádio } \\
\text { CAS 7632-51-1 }\end{array}$ & $\begin{array}{l}\text { Nenhuma referência encontrada. Para } \\
\text { o pentóxido de vanádio - adicionar } \\
\text { carbonato de amônia e hidróxido de } \\
\text { amônia } 6 \mathrm{M} \text { (nebulizar). Filtrar e } \\
\text { devolver o residuo para of fabricante }\end{array}$ & $\begin{array}{l}\mathrm{US} \$ 0,039 / 10 \\
\mathrm{ml} \mathrm{NH} \mathrm{OH}_{4} \mathrm{e} \\
\mathrm{USS} 0,04 / \mathrm{g} \mathrm{de} \\
\left(\mathrm{NH}_{4}\right)_{2} \mathrm{CO}_{3}^{9}\end{array}$ & $\begin{array}{l}\text { Reage violentamente com a } \\
\text { água formando } \mathrm{HCL} \text {, } \\
\text { tricloreto de vanádio e } \\
\text { oxicloreto de vanádio }\end{array}$ & $\begin{array}{l}\text { - Incêndio }-\mathrm{CO}_{2} \text {, pó químico } \\
\text { - Derramamento: adsorver com areia }{ }^{\prime \prime}\end{array}$ \\
\hline $\begin{array}{l}\text { Diazometano } \\
\text { CAS 334-88-3 }\end{array}$ & $\begin{array}{l}\text { 1. Adicionar cuidadosamente } \\
\text { ácido acético até que a solução } \\
\text { perca a coloração amarelada }{ }^{1} \\
\text { 2. Incineração }{ }^{11}\end{array}$ & $\begin{array}{l}\text { 1. US\$ } 0,02 / \mathrm{ml} \\
\text { ácido acético } \\
\text { concentrado } \\
\text { 2. até } 250 \mathrm{Kg}= \\
\text { US\$ } 343,40\end{array}$ & $\begin{array}{l}\text { Metais alcalinos, sulfato de } \\
\text { cálcio, agua. Altamente } \\
\text { explosivo em situaçdes de } \\
\text { choque, calor ou reação } \\
\text { quimica }{ }^{8} \text {.Soluções concentradas } \\
\text { podem explodir violentamente } \\
\text { especialmente se impurezas } \\
\text { estiverem presentes }{ }^{11} \text {. }\end{array}$ & $\begin{array}{l}\text { - Incêndio }-\mathrm{CO}_{2} \text {, pó químico } \\
\text { - Derramamento: adsorver com areia ou outro } \\
\text { adsorvente e inativar com ácido acético. Evitar } \\
\text { contato com água }{ }^{11}\end{array}$ \\
\hline $\begin{array}{l}\text { Magnésio } \\
\text { metálico } \\
\text { CAS 7439-95-4 }\end{array}$ & $\begin{array}{l}\text { Para } 10 \mathrm{~g} \text { de magnésio adicionar } \\
\text { cuidadosamente } 0,5 \mathrm{~L} \text { de água } \\
\text { Adicionar HCL } 5 \% \text { lentamente até que a } \\
\text { reação inicie. Quando a reação cessar, } \\
\text { adicione mais ácido e descarte quando a } \\
\text { acidificação não tiver mais efeito } \\
\end{array}$ & $\begin{array}{l}\text { US\$ } 0,09 / 10 \mathrm{~g} \\
\mathrm{Mg}^{9}\end{array}$ & $\begin{array}{l}\text { Ar, hidrocarbonetos } \\
\text { halogenados, oxidos } \\
\text { metálicos, metanol, carbonato } \\
\text { de potássio, halogênios } 1,8\end{array}$ & $\begin{array}{l}\text { - Incêndio - pó químico } \\
\text { - Derramamento: adsorver ou cobrir com mistura de } \\
\text { carbonato de sódio, betonita e areia (1:1:1). Adicionar, na } \\
\text { capela, um grande volume de butanol. Filtrar quando a } \\
\text { reação se completou e descartar o resíduo como rejeito } \\
\text { comum }\end{array}$ \\
\hline
\end{tabular}


Cont. Tabela A-30

\begin{tabular}{|c|c|c|c|c|}
\hline Substância & Tratamento/disposição & Custo* & Incompatibilidade & $\begin{array}{l}\text { Característica relevante da substância / } \\
\text { Procedimento em situações de emergência }\end{array}$ \\
\hline $\begin{array}{l}\text { Sais de cianeto } \\
\text { CAS: } \\
\text { NaCN 143-33-9 } \\
\text { KCN 151-50-8 }\end{array}$ & $\begin{array}{l}\text { Para cada } 50 \mathrm{ml} \text { de solução } \leq 2 \% \text { de } \\
\mathrm{CN}^{-} \text {, adicionar } 5 \mathrm{ml} \mathrm{NaOH} 10 \% \text { e } \\
60-70 \text { de hipoclorito de sódio } 2 \%{ }^{1} * *\end{array}$ & $\begin{array}{l}\text { US } \$ 0,006 / \mathrm{ml} \\
\text { de soluçãa de } \\
\text { CN }^{-} \text {até } 2 \%{ }^{9}\end{array}$ & $\begin{array}{l}\text { Ácidos, alcalóides, peróxidos, } \\
\text { permanganatos, peróxidos, } \\
\text { oxidantes fortes, prata } \\
\text { amoniacal, nitritos }{ }^{11}\end{array}$ & $\begin{array}{l}\text { - Incêndio - pó químico, areia } \\
\text { - Derramamento: adsorver com areia. Não deixar } \\
\text { entrar em contato com ácidos evitando a formação de } \\
\text { ácido cianídrico }\end{array}$ \\
\hline $\begin{array}{l}\text { Sódio metálico } \\
\text { CAS 7440-23-5 }\end{array}$ & $\begin{array}{l}\text { Em balão de fundo redondo adicionar } \\
13 \mathrm{ml} \text { de etanol } 95 \% \text { para cada grama } \\
\text { de sódio. A mistura deve ser agitada e } \\
\text { aquecida até que todo o sódio esteja } \\
\text { solubilizado. Desliga-se o o } \\
\text { aquecimento e adiciona-se igual } \\
\text { volume de água. Resfria-se a solução, } \\
\text { neutraliza-se com } \mathrm{H}_{2} \mathrm{SO}_{4} 6 \mathrm{~N} \text { e } \\
\text { descarta-se na rede de esgoto }\end{array}$ & US $\$ 0,23 / \mathrm{g}^{9}$ & $\begin{array}{l}\text { Ácidos, ar, clorofórmio- } \\
\text { metanol, éter etilico, } \\
\text { dimetilformamida, hidrazina, } \\
\text { mercúrio, hidrocarbonetos } \\
\text { halogenados, sulfetos, haletos. } \\
\text { Reage violentamente com a } \\
\text { água formando gás hidrogênio } \\
\text { e hidróxido de sódio }\end{array}$ & $\begin{array}{l}\text { - Incêndio: pó químico }{ }^{11} \\
\text { Derramamento: adsorver ou cobrir com mistura de } \\
\text { carbonato de sódio, bentonita e areia }(1: 1: 1) \text {. } \\
\text { Adicionar, na capela, excesso de 2-propanol seco. } \\
\text { Deixe em contato por } 24 \mathrm{~h} \text {, dilua com bastante água e } \\
\text { descarte }^{11}\end{array}$ \\
\hline $\begin{array}{l}\text { Trimetiliodo } \\
\text { silano }+ \\
\text { n-metil-n } \\
\text { (trimetilsililfluo } \\
\text { roacetamida) } \\
\text { CAS: } \\
\text { a. } 16029-98-9\end{array}$ & $\begin{array}{l}\text { A literatura não apresenta } \\
\text { informações especificas sobre esses } \\
\text { agentes de derivatização. Porém, } \\
\text { para o trimetilcloro silano } \\
\text { recomenda a adição de água (para } \\
\text { cada } 5 \mathrm{ml} \text { do composto, } 100 \mathrm{ml} \text { de } \\
\text { água), com formação de ácido } \\
\text { clorídrico e trimetilsilanol. } \\
\text { Neutralizar e descartar } 1,7\end{array}$ & & Água e oxidantes fortes $" 11$ & $\begin{array}{l}\text { - } \mathrm{FP}-28^{\circ} \mathrm{C} \text { (trimetilclorosilano) } \\
\text { - Incêndio: pó químico, } \mathrm{CO}_{2} \text { ou água. } \\
\text { - Derramamento : adsorver e tratar com água, } \\
\text { neutralizando em seguida }\end{array}$ \\
\hline \multicolumn{5}{|c|}{ 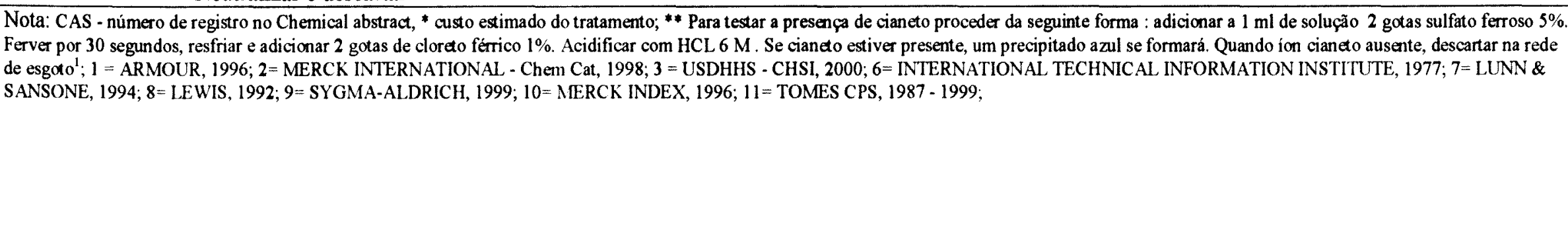 } \\
\hline
\end{tabular}


Tabela A-31 - Tratamento e disposição, incompatibilidade e procedimentos a serem adotados em situações de emergência para as substâncias tóxicas levantadas.

\begin{tabular}{|c|c|c|c|c|}
\hline Substância & Tratamento/disposição & Custo* & Incompatibilidade & $\begin{array}{l}\text { Característica relevante da substância / } \\
\text { Procedimento em situações de emergência }\end{array}$ \\
\hline $\begin{array}{l}\text { 2- mercaptoetanol } \\
\text { CAS } 60-24-2\end{array}$ & $\begin{array}{l}\text { Tratar com hipoclorito de sódio } \\
5.25 \% \text { e } \mathrm{NaOH} 1 \mathrm{M} \text {, agitar por } 1 \\
\text { hora e deixar interagir por } 18 \mathrm{~h} \text {. } \\
\text { Testar * e se negativo descartar na } \\
\text { rede de esgoto }\end{array}$ & $\begin{array}{l}\text { US } \$ 0,028 / \mathrm{ml} \\
\text { de hipoclorito }+ \\
\text { US } \$ 0,002 / \mathrm{ml} \\
\text { de } \mathrm{NaOH} \\
\text { utilizado }^{9}\end{array}$ & Oxidantes & $\begin{array}{l}\text { - Incêndio: } \mathrm{CO}_{2} \text {; pó químico } \\
\text { - Derramamento: adsorver com areia ou papel e } \\
\text { tratar como descrito }\end{array}$ \\
\hline $\begin{array}{l}\text { 2-acetil } \\
\text { aminofluoreno } \\
\text { CAS 53-96-3 }\end{array}$ & Incineração ${ }^{11}$ & $\begin{array}{l}\text { Até } 250 \mathrm{Kg}= \\
\mathrm{R} \$ 650,00\end{array}$ & $\begin{array}{l}\text { Ácidos, bases e agentes } \\
\text { oxidantes }{ }^{3}\end{array}$ & $\begin{array}{l}\text { - Incêndio: pó químico. } \mathrm{CO}_{2} \text { ou água. } \\
\text { - Derramamento: adsorver e incinerar }\end{array}$ \\
\hline $\begin{array}{l}\text { Ácido ósmico } \\
\text { CAS 20816-12-0 }\end{array}$ & $\begin{array}{l}\text { Reduzir com uma olefina formando } \\
\text { um éster, borbulhar, então, } \mathrm{H}_{2} \mathrm{~S} \text {, } \\
\text { através da solução. Um precipitado } \\
\text { preto indica a formação de dióxido } \\
\text { de ósmio, removido por filtração. } \\
\text { Este deve ser encaminhado para } \\
\text { aterro industrial ou reutilizado'. }\end{array}$ & $\begin{array}{l}\text { US } \$ 0,167 / \mathrm{ml} \\
\text { de octeno }{ }^{9}\end{array}$ & $\begin{array}{l}\text { Ácido cloridrico, substâncias } \\
\text { orgânicas facilmente ionizáveis } \\
11 \\
\text { Explode em contato com 1- } \\
\text { metilimidazol. A } \\
\text { decomposição catalizada por } \\
\text { peróxido de hidrogênio pode } \\
\text { ser perigosa }^{8} \text {. }\end{array}$ & $\begin{array}{l}\text { - Incêndio: pó químico, } \mathrm{CO}_{2} \\
\text { - Derramamento: adsorver com areia, vermiculite, } \\
\text { oxidar a dióxido de ósmio e encaminhar para } \\
\text { aterro industrial }\end{array}$ \\
\hline $\begin{array}{l}\text { Ácido orótico } \\
\text { CAS 50887-69-9 }\end{array}$ & $\begin{array}{l}\text { Nenhuma referência encontrada na } \\
\text { literatura }\end{array}$ & & Agentes oxidantes fortes ${ }^{3}$ & $\begin{array}{l}\text { - Incêndio:pó químico, } \mathrm{CO}_{2} \\
\text { - Derramamento:Adsorver com material sólido } 3\end{array}$ \\
\hline $\begin{array}{l}\text { Ácido sulfanilico } \\
\text { CAS } 121-57-3\end{array}$ & Incineração $^{3}$ & $\begin{array}{l}\text { Até } 250 \mathrm{Kg}= \\
\text { US\$ } 343,40\end{array}$ & Ácidos ${ }^{3}$ & $\begin{array}{l}\text { - Incêndio: } \mathrm{CO}_{2} \text {, pó químico } \\
\text { - Derramamento adsorver com material sólido }{ }^{3}\end{array}$ \\
\hline $\begin{array}{l}\text { Ácido sulfídrico } \\
\text { CAS 7783-06-04 }\end{array}$ & $\begin{array}{l}\text { Adicione excesso de uma solução aquosa } \\
\text { de hidróxido de sódio e depois, adicione } \\
25 \% \text { do volume de hipoclorito de sódio } \\
5 \% \text {, cuidadosamente. Deixe a solução } \\
\text { em repouso por algumas horas e descarte } \\
\text { na rede de esgoto }\end{array}$ & $\begin{array}{l}\text { US\$ } 0,004 / \mathrm{ml} \\
\text { de } \mathrm{NaOH} 2 \mathrm{~N} \\
\text { utilizado + US\$ } \\
0,028 / \mathrm{ml} \mathrm{de} \\
\text { NaCLO } 5 \% \\
\text { utilizado }^{9} \\
\end{array}$ & $\begin{array}{l}\text { Oxidantes fortes, ácido } \\
\text { nítrico concentrado e metais } \\
11\end{array}$ & $\begin{array}{l}\text { - Incêndio pó químico, } \mathrm{CO}_{2} \text { e água }{ }^{11} \\
\text { - Derramamento vazamento de gás, fazê-lo passar } \\
\text { por uma solução de cloreto férrico }\end{array}$ \\
\hline
\end{tabular}


Cont. Tabela A-31

\begin{tabular}{|c|c|c|c|c|}
\hline \multirow{2}{*}{$\begin{array}{l}\text { Substância } \\
\text { Acrilamida } \\
\text { CAS 79-06-1 }\end{array}$} & Tratamento/disposiçăo & usto* & Incompatibilidade & $\begin{array}{l}\text { Característica relevante da substância / } \\
\text { Procedimento em situações de emergência }\end{array}$ \\
\hline & Incineração" & $\begin{array}{l}\text { Até } 250 \mathrm{Kg}= \\
\text { US\$ } 343,40\end{array}$ & $\begin{array}{l}\text { Polimeriza-se rapidamente. } \\
\text { Os produtos de combustão } \\
\text { são tóxicos }\end{array}$ & $\begin{array}{l}\text { Combustivel } \\
\text { - Incêndio: não usar } \mathrm{CO}_{2} \text { Usar água ou espuma } \\
\text { - Derramamento: colocar o pó em saco plástico e } \\
\text { incinerar }\end{array}$ \\
\hline $\begin{array}{l}\text { Arseniato de sódio } \\
\text { CAS 7778-43-0 }\end{array}$ & $\begin{array}{l}\text { Adicionar solução de tioacetamida (9:1) } \\
\text { para cada grama de arsênio. (Usar } \\
\text { soluçáa } 0,01 \mathrm{~g} / \mathrm{ml} \text { de água acidulada com } \\
\text { HCL). Levarà à fervura por } 20 \text { minutos e } \\
\text { alcalinizar com NaOH } 2 \mathrm{M} \text {. Filtrar o } \\
\text { precipitado e dispor o residuo em aterro }_{\text {industrial }}{ }^{1}\end{array}$ & $\begin{array}{l}\text { USS } 2,8 / \mathrm{g} \text { de } \\
\text { arsênio }+ \text { USS } \\
0,004 / \mathrm{mL} \text { de } \\
\mathrm{NaOH} 2 \mathrm{M} \\
\text { utilizado }^{9}\end{array}$ & $\begin{array}{l}\text { Ácidos e metais como ferro, } \\
\text { alumínio e zinco }\end{array}$ & $\begin{array}{l}\text { - Listado como extremamente perigoso à saúde } \\
\text { - Incêndio: } \mathrm{CO}_{2} \text {, pó químico, água } \\
\text { - Derramamento: adsorver e tratar como descrito no } \\
\text { item tratamento e disposição }\end{array}$ \\
\hline \multirow[t]{2}{*}{$\begin{array}{l}\text { Auramina } \\
\text { CAS 2465-27-2 }\end{array}$} & $\begin{array}{l}\text { 1. Para cada } 10 \mathrm{ml} \text { de solução adicionar } \\
5 \mathrm{ml} \text { de } \mathrm{KMnO}_{4} 0.2 \mathrm{Me} 5 \mathrm{ml} \text { de } \mathrm{H}_{2} \mathrm{SO}_{4} 2 \\
\mathrm{M} \text {. Deixe a mistura reagir por no mínimo } \\
10 \mathrm{~h} \text {. Descolorir a mistura pela adição } \\
\text { de metabissulfito de sódio e alcalinizar } \\
\text { pela adição de } \mathrm{KOH} 10 \mathrm{M} \text {. Descartar na } \\
\text { rede de esgoto. Este método pode ser } \\
\text { utilizado para soluçðes de aminas } \\
\text { aromáticas em solventes orgânicos, } \\
\text { desde que esses sejam evaporados } \\
\text { previamente } \\
\text { 2. Incineraçãa }\end{array}$ & $\begin{array}{l}\text { 1.US\$ } 0,013 / \\
10 \mathrm{ml} \mathrm{de} \\
\text { auramina }+ \\
\text { US\$ } 0,018 / \mathrm{ml} \\
\text { de KOH } 10 \mathrm{~N} \\
\text { utilizado } \\
\\
\text { 2. até } 250 \mathrm{Kg}= \\
\text { US\$ } 343,40\end{array}$ & Oxidantes fortes $"$ & $\begin{array}{l}\text { - Incêndio: pó químico, água, espuma química } \\
\text { - Derramamento: adsorver e tratar como descrito no } \\
\text { item precedente? }\end{array}$ \\
\hline & $\begin{array}{l}\text { 3. O hipoclorito de sódio também } \\
\text { pode ser utilizado como agente } \\
\text { oxidante } 11\end{array}$ & & & \\
\hline
\end{tabular}


Cont. Tabela A-31

\begin{tabular}{|c|c|c|c|c|}
\hline Substância & Tratamento/disposiçåo & Custo & Incompatibilidade & $\begin{array}{l}\text { Caracteristica relevante da substância / } \\
\text { Procedimento em situações de emergência }\end{array}$ \\
\hline $\begin{array}{l}\text { Azida sódica } \\
\text { CAS 26628-22-8 }\end{array}$ & 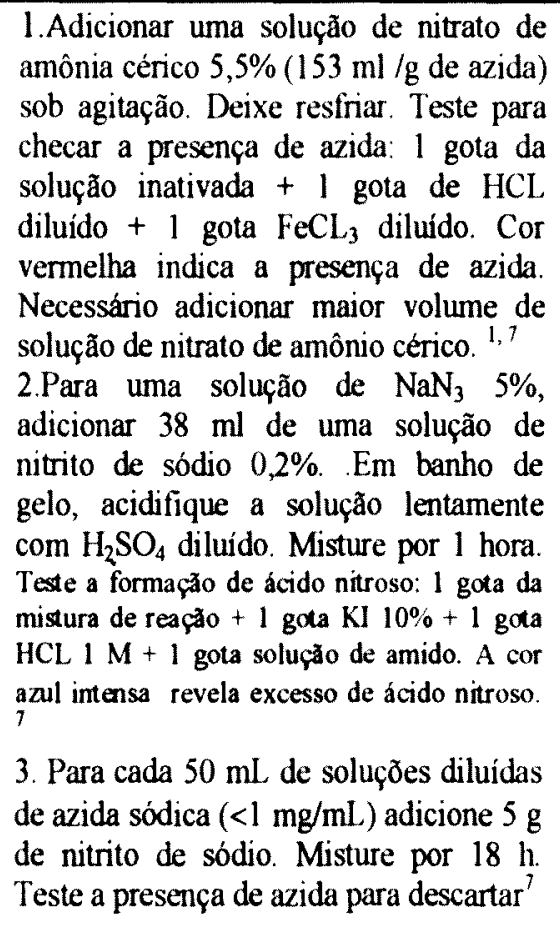 & $\begin{array}{l}\text { 1. US\$ } 2,10 / g \\
\text { de azida } \\
\text { sódica } 9\end{array}$ & $\begin{array}{l}\text { Ácidos (forma ácido } \\
\text { hidrazóico), metais pesados } \\
\text { (chumbo, mercúrio, cobre, } \\
\text { prata, ouro), brometo, } \\
\text { dissulfeto de carbono, } \\
\text { cloreto de amônia, fosgênio } \\
\text { Usado como conservante } \\
\text { de certos reagentes de uso } \\
\text { laboratorial ou hospitalar na } \\
\text { concentração de } 0,1 \text { a } 4 \% \text {, } \\
\text { se disposto na rede de } \\
\text { esgoto pode ser acumulado } \\
\text { nas tubulaçðes e formar } \\
\text { azidas de cobre, chumbo ou } \\
\text { prata, as quais são } \\
\text { explosivas }{ }^{8,11 .}\end{array}$ & $\begin{array}{l}\text { - Classificado como lóxico, corrosivo, explosivo } \\
\text { - Incêndio: pó químico, } \mathrm{CO}_{2}{ }^{11} \\
\text { - Derramamento: adsorver com areia ou uma } \\
\text { mistura de carbonato de sódio, betonita, areia } \\
(1: 1: 1) \text { e tratar como descrito no item precedente.' }\end{array}$ \\
\hline $\begin{array}{l}\text { Benzidina } \\
\text { CAS 92-87-5 }\end{array}$ & Vide auramina & & Ácido nítrico ${ }^{11}$ & $\begin{array}{l}\text { - Incêndio: pó químico, } \mathrm{CO}_{2} \text { ou água. } \\
\text { - } \quad \text { Derramamento: vide auramina }{ }^{7}\end{array}$ \\
\hline
\end{tabular}


Cont. Tabela A-31

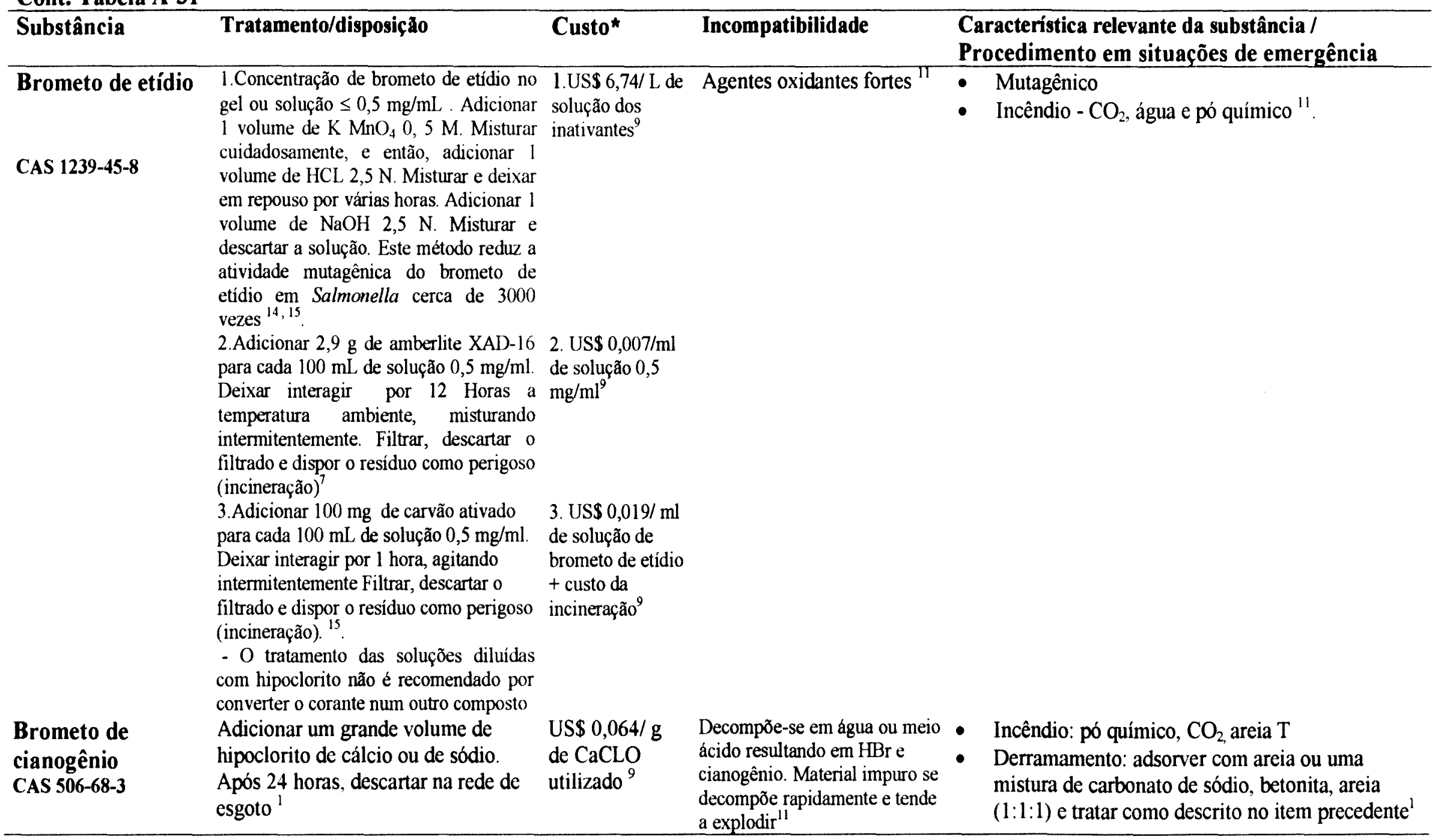


Cont. Tabela A-31

\begin{tabular}{|c|c|c|c|c|}
\hline Substância & Tratamento/disposição & Custo* & Incompatibilidade & $\begin{array}{l}\text { Característica relevante da substância / } \\
\text { Procedimento em situações de emergência }\end{array}$ \\
\hline $\begin{array}{l}\text { Cádmio } \\
\text { CAS 7440-43-9 }\end{array}$ & $\begin{array}{l}\text { Para compostos de cádmio, adicionar } \\
\text { solução de metassilicato de sódio } 0,125 \\
\mathrm{~g} / \mathrm{mL} \text { a solução de cádmio }<0,45 \mathrm{mg} / \mathrm{ml} \\
\text { Um precipitado branco (silicato de } \\
\text { cádmio) se forma imediatamente. } \\
\text { Aqueça a mistura a } 80^{\circ} \mathrm{C} \text { por } 15 \text { minutos } \\
\text { para completar a reação. Resfrie e filtre, } \\
\text { descartando o filtrado na rede de esgoto } \\
\text { e encaminhando o residuo para o aterro } \\
\text { industrial. }\end{array}$ & $\begin{array}{l}\text { US } \$ 0,0027 / \mathrm{ml} \\
\text { de solução de } \\
\text { metassilicato } \\
\text { de sódio } \\
\text { utilizada }^{9}\end{array}$ & ${ }_{11}^{\text {Agentes oxidantes e metais. }}$ & $\begin{array}{l}\text { - Incêndio pó químico, } \mathrm{CO}_{2} \text { e água }{ }^{11} \\
\text { - Derramamento: adsorver com areia e tratar para } \\
\text { obtenção de sal }\end{array}$ \\
\hline $\begin{array}{l}\text { Cloreto de paládio } \\
\text { CAS 7647-10-1 }\end{array}$ & Reciclar $^{1}$ & & $\begin{array}{l}\text { Paládio metálico reage com } \\
\text { álcool isopropilico, ácido } \\
\text { fórmico, alumínio, arsênico, } \\
\text { metanol, enxofre }\end{array}$ & $\begin{array}{l}\text { - Incêndio: pó químico, } \mathrm{CO}_{2} \text { ou água. } \\
\text { - Derramamento: adsorver com areia }\end{array}$ \\
\hline $\begin{array}{l}\text { Cloreto estanoso } \\
\text { CAS 7772-99-8 }\end{array}$ & $\begin{array}{l}\text { 1. Ig de resina amberlite IR-120 ou } \\
\text { Dowex 50X8-100 para } 40 \mathrm{~mL} \text { de } \\
\text { solução contendo no máximo } 1000 \\
\text { ppm do metal. Misturar por } 24 \mathrm{~h} \text {, } \\
\text { filttrar. O resíduo deve ser } \\
\text { encaminhado para aterro industrial } \\
\text { 2. precipitar com fosfato de sódio }{ }^{11}\end{array}$ & $\begin{array}{l}\text { 1. US\$ } \\
0,0008 / \mathrm{ml} \mathrm{de} \\
\text { solução } \\
\text { contendo no } \\
\text { máximo } 1000 \\
\text { ppm do metal }\end{array}$ & $\begin{array}{l}\text { Peróxido de hidrogênio, } \\
\text { oxido de etileno, nitratos, } \\
\text { potássio, sódio, trifluoreto } \\
\text { de bromo } \\
3,8\end{array}$ & $\begin{array}{l}\text { - Incêndio: } \mathrm{CO}_{2} \text {, água, pó químico }{ }^{11} \\
\text { - Deramamento: adsorver com material adequado }{ }^{3}\end{array}$ \\
\hline $\begin{array}{l}\text { Clorofórmio } \\
\text { CAS 67-66-3 }\end{array}$ & $\begin{array}{l}\text { Incineração }\left(\mathrm{DRE} 950^{\circ} \mathrm{C}=99,99 \%\right. \\
\mathrm{p} / \text { tempo de residência de } 2 \mathrm{~s})^{11}\end{array}$ & & $\begin{array}{l}\text { Metais alcalinos e alcalinos } \\
\text { terrosos, metais em pó, alcalis } \\
\text { fortes, cetonas/alcalis, } \\
\text { hidróxidos/alcoóis, oxigênio, } \\
\text { fluoretos, NOx e compostos } \\
\text { orgânicos nitrados }^{2}\end{array}$ & $\begin{array}{l}\text { - Volátil mas não é inflamável } \\
\text { - Incêndio - pó químico, } \mathrm{CO}_{2} \text {, água } \\
\text { - Derramamento - adsorver com areia, vermiculite, } \mathrm{T} \text { ou } \\
\text { mistura 1:1:1 de } \mathrm{Na}_{2} \mathrm{CO}_{3} \text { ou } \mathrm{Ca} \mathrm{CO}_{3} \text {, bentonita e areia - } \\
\text { incinerar }{ }^{1}\end{array}$ \\
\hline $\begin{array}{l}\text { Dimetilaminoazo } \\
\text { benzeno } \\
\text { CAS 60-11-7 }\end{array}$ & Vide auramina & & $\begin{array}{l}\text { Agentes oxidantes forte e } \\
\text { ácidos fortes } 3\end{array}$ & $\begin{array}{l}\text { - Incêndio: } \mathrm{CO}_{2} ; \text { pó químico, água } \\
\text { - Derramamento: adsorver e tratar como descrito no item } \\
\text { precedente }\end{array}$ \\
\hline
\end{tabular}
álcool isopropilico, ácido fórmico, alumínio, arsênico soluça filtrar $O$ residuo deve ser encaminhado para aterro industrial precipitar com fosfato de sodio

Incineração (DRE $950^{\circ} \mathrm{C}=99,99 \%$ $\mathrm{p} /$ tempo de residência de $2 \mathrm{~s}$ )
Agentes oxidantes forte CAS 60-11-7 Derramamento: adsorver e tratar como descrito no item
precedente 
Cont. Tabela A-31

\begin{tabular}{|c|c|c|c|c|}
\hline Substância & Tratamento/disposiçăo & Custo* & Incompatibilidade & $\begin{array}{l}\text { Característica relevante da substância / } \\
\text { Procedimento em situações de emergência }\end{array}$ \\
\hline $\begin{array}{l}\text { Diclorometano } \\
\text { CAS 75-09-2 }\end{array}$ & Incineração & $\begin{array}{l}\text { Até } 250 \mathrm{Kg}= \\
\text { US } \$ 343,40\end{array}$ & $\begin{array}{l}\text { Oxidantes fortes, cáusticos, } \\
\text { ácido nitrico e metais reativos } \\
(\mathrm{Mg}, \mathrm{K}, \mathrm{Na}, \mathrm{Ti}, \mathrm{Al})^{11}\end{array}$ & $\begin{array}{l}\text { Incêndio - } \mathrm{CO}_{2}, \mathrm{po} \text { químico, água } \\
\text { - Derramamento- adsorver com areia, vermiculite, terra }\end{array}$ \\
\hline $\begin{array}{l}\text { Dietilnitrosamina } \\
\text { CAS 55-18-5 }\end{array}$ & 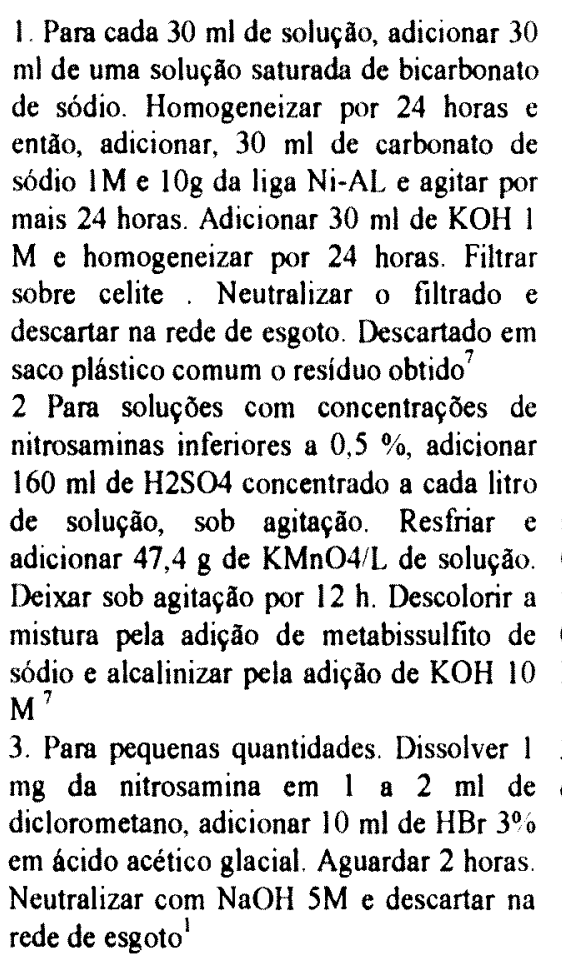 & 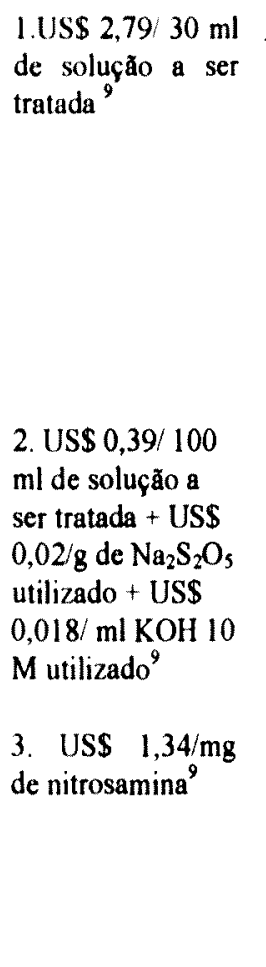 & Agentes redutores ${ }^{3}$ & $\begin{array}{l}\text { - Incêndio: } \mathrm{CO}_{2} ; \text { pó químico, água } \\
\text { - Derramamento: adsorver com areia ou papel e } \\
\text { tratar com permanganato de potássio., como } \\
\text { descrito anteriormente. }\end{array}$ \\
\hline $\begin{array}{l}\text { Difenilamina } \\
\text { CAS 122-39-4 }\end{array}$ & Incineração ${ }^{6}$ & $\begin{array}{l}\text { Até } 250 \mathrm{Kg}= \\
\text { US } \$ 343,40\end{array}$ & $\begin{array}{l}\text { Oxidantes, } \\
\text { hexacloromelanina, } \\
\text { tricloromelanina, sais de } \\
\text { ferro e de prata } \\
\text {,i1 }\end{array}$ & $\begin{array}{l}\text { - Sólido, inflamável ,FP } 153^{\circ} \mathrm{C} \text {, tóxico, corrosivo) }{ }^{11} \\
\text { - Incêndio: } \mathrm{CO}_{2} ; \text { pó químico, água } \\
\text { - Derramamento: adsorver com areia ou papel e } \\
\text { incinerar }{ }^{6} \text {. }\end{array}$ \\
\hline
\end{tabular}


Cont. Tabela A-31

\begin{tabular}{|c|c|c|c|c|}
\hline Substância & Tratamento/disposição & Custo* & Incompatibilidade & $\begin{array}{l}\text { Característica relevante da substância / } \\
\text { Procedimento em situações de emergência }\end{array}$ \\
\hline $\begin{array}{l}\text { Dimetilformamida } \\
\text { CAS 68-12-2 }\end{array}$ & $\begin{array}{l}\text { 1.Para } 1 \mathrm{ml} \text { dimetilformamida, adicionar } \\
10 \mathrm{ml} \mathrm{NaOH} 10 \% \text {. Aquecer a mistura } \\
\text { sob refluxo por } 30 \mathrm{~min} \text {, deixar a } \\
\text { temperatura ambiente por } 48 \mathrm{~h} \text {. } \\
\text { Desprezar na rede de esgoto com volume } \\
\text { de água } 50 \text { vezes maior que o volume } \\
\text { vertido }^{1} \\
\text { 2. Incineração }{ }^{11}\end{array}$ & $\begin{array}{l}\text { l,US\$ } 0,049 / \mathrm{ml} \\
\text { de residuo }\end{array}$ & $\begin{array}{l}\text { Tetracloreto de carbono e } \\
\text { outros halogenados quando } \\
\text { em contato com ferro, } \\
\text { oxidantes fortes, nitratos } \\
\text { inorgânicos } 8,11\end{array}$ & $\begin{array}{ll}\text { - } & \text { FP } 67^{\circ} \mathrm{C} \\
\text { - Irritante evidências limitada de teratogênese } & \\
\text { - } & \text { Incêndio }-\mathrm{CO}_{2} \text {, pó quimico, água } \\
\text { Derramamento - adsorver com areia ou mistura } \\
\text { l:1:1 de } \mathrm{Na}_{2} \mathrm{CO}_{3} \text { ou } \mathrm{Ca} \mathrm{CO}_{3} \text {, bentonita e areia - e } \\
\text { tratar como recomendado }\end{array}$ \\
\hline $\begin{array}{l}\text { Fluoreto de } \\
\text { fenilmetilsulfonio } \\
\text { (PMSF)l } \\
\text { CAS 329-98-6 }\end{array}$ & $\begin{array}{l}\text { Para cada } 1 \mathrm{ml} \text { de solução PMSF } \\
\text { inferior a } 17,4 \mathrm{mg} / \mathrm{ml} \text { em etanol ou } \\
\text { isopropanol , adicionar } 5 \mathrm{ml} \mathrm{de} \\
\mathrm{NaOH} 1 \mathrm{M} \text {. Deixar interagir por } 24 \\
\text { h. Neutralizar com ácido acético } \\
\text { (1 } \mathrm{ml} \text { ). Descartar }{ }^{7}\end{array}$ & $\begin{array}{l}\text { US\$ } 0,031 / \mathrm{ml} \\
\text { solução }<17,4 \\
\mathrm{mg} / \mathrm{ml}^{9}\end{array}$ & Não relatado & - Mutagênico ${ }^{8} \mathrm{e}$ inibidor de proteases \\
\hline $\begin{array}{l}\text { Formaldeído } \\
\text { CAS 50-00-0 }\end{array}$ & $\begin{array}{l}\text { 1. Diluir } 1: 10 \text { a solução de } \\
\text { formaldeído } 37 \%+\mathrm{NaCLO} \text {,sol. } 2 \% \\
\text { ( } 25 \text { NaCLO:1 formaldeído). } \\
\text { Misturar durante } 20 \text { min, desprezar } \\
\text { na rede de esgoto com volume de } \\
\text { água } 50 \text { vezes maior que o do } \\
\text { resíduo }{ }^{1,4} \\
\text { 2.Tratar com sais de amônia para } \\
\text { formar metenamina, menos tóxica } \\
\text { 3. Incineraçãa }{ }^{1}\end{array}$ & $\begin{array}{l}\text { 1.US } \$ 0,013 / \mathrm{ml} \\
\text { de formaldeido } \\
\text { diluido } 1: 10^{9}\end{array}$ & $\begin{array}{l}\text { Ácidos, alcalis, aminas e } \\
\text { oxidantes, fenóis e uréia } \\
\text { Reage com HCL formando } \\
\text { éter biclorometila, } \\
\text { carcinogênico para o } \\
\text { homem }^{11}\end{array}$ & $\begin{array}{l}\text { - } \quad \mathrm{FP} 56^{\circ} \mathrm{C}^{10} \\
\text { - Listado como extremamente perigoso à saúde } \\
\text { - Incêndio - } \mathrm{CO}_{2} \text {, pó químico, água } \\
\text { - Derramamento: adsorver com areia }\end{array}$ \\
\hline
\end{tabular}


Cont. Tabela A-31

\begin{tabular}{|c|c|c|c|c|}
\hline Substância & Tratamento/disposiçảo & Custo* & Incompatibilidade & $\begin{array}{l}\text { Característica relevante da substância / } \\
\text { Procedimento em situações de emergência }\end{array}$ \\
\hline $\begin{array}{l}\text { Iodeto de cádmio } \\
\text { CAS } 10102-68-8\end{array}$ & $\begin{array}{l}\text { 1. Adicionar em excesso a solução } 125 \\
\text { mg/ml de metasilicato de sódio. Aquecer } \\
\text { a } 80^{\circ} \mathrm{C} \text { por } 15 \text { minutos para completar a } \\
\text { precipitação. Esfriar, filtrar, secar o } \\
\text { resíduo e encaminhá-lo para o aterro } \\
\text { industrial }{ }^{1} \\
2.1 \mathrm{~g} \text { de resina amberlite } \mathrm{IR}-120 \text { ou } \\
\text { Dowex } 50 \times 8-100 \text { para } 40 \mathrm{ml} \text { de solução } \\
\text { contendo no máximo } 1000 \mathrm{ppm} \text { do } \\
\text { metal. Misturar por } 24 \mathrm{~h} \text {, filtrar. O } \\
\text { resíduo deve ser encaminhado para } \\
\text { aterro industrial }\end{array}$ & $\begin{array}{l}\text { 2. US\$ } \\
0,0008 / \mathrm{ml} \\
\text { solução }(\mathrm{Cd}< \\
1000 \mathrm{ppm})^{9}\end{array}$ & $\begin{array}{l}\text { Quando aquecido se } \\
\text { decompóe emitindo fumos } \\
\text { tóxicos de cádmio }^{8}\end{array}$ & $\begin{array}{l}\text { - Incêndio - } \mathrm{CO}_{2} \text {, água, pó químico } \\
\text { - Derramamento - adsorver a solução e tratar como } \\
\text { descrito no item precedente }\end{array}$ \\
\hline $\begin{array}{l}\text { Ninhidrina } \\
\text { CAS 485-72-2 }\end{array}$ & Não relatado & & É sensível à luz. ${ }^{3}$ & $\begin{array}{l}\text { - Incêndio: pó químico, } \mathrm{CO}_{2} \\
\text { - Derramamento: se sólido umedecer com etanol } \\
60-70 \% \text {, adsorver com material adequado e } \\
\text { transferir para contêiner }\end{array}$ \\
\hline $\begin{array}{l}\text { 0-fenilenodiamina } \\
\text { CAS } 106-50-3\end{array}$ & Vide auramina & & $\begin{array}{l}\text { Oxidantes }^{11} \text {. Quando } \\
\text { aquecido emite fumos } \\
\text { tóxicos de NOx }\end{array}$ & $\begin{array}{l}\text { - Incêndio: pó químico, } \mathrm{CO}_{2} \text { ou água }{ }^{11} \\
\text { - Derramamento: vide auramina }\end{array}$ \\
\hline $\begin{array}{l}\text { Sais de chumbo } \\
\text { CAS : } \\
\text { Acetato }=546-67-8 \\
\text { Oxido }=1317-36-8 \\
\text { Nitrato }=10099-74-8\end{array}$ & $\begin{array}{l}\text { 1. } 1 \mathrm{~g} \text { de resina amberlite IR- } 120 \text { ou } \\
\text { Dowex } 50 X 8-100 \text { para } 40 \mathrm{ml} \text { de solução } \\
\text { contendo no máximo } 1000 \mathrm{ppm} \text { do } \\
\text { metal. Misturar por } 24 \mathrm{~h} \text {, filtrar. O } \\
\text { resíduo deve ser encaminhado para } \\
\text { aterro industrial } \\
2.260 \mathrm{ml} \text { de solução de metasilicato de } \\
\text { sódio } 0,1 \mathrm{~g} / \mathrm{ml}+200 \mathrm{ml} \text { solução do sal } \\
\text { de chumbo } 0,05 \mathrm{~g} / \mathrm{ml} \text {. Ajustar o pH para } \\
7.2 \text { com } \mathrm{H}_{2} \mathrm{SO}_{4} 2 \mathrm{M} \text {. Misturar e filtrar. } \\
\text { Dispor o residuo sólido em aterro } \\
\text { industrial }^{1}\end{array}$ & $\begin{array}{l}\text { 2. US\$0,0028 } \\
\text { /ml solução Pb } \\
0,05 \mathrm{~g} / \mathrm{ml}+\mathrm{US \$} \\
0,0006 / \mathrm{ml} \\
\mathrm{H}_{2} \mathrm{SO}_{4} 2 \mathrm{M}^{9}\end{array}$ & $\begin{array}{l}\text { Nitrato de chumbo - alcoóis, } \\
\text { éteres, sais de amônio, } \\
\text { acetatos. } \\
\text { Acetato de chumbo - agentes } \\
\text { oxidantes } \\
\text { Óxido de chumbo - alumínio, } \\
\text { metais alcalinos, silanos, óxido } \\
\text { de enxofre, peróxido de } \\
\text { hidrogênio, halogênios e } \\
\text { alcenos }{ }^{3}\end{array}$ & $\begin{array}{l}\text { - Incêndio }-\mathrm{CO}_{2} \text {, pó químico, água } \\
\text { - Derramamento : sais solúveis absorver e tratar } \\
\text { como descrito item tratamento/disposição }\end{array}$ \\
\hline
\end{tabular}


Cont. Tabela A-31

\begin{tabular}{|c|c|c|c|c|}
\hline Substância & Tratamento/disposiçåa & Custo* & Incompatibilidade & $\begin{array}{l}\text { Característica relevante da substância / } \\
\text { Procedimento em situações de emergência }\end{array}$ \\
\hline $\begin{array}{l}\text { Sais de mercúrio } \\
\mathrm{CAS}: \\
\mathrm{Hg} \mathrm{I}_{2}=7774-29-0 \\
\mathrm{HgO}^{2} 21908-53-2 \\
\mathrm{Hg}_{2}\left(\mathrm{NO}_{3}\right)_{2} \cdot 2 \mathrm{H}_{2} \mathrm{O}= \\
14836-60-3 \\
\mathrm{Hg} \mathrm{SO}=7783-35-9\end{array}$ & $\begin{array}{l}\text { 1. Para soluções na concentração de } \\
\mathrm{lg} / \mathrm{mL} \text {, ajustar o pH para } 10 \mathrm{com} \mathrm{NaOH} \\
10 \% \text {. Adicionar a solução } \mathrm{Na}_{2} \mathrm{~S} 20 \% \mathrm{em} \\
\text { excesso até precipitação total de } \mathrm{HgS} \text {. } \\
\text { Deixe decantar, filtre, descarte o filtrado } \\
\text { na rede de esgoto com um volume } 50 \\
\text { vezes maior de água e o residuo } \\
\text { encaminhe para um aterro industrial. } \\
\text { 2. Para cada } 200 \mathrm{ml} \text { da solução de } \mathrm{Hg} \\
\text { contendo no máximo } 1000 \mathrm{ppm} \text { do } \\
\text { metal, adicionar lg de resina amberlite } \\
\text { IRA-120 ou Dowex IX8-100 (acetato de } \\
\text { Hg) ou amberlite IRA- } 400 \text { (CI) ou } \\
\text { Dowex IX8-50. Misturar por } 24 \mathrm{~h} \text {, } \\
\text { filtrar e dispor o resíduo em aterro } \\
\text { industrial }\end{array}$ & $\begin{array}{l}\text { US\$ } 0,0049 / \mathrm{ml} \\
\mathrm{NaOH} 10 \% \\
\text { empregado }+ \\
\text { US } \$ 0,453 / \mathrm{mL} \\
\mathrm{Na}_{2} \mathrm{~S} 20 \%{ }^{9}\end{array}$ & $\begin{array}{l}\text { Para } \mathrm{HgCl}_{2} \text { - sulfetos, } \\
\text { hipofosfitos, fosfatos, } \\
\text { sulfetos, carbonatos, } \\
\text { brometos, arsênico, amônia, } \\
\text { chumbo, cobre, prata, } \\
\text { alcalis }{ }^{2} \\
\text { Quando aquecidos liberam } \\
\text { vapores de mercúrio }\end{array}$ & $\begin{array}{l}\text { - Incêndio - } \mathrm{CO}_{2} \text {, água } \\
\text { Derramamento - adsorver a solução e tratar como } \\
\text { descrito no item precedente }\end{array}$ \\
\hline $\begin{array}{l}\text { Sais de prata } \\
\text { CAS: } \\
\text { Nitrato de prata } 7761- \\
88-8 \\
\text { Dietiliditiocarbamato } \\
\text { de prata } 1470-61-7\end{array}$ & $\begin{array}{l}\text { 1. Tratamento com NaCL ou carbonatos } \\
\text { 1I } \\
\text { 2. Para cada } 200 \mathrm{ml} \text { da solução de } \mathrm{Ag} \\
\text { contendo no máximo } 1000 \mathrm{ppm} \text { do } \\
\text { metal, adicionar } 1 \mathrm{~g} \text { de resina amberlite } \\
\text { IRA-400 (CI) ou Dowex LX8-50. } \\
\text { Misturar por } 24 \mathrm{~h} \text {, filtrar e dispor o } \\
\text { resíduo em aterro industrial. }^{7}\end{array}$ & $\begin{array}{l}\text { 1. US\$ } 0,019 / \mathrm{g} \\
\text { de NaCL utilizado } \\
\text { 2. US\$ } 0,0004 / \\
\text { ml de solução } \\
(\mathrm{Ag}<1000 \mathrm{ppm})\end{array}$ & $\begin{array}{l}\text { Substâncias orgânicas, } \\
\text { hidróxidos, acetileno, } \\
\text { substâncias combustiveis, } \\
\text { alcoóis, aldeídos, } \\
\text { compostos orgânicos } \\
\text { nitrados, nitrilas, calor } \\
\text { (decomposição) }\end{array}$ & $\begin{array}{l}\text { - } \text { oxidante } \\
\text { - Incêndio }-\mathrm{CO}_{2} \text {, pó químico, água } \\
\text { - Derramamento : adsorver com areia, betonita, } \\
\text { carbonato de sódio. Reciclar (indicação para } \\
\text { perclorato de prata)! }\end{array}$ \\
\hline $\begin{array}{l}\text { Sais de selênio } \\
\text { CAS selenito de sódio } \\
=10102-18-8\end{array}$ & $\begin{array}{l}\text { Solução aquosa de selenito deve ser } \\
\text { neutralizada pela adição de } \mathrm{NaOH} 1 \mathrm{M} \\
\text { ou } \mathrm{H}_{2} \mathrm{SO}_{4} 1 \mathrm{M} \text {. Adicionar a solução de } \\
\mathrm{Na}_{2} \mathrm{~S} 1 \mathrm{Me} \text { ajustar novamente o pH para } \\
7,0 \text { com a solução de } \mathrm{H}_{2} \mathrm{SO}_{4} \text {. Filtrar. } \\
\text { Descartar o filtrado na rede de esgoto e } \\
\text { deixar secar o precipitado. Encaminhar a } \\
\text { borra para o aterro industrial }\end{array}$ & $\begin{array}{l}\text { US\$ } 0,002 / \mathrm{ml} \\
\mathrm{NaOH} \quad \mathrm{IM} \\
\text { utilizado ou } \mathrm{US} \$ \\
0,0006 / \mathrm{mL} \\
\mathrm{H}_{2} \mathrm{SO}_{4} \mathrm{IM} \\
\text { utilizado }+\mathrm{US \$} \\
0,18 / \mathrm{g}_{2} \mathrm{~S} \\
\text { empregado }\end{array}$ & Ácidos fortes ${ }^{3}$ & $\begin{array}{l}\text { - Incêndio: pó químico e } \mathrm{CO}_{2}{ }^{3} \\
\text { - Derramamento: selenitos solúveis e selenatos podem } \\
\text { ser dissolvidos em água e descartados na rede de } \\
\text { esgoto. Soda deve ser aplicada no derramamento de } \\
\text { dióxido de selênio, ácidos selenoso e selênico e cloretos } \\
\text { de selênio, os quais podem ser descartados após } \\
\text { diluição na rede de esgoto }{ }^{1}\end{array}$ \\
\hline
\end{tabular}


Cont. Tabela A-31

\begin{tabular}{|c|c|c|c|}
\hline Substância & Tratamento/disposiçăo & Custo* & Incompatibilidade \\
\hline $\begin{array}{l}\text { Tetracloreto de } \\
\text { carbono } \\
\text { CAS 56-23-5 }\end{array}$ & $\begin{array}{l}\text { 1. } \mathrm{CCl}_{4} \text { em solução aquosa }+\mathrm{H}_{2} \mathrm{~S} \text {, na } \\
\text { presença de minerais biotite ou } \\
\text { vermiculite e pH } 6-9 \text {, convertido a } \mathrm{CO}_{2} \\
(80-85 \% \text { de eficiência) } \\
\text { 2. Incineração }\end{array}$ & $\begin{array}{l}\text { 2. atc } 250 \mathrm{Kg}= \\
\text { US\$ } 343,40\end{array}$ & $\begin{array}{l}\text { Metais alcalinos, peróxido } \\
\text { de benzoíla, cloreto de } \\
\text { alumínio, fluoreto } \\
\text { dimetilformamida }^{2}\end{array}$ \\
\hline $\begin{array}{l}\text { Tioacetamida } \\
\text { CAS 62-55-5 }\end{array}$ & $\begin{array}{l}\text { Não relatado na literatura } \\
\text { Sugestão: proceder sua hidrólise } \\
\text { com ácidos e bases. }\end{array}$ & & $\begin{array}{l}\text { Reage com metais pesados } \\
\text { e é hidrolizado por ácidos e } \\
\text { bases }^{3}\end{array}$ \\
\hline
\end{tabular}

Característica relevante da substância /

Procedimento em situações de emergência

- Incêndio - $\mathrm{CO}_{2}$, po químico, água

- Derramamento - arcia, vermiculite mistura 1:1:1

de $\mathrm{Na}_{2} \mathrm{CO}_{3}$ ou $\mathrm{Ca} \mathrm{CO}_{3}$, bentonita e areia -

incinerar 1,6

- Potente hepatocarcinógeno, suspeito de carcinogenicidade para o homem ${ }^{3,11}$

- Incêndio: pó químico, $\mathrm{CO}_{2}$

- Derramamento: se o sólido for derramado, deve ser umedecido com acetona e transferido para um contêiner adequado ${ }^{3}$

Nota: CAS $=$ número de registo no Chemical abstrad; Custo estimado calculado em dólar a partir de reagentes $p$ a Aldrich * teste para verificar a eficiência do tratamento para 2-mercaptactanol: adicionar gotas de uma soluçăo de $\mathrm{KI} 10 \%$, acidificar com HCL $1 \mathrm{M}$ e adicionar gotas de uma soluçăo de amido (indicador) para verificar a presença de oxidante (coloração azul). Referencias: 1 = ARMOUR, 1996; 2 MERCK INTERNATIONAL - Chem Cat, 1998; 3 = USDHHS - CHSI, 2000; 4 = FIELDS e col., 1996; $5=$ GERSBERG, 1995; 6= INTERNATIONAL TECHNICAL. INFORMATION INSTITUTE, 1977; $7=$ LUNN \& SANSONE, 1994; 8- LEWIS, 1992; 9- SYGMA-ALDRICH, 1999; 10= MERCK INDEX, 1996; 11 = TOMES CPS, 1987- 1999; 14 = QUILLARDET e HOFNUNG, 1988; 15= SAMBROOK e col, $1989 ; 16=$ KRIEGMAN e col., 1992 
Tabela A-32 - Tratamento e disposição, incompatibilidade e procedimentos a serem adotados em situações de emergência para as substâncias radioativas levantadas

\begin{tabular}{|c|c|c|c|c|}
\hline Substância & Tratamento/disposiçăo & Incomps & atibilidade & $\begin{array}{l}\text { Característica relevante da substância / } \\
\text { Procedimento em situações de emergência }\end{array}$ \\
\hline $\begin{array}{l}\text { Acetato de } \\
\text { uranila } \\
\text { CAS 541-09-3 }\end{array}$ & $\begin{array}{l}\text { 1. Encaminhar para o IPEN } \\
\text { 2. Misturar a solução de acetato de uranila com } \\
\text { a resina amberlite IR- } 120 \text { (plus) (1g de } \\
\text { resina para } 200 \mathrm{ml} \text { de solução } 1000 \mathrm{ppm} \text { ou } \\
1 \mathrm{~g} \text { para } 1 \text { litro de solução } 60 \mathrm{ppm} \text { ). Misturar } \\
\text { por } 24 \mathrm{~h} \text { se a concentração da soluçào for de } \\
\text { 1000ppm e } 4 \text { h se equivalente a } 60 \mathrm{ppm} \text {. } \\
\text { Filtrar, descartar o filtrado na rede de esgoto } \\
\text { e a resina complexada ao sal como resíduo } \\
\text { radioativo?. }\end{array}$ & $\begin{array}{l}\text { 1. Sem ônus } \\
\text { para pequenas } \\
\text { quantidades } \\
\text { 2. US\$ } 0,0317 / \mathrm{g} \\
\text { de resina }^{9}\end{array}$ & $\begin{array}{l}\text { Dados não } \\
\text { disponiveis }\end{array}$ & $\begin{array}{l}\text { - Incêndio - pó químico, } \mathrm{CO} \text {, água, espuma } \\
\text { - Derramamento - absorver com areia, } \\
\text { vermiculite e dispor como radioativo " }\end{array}$ \\
\hline Carbono 14 & Disposição como residuo radioativo ${ }^{11}$ & & $\begin{array}{l}\text { Dados não } \\
\text { disponiveis }\end{array}$ & $\begin{array}{l}\text { - Derramamento - absorver com areia, vermiculit } \\
\text { dispor como radioativo "1 }\end{array}$ \\
\hline Fósforo 32 & Disposição com resíduo radioativo " & & $\begin{array}{l}\text { Dados não } \\
\text { disponiveis }\end{array}$ & $\begin{array}{l}\text { - Incêndio - pó químico, } \mathrm{CO} \text {, água, espuma } \\
\text { - Derramamento - absorver com areia, } \\
\text { vermiculite e dispor como radioativo }\end{array}$ \\
\hline
\end{tabular}




\section{ANEXO 21}

- Cuidados na manipulação, Padrões de segurança e Síndrome tóxica decorrente da exposição ocupacional à substâncias perigosas 
Tabela A-33 - Cuidados na manipulação, Limites de exposição para o ambiente de trabalho e efeitos nocivos na exposição aguda e crônica das principais substâncias químicas levantadas nas três Instituições avaliadas.

\begin{tabular}{|c|c|c|c|c|}
\hline \multirow[t]{2}{*}{ Substância } & \multirow[t]{2}{*}{ Cuidados manipulação } & \multirow{2}{*}{$\begin{array}{l}\text { Limites de } \\
\text { exposiçãa }\end{array}$} & \multicolumn{2}{|c|}{ Efeitos } \\
\hline & & & Agudo & Crônico \\
\hline Acetaldeído & $\begin{array}{l}\text { EPI- avental, óculos, } \\
\text { trabalhar em capela quimica, } \\
\text { luva borracha nitrilica }{ }^{1}\end{array}$ & $\begin{array}{l}\text { ACGIH/ } / 99^{2}-25 \mathrm{ppm} \\
\text { teto } \\
\text { NR-15 }-78 \mathrm{ppm}\end{array}$ & $\begin{array}{l}\text { Irritante de pele e mucosas, bronquite, } \\
\text { edema e depressåo do } \mathrm{SNC}^{4}\end{array}$ & $\begin{array}{l}\text { Mutagênico para o homem }{ }^{5} \text { Carcinogênico } \\
\text { para animais de experimentaçăo (câncer } \\
\text { nasal e adenocarcinoma) } 4.5 \text {. }\end{array}$ \\
\hline Acetato de butila & $\begin{array}{l}\text { EPI- avental, óculos/capela, } \\
\text { luva borracha nitrilica }\end{array}$ & $\begin{array}{l}\text { ACGIH/99 } 150 \text { ppm } \\
\text { NR-15 não listado }\end{array}$ & $\begin{array}{l}\text { Irritante de pele e mucosas, conjuntivite e } \\
\text { sonolência }\end{array}$ & $\begin{array}{l}\text { Ressecamento de pele, cefaléia, náusea, } \\
\text { tontura, fraqueza muscular }{ }^{4}\end{array}$ \\
\hline Acetato de etila & $\begin{array}{l}\text { EPI- avental, oculos, capela, } \\
\text { Luva Teflon, butilica }\end{array}$ & $\begin{array}{l}\text { ACGIH - TWA } 400 \\
\text { ppm } \\
\text { NR-15-310 ppm }\end{array}$ & $\begin{array}{l}\text { baixa toxicidade- irritante moderado de } \\
\text { pele e mucosa. Em altas concentraçðes } \\
\text { deprime o SNC } \\
\text { Edema pulmonar, diminuição da } \\
\text { contractilidade cardiaca, convulsð̃es e dano } \\
\text { hepático(observados em animais de } \\
\text { experimentação) }{ }^{4}\end{array}$ & $\begin{array}{l}\text { Anemia, leucocitose, bronquite, fadiga } \\
\text { diminuição da coordenação e da memória, } \\
\text { irritabilidade, ressecamento da pele. Dano } \\
\text { renal, hepático (degeneração gordurosa) e } \\
\text { cardíaco observados em animais de } \\
\text { experimentaçåo }\end{array}$ \\
\hline $\begin{array}{l}\text { Acetato de } \\
\text { uranila }\end{array}$ & $\begin{array}{l}\text { EPI avental, luva, máscara. } \\
\text { óculos, manipular com um } \\
\text { potente carcinogênico }{ }^{4} \text {. }\end{array}$ & $\begin{array}{l}\text { ACGIH } 0,2 \mathrm{mg} / \mathrm{m}^{3} \\
\text { (urânio) STEL } 0,6 \\
\mathrm{mg} / \mathrm{m}^{3} \\
\mathrm{NR}-15 \text { não listado }\end{array}$ & $\begin{array}{l}\text { Substância de forte odor, cefaléia, tontura, } \\
\text { fraqueza, náusea, irritação de olhos, pele e } \\
\text { tratos gastrintestinal e respiratório. } \\
\text { Dermatite alérgica }{ }^{4}\end{array}$ & $\begin{array}{l}\text { Asma, muco, câncer linfático }{ }^{4} \text {. } \\
\text { Carcinogenicidade comprovada para o } \\
\text { homem }\end{array}$ \\
\hline $\begin{array}{l}\text { 2-acetilamino } \\
\text { fuoreno }\end{array}$ & Não mencionado & Não listado & Não descrito & $\begin{array}{l}\text { Carcinogenicidade comprovada em animais } \\
\text { de experimentação. Evidências de } \\
\text { mutagenicidade para o homem }{ }^{4} \text {. }\end{array}$ \\
\hline Acetona & $\begin{array}{l}\text { EPI - avental, óculos/ capela } \\
\text { Luva teflon ou borracha } \\
\text { butílica }{ }^{4}\end{array}$ & $\begin{array}{l}\text { ACGIH : TWA - } \\
500 \mathrm{ppm} / \mathrm{STEL}-750 \\
\text { ppm } \\
\text { NR-15- } 780 \mathrm{ppm}\end{array}$ & $\begin{array}{l}\text { SNC - sedação, tontura, coma, depressão } \\
\text { respiratória.Outros efeitos- náusea, vômito, } \\
\text { dermatite, irritação leve da mucosa ocular } \\
\text { e respiratória }{ }^{4}\end{array}$ & $\begin{array}{l}\text { Nenhum efeito crônico sério observado no } \\
\text { homem }^{4} \text {. }\end{array}$ \\
\hline
\end{tabular}


Cont. Tabela A-33

\begin{tabular}{|c|c|c|c|c|}
\hline \multirow[t]{2}{*}{ Substância } & \multirow[t]{2}{*}{ Cuidados manipulação } & \multirow{2}{*}{$\begin{array}{l}\text { Limites de } \\
\text { exposição }\end{array}$} & \multicolumn{2}{|c|}{ Efeitos } \\
\hline & & & Agudo & Crônico \\
\hline Acetonit rila & $\begin{array}{l}\text { EPI - avental. óculos/ capela } \\
\text { Luva teflon ou borracha } \\
\text { butílica }\end{array}$ & $\begin{array}{l}\text { ACGIH TWA 40 ppm } \\
\text { STEL, 160 ppm } \\
\text { NR-15-30 ppm }\end{array}$ & $\begin{array}{l}\text { Exposição a altas concentrações - náusea. } \\
\text { vômito, cefaléia, lassitude, fraqueza, } \\
\text { depressão respiratória, acidose, choque, } \\
\text { convulsões, coma }{ }^{4} \text {. }\end{array}$ & $\begin{array}{l}\text { Alterações Sistema Nervoso } \\
\text { Cardiovascular } \\
\text { cianometemoglobina), } \\
\text { hepática, aumento da tireóide }{ }^{4} \text {. insuficiência }\end{array}$ \\
\hline Ácido Acético & $\begin{array}{l}\text { EPI- avental, óculos/capela, } \\
\text { luva de neoprene, teflon e } \\
\text { borracha butílica } 1,4\end{array}$ & $\begin{array}{l}\text { ACGIH: TWA- } 10 \\
\text { ppm/ STEL - } 15 \mathrm{ppm} \\
\text { NR-15-8ppm }\end{array}$ & $\begin{array}{l}\text { Inalação- dispnéia, dor torácica, edema } \\
\text { pulmonar, hipoxemia, espasmo brônquico, } \\
\text { pneumonite, traqueite, asma. Irritação dos } \\
\text { olhos e queimaduras da pele }{ }^{4} \text {. }\end{array}$ & $\begin{array}{l}\text { Hiperqueratose das mãos, bronquite } \\
\text { crônica, escurecimento do esmalte dos } \\
\text { dentes, faringite, gastrite, edema palpebral, } \\
\text { hipertrofia dos linfonodos, hiperemia da } \\
\text { conjuntiva, asma ocupacional. Promotor de } \\
\text { carcinogenicidade }{ }^{4}\end{array}$ \\
\hline Ácido clorídrico & $\begin{array}{l}\text { EPI- avental, oculos/capela, } \\
\text { luva de butilica, } \\
\text { fluorcarbonada }\end{array}$ & $\begin{array}{l}\text { ACGIIH } 5 \text { ppm teto } \\
\text { NR-15-4 ppm teto }\end{array}$ & $\begin{array}{l}\text { Conjuntivite, queimaduras, irritação da } \\
\text { garganta ,bronquite, edema, náusea e } \\
\text { vômitos se ingerido, perfuração do trato } \\
\text { gastrintestinal. }\end{array}$ & $\begin{array}{l}\text { Alteraçðes da função pulmonar, bronquite } \\
\text { crônica, conjuntivite, enfisema, infeções } \\
\text { respiratórias freqüentes, gastrite, erosão do } \\
\text { esmalte dentário Não é carcinogênico }{ }^{4,6} \text {. }\end{array}$ \\
\hline Ácido fórmico & $\begin{array}{l}\text { EPI- avental, óculos/capela, } \\
\text { luva de e borracha nítrilica }\end{array}$ & $\begin{array}{l}\text { ACGIH: TWA- } 5 \\
\text { ppm /STEL - } 10 \text { ppm } \\
\text { NR-15- } 4 \text { ppm }\end{array}$ & $\begin{array}{l}\text { Conjuntivite, queimaduras, irritação da } \\
\text { garganta náusea e vômitos se ingerido, } \\
\text { corrosão da glote dor de estômago, } \\
\text { diarréia, choque }{ }^{4}\end{array}$ & $\begin{array}{l}\text { alteraçð̃es da função pulmonar, bronquite } \\
\text { crônica, enfisema, erosão do esmalte dos } \\
\text { dentes }{ }^{4} \text {. }\end{array}$ \\
\hline Ácido fosfórico & $\begin{array}{l}\text { EPI- avental, óculos/capela, } \\
\text { luva de e borracha nitrilica }\end{array}$ & $\begin{array}{l}\text { ACGIH: TWA } 1 \\
\mathrm{mg} / \mathrm{m}^{3} / \text { STEL } 3 \\
\mathrm{mg} / \mathrm{m}^{3} \\
\mathrm{NR}-15 \text { não listado }\end{array}$ & $\begin{array}{l}\text { Conjuntivite, queimaduras, irritação da } \\
\text { traquéia, náusea e vômitos se ingerido, dor } \\
\text { de estômago, diarréia, choque }{ }^{4} \text {. }\end{array}$ & $\begin{array}{l}\text { alterações da função pulmonar, bronquite } \\
\text { crônica, enfisema, erosão do esmalte dos } \\
\text { dentes }{ }^{4} \text {. }\end{array}$ \\
\hline Ácido nítrico & $\begin{array}{l}\text { EPI- avental, óculos/capela, } \\
\text { luva butílica? }\end{array}$ & $\begin{array}{l}\text { ACGIH -TWA } 2 \\
\text { ppm/ STEL } 4 \text { ppm } \\
\text { NR-15 não listado }\end{array}$ & $\begin{array}{l}\text { Conjuntivite, queimaduras, irritação da } \\
\text { garganta, bronquite, edema, náusea e } \\
\text { vômitos se ingerido, perfuração do trato } \\
\text { gastrintestinal }{ }^{4} \text {. }\end{array}$ & $\begin{array}{l}\text { Alteraçðes da função pulmonar, bronquite } \\
\text { crônica, conjuntivite, enfisema, infeções } \\
\text { respiratórias freqüentes, gastrite, erosão do } \\
\text { esmalte dentário }{ }^{4}\end{array}$ \\
\hline
\end{tabular}


Cont. Tabela A-33

\begin{tabular}{|c|c|c|c|c|}
\hline \multirow[t]{2}{*}{ Substância } & \multirow[t]{2}{*}{ Cuidados manipulação } & \multirow{2}{*}{$\begin{array}{c}\text { Limites de } \\
\text { exposição }\end{array}$} & \multicolumn{2}{|c|}{ Efeitos } \\
\hline & & & Agudo & Crônico \\
\hline Ácido ósmico & $\begin{array}{l}\text { EPI - Avental impermeável } \\
\text { (troca diária) }{ }^{4} \text { luva nitrilica, } \\
\text { máscara, óculos }{ }^{1}\end{array}$ & $\begin{array}{l}\text { ACGIH: TWA 0,0002 } \\
\mathrm{ppm} / \text { STEL. } 0,0006 \\
\mathrm{ppm} \\
\text { NR-15 não listado }\end{array}$ & $\begin{array}{l}\text { Irritaçåo de pele e mucosas. Conjuntivite, } \\
\text { distúrbios visuais (sensação de halos e } \\
\text { luzes), sensação cáustica, tosse, edema } \\
\text { pulmonar, cefaléia, depressão SNC, como, } \\
\text { dano renal }{ }^{4} \text {. }\end{array}$ & $\begin{array}{l}\text { Inalação de baixas concentraçðes - insônia, } \\
\text { distúrbios digestivos, inflamação de laringe } \\
\text { e faringe. Afeta a reprodução e } \\
\text { espermatogênese em animais de } \\
\text { experimentação. Há evidências de } \\
\text { mutagenicidade. }\end{array}$ \\
\hline Ácido oxálico & $\begin{array}{l}\text { EPI avental, óculos, máscara, } \\
\text { luvas nitrílicas }\end{array}$ & $\begin{array}{l}\text { ACGIH } 1 \mathrm{mg} / \mathrm{m}^{3} \\
\text { STEL } 2 \mathrm{mg} / \mathrm{m}^{3} \\
\text { NR- } 15 \text { não listado }\end{array}$ & $\begin{array}{l}\text { Efeitos tóxicos semelhantes aos demais } \\
\text { ácidos (cáusticos) }{ }^{4} \text {. }\end{array}$ & \\
\hline Ácido perclórico & $\begin{array}{l}\text { EPI- avental, protetor facial, } \\
\text { óculos/capela, luva de e } \\
\text { borracha nitrilica } 1,4\end{array}$ & Não listado & $\begin{array}{l}\text { Irritação dos olhos e trato respiratório; } \\
\text { queimaduras da cómea, tosse, náusea, } \\
\text { vômito, queimaduras do trato } \\
\text { gastrintestinal se ingerido; queimaduras de } \\
\text { pele } 4.8\end{array}$ & $\begin{array}{l}\text { Exantema em individuos suscetíveis; } \\
\text { alterações da função pulmonar, bronquite } \\
\text { crônica, enfisema, erosão do esmalte dos } \\
\text { dentes }^{4} \text {. }\end{array}$ \\
\hline Ácido sulfídrico & $\begin{array}{l}\text { EPI avental, luva de borracha } \\
\text { butílica, óculos de proteção, } \\
\text { máscara, capela química? }\end{array}$ & $\begin{array}{l}\text { ACGIH } 10 \mathrm{ppm} \\
\text { STEL } 15 \mathrm{ppm} \\
\text { NR-15-8 ppm }\end{array}$ & $\begin{array}{l}\text { Na concentração de } 250 \mathrm{ppm} \text { : irritação de } \\
\text { mucosa, conjuntivite, fotofobia, opacidade } \\
\text { de córnea, rinite, bronquite, cianose, edema } \\
\text { pulmonar, } \\
\text { Na concentração de } 250-500 \mathrm{ppm} \text { : cefaléia, } \\
\text { náusea, vômito, diarréia, vertigem, } \\
\text { amnésia, tontura, apnéia, palpitação, } \\
\text { taquicardia, hipotensão, fraqueza, } \\
\text { desorientação, coma; Na concentração de } \\
750 \text { - } 1000 \text { ppm - parada respiratória, } \\
\text { convulsão, morte }\end{array}$ & Não relatado \\
\hline
\end{tabular}


Cont. Tabela A-33

\begin{tabular}{|c|c|c|c|c|}
\hline \multirow{3}{*}{$\begin{array}{l}\text { Substância } \\
\text { Ácido sulfúrico }\end{array}$} & \multirow{3}{*}{$\begin{array}{l}\text { Cuidados manipulação } \\
\text { EPI- avental, óculos/capela, } \\
\text { luva de butílica, } \\
\text { fluorcarbonada }\end{array}$} & \multirow{3}{*}{$\begin{array}{l}\begin{array}{l}\text { Limites de } \\
\text { exposição }\end{array} \\
\text { ACGIH :TWA } 1 \\
\mathrm{mg} / \mathrm{m}^{3} / \text { STEL } 3 \\
\mathrm{mg} / \mathrm{m}^{3} \\
\mathrm{NR}-15 \text { não listado }\end{array}$} & \multicolumn{2}{|c|}{ Efeitos } \\
\hline & & & Agudo & Crônico \\
\hline & & & $\begin{array}{l}\text { Conjuntivite, queimaduras, irritação da } \\
\text { garganta, bronquite, edema, náusea e } \\
\text { vômitos se ingerido, perfuração do trato } \\
\text { gastrintestinal }^{4} \text {. }\end{array}$ & $\begin{array}{l}\text { Alteraçð̃es da função pulmonar, bronquite } \\
\text { crônica, conjuntivite, enfisema, infeções } \\
\text { respiratórias freqüentes, gastrite, erosão do } \\
\text { esmalte dentário e possivel câncer de trato } \\
\text { respiratório/digestivo superior }{ }^{4,8}\end{array}$ \\
\hline Acrilamida & $\begin{array}{l}\text { EPI avental, óculos, máscara } \\
\text { luvas polietileno, vinil }{ }^{4}\end{array}$ & $\begin{array}{l}\text { ACGIH TWA } \\
0,03 \mathrm{mg} / \mathrm{m}^{3} \text { pele } \\
\text { NR-15 não listado }\end{array}$ & $\begin{array}{l}\text { Sonolência, confusão, alucinação, } \\
\text { desorientação, ataxia, convulsð̃es com } \\
\text { colapso cardiovascular aparecem após } \\
\text { algumas horas na exposição a } \\
\text { concentraçð̃es elevadas. Neuropatia } \\
\text { periférica pode surgir } 1 \text { a } 2 \text { dias após a } \\
\text { exposição. }\end{array}$ & $\begin{array}{l}\text { Neuropatia periférica com perda dos } \\
\text { reflexos dos tendðes, fraqueza muscular, } \\
\text { parestesia das extremidades. Suor excessivo } \\
\text { e exantemas esfoliativos são comuns na } \\
\text { exposição crônica. Carcinogênico para } \\
\text { animais (neoplasia de glândulas mamárias, } \\
\text { sistema nervoso, escroto pele, tireóide e } \\
\text { útero em ratos) }\end{array}$ \\
\hline Anidrido acético & $\begin{array}{l}\text { EPI avental, óculos, máscara } \\
\text { luvas nitrílicas }{ }^{1}\end{array}$ & $\begin{array}{l}\text { ACGIH TWA } 5 \text { ppm } \\
\text { NR-15 não listado }\end{array}$ & $\begin{array}{l}\text { Queimadura de pele e mucosas, erosão de } \\
\text { córnea, dispnéia, edema, espasmo } \\
\text { brônquico, pneumonite, traqueobronquite, } \\
\text { anomalias pulmonares persistentes, } \\
\text { isquemia do miocárdio }{ }^{4} \text {. }\end{array}$ & Efeito acumulativo não conhecido ${ }^{4}$. \\
\hline Auramina & $\begin{array}{l}\text { EPI avental, óculos, máscara, } \\
\text { luvas (não dão proteção total } \\
\text { para agentes carcinogênicos) }\end{array}$ & $\begin{array}{l}\text { ACGIH /NR-15 não } \\
\text { listado }\end{array}$ & $\begin{array}{l}\text { Agente metemoglobinizante - fadiga, } \\
\text { respiração curta, extremidades azuladas }\end{array}$ & $\begin{array}{l}\text { Dano renal e hepático. Possivelmente } \\
\text { carcinogênico para o homem }{ }^{4} \text {. }\end{array}$ \\
\hline Azida sódica & $\begin{array}{l}\text { EPI avental, luva nitrílica, } \\
\text { protetor facial, óculos de } \\
\text { proteção }\end{array}$ & $\begin{array}{l}\text { ACGIH } 0,29 \mathrm{mg} / \mathrm{m}^{3} \\
\text { teto }\left(\mathrm{NaN}_{3}\right) \text { e } 0,11 \\
\text { ppm }\left(\mathrm{HN}_{3}\right) \\
\text { NR- } 15 \text { não listado }\end{array}$ & $\begin{array}{l}\text { Cefaléia, depressão do SNC, desconforto, } \\
\text { hiper ou hipotermia, edema pulmonar, } \\
\text { acidose láctica, bradicardia ou taquicardia, } \\
\text { hipotensão, arritmias, náuseas, vômito, } \\
\text { diarréia, leucositose, convulsões. Exposição } \\
\text { aos vapores de ácido hidrazóico - irritação } \\
\text { mucosas, bronquite, edema }{ }^{4}\end{array}$ & $\begin{array}{l}\text { Nada relata no homem. Em animais de } \\
\text { experimentação: necrose cerebral } \\
\text { desmielinização do nervo ótico e de fibras } \\
\text { nervosas do SNC, hipotensão, letargia e } \\
\text { inatividade, mutagenicidade. }\end{array}$ \\
\hline
\end{tabular}


Cont. Tabela A-33

\begin{tabular}{|c|c|c|c|c|}
\hline \multirow[t]{2}{*}{ Substância } & \multirow[t]{2}{*}{ Cuidados manipulação } & \multirow{2}{*}{$\begin{array}{c}\text { Limites de } \\
\text { exposição }\end{array}$} & \multicolumn{2}{|c|}{ Efeitos } \\
\hline & & & Agudo & Crônico \\
\hline Benzeno & $\begin{array}{l}\text { EPI- avental, óculos, protetor } \\
\text { facial/ capela } \\
\text { Luva teflon, viton, polivinil } \\
\text { álcool? }^{\text {? }}\end{array}$ & $\begin{array}{l}\text { ACGIH: TWA 0,5 } \\
\text { ppm / STEL 2,5 ppm } \\
\text { NR-15 não listado }\end{array}$ & $\begin{array}{l}\text { SNC - depressão, fibrilação ventricular } \\
\text { Cutâneo- eritema, queimadura } \\
\text { Pulmão: edema, hemorragia alveolar }\end{array}$ & $\begin{array}{l}\text { Anemia aplástica, cefaléia, perda do } \\
\text { apetite, perda de peso, fraqueza (queixas } \\
\text { mais comuns). Palidez, epistaxe, } \\
\text { sangramento das gengivas, petéquias } \\
\text { purpuras podem se desenvolver mais tarde }{ }^{4}\end{array}$ \\
\hline Benzidina & Vide auramina & $\begin{array}{l}\text { ACGIH notação pele } \\
\text { NR-15 não listada }\end{array}$ & $\begin{array}{l}\text { Hemólise, depressão medula óssea. } \\
\text { Ingestão náusea e vômito }{ }^{4}\end{array}$ & $\begin{array}{l}\text { Carcinogênico comprovado para o homem } \\
\text { (hepatocarcinoma) }\end{array}$ \\
\hline $\begin{array}{l}\text { Brometo de } \\
\text { cianogênio }\end{array}$ & $\begin{array}{l}\text { EPI avental, luva nitrílica, } \\
\text { óculos de proteçăo }{ }^{1}\end{array}$ & $\begin{array}{l}\text { ACGIH } 5 \mathrm{mg} / \mathrm{m}^{3} \text { teto } \\
\text { (como sal de CN) } \\
\text { NR- } 15 \text { não listado }\end{array}$ & $\begin{array}{l}\text { Irritação dos olhos, nariz, garganta, trato } \\
\text { respiratório. Pode liberar bometo e ácido } \\
\text { brômico durante a hidrólise ou } \\
\text { decomposição térmica e produzir irritação } \\
\text { severa dos olhos, edema e hemorragia } \\
\text { Irritante severo de pele. Ingestão - irritação } \\
\text { do trato gastrintestinal e intoxicação } \\
\text { sistêmica por cianeto. Exposição a baixas } \\
\text { concentraç̃̃es - náusea, vômito, } \\
\text { palpitaçðes, confusão, hiperventilação, } \\
\text { vertigem, hipóxia, taquicardia, taquipnéia, } \\
\text { cefaléia, tontura, agitação, estupor, } \\
\text { convulsão, apnéia, bradicardia, hipotensão } \\
{ }_{4}\end{array}$ & Efeitos menos severos que os agudos ${ }^{4}$ \\
\hline $\begin{array}{l}\text { Brometo de } \\
\text { etídio }\end{array}$ & $\begin{array}{l}\text { EPI avental, óculos, máscara } \\
\text { luvas }^{4}\end{array}$ & $\begin{array}{l}\text { ACGII e NR-15 não } \\
\text { listado }\end{array}$ & $\begin{array}{l}\text { Irritação de pele, olhos, trato respiratório e } \\
\text { digestivo }{ }^{4}\end{array}$ & $\begin{array}{l}\text { Intercala-se nas bandas de DNA, apresentando } \\
\text { mutagenicidade em vários testes. É possivel que } \\
\text { as altera̧̧⿸尸es do ácido nucleico induzidas pelo } \\
\text { toxicante tornem as células mais suscetiveis aos } \\
\text { efeitos de outros citotóxicos. Nenhum dos } \\
\text { achados de mutagenicidade ou embriotoxicidade } \\
\text { podem predizer a resposta humana }{ }^{4} \text {. }\end{array}$ \\
\hline
\end{tabular}


Cont. Tabela A-33

\begin{tabular}{|c|c|c|c|c|}
\hline Substância & Cuidados manipulação & $\begin{array}{l}\text { Limites de } \\
\text { exposição }\end{array}$ & \multicolumn{2}{|c|}{ Efeitos } \\
\hline Butanol & $\begin{array}{l}\text { EPI - avental, óculos/capela } \\
\text { Luva teflon }{ }^{4}\end{array}$ & $\begin{array}{l}\text { ACGIH, NIOSH } \\
50 \mathrm{ppm} \text { teto } \\
\text { NR-15-40 ppm teto }\end{array}$ & $\begin{array}{l}\text { Depressão SNC - hipotensão, náusea, } \\
\text { vômito, diarréia. Irritante de pele e } \\
\text { mucosas promovendo dermatites, e } \\
\text { conjuntivite, visão turva.. Se aspirado } \\
\text { provoca pneumonite hemorrágica }{ }^{4}\end{array}$ & $\begin{array}{l}\text { Não foram encontrados dados de } \\
\text { intoxicação crônica }\end{array}$ \\
\hline Carbono 14 & $\begin{array}{l}\text { Nenhum anteparo requerido. } \\
\text { Usar avental e luvas. } \\
\text { Possivelmente os compostos } \\
\text { orgânicos de }{ }^{14} \mathrm{C} \text { são } \\
\text { absorvidos através das luvas. } \\
\text { Monitores passivos não } \\
\text { necessários (energia } \beta \text { muito } \\
\text { baixa) }{ }^{9}\end{array}$ & 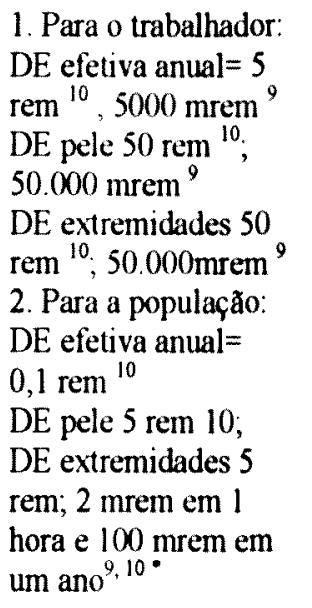 & $\begin{array}{l}\text { Relacionado à exposição e área do corpo } \\
\text { atingida: a) corpo inteiro - } 10.000 \mathrm{R} \text {, dose } \\
\text { única = 'sindrome cerebrovascular e óbito } \\
\text { em horas; } 500-1200 \mathrm{R} \text { - síndrome } \\
\text { gastrintestinal, óbito em dias; } 250-500 \mathrm{R}= \\
\text { sindrome hematopoiética, óbito após várias } \\
\text { semanas devido dano sobre a medula } \\
\text { óssea; } 25 \mathrm{R} \text {, dose única + linfocitopenia } \\
\text { temporária B) olhos- } 600-900 \mathrm{R}=\text { catarata; } \\
\text { c) pele, dose única, } 500-600 \mathrm{R}=\text { eritema } \\
\text { em 7-10 dias com redução gradual e } \\
\text { pigmentação da pele; } 1500-2000 \mathrm{R}= \\
\text { eritema, bolhas e escaras. }\end{array}$ & $\begin{array}{l}\text { Tecido alvo: adiposo. Vias de Introdução } \\
\text { ingestão, inalação e contato com a pele } \\
\text { Efeitos genéticos e carcinomas relatados }\end{array}$ \\
\hline Cádmio metálico & $\begin{array}{l}\text { EPI avental, luva nitrilica, } \\
\text { óculos de proteção, máscara }\end{array}$ & $\begin{array}{l}\text { ACGIH } 0,01 \mathrm{mg} / \mathrm{m}^{3} \\
\text { NR-15 não listado }\end{array}$ & $\begin{array}{l}\text { Ingestão ou inalação dos fumos de cádmio: } \\
\text { sintomatologia inicial semelhante a gripe. Em } \\
\text { alguns casos evolui para traqueobronquite } \\
\text { severa, pneumonite e edema pulmonar }\end{array}$ & $\begin{array}{l}\text { Proteinúria, doença pulmonar obstrutiva } \\
\text { crônica, anosmia, rinite, osteomalácia, } \\
\text { anemia, dor generalizada. Possivel } \\
\text { carcinogênico para o homem. }{ }^{4}\end{array}$ \\
\hline Ciclohexano & $\begin{array}{l}\text { EPI- avental, óculos/capela, } \\
\text { luva nitrilica ou de viton? }\end{array}$ & $\begin{array}{l}\text { ACGIH, } 1998-300 \\
\text { ppm } \\
\text { NR-15 - } 235 \mathrm{ppm}\end{array}$ & $\begin{array}{l}\text { Irritante de pele e mucosas, depressão SNC e } \\
\text { arritmias cardiacas promovendo cefaléia, } \\
\text { náuseas, vômito, fraqueza, tontura, diminuição } \\
\text { da coordenação motora, confusão mental, } \\
\text { inconsciência, coma e morte por parada } \\
\text { respiratória }{ }^{4}\end{array}$ & $\begin{array}{l}\text { Dermatite. Nenhum efeito sobre a condução } \\
\text { do impulso nervoso observado. Injúria } \\
\text { tubular renal observada em ratos }{ }^{4} \text {. }\end{array}$ \\
\hline
\end{tabular}




\begin{tabular}{|c|c|c|c|c|}
\hline \multirow{3}{*}{$\begin{array}{l}\text { Substância } \\
\begin{array}{l}\text { Cloreto de } \\
\text { alumínio }\end{array}\end{array}$} & \multirow{3}{*}{$\begin{array}{l}\text { Cuidados manipulação } \\
\begin{array}{l}\text { EPI avental, óculos, máscara, } \\
\text { luvas nitrilicas }\end{array}\end{array}$} & \multirow{3}{*}{$\begin{array}{l}\begin{array}{r}\text { Limites de } \\
\text { exposição }\end{array} \\
\text { ACGIH TWA } 10 \\
\mathrm{mg} / \mathrm{m}^{3} \\
\mathrm{NR}-15 \text { não listado }\end{array}$} & \multirow{2}{*}{\multicolumn{2}{|c|}{ Efeitos }} \\
\hline & & & & \\
\hline & & & $\begin{array}{l}\text { Efeito agudo só ocorre em individuos com } \\
\text { falha renal crônica e pessoas expostas a } \\
\text { Aluminio no ambiente de trabalho. Irritante } \\
\text { leve promovendo tosse e espirro }{ }^{4} \text {. }\end{array}$ & $\begin{array}{l}\text { Em pacientes de diálise: encefalopatia, } \\
\text { osteomalácia, osteodistrofia e anemia } \\
\text { microcitica. Ocupacional - asma, bronquite } \\
\text { crônica, fibrose pulmonar, broncoespasmos, } \\
\text { doença pulmonar obstrutiva }{ }^{4} \text {. }\end{array}$ \\
\hline $\begin{array}{l}\text { Cloreto de } \\
\text { antimônio }\end{array}$ & $\begin{array}{l}\text { EPI avental, luva nitrilica, } \\
\text { oculos de proteção }{ }^{4}\end{array}$ & $\begin{array}{l}\text { ACGIH } 0,5 \mathrm{mg} / \mathrm{m}^{3} \\
\text { (Sb) } \\
\text { NR-15 não listado }\end{array}$ & $\begin{array}{l}\text { Dores abdominais, náusea, vômitos, } \\
\text { diarréia, conjuntivite, epistaxe, } \\
\text { tromboflebite, tosse, febre dos fumos } \\
\text { metálicos, leucopenia }{ }^{4} \text {. }\end{array}$ & Mutagênicos 5 \\
\hline $\begin{array}{l}\text { Cloreto de } \\
\text { paládio }\end{array}$ & EPI: avental, luva & Não listado & Irritante de pele e mucosas ${ }^{5}$ & $\begin{array}{l}\text { Evidências de mutagenicidade para o } \\
\text { homem. Carcinogenicidade questionável } \\
\text { (animais de experimentação) }\end{array}$ \\
\hline $\begin{array}{l}\text { Cloreto de } \\
\text { tionila }\end{array}$ & $\begin{array}{l}\text { EPI avental, óculos, máscara, } \\
\text { luvas }\end{array}$ & $\begin{array}{l}\text { ACGIH } 1 \text { ppm teto } \\
\text { NR-15 não listado }\end{array}$ & $\begin{array}{l}\text { Conjuntivite, dermatite, rinite, bronquiolite } \\
\text { e pneumonia }{ }^{4}\end{array}$ & Não descritos na literatura consultada. \\
\hline $\begin{array}{l}\text { Cloreto de } \\
\text { vanádio }\end{array}$ & $\begin{array}{l}\text { EPI avental, óculos, máscara, } \\
\text { luvas }\end{array}$ & $\begin{array}{l}\text { ACGIH /NR-15 não } \\
\text { listado }\end{array}$ & $\begin{array}{l}\text { Irritante e corrosivo para as mucosas. } \\
\text { Tosse, edema, respiração curta }{ }^{4} \text {. }\end{array}$ & Tosse, muco e respiração curta ${ }^{4}$. \\
\hline Clorofórmio & $\begin{array}{l}\text { EPI - avental, óculos, } \\
\text { máscara/capela, protetor } \\
\text { facial, luvas viton } 1,4\end{array}$ & $\begin{array}{l}\text { ACGIII, } 199810 \mathrm{ppm} \\
\text { NR- } 15-20 \mathrm{ppm}\end{array}$ & $\begin{array}{l}\text { Irritante de pele e mucosas, depressor SNC e } \\
\text { cardiovascular, nefro e hepatotóxico } \\
\text { promovendo tontura, cefáléia, anorexia, } \\
\text { desorientação, fadiga, arritmias, pneumonite, } \\
\text { edema pulmonar, dermatite, necrose hepática, } \\
\text { hepatomegalia, glicosúria, albuminuuria e } \\
\text { cetonúria }\end{array}$ & $\begin{array}{l}\text { Secura de boca, cefaléia, comportamento } \\
\text { psicótico, alucinaçðes, disartria, ataxia, } \\
\text { diminuição dos reflexos, hepatotoxicidade } \\
\text { Exposição crônica a concentraçð̃es muito baixas } \\
\text { - hepatomegalia, figado gorduroso, e câncer } \\
\text { renal em ratos }{ }^{4} \text {. }\end{array}$ \\
\hline $\begin{array}{l}\text { Dimetilaminoazo } \\
\text { benzeno }\end{array}$ & $\begin{array}{l}\text { EPI avental, óculos, máscara, } \\
\text { luvas (não dão proteção total } \\
\text { para agentes carcinogênicos) }\end{array}$ & $\begin{array}{l}\text { ACGIH /NR-15 não } \\
\text { listado }\end{array}$ & $\begin{array}{l}\text { Dermatite de contato, hepato e } \\
\text { nefromegalia, tosse, espirro, dispnéia, } \\
\text { secreção bronquial, hematuria }{ }^{4} \text {. }\end{array}$ & $\begin{array}{l}\text { Câncer de figado e bexiga em animais de } \\
\text { experimentação }{ }^{4}\end{array}$ \\
\hline
\end{tabular}


Cont. Tabela A-33

\begin{tabular}{lllccc} 
Substância & Cuidados manipulação & $\begin{array}{l}\text { Limites de } \\
\text { exposição }\end{array}$ & Agudo & Efeitos & Crônico \\
\hline
\end{tabular}

Diazometano

Evental, oculos, máscara, ACGII $02 \mathrm{ppm}$

15 não listado

Altamente irritante- conjuntivite, ulceração

Alergia, asma. Promover câncer pulmonar em luvas de couro

de cómea, tontura, dor no peito, asma, tosse

animais. Há evidências de mutagenicidade ${ }^{4}$

febre, pneumonia, edema, cianose moderada,

choque e morte Tremor, hepatomegalia

hemólise. Ulceração do lábio em exposição

ao líquido ${ }^{4}$

Diclorometano EPI - avental, óculos, máscara/capela, protetor facial, luvas ppm, no STEL

OSHA/Pel $/ 97$ - 25

ppm ${ }^{4}$

NR-15-156 ppm
ACGIH/98 TWA 50

Irritante de mucosas e pele, cefaléia, tontura, apatia, náusea e vômitos, depressåo do SNC pode evoluir até parada respiratória. Aos efeitos do diclorometano somam-se os efeitos do $\mathrm{CO}$ (produto de biotransformaçăo), provocando alteraçðes no transporte de $\mathrm{O}_{2}$ $(\mathrm{COHb})^{4}$

\section{Dietilamina}

EPI- avental, óculos/capela, luva de teflon

ACGIH/98 TWA $5 \mathrm{ppm}$ STEL $15 \mathrm{ppm}$ NR-15 - $20 \mathrm{ppm}$

ACGIH /NR-15 não listado

luvas nitrílicas ${ }^{4}$

EPI avental, óculos, máscara, luvas não especificadas

\section{ACGIH TWA 10 $\mathrm{mg} / \mathrm{m}^{3}$ NR-15 não listado}

ACGIH/99 TWA 10 ppm no STEL $\mathrm{NR}-15-8 \mathrm{ppm}$
Tosse, rinite, edema pulmonar, traqueite, bronquite, pneumonite, dispnéia. Pode ser fatal dependendo da concentração. Irritante de pele e mucosas ${ }^{4}$.

Fadiga, dispnéia, taquicadia, vertigens devido à hipóxia, metemoglobinemia ${ }^{4,11}$

Irritante de pele e mucosas, hipertensão, taquicardia, tose, espirro, anorexia, eczema metemoglobinemia, anemia

Irritante de pele e mucosas, vômito, dor abdominal, vertigem ,cefaléia, anorexia, hipertensão, palpitaça, trombocitopenia, aumento da atividade das enzimas hepáticas
Cefaléia, tontura, náusea, alteraçåo do comportamento. Promove adenomas ou carcinoma hepatocelular em camundongos. Estas evidências sugerem sua ação carcinogênica também para o homem ${ }^{4}$.

Irritação garganta, brônquios e pulmão, edema pulmonar, degeneração parenquimatosa hepática (em ratos). Efeitos sutis ao nivel de $\mathrm{SNC}^{4}$.

Comprovadamente carcinogênico para animais ( $\mathrm{Ca}$ de bexiga). Suspeito de carcinogenicidade para o homem ${ }^{4}$.

Evidência limitada de promover câncer de bexiga em animais ${ }^{4}$

Promove dano hepático e renal. Evidências limitadas de carcinoma testicular e de teratogênese - deve ser tratado como tal até que se tenha evidências contrárias ${ }^{4}$ 
Cont. Tabela A-33

\begin{tabular}{|c|c|c|c|c|}
\hline \multirow{3}{*}{$\begin{array}{l}\text { Substância } \\
\begin{array}{l}\text { Dissulfeto de } \\
\text { carbono }\end{array}\end{array}$} & \multirow{3}{*}{$\begin{array}{l}\text { Cuidados manipulaçåo } \\
\text { EPI avental, luva de viton } \\
\text { máscara, óculos, capela }\end{array}$} & \multirow{3}{*}{\begin{tabular}{l}
\multicolumn{1}{c}{$\begin{array}{c}\text { Limites de } \\
\text { exposição }\end{array}$} \\
$\begin{array}{l}\text { ACGIH TWA 10 ppm } \\
\text { (pele) }\end{array}$ \\
NR-15 - $16 \mathrm{ppm}$ \\
(pele)
\end{tabular}} & \multirow{2}{*}{\multicolumn{2}{|c|}{ Efeitos }} \\
\hline & & & & \\
\hline & & & $\begin{array}{l}\text { Irritação do olhos. Contato com a pele pode } \\
\text { formar bolhas. SNC: cefaléia, delírio, tontura, } \\
\text { tremor, insônia, fadiga, convulsão, coma, } \\
\text { anóxia, degeneração hepática gordurosa, } \\
\text { dispnéia e falha respiratória }{ }^{4} \text {. }\end{array}$ & $\begin{array}{l}\text { Arteriosclerose, cefaléia, tontura, fadiga, } \\
\text { irritação, distúrbios do sono, anorexia, perda } \\
\text { de peso. Microaneurismas de retina, distúrbios } \\
\text { de personalidade, tremores, distúrbios extra } \\
\text { piramidais. Genotóxico e mutagênico para o } \\
\text { homem }^{4}\end{array}$ \\
\hline Etanol & $\begin{array}{l}\text { EPI- avental, óculos/capela, } \\
\text { luva borracha butílica }{ }^{l}\end{array}$ & $\begin{array}{l}\text { ACGIH -TWA } 1000 \\
\text { ppm } \\
\text { NR-15 - } 780 \text { ppm }\end{array}$ & $\begin{array}{l}\text { Irritante de mucosas, narcose, coma, parada } \\
\text { respiratória, hipotermia, hipoglicemia, } \\
\text { acidose, desequilibrio eletrolítico, distúrbios } \\
\text { gastrintestinais }{ }^{4}\end{array}$ & $\begin{array}{l}\text { Amnésia, demência, sonolência, miopatia } \\
\text { cardiaca, hepatotoxicidade, varizes esofágicas } \\
\text { e pancreatite.Efeitos teratogênicos - Síndrome } \\
\text { etanólica fetal }^{4}\end{array}$ \\
\hline Éter de petróleo & $\begin{array}{l}\text { EPI- avental, óculos/capela, } \\
\text { luva PVA, nitrilica, } \\
\text { fluorcarbonada }\end{array}$ & $\begin{array}{l}\text { ACGIH/99 TWA } 400 \\
\text { ppm } \\
\text { NR-15 não listado }\end{array}$ & $\begin{array}{l}\text { Irritante dos olhos e trato respiratório, } \\
\text { cefaléia, fadiga, náusea, incoordenação. A } \\
\text { aspiração do líquido promove pneumonite } \\
\text { lipóide }^{4} \text {. }\end{array}$ & $\begin{array}{l}\text { Dermatite, neuropatia periférica, } \\
\text { encefalopatia. Dano renal só observado em } \\
\text { animais de esperimentação. }\end{array}$ \\
\hline Éter etílico & $\begin{array}{l}\text { EPI- avental, óculos/capela, } \\
\text { luva Teflon }\end{array}$ & $\begin{array}{l}\text { ACGIH- TWA } 400 \\
\text { ppm STEL } 500 \text { ppm } \\
\text { NR-15- } 310 \mathrm{ppm}\end{array}$ & $\begin{array}{l}\text { Conjuntivite, irritação do trato respiratório, } \\
\text { dermatite, cefaléia, tontura, anorexia, } \\
\text { vômito, albuminúria }{ }^{4}\end{array}$ & $\begin{array}{l}\text { Anorexia, constipação, tontura, cefaléia, } \\
\text { distúrbios psiquiátricos }{ }^{4} \text {. }\end{array}$ \\
\hline Fenol & $\begin{array}{l}\text { EPI- avental, óculos/capela, } \\
\text { luva borracha butílica, } \\
\text { nitrílica, neoprene }\end{array}$ & $\begin{array}{l}\text { ACGIH- TWA } 5 \text { ppm } \\
\text { NR-15- } 4 \text { ppm }\end{array}$ & $\begin{array}{l}\text { Náusea, vômito, diarréia, anemia } \\
\text { hemolitica, metemoglobinemia, palidez, } \\
\text { hipotensão, arritmia, edema pulmonar, } \\
\text { taquicardia, letargia, convulsão, coma, } \\
\text { dano renal e hepático }{ }^{4} \text {. }\end{array}$ & $\begin{array}{l}\text { Cefaléia, tosse, fraqueza, fadiga, náusea, } \\
\text { vômito, insônia, perda de peso, nervosismo, } \\
\text { parestesia, albuminúria }{ }^{4} \text {. }\end{array}$ \\
\hline
\end{tabular}


Cont. Tabela A-33

\begin{tabular}{|c|c|c|c|c|}
\hline \multirow{3}{*}{\begin{tabular}{|l} 
Substância \\
Formaldeído
\end{tabular}} & \multirow{3}{*}{$\begin{array}{l}\text { Cuidados manipulaçåo } \\
\text { EPI- avental, óculos/capela, } \\
\text { luva neoprene ou borracha } \\
\text { butílica }\end{array}$} & \multirow{3}{*}{\begin{tabular}{l}
\multicolumn{1}{c}{$\begin{array}{c}\text { Limites de } \\
\text { exposição }\end{array}$} \\
ACGII $/ 990,3 \mathrm{ppm}$ \\
teto - \\
NR-15-1,6 ppm teto
\end{tabular}} & \multicolumn{2}{|c|}{ Efeitos } \\
\hline & & & Agudo & Crônico \\
\hline & & & $\begin{array}{l}\text { Ingestão - corrosivo, náusea, vômito, dor, } \\
\text { sangramento, perfuração esôfago } \\
\text { Inalação- (irritante) espirro, laringoespasmo, } \\
\text { bronquite e pneumonia } \\
\text { Olhos e Pele- irritante, lacrimejamento, } \\
\text { desconforto. Resinas contendo formaldeido } \\
\text { podem provocar necrose epidérmica } \\
\text { SNC - depressão coma, acidose metabólica }\end{array}$ & $\begin{array}{l}\text { Cefaléia, irritabilidade, náusea, perda do } \\
\text { apetite, irritação dos olhos e vias aéreas } \\
\text { superiores, distúrbio da memória, equilibrio } \\
\text { e da destreza em técnicos de histologia } \\
\text { ocupacionalmente expostos. Ainda } \\
\text { observado, eritema, lesão ecmatosa, } \\
\text { hiperestesia }\end{array}$ \\
\hline Fósforo 32 & $\begin{array}{l}\text { Anteparo d madeira, plástico, } \\
\text { acrílico de } 0,61 \text { cm de espessura; } \\
\text { avental e luvas, óculos de } \\
\text { proteção e monitores individuais } \\
\text { para concentraçð̃es superiores a } \\
1.0 \mathrm{mCi}^{9}\end{array}$ & Vide carbono 14 & Vide carbono 14 & $\begin{array}{l}\text { Órgãos críticos: formas solúveis- ossos; } \\
\text { formas insolúveis e não transportáveis: } \\
\text { pulmão (inalação) e trato gastrintestinal } \\
\text { (ingestão) } \\
\text { Efeitos estocásticos }={ }^{14} \text { carbono }{ }^{9}\end{array}$ \\
\hline Heptano & $\begin{array}{l}\text { EPI- avental, óculos/capela, } \\
\text { luva borracha nitrilica ou } \\
\text { fluorcarbonada }^{4}\end{array}$ & $\begin{array}{l}\text { ACGIH TWA } 400 \\
\text { ppm } \\
\text { NR-15 não listado }\end{array}$ & $\begin{array}{l}\text { tosse, irritação pulmonar, dermatite, irritação } \\
\text { ocular, edema, excitação seguida de } \\
\text { depressão, cefaléia e arritmias cardíacas }{ }^{4}\end{array}$ & Leve dano renal descrito ${ }^{4}$ \\
\hline Hexano & $\begin{array}{l}\text { EPI- avental, óculos/capela, } \\
\text { luva neoprene ou borracha } \\
\text { nitrílica }\end{array}$ & $\begin{array}{l}\text { ACGII } / 99 \text { TWA } 50 \\
\text { ppm } \\
\text { NR-15 não listado }\end{array}$ & $\begin{array}{l}\text { Ingestão- náuseas, irritação do trato } \\
\text { gastrintestinal, depressão SNC } \\
\text { Inalação- euforia, tontura, parestesia das } \\
\text { extremidades e depressão SNC }{ }^{4}\end{array}$ & $\begin{array}{l}\text { Neuropatia periférica, dermatites. Podem } \\
\text { ocorrer em intoxicações mais graves } \\
\text { alterações visuais e perdas da memória }{ }^{4}\end{array}$ \\
\hline $\begin{array}{l}\text { Hidróxido de } \\
\text { amônia }\end{array}$ & $\begin{array}{l}\text { EPI- avental, óculos/capela, } \\
\text { luva nitrílica! }\end{array}$ & $\begin{array}{l}\text { ACGIH não listado } \\
\text { NR-15 não listado }\end{array}$ & $\begin{array}{l}\text { Ulceração da conjuntiva e córnea; irritação } \\
\text { e queimaduras da pele e mucosas. Cefaléia, } \\
\text { salivação, náusea, vômito, dificuldade } \\
\text { respiratória, tosse, bronquite, edema } \\
\text { pulmonar }\end{array}$ & Não há referência. \\
\hline
\end{tabular}


Cont. Tabela A-33

\begin{tabular}{|c|c|c|c|c|}
\hline \multirow[t]{2}{*}{ Substância } & \multirow[t]{2}{*}{ Cuidados manipulação } & \multirow{2}{*}{$\begin{array}{l}\text { Limites de } \\
\text { exposição }\end{array}$} & \multicolumn{2}{|c|}{ Efeitos } \\
\hline & & & Agudo & Crônico \\
\hline $\begin{array}{l}\text { Hidróxido de } \\
\text { potássio }\end{array}$ & $\begin{array}{l}\text { EPI- avental, óculos/capela, } \\
\text { luva nitrílica }\end{array}$ & $\begin{array}{l}\text { ACGIH TWA 2 } \\
\mathrm{mg} / \mathrm{m} 3 \text { teto } \\
\mathrm{NR}-15 \text { não listado }\end{array}$ & $\begin{array}{l}\text { lingestão- queimadura do trato superior, } \\
\text { esôfago e ocasionalmente estômago, hipotensão } \\
\text { e taquicardia em função da hemorragia } \\
\text { gastrintestinal. Inalação dos vapores - edema, } \\
\text { falha respiratória, pneumonite Irritação } \\
\text { conjuntiva e até perda permanente da visão } \\
\text { (contato com o liquido), irritação e queimaduras } \\
\text { da pele. }\end{array}$ & $\begin{array}{l}\text { Como consequência da ingestão - câncer } \\
\text { esofágico }{ }^{4} \text {. }\end{array}$ \\
\hline $\begin{array}{l}\text { Hidróxido de } \\
\text { sódio }\end{array}$ & $\begin{array}{l}\text { EPI- avental, óculos/capela, } \\
\text { luva nitrílica }\end{array}$ & $\begin{array}{l}\text { ACGIH TWA } 2 \\
\mathrm{mg} / \mathrm{m} 3 \text { teto } \\
\mathrm{NR}-15 \text { não listado }\end{array}$ & $\begin{array}{l}\text { Ingestão - queimadura do trato superior, } \\
\text { esôfago e ocasionalmente estômago, hipotensão } \\
\text { e taquicardia em função da hemorragia } \\
\text { gastrintestinal. } \\
\text { Inalação dos vapores - edema, falha respiratória, } \\
\text { pneumonite. } \\
\text { Irritação/ulceração conjuntiva e até perda } \\
\text { permanente da visão (contato com o liquido), } \\
\text { irritação e queimaduras da pele. }\end{array}$ & $\begin{array}{l}\text { Como consequiência da ingestão - câncer } \\
\text { esofágico }{ }^{4} \text {. }\end{array}$ \\
\hline Iodo & $\begin{array}{l}\text { EPI avental, óculos, máscara } \\
\text { luvas de borracha nitrílica }{ }^{1}\end{array}$ & $\begin{array}{l}\text { ACGIH TWA } 0,1 \\
\text { ppm teto } \\
\text { NR-15 não listado }\end{array}$ & $\begin{array}{l}\text { Ingestão- gastroenterite corrosiva, vômito, } \\
\text { delírio, cefaléia, hipotensão, convulsão, } \\
\text { taquicardia. Inalação- irritação das } \\
\text { mucosas, rinite, faringite, blefarite (olhos) }\end{array}$ & $\begin{array}{l}\text { Conjuntivite, erupção cutânea semelhante à } \\
\text { acne, estomatite, rinorréia, anorexia, } \\
\text { anemia, irritaçãos }\end{array}$ \\
\hline Isopropanol & $\begin{array}{l}\text { EPI- avental, óculos/capela, } \\
\text { luva borracha nitrilica }\end{array}$ & $\begin{array}{l}\text { ACGIH /99 TWA } 400 \\
\text { ppm STEL } 500 \text { ppm }\end{array}$ & $\begin{array}{l}\text { Irritação nariz, garganta e trato respiratório. Em } \\
\text { altas concentraç̃es deprime o SNC, } \\
\text { taquicardia, cetonuria, oligúria, coma. } \\
\text { Ingestão - vômito, cefaléia, tontura, hipotensão }\end{array}$ & $\begin{array}{l}\text { Hipersensibilidade, dermatite, ressecamento } \\
\text { da pele, conjuntivite alérgica. Ataxia } \\
\text { observado em ratos }{ }^{4} \text {. }\end{array}$ \\
\hline $\begin{array}{l}\text { Magnésio } \\
\text { metálico }\end{array}$ & $\begin{array}{l}\text { EPI avental, óculos, máscara, } \\
\text { luvas nitrílicas }{ }^{1}\end{array}$ & $\begin{array}{l}\text { ACGIH TWA } \\
10 \mathrm{mg} / \mathrm{m}^{3} \text { ( fumos de } \\
\text { óxido) } \\
\text { NR-15 não listado }\end{array}$ & $\begin{array}{l}\text { Partículas de magnésio metálico podem perfurar } \\
\text { a pele desencadeando uma severa reação } \\
\text { inflamatória. A toxicidade dos compostos de } \\
\text { magnésio estão, em geral, associadas ao ânions. }\end{array}$ & Não relatado \\
\hline
\end{tabular}

\section{Hidróxido de}

EPI- avental, óculos/capela,

ACGIH TWA 2

$\mathrm{mg} / \mathrm{m} 3$ teto

NR-15 não listado

EPI avental, óculos, máscara

EPI- avental, óculos/capela,

luva borracha nitrilica

ACGIH /99 TWA 400
ppm STEL 500 ppm

allas concentraçoes deprime o SNC,

aquicardia, cetonuria, oligúria, coma

da pele conjuntivite alérgica. Ataxia da pele, conjuntivit

pele desencadeando uma severa reação

NR-15 não listado magnésio estão, em geral, associadas ao ânion ${ }^{5}$ 
Cont. Tabela A-33

\begin{tabular}{|c|c|c|c|c|}
\hline \multirow{3}{*}{$\begin{array}{l}\text { Substância } \\
\text { 2- } \\
\text { mercaptoetanol }\end{array}$} & \multirow{3}{*}{$\begin{array}{l}\text { Cuidados manipulação } \\
\text { EPI avental, óculos, máscara, } \\
\text { luvas }\end{array}$} & \multirow{3}{*}{\begin{tabular}{l}
\multicolumn{1}{c}{$\begin{array}{l}\text { Limites de } \\
\text { exposição }\end{array}$} \\
ACGIll /NR-15 não \\
listado
\end{tabular}} & \multicolumn{2}{|c|}{ Efeitos } \\
\hline & & & Agudo & Crônico \\
\hline & & & $\begin{array}{l}\text { Irritante severo de pele e mucosa, tosse, } \\
\text { faringite, edema, cefaléia, vertigem, } \\
\text { amnésia }{ }^{4} \text {. }\end{array}$ & $\begin{array}{l}\text { Citotóxico. Foram reportados achados de } \\
\text { mutagenicidade para o homem } \\
4,5\end{array}$ \\
\hline Metanol & $\begin{array}{l}\text { EPI- avental, óculos/capela, } \\
\text { luva borracha butílica, } \\
\text { natural e neoprene }\end{array}$ & $\begin{array}{l}\text { ACGHH TWA } 200 \\
\text { ppm } \\
\text { NR- } 15-156 \mathrm{ppm}\end{array}$ & $\begin{array}{l}\text { Dermatite, conjuntivite, euforia, incoordenação } \\
\text { muscular, cefaleia, tontura, náusea, vômito, } \\
\text { dores abdominais, fraqueza, traqueite, } \\
\text { bronquite, narcose, delírio, coma, falha } \\
\text { respiratória, cianose, alteraçð̃es visuais, acidose, } \\
\text { albuminúria, convulsões. Sequelas - neuropatia, } \\
\text { cegueira, parkinsonismo, encefalopatia tóxica }{ }^{4} \text {. }\end{array}$ & $\begin{array}{l}\text { Os efeitos decorrentes da exposição crônica } \\
\text { são menos conhecidos. Exposição aos } \\
\text { vapores pode levar a lesões irritativas leve } \\
\text { da pele e trato respiratório }{ }^{13}\end{array}$ \\
\hline $\begin{array}{l}\text { Metiliso } \\
\text { butilcetona }\end{array}$ & $\begin{array}{l}\text { EPI- avental, óculos/capela, } \\
\text { luva nåo especificada? }\end{array}$ & $\begin{array}{l}\text { ACGIH Sppm, STEL } \\
10 \text { ppm } \\
\text { NR-15 não listada }\end{array}$ & $\begin{array}{l}\text { Genérico para cetonas - irritação de garganta, } \\
\text { náusea, cefaléia, vertigem incoordenação, } \\
\text { depressão SNC com narcose e parada cardio- } \\
\text { respiratória. Irritação dos olhos } 4\end{array}$ & $\begin{array}{l}\text { Neuropatia axonal, parestesia, fraqueza } \\
\text { muscular }^{4}\end{array}$ \\
\hline Ninhidrina & EPI avental, máscara, luva & Não listado & Irritante de pele & $\begin{array}{l}\text { Rinite alérgica }{ }^{14} \text { Promotor da carcinogênese } \\
\text { (Ca de pele) em animais de experimentação }{ }^{15}\end{array}$ \\
\hline $\begin{array}{l}\text { o- } \\
\text { fenilenodiamina }\end{array}$ & $\begin{array}{l}\text { EPI avental, óculos, máscara, } \\
\text { luvas nitrilicas }\end{array}$ & $\begin{array}{l}\text { ACGIH TWA } 0,1 \\
\text { ppm } \\
\text { NR-15 não listado }\end{array}$ & $\begin{array}{l}\text { Dermatite de contato, hipotensão, edema } \\
\text { de laringe, dispnéia, cianose, necrose } \\
\text { tubular, necrose hepática, hemólise } \\
\text { intravascular, metemoglobinemia }^{4} .\end{array}$ & Carcinogênico para animais. mutagênico ${ }^{4}$ \\
\hline $\begin{array}{l}\text { Permanganato } \\
\text { de potássio }\end{array}$ & $\begin{array}{l}\text { EPI avental, óculos, máscara, } \\
\text { luvas nitrílicas }\end{array}$ & $\begin{array}{l}\text { ACGIH TWA } 0,2 \\
\mathrm{mg} / \mathrm{m}^{3}(\mathrm{Mn}) \\
\text { NR-15 não listado }\end{array}$ & $\begin{array}{l}\text { Cáustico para o trato gastrintestinal. Em casos } \\
\text { severos promove metemoglobinemia, } \\
\text { hipotensão, coagulopatia, necrose hepática, } \\
\text { pancreatite, dano renal agudo parestesia, } \\
\text { desordem extrapiramidal. O contato com a } \\
\text { mucosa ocular pode provocar diplopia e } \\
\text { queimaduras }{ }^{4} \text {. }\end{array}$ & $\begin{array}{l}\text { Efeitos neurológicos semelhantes ao } \\
\text { parkinsonismo }(\mathrm{Mn})^{4} \text {. }\end{array}$ \\
\hline
\end{tabular}


Cont. Tabela A-33

\begin{tabular}{|c|c|c|c|c|}
\hline \multirow[t]{2}{*}{ Substância } & \multirow[t]{2}{*}{ Cuidados manipulação } & \multirow{2}{*}{$\begin{array}{l}\text { Limites de } \\
\text { exposição }\end{array}$} & \multicolumn{2}{|c|}{ Efeitos } \\
\hline & & & Agudo & Crônico \\
\hline $\begin{array}{l}\text { Peróxido de } \\
\text { hidrogênio }\end{array}$ & $\begin{array}{l}\text { EPI avental. óculos. máscara } \\
\text { luvas de borracha butilica' }\end{array}$ & $\begin{array}{l}\text { ACGIH TWA } 1 \text { ppm } \\
\text { NR-15 naao listado }\end{array}$ & $\begin{array}{l}\text { Em concentrações superiores a } 10 \% \text { é um } \\
\text { oxidante forte e corrosivo promovendo) } \\
\text { queimadura das mucosas (ingestão), } \\
\text { inflamação, edema, coma e convulsão. A } \\
\text { inalação de baixas concentraçõos leva a leve } \\
\text { irritação ocular e respiratónia }\end{array}$ & $\begin{array}{l}\text { Bronquite, tosse, muco e respiração curta } \\
\text { Mutagênico para o homem. Evidências } \\
\text { questionáveis de carcinogenicidade em } \\
\text { animais }^{5}\end{array}$ \\
\hline Piridina & $\begin{array}{l}\text { EPI avental, óculos, máscara, } \\
\text { luvas nitrilicas }{ }^{1}\end{array}$ & $\begin{array}{l}\text { ACGIH TWA } 5 \text { ppm } \\
\text { NR-15- } 4 \text { ppm }\end{array}$ & $\begin{array}{l}\text { Enfisema, bronquite, cefaléia, tontura, dor } \\
\text { abdominal, náusea, insônia, anorexia, tremor e } \\
\text { ataxia. Irritą̧ão de pele }\end{array}$ & $\begin{array}{l}\text { Enfisema e bronquite crônica, cefaléia, náusea, } \\
\text { insônia e vertigens temporárias, dano renal e } \\
\text { hepático (cirrose e esteatose) }{ }^{4} \text {. }\end{array}$ \\
\hline Sais de arsênico & $\begin{array}{l}\text { EPI avental, óculos, máscara } \\
\text { luvas nitrilicas }{ }^{4}\end{array}$ & $\begin{array}{l}\text { ACGIH TWA } 0,01 \\
\mathrm{mg} / \mathrm{m}^{3} \\
\mathrm{NR}-15-0,04 \\
\left.\mathrm{mg} / \mathrm{m}^{3} \text { arsina }\right)\end{array}$ & $\begin{array}{l}\text { Ingestão- dor gástrica, vômito, constriçãa } \\
\text { da garganta, diarréia, cãibras, sede, } \\
\text { oligúria, albuminúria, hematúria, } \\
\text { convulsão, coma e morte. } \\
\text { Inalação- irritação das vias respiratórias } \\
\text { (dor e tosse), cefaléia, náuseas e vômitos, } \\
\text { cianose da face }^{4,16} \text {. }\end{array}$ & $\begin{array}{l}\text { Fraqueza, anorexia, náusea, vômito, diarréia ou } \\
\text { constipação, inflamação do nariz, garganta, } \\
\text { espirros, rouquidão, conjuntivas congestionadas, } \\
\text { perfuração de septo, melanose arsenical, queratose } \\
\text { plantar e palmar, edema palpebral, queda de cabelo } \\
\text { e unhas, estomatite, salivação, icterícia, cirrose, } \\
\text { gangrena, lesão glomerular, nefrite crônica, } \\
\text { encefalopatia arsenical (apatia, idiotia, neurite } \\
\text { periférica).Evidência de ação carcinogênica para o } \\
\text { homem (pele e brônquios) }\end{array}$ \\
\hline Sais de cádmio & $\begin{array}{l}\text { EPI avental, óculos, máscara } \\
\text { luvas nitrílicas }\end{array}$ & $\begin{array}{l}\text { ACGIH TWA } 0,01 \\
\mathrm{mg} / \mathrm{m}^{3}(\mathrm{Cd} \text { elementar } \\
\text { e compostos) } \\
\mathrm{NR}-15 \text { não listado }\end{array}$ & $\begin{array}{l}\text { Distúrbios gastrintestinais após a ingestão. } \\
\text { Inalação poeiras do metal promovem } \\
\text { traqueobronquite, pneumonite e edema } \\
\text { pulmonar }{ }^{16}\end{array}$ & $\begin{array}{l}\text { Anemia, eosinofilia, rinite, descoloração do } \\
\text { esmalte dos dentes, anosmia, microfraturas, } \\
\text { enfisema pulmonar e distúrbios renais (excreção } \\
\text { de proténas de baixo peso molecular, seguida de } \\
\text { aminoacidúria, glicosúria e distúrbios na } \\
\text { depuração do acido único). Promove câncer } \\
\text { pulmonar em animais de experimentaçãa }{ }^{5,16}\end{array}$ \\
\hline
\end{tabular}


Cont. Tabela A-33

\begin{tabular}{|c|c|c|c|}
\hline Substância & Cuidados manipulação & $\begin{array}{l}\text { Limites de } \\
\text { exposiçåo }\end{array}$ & Aqudo \\
\hline Sais de chumbo & $\begin{array}{l}\text { EPI avental, } 6 \text { culos, máscara } \\
\text { luvas nitrílicas }{ }^{4}\end{array}$ & $\begin{array}{l}\text { ACGIH TWA } 0,05 \\
\mathrm{mg} / \mathrm{m}^{3} \\
\text { NR-15-0,1 mg/m }\end{array}$ & $\begin{array}{l}\text { Gastrintestinal: sabor metálico; dores } \\
\text { abdominais, vômitos, diarréias; } \\
\text { Renal: albuminúria, cilindrúria, oligúria; } \\
\text { SN: parestesia, fraqueza, convulsão, coma e } \\
\text { morte }\end{array}$ \\
\hline
\end{tabular}

feitos

Crônico

Gastrintestinal: anorexia, dispepsia, dores espasmódicas, constipação persistente, sabor metálico; Renal: triade de Fanconi, nefropatia crônica. Neuromuscular: fraqueza muscular e fadiga; SNC encefalopatia hipertensiva (irritação, vertigem, cefaléia, insônia, delirio, convulsão, coma).Anemia normocítica e hipocrômica. È promotor na formação do câncer

$\begin{array}{lll}\text { Sais de cianeto } & \begin{array}{l}\text { EPI avental, óculos, máscara, } \\ \text { luvas nitrilicas }{ }^{1}\end{array} & \begin{array}{l}\text { ACGIH TWA 4,7 } \\ \text { ppm teto }\end{array}\end{array}$

\section{Sais de cromo EPI avental, óculos, máscara ACGIH TWA 0,05 luvas nitrílicas ${ }^{4} \quad \mathrm{mg} / \mathrm{m}^{3}(\mathrm{Cr}$ Vl \\ solúveis) \\ NR-15 não listado}

Sais de estanho

EPI avental, óculos, máscara luvas nitrilicas ${ }^{4}$

Sais de mercúrio EPI avental, óculos, máscara luvas nitrilicas ${ }^{4}$

Sais de prata

EPI avental, óculos, máscara luvas nitrilicas $\mathrm{NR}-15$ - 8 ppm teto

Contato com pele e mucosas provoca ulceração e irritação. Taquicardia, taquipnéia, cefaléia, edema pulmonar, tontura, agitação, estupor, bradicardia, hipotensão, apnéia, convulsão, morte

Ingestão - corrosăo do trato gastrintestinal, dano hepático e renal, hemorragia. Inalaçầ das poeiras e fumos - ulceração da mucosa nasal, perfuração

de septo, rinite, epistaxe, edema pulmonar,

broncoespasmo, erosão e descoloração dos dentes, dermatite, ulceração de pele ${ }^{4}$.

Irritante de pele e mucosas, diarréia

ACGIH TWA 2 $\mathrm{mg} / \mathrm{m}^{3}(\mathrm{Sn}$ inorgânico) NR-15 não listado

fadiga, cefaléia, pneumoconiose e bronquite ${ }^{4}$

ACGIH TWA 0,025 $\mathrm{mg} / \mathrm{m}^{3}(\mathrm{Hg}$ inorgànico) NR-15- 0,04

$\mathrm{mg} / \mathrm{m}^{3}$ (todas as formas

Ingestão - corrosão da mucosas, náusea, vômito, dores abdominais, diarréia, distúrbios renais. Dermatite e conjuntivite

exceto orgânicas)

ACGIH TWA 0,01

$\mathrm{mg} / \mathrm{m}^{3}$ ( compostos

solúveis de $\mathrm{Ag}$ )

NR-15 não listado
Prata - promove gengivite, irritação ocular, bronquite, rinorréia, epistaxe, neuropatia, convulsão e tontura, dermatite, nefrotóxico (nefropatia tóxica, glomerulonefrite) ${ }^{4}$
Intoxicação crônica é rara - disfunç̧ão subclinica de tireóide, cefaléias, vertigens, palpitação, irritação olhos, dermatite, fadiga, tontura, alteração auditiva, são as queixas mais comuns ${ }^{4}$.

Nefropatia tóxica, alergia, bronquite

Promove câncer pulmonar no homem ${ }^{4}$

Afeta a habilidade de absorver ferro da dieta $=$ anemia ferropriva ${ }^{4}$

Glomerulonefrite, gengivite, salivação, estomatite, distúrbio psiquico (eretismo), com perda da memória, insônia, irritabilidade, depressãos

Dano renal, ocular, na mucosa nasal, unha apresenta cor azul esverdeada em 2 a 20 anos de exposição. Pode causar mutaçð̃es em células vivas. ${ }^{4}$ 
Cont. Tabela A-33

\section{Substância}

\section{Cuidados manipulação}

Sódio metálico luvas nitrílicas ${ }^{1}$

EPI- avental, óculos, máscara luvas de viton ${ }^{4}$

Tetracloreto de carbono

Tetrahidro

furano

EPI- avental, óculos/capela. luva não especificada ?

Tioacetamida

Não mencionado

EPI- avental, óculos/capela, luva teflon, viton ${ }^{4}$

EPI- avental, óculos/capela, luva borracha nitrilica
Tolueno

Xileno

Limites de
exposiçăo

listado
ACGIH TWA 5 ppm STEL $10 \mathrm{ppm}$

NR-15 - 8 ppm

ACGIH /99 TWA 200 ppm; STEL $250 \mathrm{ppm}$ NR- $15-156 \mathrm{ppm}$

Não listado

Irritante ${ }^{4}$

ACGIH/99 TWA 50

ppm

NR-15 - $78 \mathrm{ppm}$

ACGIH/99 $100 \mathrm{ppm}$ STEL $150 \mathrm{ppm}$ NR-15 - $78 \mathrm{ppm}$
Euforia, tremor, insônia, cefaléia, tontura, fadiga, fraqueza muscular, confusão, vertigem náusea, pneumonite química, conjuntivite, arritmias. T

Euforia, tremor, insônia, cefaléia, tontura, fadiga, fraqueza muscular, confusão, vertigem náusea, conjuntivite, anritmias. Hepatotóxico
Efeitos

Caustico, Reage exotermicamente com a Inflamação, ulceras labiais e bucais, umidade dos corpos promovendo queimaduras. distúrtios gastrintestinais e brônquicos ${ }^{4}$. Vapores provocam tosse, dor e edema pulmonar

Imitante de pele e mucosas. Deprime o SNC em Severo dano hepático e renal. Promove confusão mental Ingestão: vômito,

carcinoma hepático em animais de experimentaçăo. Suspeito de ser carcinogênico para o homem

náusea, tontura, cefaléia, depressào SNC,

Dano renal e hepático, diminuição das células brancas e vermelhas do sangue ${ }^{4}$.

Carcinogenicidade comprovada em animais de experimentaçăo. Possivel carcinogênico para o homem.Evidências de mulagenicidade

Fraqueza muscular devido ao desequilibrio eletrolítico, acidose tubular renal, hipocalemia, hematuria, proteinuria, oligúria, alucinacão auditiva e visual, reflexos hiperativos, labilidade emocional ${ }^{4}$

Cefaléia, fadiga, sonolência, vertigens, distúrbios cardiovasculares, dispnéia, náuseas, vômitos, desconforto epigástrico, conjuntivite, epistaxe. Contato prolongado com a pele pode

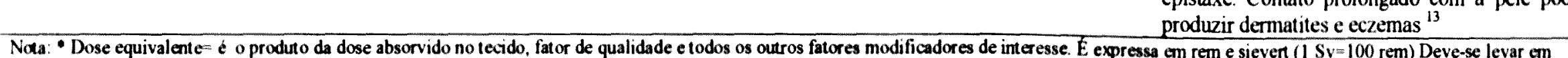

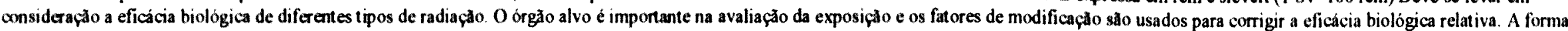
quimica da radiaça é critica na deuerminação da dose interna uma vez as substâncias podem se ligar a diferentes células ou órgãos alvo. Além disso, alguns tipos de radiaçăo podem causar mais danoa os tecidos biológicos que outros. Por exemplo, 1 rad de particula alfa é 20 vezes mais lesivo que 1 rad de raios gama. Para levar em consideraçào essas diferencas, a unidade fator de qualidade foi utilizada para se determinar a dose equivalente em rem?. Referencias: $1=$ ARMOUR, 1996; $2=$ ACGIH, 1999; $3=$ Brasil - NR $-15,1978 ; 4=$ TOMES CPS, 1987-1999; $5=$ LEWIS, 1992; 1996; $6=$ COGGON e col 7 $=$ QUIGLEY, 1994; 8=INTERNATIONAL TECHNICAL. INFORMATION INSTITUTE, 1977; 9= MICHIGAN STATE UNIVERSITY, 1999b; 10= CNEN. NE 3.01, 1988; $11=$ LEPERA JS, 1996;

13 - IEITE EMA, 1996; 14 - HYTONEN e col, 1996; 15 = SKULA E COL, 1994; 16 = SALGADO PET, 1996. 
Tabela A-34- Parâmetros utilizados na extrapolação das doses de referência disponiveis na literatura para algumas das substâncias manipuladas nas Instituições avaliadas.

\begin{tabular}{|c|c|c|c|c|c|}
\hline Substância química & Estudo realizado & Efeito crítico & Doses experimentais & $\begin{array}{l}\text { Fator de } \\
\text { incerteza }\end{array}$ & $\begin{array}{l}\text { Dose de } \\
\text { referência }\end{array}$ \\
\hline Acetaldeído & $\begin{array}{l}\text { Ratos Wistar, M, 10/gr, 6h/d, 5d/s, } 4 \text { sem. } \\
\text { Concentraçðes: } 0,150 \text { e } 500 \mathrm{ppm}\end{array}$ & Degeneraça do epitélio olfativo & $\begin{array}{l}\text { DNEAO }=150 \mathrm{ppm}=273 \mathrm{mg} / \mathrm{m}^{3} \\
\text { DNEAO (aj) } 48.75 \mathrm{mg} / \mathrm{m}^{3} \\
\text { DNEAO }(\mathrm{Hec})=8,7 \mathrm{mg} / \mathrm{m}^{3}\end{array}$ & $1000^{\prime}$ & $\begin{array}{l}9 \times 10^{-3} \mathrm{mg} / \mathrm{m}^{3} \\
\text { Inalação }\end{array}$ \\
\hline Acetato de etila & $\begin{array}{l}\text { Ratos, } 4 \mathrm{gr}(30 / \mathrm{gr} / \mathrm{sexo}), 6 \mathrm{~s}, 90 \mathrm{~d} \text {. Dose } 0 \\
300,900,3600 \mathrm{mg} / \mathrm{Kg} / \mathrm{d}\end{array}$ & Mortalidade e diminuição do peso & DNEAO: $900 \mathrm{mg} / \mathrm{Kg} / \mathrm{d}$ & 1000 & $\begin{array}{l}9 \times 10^{-1} \mathrm{mg} / \mathrm{Kg} / \mathrm{d} \\
\text { oral }\end{array}$ \\
\hline Acetona & $\begin{array}{l}\text { Ratos albinos, 30/sexo/gr, } 90 \mathrm{~d} \text {. Doses } 0 \\
100,500,2500 \mathrm{mg} / \mathrm{Kg} / \mathrm{d}\end{array}$ & $\begin{array}{l}\text { Hepato e nefromegalia, } \\
\text { degeneração tubular renal }\end{array}$ & DNEAO $: 100 \mathrm{mg} / \mathrm{Kg} / \mathrm{d}$ & 1000 & $1 \times 10^{-1} \mathrm{mg} / \mathrm{Kg} / \mathrm{d}$ \\
\hline Acetonitrila & $\begin{array}{l}\text { Camundongo } \mathrm{B}_{6} \mathrm{C}_{3} \mathrm{~F}_{1}, 10 \mathrm{M}, 10 \mathrm{~F}, 6 \mathrm{~h} / \mathrm{d} \text {, } \\
65 \mathrm{~d} \text { exposiça } \mathrm{a} / 92 \mathrm{~d} \text { estudo. Conc. } 0,25,50 \text {, } \\
100,200,400 \mathrm{ppm}\end{array}$ & $\begin{array}{l}\text { Lesðes hepáticas, diminuição da } \\
\text { contagem de eritrócitos e } \\
\text { hematócrito }\end{array}$ & $\begin{array}{l}\text { DNEAO } 100 \mathrm{ppm}=168 \mathrm{mg} / \mathrm{m}^{3} \\
\text { DNEAO aj }=19,3 \mathrm{mg} / \mathrm{Kg} / \mathrm{d}(168 \mathrm{x} \\
\left.6 \mathrm{~h} / 24 \mathrm{~d} \times 65 \mathrm{~d} / 92 \mathrm{~d} \times 0,039 / 0,03^{\mathrm{b}} \times 0,5^{\circ}\right)\end{array}$ & $3000^{d}$ & $\begin{array}{l}6 \times 10^{-3} \mathrm{mg} / \mathrm{Kg} / \mathrm{d} \\
\text { inalação }\end{array}$ \\
\hline Ácido clorídrico & $\begin{array}{l}100 \text { ratos sprague-dawley, } 6 \mathrm{~W} / \mathrm{d}, 5 \mathrm{~d} / \mathrm{s}, 10 \\
\text { ppm, life-time }\end{array}$ & $\begin{array}{l}\text { Hiperplasia da mucosa nasal, da } \\
\text { laringe e traquéia }\end{array}$ & $\mathrm{MDEAO}^{\mathrm{e}}=15 \mathrm{mg} / \mathrm{m}^{3}=10 \mathrm{ppm}$ & $300^{f}$ & $\begin{array}{l}2 \times 10-2 \mathrm{mg} / \mathrm{m}^{3} \\
\text { inalação }\end{array}$ \\
\hline Acrilamida & $\begin{array}{l}\text { Ratos, } 90 \text { dias. Dose }: 0 ; 0,05 ; 0,2 ; 1 ; 520 \\
\mathrm{mg} / \mathrm{Kg} / \mathrm{d}\end{array}$ & neurotoxicidade & $\begin{array}{l}\text { DNEAO }=0,2 \mathrm{mg} / \mathrm{Kg} / \mathrm{d} \\
\mathrm{MDEAO}=1 \mathrm{mg} / \mathrm{Kg} / \mathrm{d}\end{array}$ & 1000 & $\begin{array}{l}2 \times 10^{-4} \mathrm{mg} / \mathrm{Kg} / \mathrm{d} \\
\text { oral }\end{array}$ \\
\hline Benzidina & $\begin{array}{l}\text { Camundongo monohibridos e hibridos } \mathrm{M} \\
\text { e } \mathrm{C} 57 \mathrm{~B} 1 / 65 \mathrm{~F}, 72 \text { a } 120 / \mathrm{sexo} / \text { inhagem, } 0 \\
\text { a } 160 \mathrm{ppm}, 33 \text { meses }\end{array}$ & $\begin{array}{l}\text { Alteração das células hepáticas nas } \\
\text { fêmeas e vacuolização das células } \\
\text { cerebrais }\end{array}$ & $\begin{array}{l}\text { MDEAO }=20 \mathrm{ppm} \text { na água de beber } \\
=2,7 \mathrm{mg} / \mathrm{Kg} / \mathrm{dia}\end{array}$ & 1000 & $\begin{array}{l}3 \times 10^{-3} \mathrm{mg} / \mathrm{Kg} / \mathrm{d} \\
\text { oral }\end{array}$ \\
\hline Bromocianogênio & $\begin{array}{l}\text { Ratos, } 10 \mathrm{M}, 10 \mathrm{~F} \text {, oral, } 0 \text { a } 30 \mathrm{mg} / \mathrm{Kg} / \mathrm{d} \text { de } \\
\mathrm{KCN}, 11,5 \text { meses }\end{array}$ & $\begin{array}{l}\text { Diminuição do peso, degeneração } \\
\text { da bainha de mielina, efeito sobre } \\
\text { a tireóide }\end{array}$ & $\begin{array}{l}\text { MDNEAO }=30 \mathrm{mg} / \mathrm{Kg} / \mathrm{d} \\
\text { DNEAO= } 10,8 \mathrm{mg} / \mathrm{Kg} / \mathrm{d} \mathrm{CN} \text { - } \\
\text { convertido a } 44 \mathrm{mg} / \mathrm{Kg} / \mathrm{d} \text { cianogênio }= \\
10.8 \mathrm{mg} \mathrm{CN} \text { x PM bromocianogênio } / \mathrm{PM} \\
\mathrm{CN}(105.93 / 26.02)\end{array}$ & 1000 & $\begin{array}{l}9 \times 10^{-2} \mathrm{mg} / \mathrm{Kg} / \mathrm{d} \\
\text { oral, crônico }\end{array}$ \\
\hline Butanol & $\begin{array}{l}\text { Rato, } 30 / \mathrm{sexo} / \mathrm{G}, 13 \text { semanas, doses } 0,30 \\
125,500 \mathrm{mg} / \mathrm{Kg} / \mathrm{d}\end{array}$ & Hipoatividade e ataxia & $\mathrm{DNEAO}=125 \mathrm{mg} / \mathrm{Kg} / \mathrm{d}$ & 1000 & $\begin{array}{l}1 \times 10-1 \mathrm{mg} / \mathrm{Kg} / \mathrm{d} \\
\text { oral, subcrônico }\end{array}$ \\
\hline
\end{tabular}


Cont. Tabela A-34

\begin{tabular}{|c|c|c|c|c|c|}
\hline Substância química & Estudo realizado & Efeito crítico & Doses experimentais & $\begin{array}{l}\text { Fator de } \\
\text { incerteza }\end{array}$ & $\begin{array}{l}\text { Dose de } \\
\text { referência }\end{array}$ \\
\hline Cádmio & $\begin{array}{l}\text { Homem, exposição crônica, Modelo } \\
\text { assume: excrę̧ão da carga corpórea de Cd }= \\
0,01 \% \text { d. absorção } 2,5 \% \text { através alimento e } 5 \% \\
\text { através da água }\end{array}$ & Proteinúria significativa & $\begin{array}{l}\text { DNEAO(água): } 0,005 \mathrm{mg} / \mathrm{Kg} / \mathrm{d} \\
\text { MDEAO (alimento) }=0,01 \mathrm{mg} / \mathrm{Kg} / \mathrm{d}\end{array}$ & 10 & $\begin{array}{l}5 \times 10^{-4} \mathrm{mg} / \mathrm{Kg} / \mathrm{d} \\
\text { (água) oral }\end{array}$ \\
\hline Cianeto & $\begin{array}{l}\text { Ratos, } 10 / \mathrm{sexo} / \mathrm{G}, 2 \text { anos, } 4,3 \text { e } 10,8 \mathrm{mg} \text { de } \\
\mathrm{CN} / \mathrm{Kg}\end{array}$ & $\begin{array}{l}\text { Efeito sobre o crescimento, Lesão } \\
\text { histologica, qualquer efeito adverso }\end{array}$ & $\begin{array}{l}\mathrm{DNEAO}=10,8 \mathrm{mg} / \mathrm{Kg} / \mathrm{d}, \mathrm{CN}^{-} \\
\text {convertido a } 27,0 \mathrm{mg} / \mathrm{Kg} / \mathrm{d} \text { de } \mathrm{KCN}\end{array}$ & $\begin{array}{l}100 \\
\mathrm{e} F M=5\end{array}$ & $5 \times 10^{-2} \mathrm{mg} / \mathrm{Kg} / \mathrm{d}$ \\
\hline Clorofórmio & $\begin{array}{l}\text { Cão, } 8 \text { animais/sexo, controle } 16 \mathrm{Me} 16 \\
\mathrm{~F}, 6 \mathrm{~d} / 7,5 \text { anos, } 15 \text { a } 30 \mathrm{mg} \\
\text { clorofórmio } / \mathrm{Kg} / \mathrm{d}\end{array}$ & $\begin{array}{l}\text { Formação de cisto gorduroso } \\
\text { hepático }\end{array}$ & $\begin{array}{l}\text { DNEAO = nenhuma } \\
\text { MDEAO }=15 \mathrm{mg} / \mathrm{Kg} / \mathrm{d} \text { convertido a } \\
12,9 \mathrm{mg} / \mathrm{Kg} / \mathrm{d}(15 \mathrm{mg} / \mathrm{Kg} / \mathrm{d} \times 6 \mathrm{~d} / 7 \mathrm{~d})\end{array}$ & 1000 & $\begin{array}{l}1 \times 10^{-2} \mathrm{mg} / \mathrm{Kg} / \mathrm{d} \\
\text { oral, crônico }\end{array}$ \\
\hline Diclorometano & $\begin{array}{l}\text { Ratos, } 85 / \mathrm{sexo} \text {, controle } 85 \mathrm{e} 50 / \mathrm{sexo}, 2 \\
\text { anos. Dose: } 5,50,125,250 \mathrm{mg} / \mathrm{Kg} / \mathrm{d}\end{array}$ & hepatotoxicidade & $\begin{array}{l}\mathrm{DNEAO}=5,85 \text { a } 6,47 \mathrm{mg} / \mathrm{Kg} / \mathrm{d} \\
\text { respectivamente, } \mathrm{M} \mathrm{e} \mathrm{F}\end{array}$ & 100 & $6 \times 10^{-2} \mathrm{mg} / \mathrm{Kg} / \mathrm{d}$ \\
\hline \multirow[t]{2}{*}{$\begin{array}{l}\text { Dissulfeto de } \\
\text { carbono }\end{array}$} & $\begin{array}{l}\text { 1. Ratos e coelhos, } 20 \text { e } 40 \text { ppm durante } \\
\text { gestação }\end{array}$ & Toxicidade fetal/malformações & 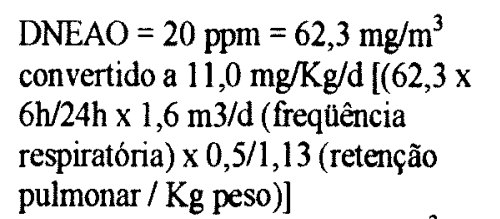 & 100 & $1 \times 10^{-1} \mathrm{mg} / \mathrm{Kg} / \mathrm{d}$ \\
\hline & $\begin{array}{l}\text { 2. Estudo ocupacional, } 145 \\
\text { trabalhadores fábrica de rayon, } \\
\text { controle }=233 \text {, tempo de exposição } \\
12,1 \pm 6,9 \mathrm{ppm} / 8 \mathrm{~h} / \mathrm{d}, \text { concentraçðes } \\
\text { de } \mathrm{CS}_{2}=12,6 \text { a } 517,3 \mathrm{ppm}\end{array}$ & $\begin{array}{l}\text { Disfunção do Sistema Nervoso } \\
\text { Periférico }\end{array}$ & $\begin{array}{l}\text { Dose Benchmark }=55,1 \mathrm{mg} / \mathrm{m}^{3} \times[ \\
10 \mathrm{~m}^{3} / \mathrm{d} / 20 \mathrm{~m}^{3} / \mathrm{d}(\text { volume de } \\
\text { ventilação pulmonar } / \mathrm{min} \mathrm{na} \\
\text { exposição ocupacional, } 8 \mathrm{~h} / \mathrm{d} / \\
\text { volume de ventilação pulmonar } / \mathrm{min} \\
\text { para o homem) } \mathrm{5 \textrm {d }} / / 7 \mathrm{~d}]\end{array}$ & $\begin{array}{l}30 \text { (intra- } \\
\text { espécie x } 3 \text { - } \\
\text { falta de } \\
\text { dados sobre } \\
\text { ativação } \\
\text { metabólica) }\end{array}$ & $7 \times 10^{-1} \mathrm{mg} / \mathrm{m}^{3}$ \\
\hline Difenilamina & $\begin{array}{l}\text { Cachorro, } 2 \text { anos, } 8 \mathrm{M}, 8 \mathrm{~F} \text {, dieta com } 0,01 \text {, } \\
0,1 \text { e } 1 \% \text { de difenilamina }\end{array}$ & $\begin{array}{l}\text { Hepato e nefromegalia, diminuição } \\
\text { no ganho de peso }\end{array}$ & $\begin{array}{l}\mathrm{DNEAO}=0,01 \% \text { dieta }=2,5 \\
\mathrm{mg} / \mathrm{Kg} / \mathrm{d}\end{array}$ & 100 & $\begin{array}{l}2,5 \times 10^{-2} \\
\mathrm{mg} / \mathrm{Kg} / \mathrm{d}\end{array}$ \\
\hline Éter etílico & $\begin{array}{l}\text { Rato, } 30 / \mathrm{sexo} / \mathrm{G}, 90 \text { dias, dose: } 0,500, \\
2000,3500 \mathrm{mg} / \mathrm{Kg} / \mathrm{d}\end{array}$ & Perda de peso & $\mathrm{DNEAO}=500 \mathrm{mg} / \mathrm{Kg} / \mathrm{d}$ & $3000^{h}$ & $2 \times 10^{-1} \mathrm{mg} / \mathrm{Kg} / \mathrm{d}$ \\
\hline Fenol & $\begin{array}{l}\text { Ratos, oral, } 6 \text { ao } 150 \text {. Dia de gestação, } 20 \\
\text { a } 22 \mathrm{~F} / \mathrm{G} \text {, doses: } 0,30,60,120 \mathrm{mg} / \mathrm{Kg} / \mathrm{d}\end{array}$ & Diminuição do peso fetal & $\mathrm{DNEAO}=60 \mathrm{mg} / \mathrm{Kg} / \mathrm{d}$ & 100 & $6 \times 10^{-1} \mathrm{mg} / \mathrm{Kg} / \mathrm{d}$ \\
\hline
\end{tabular}


Cont. Tabela A-34

\begin{tabular}{|c|c|c|c|c|c|}
\hline Substância química & Estudo realizado & Efeito crítico & Doses experimentais & $\begin{array}{l}\text { Fator de } \\
\text { incerteza }\end{array}$ & $\begin{array}{l}\text { Dose de } \\
\text { referência }\end{array}$ \\
\hline Formaldeido & $\begin{array}{l}\text { Ratos } 1 \text { istar, } 70 / \text { sexo/d, } 24 \text { meses, dose: } 0 \text {, } \\
1,2,15,82, \mathrm{mg} / \mathrm{Kg} / \mathrm{d} \mathrm{M} \mathrm{e} 0,1,8,21,109 \\
\mathrm{mg} / \mathrm{Kg} / \mathrm{d}\end{array}$ & $\begin{array}{l}\text { Lesðes histopatológicas e redução } \\
\text { no ganho de peso }\end{array}$ & $\mathrm{DNEAO}=15 \mathrm{mg} / \mathrm{Kg} / \mathrm{d}$ & 100 & $2 \times 10^{-1} \mathrm{mg} / \mathrm{Kg} / \mathrm{d}$ \\
\hline Hexano & $\begin{array}{l}\text { Estudo epidemiologico, inalą̧ão, } 14 \\
\text { trabalhadores expostos, } 14 \text { controles, } \\
\text { tempo de exposição } 1 \text { a } 2 \text { anos, } \\
\text { concentração } 58 \pm 41 \text { ppm }\end{array}$ & $\begin{array}{l}\text { Neurotoxicidade, alteraçðes } \\
\text { eletrofisiológicas }\end{array}$ & $\begin{array}{l}\text { DNEAO = nenhuma } \\
\text { MDEAO }=58 \mathrm{ppm} ; \text { MDEAO } \\
\text { (ajustada) }=73 \mathrm{mg} / \mathrm{m}^{3 \mathrm{i}}\end{array}$ & $300^{j}$ & $2 \times 10^{-1} \mathrm{mg} / \mathrm{m}^{3}$ \\
\hline Metanol & $\begin{array}{l}\text { Ratos Sprague-dawley, } 30 / \mathrm{sexo}, 90 \mathrm{dias} \text {, } \\
\text { oral, dose: } 0,100,500,2500 \mathrm{mg} / \mathrm{Kg} / \mathrm{d} \text {. }\end{array}$ & $\begin{array}{l}\text { eleveção da atividade das } \\
\text { transaminases }\end{array}$ & $\mathrm{DNEAO}=500 \mathrm{mg} / \mathrm{Kg} / \mathrm{d}$ & 1000 & $5 \times 10^{-1} \mathrm{mg} / \mathrm{Kg} / \mathrm{d}$ \\
\hline Metiletilcetona & $\begin{array}{l}\text { a) Ratos wistar, } 30 / \mathrm{sexo} / \mathrm{G} \text {, Dose } \mathrm{F}=0 \text {, } \\
538,1664 \text { e } 5089 \mathrm{mg} / \mathrm{Kg} / \mathrm{d} \text { e } \mathrm{M}=0 \text {, } \\
594,1771 \text { e } 4571 \mathrm{mg} / \mathrm{Kg} / \mathrm{d} \text {. } \\
\text { b) Camundongo Swiss, } 7 \mathrm{~h} / \mathrm{d}, 6^{\circ} \text { ao } 15^{\circ} \\
\text { dia de gestação, dose: } 0,398,1010 \\
\text { 3(120 ppm. } \\
\text { c) }\end{array}$ & $\begin{array}{l}\text { a) diminuição do } \\
\text { desenvolvimento do rato e } \\
\text { fetal } \\
\text { b) diminuição peso fetal e do } \\
\text { desenvolvimento do } \\
\text { camundongo }\end{array}$ & $\begin{array}{l}\text { a) } \mathrm{DNEAO}=1771 \mathrm{mg} / \mathrm{Kg} / \mathrm{d} \\
\text { b) } \mathrm{DNEAO}=1010 \mathrm{ppm}=2978 \\
\mathrm{mg} / \mathrm{m}^{3}\end{array}$ & $\begin{array}{l}\text { a) } 3000 \\
\text { b) } 1000\end{array}$ & $\begin{array}{l}\text { a) } 6 \times 10^{-1} \\
\mathrm{mg} / \mathrm{Kg} / \mathrm{d} \\
\text { b) } 1 \mathrm{mg} / \mathrm{m}^{3}\end{array}$ \\
\hline Prata & Homem, intravenoso, 2 a 9 anos, $1 \mathrm{~g}$ & argiria & $\begin{array}{l}\text { DNEAO }=\text { nenhuma } \\
\text { MDEAO }=1 \mathrm{~g} \text { convertido a dose oral } \\
\text { de } 0,014 \mathrm{mg} / \mathrm{Kg} / \mathrm{d}(\mathrm{g} / 0,04 \text { (fator } \\
\text { de retenção oral) }\end{array}$ & 3 & $5 \times 10^{-3} \mathrm{mg} / \mathrm{Kg} / \mathrm{d}$ \\
\hline Piridina & $\begin{array}{l}\text { Ratos Sprague-dawley, } 10 / \mathrm{sexo} / \mathrm{dose}, 90 \\
\text { dias, doses: } 0,0,25,1,10,25,50 \mathrm{mg} / \mathrm{Kg} / \mathrm{d}\end{array}$ & hepatomegalia & $\mathrm{DNEAO}=10 \mathrm{mg} / \mathrm{Kg} / \mathrm{d}$ & 1000 & $1 \times 10^{-3} \mathrm{mg} / \mathrm{Kg} / \mathrm{d}$ \\
\hline Selênio & $\begin{array}{l}40 \text { individuos (China), dose }: F=62,198 \\
1238 \mu \mathrm{e} \mathrm{M}=70,195,1438 \mu \mathrm{g}\end{array}$ & $\begin{array}{l}\text { Selenose clínica = perda de cabelo } \\
\text { e unha, alteração na morfologia } \\
\text { das unhas, disfunção hepática ( } \\
\text { tempo de coagulação e glutationa } \\
\text { sérica). }\end{array}$ & $\begin{array}{l}\text { DNEAO }=0,015 \mathrm{mg} / \mathrm{Kg} / \mathrm{d} \\
\text { (calculada por regressão } \log y= \\
0,767 \log X-2,248, \text { onde } x= \\
\text { ingestão de selênio e } y=\text { selênio no } \\
\text { sangue) }\end{array}$ & $\begin{array}{l}3 \\
\text { (intraespecie) }\end{array}$ & $5 \times 10^{-3} \mathrm{mg} / \mathrm{Kg} / \mathrm{d}$ \\
\hline $\begin{array}{l}\text { Tetracloreto de } \\
\text { carbono }\end{array}$ & $\begin{array}{l}\text { Ritnos Sprague-dawlwy, } 5 \mathrm{~d} / \mathrm{s}, 12 \mathrm{~s} \text {, doses: } \\
1,11 . \therefore \mathrm{mg} / \mathrm{Kg} / \mathrm{d}\end{array}$ & $\begin{array}{l}\text { Lesão hepática - vacualização } \\
\text { centrilobular }\end{array}$ & $\begin{array}{l}\text { DNEAO }=1 \mathrm{mg} / \mathrm{Kg} / \mathrm{d} . D N E A O \\
\text { ajustadd }=0,71 \mathrm{mg} / \mathrm{Kg} / \mathrm{d}=1 \times 5 \mathrm{~d} / 7 \mathrm{~d}\end{array}$ & 1000 & $7 \times 10^{-4} \mathrm{mg} / \mathrm{Kg} / \mathrm{d}$ \\
\hline
\end{tabular}


Cont. Tabela A-34

\begin{tabular}{|c|c|c|c|c|c|}
\hline Substância química & Estudo realizado & Efeito crítico & Doses experimentais & $\begin{array}{l}\text { Fator de } \\
\text { incerteza }\end{array}$ & $\begin{array}{l}\text { Dose de } \\
\text { referência }\end{array}$ \\
\hline Tolueno & $\begin{array}{l}\text { a) ratos } \mathrm{F} 344,10 / \mathrm{sexo}, 5 \mathrm{~d} / \mathrm{s}, 13 \mathrm{~s} \text {, doses: } \\
0,312,625,2500,5000 \mathrm{mg} / \mathrm{Kg} / \mathrm{d} \\
\text { b) homem exposição ocupacional, } 30 \mathrm{M} \text {, } \\
8 \mathrm{~h} / \mathrm{d}, 5 \mathrm{~d} / \mathrm{s} \text {, concentração } 88 \mathrm{ppm} \text {; } \\
\text { grupo controle } 13 \mathrm{ppm} \text {, }\end{array}$ & $\begin{array}{l}\text { a) hepato e nefromegalia } \\
\text { b) alteraçðes } \\
\text { neurocomportamentais }\end{array}$ & $\begin{array}{l}\text { a) } \\
\text { DNEAO } 312 \mathrm{mg} / \mathrm{Kg} / \mathrm{d} \\
\mathrm{mg} / \mathrm{Kg} / \mathrm{d}(5 \mathrm{~d} / \mathrm{s}) \\
\text { bNEAO }=223 \\
\mathrm{MDEAO}=332 \mathrm{mg} / \mathrm{m}^{3}=88 \mathrm{ppm} \\
; \mathrm{MDEAO} \text {.justald }=332 \times 10 / 20 \\
\left(\mathrm{MV} \mathrm{h}_{\mathrm{ho}} / \mathrm{MV} \mathrm{V}_{\mathrm{h}}\right) \times 5 \mathrm{~d} / 7 \mathrm{~d}=119 \\
\mathrm{mg} / \mathrm{m}^{3}\end{array}$ & $\begin{array}{l}\text { a) } 1000 \\
\text { b) } 300\end{array}$ & $\begin{array}{l}\text { reterencia } \\
\text { a) } 2 \times 10^{-1} \\
\mathrm{mg} / \mathrm{Kg} / \mathrm{d} \\
\text { b) } 4 \times 10^{-1} \\
\mathrm{mg} / \mathrm{m}^{3}\end{array}$ \\
\hline Xileno & $\begin{array}{l}\text { Ratos Fischer, } 50 \mathrm{M}, 50 \mathrm{~F}, 5 \mathrm{~d} / \mathrm{s}, 103 \mathrm{~s} \text {, } \\
\text { doses: } 0,250,500 \mathrm{mg} / \mathrm{Kg} / \mathrm{d}\end{array}$ & $\begin{array}{l}\text { Hiperatividade, diminuição do } \\
\text { peso corpóreo e aumento na } \\
\text { mortalidade dos machos }\end{array}$ & $\begin{array}{l}\text { DNEAO } 250 \mathrm{mg} / \mathrm{Kg} / \mathrm{d} ; \text { DNEAO } \\
\text { austada }=179 \mathrm{mg} / \mathrm{Kg} / \mathrm{d}(5 \mathrm{~d} / \mathrm{s})\end{array}$ & 100 & $2 \mathrm{mg} / \mathrm{Kg} / \mathrm{d}$ \\
\hline \multicolumn{6}{|c|}{ 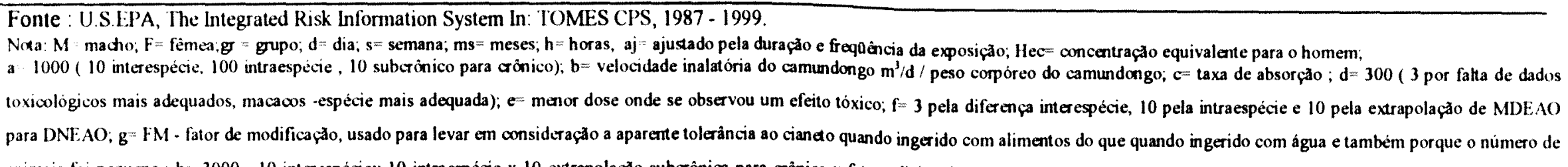 } \\
\hline
\end{tabular}


Tabela A-35- Niveis de risco mínimo estabelecidos para algumas das substâncias manipuladas pelas Instituições de estudo

\begin{tabular}{|c|c|c|c|c|c|}
\hline Substância & Via de introduçåo & Duraçåo da exposiç̧a & Fator de incerteza & Efeito adverso observado & NRM \\
\hline Acetona & oral & $15-364$ dias & 300 & Distúrbio hepático & $0,6 \mathrm{mg} / \mathrm{Kg} / \mathrm{dia}$ \\
\hline Ácido sulfidrico & pulmonar & $\begin{array}{ll}\text { a. } & 1-14 \text { dias } \\
\text { b. } & 15-364 \text { dias }\end{array}$ & $\begin{array}{ll}\text { a. } & 30 \\
\text { b. } & 30\end{array}$ & $\begin{array}{l}\text { a. alteração respiratória } \\
\text { b. alteraçåo respiratória }\end{array}$ & $\begin{array}{l}\text { a. } \quad 0,07 \mathrm{ppm} \\
\text { b. } \quad 0,03 \mathrm{ppm}\end{array}$ \\
\hline Aluminio & oral & 15.364 dias & 30 & Alteraçæo neurológica & $2.0 \mathrm{mg} / \mathrm{Kg} / \mathrm{dia}$ \\
\hline Amônia & pulmonar & $\begin{array}{l}\text { a. } 1-14 \text { dias } \\
\text { b. } \quad>365 \text { dias }\end{array}$ & $\begin{array}{ll}\text { a. } & 10 \\
\text { b. } & 100\end{array}$ & $\begin{array}{l}\text { a. distúrbios respiratórios } \\
\text { b. outros }\end{array}$ & $\begin{array}{ll}\text { a. } & 0,5 \mathrm{ppm} \\
\text { b. } & 0,3 \mathrm{ppm}\end{array}$ \\
\hline Arsênico & oral & $>365$ dias & 3 & Alteraçðes dérmicas & $0,0003 \mathrm{mg} / \mathrm{Kg} / \mathrm{dia}$ \\
\hline Benzeno & pulmonar & $\begin{array}{l}\text { a. 1-14 dias } \\
\text { b. } 15-364 \text { dias }\end{array}$ & $\begin{array}{ll}\text { a. } & 300 \\
\text { b. } & 90\end{array}$ & $\begin{array}{l}\text { a. alteraçåo imunológica } \\
\text { b. alteração neurológica }\end{array}$ & $\begin{array}{ll}\text { a. } & 0,05 \mathrm{ppm} \\
\text { b. } & 0,004 \mathrm{ppm}\end{array}$ \\
\hline Cádmio & oral & $>365$ dias & 10 & Alteração renal & $0,0002 \mathrm{mg} / \mathrm{Kg} / \mathrm{dia}$ \\
\hline Cianeto de sódio & oral & $15-364$ dias & 100 & Alteração na reprodução & $0,05 \mathrm{mg} / \mathrm{Kg} / \mathrm{dia}$ \\
\hline Cloreto de mercúrio & oral & $\begin{array}{ll}\text { a. } & 1-14 \text { dias } \\
\text { b. } & 15.364 \text { dias }\end{array}$ & $\begin{array}{ll}\text { a. } & 100 \\
\text { b. } & 100\end{array}$ & $\begin{array}{l}\text { a. alteração renal } \\
\text { b. alteração renal }\end{array}$ & $\begin{array}{ll}\text { a. } & 0,007 \mathrm{mg} / \mathrm{Kg} / \mathrm{dia} \\
\text { b. } & 0,002 \mathrm{mg} / \mathrm{Kg} / \mathrm{dia}\end{array}$ \\
\hline Clorofórmio & $\begin{array}{l}\text { a. pulmonar } \\
\text { b. oral }\end{array}$ & $\begin{array}{l}\text { a. } 1-14 \text { dias / 15-364dias / } \\
>365 \text { dias } \\
\text { b. } 1-14 \text { dias / 15-364dias / } \\
>365 \text { dias }\end{array}$ & $\begin{array}{ll}\text { a. } & 30 / 100 / 100 \\
\text { b. } & 100 / 100 / 100\end{array}$ & $\begin{array}{l}\text { a. alteração hepática } \\
\text { b. alteração hepática }\end{array}$ & $\begin{array}{l}\text { a.00,1 ppm / 0,05 ppm/ } 0,02 \mathrm{ppm} \\
\text { b. } 0,3 \mathrm{mg} / \mathrm{Kg} / \mathrm{dia} / 0,1 \\
\mathrm{mg} / \mathrm{Kg} / \mathrm{dia} / 0,01 \mathrm{mg} / \mathrm{Kg} / \mathrm{dia}\end{array}$ \\
\hline Cromo hexavalente & pulmonar & $15-364$ dias & 90 & alteração respiratória & $0,0005 \mathrm{mg} / \mathrm{m}^{3}$ \\
\hline Diclorometano & $\begin{array}{l}\text { a. pulmonar } \\
\text { b. oral }\end{array}$ & $\begin{array}{l}\text { a. } 1-14 \text { dias } / 15.364 \\
\text { dias } />365 \text { dias } \\
\text { b. } 1-14 \text { dias } />365 \text { dias }\end{array}$ & $\begin{array}{ll}\text { a. } & 100 / 30 / 30 \\
\text { b. } & 30 / 30\end{array}$ & $\begin{array}{l}\text { a. alteração neurológica/ hepática } \\
\text { / hepática } \\
\text { b. alteraçà neurológica/ hepática }\end{array}$ & $\begin{array}{l}\text { a. } 3 \mathrm{ppm} / 0.3 \mathrm{ppm} / 0.3 \mathrm{ppm} \\
\text { b. } 05 \mathrm{mg} / \mathrm{Kg} / \mathrm{dia} / 0.2 \\
\mathrm{mg} / \mathrm{Kg} / \mathrm{dia}\end{array}$ \\
\hline
\end{tabular}


Cont. Tabela A-35

\begin{tabular}{|c|c|c|c|c|c|}
\hline Substância & Via de introduçāo & Duraçăo da exposiçăo & Fator de incerteza & Efeito adverso observado & NRM \\
\hline Dissulfeto de carbono & $\begin{array}{l}\text { a. pulmonar } \\
\text { b. oral }\end{array}$ & $\begin{array}{ll}\text { a. } & >365 \text { dias } \\
\text { b. } & 1-14 \text { dias }\end{array}$ & $\begin{array}{ll}\text { a. } & 30 \\
\text { b. } & 300\end{array}$ & $\begin{array}{l}\text { a. alteração neurológica } \\
\text { b. alteraçđo hepática }\end{array}$ & $\begin{array}{ll}\text { a. } & 0,3 \mathrm{ppm} \\
\text { b. } & 0,01 \mathrm{mg} / \mathrm{Kg} / \mathrm{dia}\end{array}$ \\
\hline Formaldeído & $\begin{array}{l}\text { a.pulmonar } \\
\text { b. oral }\end{array}$ & 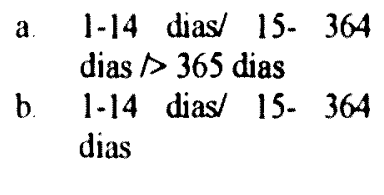 & $\begin{array}{ll}\text { a. } & 9 / 30 / 30 \\
\text { b. } & 100 / 100\end{array}$ & $\begin{array}{l}\text { a. alteração respiratória } \\
\text { b. alteração gastrintestinal }\end{array}$ & $\begin{array}{ll}\text { a. } & 0,04 \mathrm{ppm} / 0,03 \mathrm{ppm} \\
& 0,008 \mathrm{ppm} \\
\text { b. } 0,3 \mathrm{mg} / \mathrm{Kg} / \mathrm{dia} / & 0.2 \\
\mathrm{mg} / \mathrm{Kg} / \mathrm{dia}\end{array}$ \\
\hline Hexano & pulmonar & $>365$ dias & 100 & Alteração neurológica & $0,6 \mathrm{ppm}$ \\
\hline Mercúrio metálico & pulmonar & $>365$ dias & 30 & Alteração neurológica & $0,0002 \mathrm{mg} / \mathrm{m}^{3}$ \\
\hline Selênio & oral & $>365$ dias & 3 & Alteração dermatológica & $0,005 \mathrm{mg} / \mathrm{Kg} / \mathrm{dia}$ \\
\hline $\begin{array}{l}\text { Tetracloreto de } \\
\text { carbono }\end{array}$ & $\begin{array}{l}\text { a. pulmonar } \\
\text { b. oral }\end{array}$ & $\begin{array}{l}\text { a. } 1-14 \text { dias/15-365 } \\
\text { dias } \\
\text { b. 1-14/15-364 dias }\end{array}$ & $\begin{array}{l}\text { a. } 300 / 100 \\
\text { b. } 300 / 100\end{array}$ & $\begin{array}{l}\text { a. alteração hepática } \\
\text { b. alteração hepática }\end{array}$ & $\begin{array}{ll}\text { a. } & 0,2 \mathrm{ppm} / 0,05 \mathrm{ppm} \\
\text { b. } & 0,02 \mathrm{mg} / \mathrm{Kg} / \mathrm{dia} / 0,007 \\
& \mathrm{mg} / \mathrm{Kg} / \mathrm{dia}\end{array}$ \\
\hline Tolueno & $\begin{array}{l}\text { a. pulmonar } \\
\text { b. oral }\end{array}$ & $\begin{array}{ll}\text { a. } & 1-14 \text { dias } />365 \text { dias } \\
\text { b. } & 1-14 \text { dias/ } 15-364 \text { dias }\end{array}$ & $\begin{array}{ll}\text { a. } & 10 / 30 \\
\text { b. } & 300 / 300\end{array}$ & $\begin{array}{l}\text { a. alteração neurológica } \\
\text { b. alteração neurológica }\end{array}$ & $\begin{array}{ll}\text { a. } & 4 \mathrm{ppm} / 0,4 \mathrm{ppm} \\
\text { b. } 0,8 \mathrm{mg} / \mathrm{Kg} / \mathrm{dia} / 0,02 \\
\mathrm{mg} / \mathrm{Kg} / \mathrm{dia}\end{array}$ \\
\hline $\begin{array}{l}\text { Urânio, sais solúveis } \\
\text { em água }\end{array}$ & $\begin{array}{l}\text { a. pulmonar } \\
\text { b. oral }\end{array}$ & $\begin{array}{l}\text { a. } 1-14 \text { dias } />365 \text { dias } \\
\text { b. } 1-14 \text { dias }\end{array}$ & $\begin{array}{l}\text { a. } 90 / 30 \\
\text { b. } 30\end{array}$ & $\begin{array}{l}\text { a. alteração renal } \\
\text { b. alteração renal }\end{array}$ & $\begin{array}{ll}\text { a. } & 0,0004 \mathrm{mg} / \mathrm{m}^{3} / 0,0003 \\
& \mathrm{mg} / \mathrm{m}^{3} \\
\text { b. } & 0,002 \mathrm{mg} / \mathrm{Kg} / \mathrm{dia}\end{array}$ \\
\hline Vanádio & $\begin{array}{l}\text { a. pulmonar } \\
\text { b. oral }\end{array}$ & $\begin{array}{ll}\text { a. } & 1-14 \text { dias } \\
\text { b. } & 15-364 \text { dias }\end{array}$ & $\begin{array}{ll}\text { a. } & 100 \\
\text { b. } & 100\end{array}$ & $\begin{array}{l}\text { a. alteração renal } \\
\text { b. alteração renal }\end{array}$ & $\begin{array}{ll}\text { a. } & 0,0002 \mathrm{mg} / \mathrm{m}^{3} \\
\text { b. } & 0,003 \mathrm{mg} / \mathrm{Kg} / \mathrm{dia}\end{array}$ \\
\hline Xileno & $\begin{array}{l}\text { a. pulmonar } \\
\text { b. oral }\end{array}$ & $\begin{array}{l}\text { a. } 1-14 \text { dias / } 15-364 \\
\text { dias } />365 \text { dias } \\
\text { b. } 15-364 \text { dias }\end{array}$ & $\begin{array}{ll}\text { a. } 100 / 300 / \\
\text { b. } 100 \\
1000\end{array}$ & $\begin{array}{l}\text { a. aheração neurológica/ a heraçào } \\
\text { no desenvolvimento/ atteraçăo } \\
\text { neurológica } \\
\text { b. alteração renal }\end{array}$ & $\begin{array}{l}\text { a. } 1 \mathrm{ppm} / 0,7 \mathrm{ppm} / 0,1 \\
\text { ppm } \\
\text { b. } 0,2 \mathrm{mg} / \mathrm{Kg} / \mathrm{dia}\end{array}$ \\
\hline
\end{tabular}

